U.S. Department

of Transportation

National Highway

Tratfic Safety

Administration

DOT HS 807326

April 1988

Final Report

\title{
Overrepresentation of Seat Belt Non-Users in Traffic Crashes
}


The United States Government does not endorse products or manufactures. Trade or manufacturer's names appear only because they are considered essential to the object of this report. 
Technical Report Documentation Page

\begin{tabular}{|c|c|}
\hline $\begin{array}{l}\text { T. Report No. } \\
\text { DOT HS } 807326\end{array}$ & 3. Rocipiont's Coralog No. \\
\hline d. Titlo and Subritie & $\begin{array}{l}\text { 5. Roport Dole } \\
\text { April } 1998\end{array}$ \\
\hline $\begin{array}{l}\text { Overrepresentation of Seat Belt Non-Users in } \\
\text { Traffic Crashes }\end{array}$ & 6. Performing Organization Code \\
\hline & \multirow{2}{*}{$\begin{array}{l}\text { 8. Porforming Orgonization Report No. } \\
\text { HSRC-TR74 }\end{array}$} \\
\hline $\begin{array}{l}\text { 7. Authorls) W.W. Hunter, J.C. Stutts, J.R. Stewart and } \\
\text { E.A. Rodgman }\end{array}$ & \\
\hline 9. Performing Organization Name and Address & 10. Work Unit No. (TRAIS) \\
\hline \multirow{2}{*}{$\begin{array}{l}\text { Highway Safety Research Center } \\
\text { CB 非 } 3430 \\
\text { University of North Carolina } \\
\text { Chape1 Hi11, North Carolina } 27599\end{array}$} & $\begin{array}{l}\text { 11. Controct or Gront No. } \\
\text { DTNH22-Z-86-07392 }\end{array}$ \\
\hline & \multirow{2}{*}{$\begin{array}{l}\text { 13. Typo of Roport and Period Coverod } \\
\text { Final Report } \\
\text { October 1, } 1986 \text { through } \\
\text { March } 31,1988\end{array}$} \\
\hline \multirow{2}{*}{$\begin{array}{l}\text { 12. Sponsoring Agency Name and Address } \\
\text { National Highway Traffic Safety Administration } \\
400 \text { Seventh Street, S.W. } \\
\text { Washington, DC } 20590\end{array}$} & \\
\hline & 14. Sponsoring Adeney Code \\
\hline
\end{tabular}

15. Supplementary Notes

\section{Abstract}

This study used observations of driver belt use linked with driver history information to conclude that non-users of belts are overrepresented in traffic crashes. Examining average numbers of accidents and violations per observed belted and unbelted driver over the four-year (1983-1986) period, unbelted drivers had 35 percent more accidents and 69 percent more violations than did belted drivers. Results based on the drivers' self reported belt use showed that those who report using belts never or rarely have, on average, 33 percent more accidents than those stating they always wear belts. In addition, the never-rarely violation rate was more than twice as large as the always violation rate. These differences can be partially explained by the differing demographic compositions of the user groups; however, statistically significant belt use effects are found even after factors such as driver age, sex, and estimated annual mileage have been taken into account.

Differences between the types of accidents and violations of belt users and nonusers were also examined. Results showed that belt non-users had significantly more single vehicle accidents, rollover accidents, and accidents in which the driver is charged with a violation. Factors such as accident severity, vehicle deformation, and accident speed did not vary significantly by belt use group. In three separate analyses involving reckless driving, alcohol violations, and reckless and alcohol combined, no statistically significant relationships were found by belt use.

A telephone survey was conducted to examine reasons for using and not using belts by different groups of belt wearers. The survey helped to uncover programmatic ideas concerning ways to increase belt use.

\begin{tabular}{|c|c|c|c|c|}
\hline \multicolumn{2}{|c|}{$\begin{array}{l}\text { 17. Koy Words } \\
\text { Seat belt use, Occupant restraint, } \\
\text { Injury prevention, Traffic crashes, } \\
\text { Surveys }\end{array}$} & \multicolumn{3}{|c|}{$\begin{array}{l}\text { 18. Distribution Stotement } \\
\text { Document is available to the U.S. pub1ic } \\
\text { through the National Technical Information } \\
\text { Service, Springfield, Virginia } 22161\end{array}$} \\
\hline $\begin{array}{l}\text { 19. Socurity Clossil. (ol this report) } \\
\text { Unclassified }\end{array}$ & \multicolumn{2}{|c|}{$\begin{array}{l}\text { 20. Security Clossif. (of this pago) } \\
\text { Inclassified }\end{array}$} & $\begin{array}{l}\text { 21. No. of Poges } \\
X \vee 111,164\end{array}$ & 22. Price \\
\hline
\end{tabular}


EXECUTIVE SUMMARY . . . . . . . . . . . . . . . . . . ix

CHAPTER 1. INTRODUCTION . . . . . . . . . . . . . . . . . 1

Background . . . . . . . . . . . . . . . . . . . 1

Approach to the Problem . . . . . . . . . . . . . . . . 2

Literature Review . . . . . . . . . . . . . . . . . . . 3

Overrepresentation of Seat Belt Non-Users in Crashes . . . . 3

The Relationship of Belt Use to Other Risk Factors . . . . . . 6

Other Characteristics of Belt Users and Non-Users . . . . . . 6

Survey Methodology Literature . . . . . . . . . . . 8

CHAPTER 2. METHODOLOGY . . . . . . . . . . . . . . . . . 11

Mailback Survey .. . . . . . . . . . . . . . . . 11

Overall Design .................... 11

Questionnaire and Incentive Development and Pilot Testing. . . 12

Final Sampling and Distribution Procedures . . . . . . . . 13

Data Processing . . . . . . ... . . . . . . . 14

Return Characteristics . . . . . . . . . . . . . . 14

N.C. Driver History File and Linkage to Mailback Returns . . . . . 15

Telephone Survey . . . . . . . . . . . . . . . . . . 16

Purpose . . . . . . . . . . . . . . . . . . . 16

Development of Sampling Plan . . . . . . . . . . 16

Questionnaire Development and Pilot Testing . . . . . . . 18

Interview Procedures . . . . . . . . . . . . . . . 18

Data Processing . . . . . . . . . . . . . . . . 19

Characteristics of Responses . . . . . . . . . . . . 19

Data Analysis Overview . . . . . . . . . . . . . . . 20

CHAPTER 3. MAILBACK SURVEY RESULTS - OVERREPRESENTATION OF BELT

NON-USERS IN ACCIDENTS AND VIOLATIONS . . . . . . . . . . 21

Overview . . . . . . . . . . . . . . . . . . . . . 21

Information About the Sample . . . . . . . . . . . . . . 21

Survey Response Distributions . . . . . . . . . . . . . 21

Driver History File Information . . . . . . . . . . . . . 24

Seat Belt Use Among Survey Respondents . . . . . . . . . 25

Attitudinal and Demographic Differences Between Belt Users

and Non-Users . . . . . . . . . . . . . . . . . . . . . . . . 28

Overrepresentation of Non-Users in Accidents and Violations . . . . 31

Differences Between the Types of Accidents and Violations for

Belt Users and Non-Users . . . . . . . . . . . . . . . 35

Additional Analyses Concerned with Identifying Target Groups

for Seat Belt Programs . . . . . . . . . . . . . . 38

Analysis of Change in Belt Use Status . . . . . . . . . . . 38

Reasons Why North Carolina Drivers Use and/or Do Not Use

Seat Belts ... . . . . . . . . . . . . . 41

CHAPTER 4. TELEPHONE SURVEY RESULTS - CHARACTERISTICS OF USERS AND

NON-USERS OF SAFETY BELTS . . . . . . . . . . . . . . . . . 49

Background . . . . . . . . . . . . . . . . . . . . . . . . . 49

Questions Concerning Belt Use . . . . . . . . . . . . . . 50

Personal Belt Use . . . . . . . . . . . . . . . . 50

Belt Use by Friends . . . . . . . . . . . . . . . . 54 
TABLE OF CONTENTS (Con' $t$ )

Page

When Belt First Worn . . . . . . . . . . . . . . . 54

Factors That Influenced Belt Wearing . . . . . . . . . . 56

Statements About Seat Belts . . . . . . . . . . . . 56

Belt Use in Various Driving Situations . . . . . . . . . . . . 60

Items Leading to Belt Use "Every Time You Get In a Car" . . . 62

Opinion of the North Carolina Law . . . . . . . . . . . . . . . 66

Feelings About Belts and the Law . . . . . . . . . . . . 66

Main Reasons for Supporting the North Carolina Law . . . . . . 68

Main Reasons for Opposing the Law . . . . . . . . . . . . 68

Information Transfer .. . . . . . . . . . . . . . . . . . . 70

Television and Other Advertisements . . . . . . . . . . 70

Seat Belt Spokesperson.................. 71

Accident Experience . . . . . . . . . . . . . . . . 72

Enforcement Experience . . . . . . . . . . . . . . 76

Health and Lifestyle . . . . . . . . . . . . . . . . . 82

Exercise...................... 84

Smoking . . . . . . . . . . . . . . . . . . . 84

Drinking . . . . . . . . . . . . . . . . 85

Driving Speed . . . . . . . . . . . . . . . 85

CHAPTER 5. DISCUSSION . . . . . . . . . . . . . . . . . . 87

Project Considerations . . . . . . . . . . . . . . . . 87

Some Qualitative Results from the Telephone Survey . . . . . . . . 88

Personal Freedom and Belt Discomfort . . . . . . . . . . 89

The $\$ 25$ fine... . . . . . . . . . . . . . . . . . 89

Myths .......................... 90

The Lack of a Seat Belt Habit . . . . . . . . . . . . . . . 90

The Lack of Seat Belt Enforcement . . . . . . . . . . . . 90

A Complex Decision. . . . . . . . . . . . . . . . . . 91

Implications of Belt Non-Use by High Risk Drivers . . . . . . . . . 91

Strategies to Increase Seat Belt Use . . . . . . . . . . . . . . . 93

Target Groups . . . . . . . . . . . . . . . . . . . 94

Groups Whose Belt. Use Was Unchanged by the Law . . . . . . . . 94

Messages About Myths and Seat Belt Effectiveness . . . . . . 95

Messages About Various Driving Situations . . . . . . . . . . 95

Items That Would Produce Belt Wearing "Every T'ime You

Get Into Car" .. . . . . . . . . . . . . . . 96

Thoughts on Seat Belt Messages . . . . . . . . . . . . 96

Strategies Pertaining to Enforcement of the Law . . . . . . 97

Health and Lifestyle. . . . . . . . . . . . . . . . . 98

Recommendations... . . . . . . . . . . . . . . . . 98

REFERENCES . . . . . . . . . . . . . . . . . . . . . . 101

APPENDIX A: Summary Tables from Literature Review

APPENDIX B: Mailback and Telephone Survey Forms

APPENDIX C: Mailback Survey - Supplementary Tables

APPENDIX D: Telephone Survey - Supplementary Tables 
LIST OF TABLES

Fage

Table 3.1. Weighted response distributions for selected questionnaire items . . . . . . . . . . . . . . .

Table 3.2. Current self-reported belt use cross-classified by observed belt use . . . . . . . . . . . . . 26

Table 3.3. Self-reported belt use at time of survey by observed belt use . . . . . . . . . . . . . . . . . .

Table 3.4. Differences between users and non-users, as defined by current self-reported belt use and observed belt use . . . .

Table 3.5. Education by observed and current self-reported beit use . . . . . . . . . . . . . . . . . . . .

Table 3.6. Number (percent) of prior accidents by current selfreported belt use . . . . . . . . . . . . . . .

Table 3.7. Number (percent) of prior violations by current self-reported belt use . . . . . . . . . . . . .

Table 3.8. Analysis of variance from a model with violations as the dependent variable . . . . . . . . . . . . .

Table 3.9. Single and multiple vehicle accidents by current selfreported belt use . . . . . . . . . . . . . . .

Table 3.10. Reasons for wearing belts by reasons for not wearing belts

Table 4.1. Planned versus actual distribution of telephone survey belt groups ....................

Table 4.2. Characteristics of the distribution of telephone survey respondent's belt wearing . . . . . . . . . . . .

Table 4.3. Percentage estimates of belt use among groups of telephone respondents . . . . . . . . . . . . . . .

Table 4.4. Characteristics of reported beit use by friends for each respondent belt group . . . . . . . . . . . . .

Table 4.5. When telephone respondents first started wearing belt . .

Table 4.6. Effect of various driving situations on belt use of part-time wearers from the telephone survey (percent indicating more likely than usual to wear a seat belt)... 


\section{LIST OF TABLES (Con't)}

Page

Table 4.7. Amount of fine that would produce belt wearing on every trip.........................

Table 4.8. Items that would produce belt wearing for every trip (percent of telephone respondents indicating a positive response) . . . . . . . . . . . . . . . . .

Table 4.9. Telephone respondents' feelings about belts and the North Carolina law . . . . . . . . . . . . . . . . . .

Table 4.10. Telephone respondents' reported accident experience and impact on belt use................ . 74

Table 4.11. Reported violation experience and impact on belt use . . . 77

Table 4.12. Perceived belt use by local law enforcement officers. . . . 81

Table 4.13. Opinion regarding use of "seat belt salute" to encourage belt use. . . . . . . . . . . . . . . . . . . .

Table 4.14. Health behavior of telephone respondents and relationships to belt use and risk group . . . . . . . . . . . 
Figure 3.1. Predicted proportions of groups with one violation or more ..................... 34

Figure 3.2. Change in belt use by demographic and driver history factors ...................... 40

Figure 3.3. Reasons for using seat belts by demographic and driver history factors . . . . . . . . . . . . . . . .

Figure 3.4. Reasons for not using seat belts by demographic and driver history factors . . . . . . . . . . . . . 44

Figure 3.5. Anti-seat belt group membership as a function of education and prior violations . . . . . . . . . . .

Figure 4.1. Respondents' opinions regarding six statements about seat belts by telephone survey belt group . . . . . . . .

Figure 4.2. Telephone respondents' main reasons for supporting and opposing the North Carolina seat belt law ........ . 


\section{EXECUTIVE SUMMARY}

\section{Introduction and Objectives}

As of this report, 32 states and the District of Columbia have enacted mandatory safety belt use laws. Many lives have been saved and injuries avoided as a result of these laws. However, the effects have not been as great as anticipated based on observed belt use rates and the estimated effectiveness of belts in crashes. It has been speculated that this results from non-use of belts by people who are at higher risk of crash involvement.

This project was carried out to examine the overrepresentation of nonusers of seat belts in crashes, and to make programmatic recommendations for increasing belt use. Specifically, its goals were:

1. To determine whether belt non-users are overrepresented in crashes, and whether these crashes are different from the crashes of belt users; and

2. To contact non-users to learn about their reasons for non-use and to identify programs that might bring about a change in their behavior.

Method

To examine whether non-users of seat belts have worse crash records than users, 10,000 color coded surveys identifying belted and unbelted drivers were distributed at a probability sample of 72 North Carolina sites. The surveys were distributed in June/July, 1987, some 21 months after the N.C. seat belt law went into effect, and six months after initiation of a $\$ 25$ fine for noncompliance. The 72 sites are those being used to calculate statewide belt use rates and are stratified by region of state and urban/rural location. Questions on the brief mailback survey asked about personal belt use before the N.C. belt law went into effect, during the warning period of the law, and since the $\$ 25$ fine went into effect. Other questions concerned opinion of the law, reasons for wearing/not wearing belts, and perceived accident risk.

Respondents to the mailback survey were also requested to provide their name, address, telephone number and date of birth. Telephone numbers were needed to contact persons willing to participate in a more in-depth telephone interview. The other identj.fying information was needed to match survey respondents to the N.C. driver history file, in order to obtain information on prior accidents and violations. To encourage response, each survey "packet" contained a newly published N.C. road map and a pen inscribed with "A pen for 
your thoughts." Respondents were also informed that their names would be entered into a drawing for a $\$ 500$ cash prize (and a possible second $\$ 500$ prize if they participated in the telephone survey).

A total of 5,074 mailback surveys were returned for an overall survey response rate of 51 percent. Of these, 4,505 (90 percent) were successfu11y linked to their driver histories and used in the primary analysis.

In addition to the mailback survey, a telephone survey of a smaller sample of belt users and non-users was conducted to gain further insight into why people do or do not use seat belts, and possible approaches for increasing seat belt use. Participants in the telephone survey were selected from the mailback survey returns after matching with the driver history file. The sampling scheme oversampled (1) high risk drivers, and (2) sometimes and most-of-thetime belt wearers, since these groups were felt to offer the greatest potential "payoff" from programmatic interventions to increase belt use. High risk drivers were defined as those with

$$
\begin{aligned}
& 2 \text { or more accidents, } \\
& 2 \text { or more violations, or } \\
& 1 \text { accident and } 1 \text { violation }
\end{aligned}
$$

over the four-year period 1983-1986. The specific sampling scheme was:

\begin{tabular}{llc}
\multicolumn{1}{c}{$\begin{array}{c}\text { Belt Use } \\
\text { Group }\end{array}$} & $\begin{array}{l}\text { Risk } \\
\text { Group }\end{array}$ & $\begin{array}{c}\text { No. of } \\
\text { Interviews }\end{array}$ \\
Never, Rarely & High & 30 \\
& Low & 20 \\
Sometimes, Mostly & High & 60 \\
& Low & 40 \\
Always & High & 30 \\
& Low & 20
\end{tabular}

The telephone surveys generally lasted about 15 minutes and included questions on current seat belt use, beliefs and attitudes concerning belts, reasons for favoring/opposing the N.C. mandatory belt law, media messages about belts, past accident experiences and their effect on belt use, encounters with $₹$ law enforcement officials, and some general health/lifestyle practices. Responses to all of these questions were examined to provide input to programmatic ideas for increasing belt use. 
Overrepresentation of Non-Users in Accidents and Violations

The analysis found that non-users of seat belts are overrepresented in accidents and violations. Average numbers of accidents and violations per observed belted and unbelted driver over the four-year (1983-1986) period were:

\begin{tabular}{cccc} 
Observed Belt Status & $\underline{N}$ & $\begin{array}{c}\text { Average } \\
\text { Accidents } \\
\text { Per Driver }\end{array}$ & $\begin{array}{c}\text { Average } \\
\text { Violations } \\
\text { Per Driver }\end{array}$ \\
\cline { 1 - 2 } Belted & 2759 & 0.20 & 0.32 \\
Unbelted & 1746 & 0.27 & 0.54
\end{tabular}

On average, each unbelted driver had 35 percent more accidents and 69 percent more violations than did each belted driver.

In the same four-year period, of those drivers observed wearing belts

$83 \%$ had no prior accidents while

$17 \%$ had one or more.

Of those observed not belted

$79 \%$ had no accidents while

$21 \%$ had one or more.

Similarly, of the belted drivers

78\% had no prior violations,

$16 \%$ had one violation, and

$6 \%$ had two or more,

while of the drivers observed not wearing belts

$69 \%$ had no prior violations,

$19 \%$ had one violation,

$12 \%$ had 2 or more violations.

The question of overrepresentation in accidents and violations was further explored utilizing current self-reported belt use. Average numbers of accidents and violations over the four-year (1.983-1986) period were:

$\begin{array}{ccc}\begin{array}{c}\text { Current } \\ \text { Self-Reported } \\ \text { Belt Use }\end{array} & \begin{array}{c}\text { Average } \\ \text { Accidents } \\ \text { Per Driver }\end{array} & \begin{array}{c}\text { Average } \\ \text { Violations } \\ \text { Ner Driver }\end{array} \\ { } } & .28 & .69 \\ \text { Always } & .25 & .46 \\ \text { Sostly } & .21 & .31\end{array}$


Similar to the observed belted-unbelted results, the never-rarely wearers have, on average, 33 percent more accidents than the always wearers, and these differences are statistical1y significant $(p=.016)$. The relationship is monotonic, with accident involvement increasing with decreasing belt use.

Overrepresentation of non-users with respect to violations over the same four-year period is more pronounced. The never-rarely violation rate was more than twice as large as the always violation rate. Again, violation histories get progressively worse as frequency of belt use decreases.

There are many other factors that are correlated both with driver belt use and with accident and violation records. For example, young males also tend to have the highest accident and violation rates. Therefore, it was of interest to investigate the extent to which the differences in accident and violation rates between the belt use groups could be accounted for by differences in the group demographic composition. To this end higher dimensional tables were generated and categorical models were developed to model the proportions of drivers having one or more accidents and one or more violations as a function of belt use status and other factors.

Models were developed using both observed belt use and current selfreported belt use. Models for the proportion having accidents contained significant effects for belt use (both observed and self-reported) in addition to effects due to driver age and sex.

For the models concerned with violations, the variables of age, sex, annual mileage, and belt use could be taken into account. Figure 1 shows a plot of the predicted proportions having one or more violations as a function of current self-reported belt use. All factors and the age-by-sex interaction are highly significant, and the model fits well to the data. The effects of the belt use category can be seen clearly within each subpopulation defined by combinations of the other variables. Similar results were obtained in a model that substituted observed belt use for current self-reported belt use. These modeis show that drivers who do not wear seat belts tend to have worse driving records than those who do, even after demographic differences have been taken into account. 


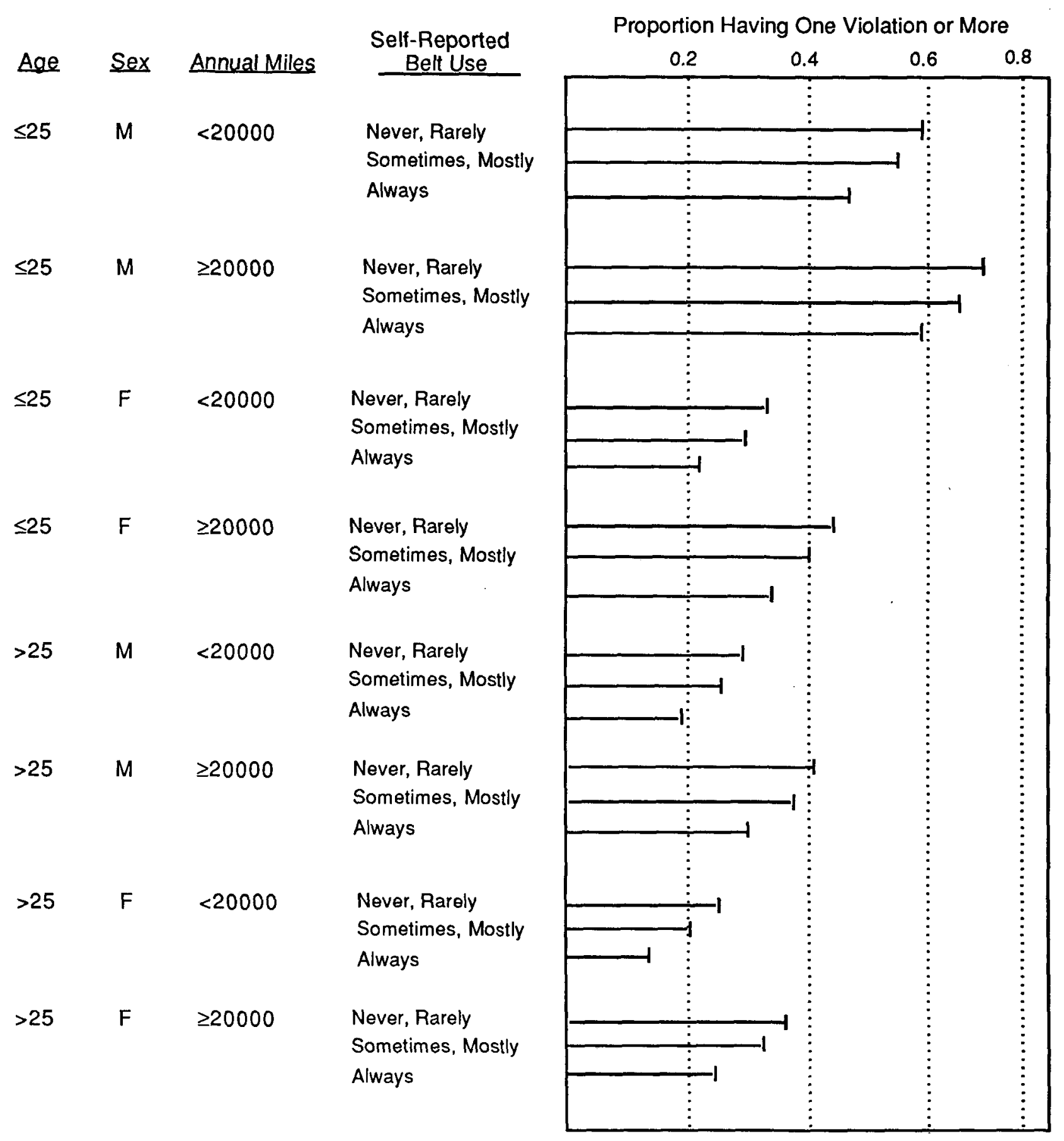

Figure 1. Predicted proportions of groups with one violation or more. 
Differences Between the Types of Accidents and Violations of Belt Users and Non-Users

Differences between the accidents and violations of belt users and nonusers were examined again using driver history records involving the mailback survey respondents in calendar years 1983-1986. Concerning accidents, contingency tables of current self-reported belt use by a variety of accident factors (e.g., acciden severity, speed of the accident, accident type, etc.) were examined. The 1,038 actual crashes of belt users and non-users were utilized in the analysis.

Results showed that the accidents of belt users differed statistically from the accidents of belt non-users only with respect to single vehicle accidents, rollover accidents, and accidents in which the driver is charged with a violation. The percentages of crashes by self-reported belt group were:

\begin{tabular}{|c|c|c|c|}
\hline $\begin{array}{l}\text { Current } \\
\text { Self-Reported } \\
\text { Belt-Use } \\
\end{array}$ & $\begin{array}{l}\text { Single } \\
\text { Vehicle } \\
\text { Accidents } \\
\end{array}$ & $\begin{array}{l}\text { Charged } \\
\text { Rollover } \\
\text { Accidents } \\
\end{array}$ & $\begin{array}{l}\text { Drivers } \\
\text { with a } \\
\text { Violation } \\
\end{array}$ \\
\hline Never, Rarely & $14 \%$ & $7 \%$ & $31 \%$ \\
\hline Sometimes, Mostly & $10 \%$ & $2 \%$ & $20 \%$ \\
\hline Always & $5 \%$ & $2 \%$ & $20 \%$ \\
\hline
\end{tabular}

Given differences with respect to these three variables, it seems rather surprising that factors such as accident severity, vehicle deformation, and accident speed did not also vary over the belt use categories, since single vehicle and rollover accidents generally tend to be more severe. Such was not the case. Even so, the group reporting never or rarely to use seat belts seems to be involved in accidents which differ from those of the rest of the North Carolina driving population, namely, single venicle crashes, rollovers, and accidents in which the driver is charged with a violation.

Similar to the accident analysis, contingency tables were anaiyzed to determine if non-users had higher rates of serious violations; namely, reckless driving and alcohol violations. In three separate analyses involving reckless driving, alcohol violations, and reckless and alcohol combined, no 
statistically significant relationships were found between current selfreported belt use and these serious violation types.

Additional Analyses Concerned with Identifying Target Groups for Seat Belt Programs

Some additional analyses were carried out which may help to identify target groups for seat belt promotion programs. Examining subpopulations within those who increased belt use as a result of the law, we found that:

- A higher percentage of female drivers increased their belt use than did male drivers.

- The percent of drivers increasing their belt use was much higher for non-white drivers than for white drivers.

- A very low percent of drivers having two or more prior violations increased their belt use, while a relatively high percent continued never or rarely to use seat belts.

Analysis of two questionnaire items concerning reasons for wearing and not wearing seat belts revealed that, relative to college graduates, drivers who did not complete high school are about three times as likely to give "avoiding the fine" as their prinary reason for wearing seat belts, and "fear of being trapped" as their reason for not wearing belts. College graduates are about twice as likely to list "safety" and "forget" as their reasons for wearing and not wearing belts. The group of respondents with two or more prior traffic violations had the highest percentage indicating that avoidance of the fine was their primary reason for wearing seat belts.

These results suggested that some combinations of factors might produce an even greater spread in the distribution of responses. A three-way tabulation of number of prior violations by education by reasons for wearing seat belts showed that for the subpopulation who only completed grade school and had two or more prior violations, 36.4 percent wore seat belts to avoid the fine, while only 15.2 percent listed safety as the primary reason. At the opposite extreme, of those who had completed college and had no prior violations, 8.6 percent said they used seat belts to avoid the fine, while 48.7 percent listed safety as the primary reason. Thus, drivers with histories of violations and relatively low educational levels might be potential candidates for educational or other programs on seat belt safety. 


\section{Characteristics of Users and Non-Users of Safety Belts}

A telephone survey was constructed with the primary purpose of discovering reasons for using or not using belts by different groups of belt wearers (based on their observed or self-reported belt use). High risk drivers and part-time wearers were oversampled in an attempt to better uncover programmatic ideas concerning ways to increase belt use. Two hundred interviews were planned, and 204 were completed.

North Carolina's mandatory belt law had a definite impact on belt wearing. Almost half of the rarely and sometimes wearers said they first started wearing a belt when the $\$ 25$ fine for non-compliance became effective. When asked about factors that influenced belt wearing, almost half of the respondents said they started wearing belts because of the law or the $\$ 25$ fine. Examining responses within belt groups, always and most-of-the-time wearers tended to state safety reasons for starting to wear belts, and rarely and sometimes wearers gave the $\$ 25$ fine as their primary reason for wearing belts.

A series of six statements were developed to gauge opinions about some frequently stated seat belt issues (e.g., "In an accident, it's better to be thrown out of the car than to stay inside"). A five-point. Likert scale ranging from strongly agree to strongly disagree was used to assess the attitudes of the respondents. It was clear that more educational information is needed to explain the effectiveness of belts and to counter fears about belts trapping people inside vehicles.

Seven different driving sj.tuations were presented to all but the never and always respondents to learn which situations would be "more likely than usual" to prompt belt use. The most likely situations to increase belt wearing overall were driving in bad weather, driving with children in the car, and making a long trip.

When asked, "What amount of fine would get you to wear your seat. belt EVERY TIME you get in a car?" 40 percent stated (without prompting) that no amount of fine would affect their belt use. This group contained two-thirds of the never wearers and one-half of the rarely wearers.

Following the question about the fine amount, a list of eight items was presented, and respondents were asked if any of these would get them to "buckle up" on every trip. The ideas generating the most positive responses overall were:

- Having the car insurance payment greatly reduced (69\%), 
- Having points assessed on the driving record in addition to the fine for belt non-use $(69 \%)$,

- Having a belt that was more comfortable or easier to use (62\%), and

- Having been personally stopped and ticketed for belt non-use $(58 \%)$.

Several questions on the survey were devoted to issues concerned with communicating seat belt information. The advertisement recalled most frequently involved the NHTSA crash dummies Vince and Larry, with about half of each belt wearing group mentioning the dummies. When asked who would be good seat belt spokespersons, television or movie celebrities were most frequently mentioned (including Bill Cosby and Barbara Mandre11). About 15 percent of the never and sometimes wearers mentioned race car drivers.

A series of questions was asked to examine how previous accident experience might impact on current use of seat belts. One-third indicated that an accident had affected their use of belts - 30 percent positively (their use had increased) and three percent negatively. The never and rareiy wearers were more likely to respond that belts did not or would not have heiped prevent injuries.

Seventy percent indicated that an enforcement encounter had not affected their belt use, and 30 percent that it had. The impact was greatest for the sometimes and mostly wearers, approximately half of whom reported an increase in belt wearing following their encounter with the law. The drivers who had been observed unbelted during the mailback survey were less likely to feel that the law was being strongly or somewhat strongly enforced, while black drivers were twice as likely as white drivers to feel that the law was being very strongly or strongly enforced. The never wearers were the most likely to report that some law enforcement officers in their community do not always wear seat beits. Finally, almost 90 percent of all respondents felt that using "seat belt salutes" (i.e., a reminder tug on the shoulder beli) was a good way for law enforcement officers to encourage belt use (with all of those 25 years old or younger agreeing).

Various target groups for seat belt promotion activities were identified, but the two that perhaps stand out most clearly are those drivers with two or more prior violations and drivers who did not complete high school. When these 
respondents wear belts it is most often to avoid the $\$ 25$ Fine. Moreover, they often give fear of being trapped or belt ineffectiveness as reasons for not wearing belts.

Recommendations

Specific recommendations growing out of the project are:

1. National television special programming of one hour in duration should be developed to deal with the topic of seat belts.

2. There needs to be more interaction with NASCAR, the national stock car racing association, in various seat belt promotions.

3. More research and demonstration projects are needed that concern learning how to increase the level of seat belt law enforcement.

4. The auto industry should strive to develop belt systems that are more comfortable, acceptable, and have a better fit. 


\section{Background}

As of March, 1988, 32 states and the District of Columbia had enacted mandatory safety belt laws (Highway and Vehicle Safety Report, March 14, 1988). Evaluators following the progress of belt use rates in these states have found a rapid increase in belt use once laws become effective, followed in many instances by a decline. The primary enforcement states (i.e., states in which the violation of the belt law alone constitutes grounds for stopping the vehicle) have shown generally higher use rates than states with a secondary enforcement provision (Campbe11, Stewart and Campbe11, 1987). Regardless of use levels, anticipated savings in terms of lives lost and injuries avoided have not been fully achieved.

In October, 1985, North Carolina implemented a mandatory seat belt use law. The law requires that drivers and front seat occupants of passenger motor vehicles manufactured with seat belts have the available belts properly fastened whenever their vehicle is in forward motion on a street or highway. The law became effective October 1, 1985. Warning tickets were issued to violators during the fifteen-month period between October 1, 1985 and December 31, 1986. Since January 1, 1987, violators have been subject to a $\$ 25 \mathrm{fine}$. North Carolina is a primary enforcement state.

The University of North Carolina Highway Safety Research Center (HSRC) is conducting an on-going evaluation of this law. The evaluation includes periodic statewide observational surveys of on-road belt use, coupled with motor vehicle injury and fatality analysis. The North Carolina belt use surveys have frequently revealed usage rates as high as any other state in the country. However, like other states we have not experienced the extent of injury reduction that might be expected. It has been speculated that this results from non-use of belts by people who are at higher risk of crash involvement.

With this background in mind, the goals of this project were twofold:

1. To determine whether belt non-users are overrepresented in crashes, and whether these crashes are different from the crashes of belt users; and

2. To contact non-users to learn about their reasons for non-use and to identify programs that might bring about a change in their behavior. 
Approach to the Problem

Two approaches were considered to study whether non-users of seat belts have worse crash records than users. Both of the approaches involved observed as well as self-reported belt use. Past experiences have shown self-reported belt use to be inflated (Waller and Barry, 1969), and in the presence of a mandatory belt law one would anticipate even greater inflation.

The first of the two approaches involved searching the state driver history file to identify a group of drivers with poor records, arranging a situation in which their belt use could be observed, then making comparisons with the belt use practices of drivers with clean records. In exploring this approach, about 4.7 million records from the most recent four years of the North Carolina driver history file were examined to update the Stewart and Campbel1 (1972) distributions of drivers by number of crashes and violations during various time periods. This showed that only one-tenth of one percent of drivers have three or more crashes in a two-year period, and two hundredths of one percent have four or more crashes in the same period. The problems in contacting and assembling such an outlying group of drivers to observe their belt use would be great. In addition, it was felt that studying a group so far removed from the mainstream accident population would not produce the desired programmatic input.

Consequently a second approach was adopted, based on the procedures used to establish statewide belt use rates in the HSRC evaluation of the North Carolina seat belt law. The statewide use rates derive from surveys in which observers stationed at pre-selected sites gather belt use data for the front seat occupants of vehicles targeted by the belt law. A probability sample of 72 sites spread across the entire state is utilized yielding a representative sample of North Carolina drivers.

To gather data for the current project, color coded surveys identifying belted and unbelted drivers were distributed at all 72 data collection sites. Drivers were asked to mail back a brief survey form that included a request for their name, address, and date of birth. As incentives, their survey packet contained a N.C. road map and pen, and drivers were told that their returned survey form would be their entry for a $\$ 500$ drawing. With the requested identifying information, it was possible to link the returned surveys to the driver history files to obtain the necessary data to examine overrepresentation 
of belt non-users in crashes. In addition, several risk and usage rate subgroups were identified from which to sample for telephone interviews concerning reasons for belt use and non-use. Participants in the telephone interviews were eligible for an additional $\$ 500$ drawing.

Concurrent with the implementation of the grant project described above for North Carolina, the National Highway Traffic Safety Administration also had in place a related effort in Michigan. The University of Michigan Transportation Research Institute (UMTRI) used trained observers to record restraint use for a probability sample of motorists on Michigan roadways. Roadside interviews with almost 1,900 drivers then measured a variety of factors related to belt use (Wagenaar, Streff, Molnar, Businski, and Schultz, 1987). HSRC received copies of the questionnaire used by UMTRI and in a few instances asked similar questions on either the mailback or telephone surveys. References to the UMTRI findings will be made in later chapters of this report.

\section{Literature Review}

The literature review was focused on the following questions:

- Are seat belt non-users overrepresented in traffic crashes?

- What are the characteristics of belt non-users?

- How do belt non-users differ from belt users?

A wide range of studies was reviewed, including studies from other countries (Canada, Great Britain, Sweden, and others) and studies conducted in the presence and absence of a mandatory use law (MUL). Since the characteristics of belt users and non-users can be expected to vary under MUL versus non-MUL conditions, this has been taken into consideration in the discussion.

\section{Overrepresentation of Seat Belt Non-Users in Crashes}

The assumption that persons who do not wear seat belts are more likely to become involved in crashes has been with us almost since seat belts were first introduced as an automotive safety feature. However, evidence is conflicting. In one of HSRC's earliest published reports, Campbel1 (1969) compared observed belt use among drivers in the population at risk with reported belt use for drivers in crashes investigated by the North Carolina State Highway Patrol. He found belt use to be "consistently and considerably greater in the non-accident population." Campbell's recommendation even at this early point in time was 
that for maximum effect, seat belt promotion attempts should be aimed more directly at identifiable groups known to have higher crash involvement rates.

In another HSRC study, however, no significant relationship was found between belt use and prior driving record (Waller and Barry, 1969). In an effort very similar to the current study, the authors observed belt use for a sample of drivers on the road, at the same time recording license plate numbers so that their observations could be linked with a name, address, and driver history. Questionnaires were then mailed to the driver sample to obtain selfreported belt use on both local and long distance driving. Results of the analysis showed that observed and self-reported belt use "matched" better on local trips than on long distance trips: 77 percent of the drivers reporting that they "always" wore belts on local trips were observed buckled up at an intown setting, compared with 46 percent of drivers reporting that they "always" wore belts on longer trips ( $>25$ miles) and observed out-of-town. More importantly for this discussion, no significant relationship was found between either observed or self-reported belt use and past driver record.

These studies were both conducted long before any mandatory belt use laws. The issue of overrepresentation of non-users of seat belts in crashes, however, has drawn increased attention in recent years with efforts to evaluate the effectiveness of mandatory seat belt legislation. In one of the earlier published evaluations of mandatory belt use laws, Robertson and Williams (1978) suggest that one reason that belt laws did not reduce deaths and injuries as much as expected in the four countries they examined was that "belts are less often worn by persons disproportionately involved in severe crashes particularly teenagers and persons driving with high blood alcohol concentrations."

Examining belt use, injury, and fatality data from 27 countries and four Canadian provinces with belt laws, McCarthy, Taylor, Sanford and Lange (1984) also found a lower than expected reduction in injuries. They note that, "Drivers who generally exhibit more risk-taking behavior and who have the most automobile accidents, are the least likely to comply voluntarily with the seat belt law, and are the last drivers to be affected by enforcement programs." Some earlier Canadian studies (Bragg (1973) and Hannah (1975), as cited in Heron (1975)) found no relationship between self-reported belt use and crash involvement. A survey of licensed U.S. drivers conducted in 1979 also found no relationship between self-reported belt use and crashes (Teknekron Research 
Inc., 1977). However, more recent studies based on observed belt use and police reported accident data do show a trend of higher crash involvement for non-users of seat belts. Evans and Wasielewski (1983) mounted cameras on overpasses outside Detroit and Toronto to use in measuring vehicle headways (following distances) and recording associated vehicle and driver characteristics, including license plate numbers. More specific information on the Michigan observations was then obtained from state data files. Their findings showed a relationship between likelihood of crash involvement and a number of driver characteristics including age, sex, number of traffic violations and seat belt use.

In a similar study of observed speeds and driver/vehicle characteristics, Wasielewski (1984) also found a decrease in belt use for drivers with crashes or violations (but no relationship between driving speed and belt use). Jonah and Lawson (1986) report on two more recent Canadian studies conducted since passage of mandatory belt legislation -- one using observed belt use and matched driver record data (Grant, 1986) and the other self-reported belt use and crash experience (Wilson, 1986). Both showed a modest correlation between belt use and previous crash involvement.

More recently Evans (1987a) has attempted to quantify relative accident involvement rates for belted and unbelted drivers. Using data from the Fatal Accident Reporting System (FARS) along with observed belt use and driver crash/violation data for a sample of Michigan drivers, he calculated involvement rates for belted and unbelted drivers in various traffic events (police-reported crashes, crashes where a driver was killed, etc.). The involvement rates for unbelted drivers ranged from 28 to 86 percent higher than those for belted drivers, with an average overinvolvement rate of 53 percent.

Evans used the phrase "selective recruitment" to describe the phenomenon whereby as belt rates increase, the remaining non-users have successively higher crash involvement rates. In an analysis of expected fatality reductions from increased safety belt use, he demonstrated that selective recruitment can sometimes increase and sometimes decrease expected fatality reductions, depending on the initial use rate and the size of the increase (Evans, 1987b). For example, an increase in belt use from 10 percent of the driving population to 24 percent would produce an expected fatality reduction of 4.6 percent without considering the effects of selective recruitment, and 3.2 percent with selective recruitment taken into account. When use rates and increases are 
higher, the effect is an increase in estimated fatality reductions. Evans gives as an example a belt use increase of from 50 to 90 percent yielding an estimated fatality reduction of 21.9 percent without, and 23.9 percent with, selective recruitment taken into account. The overall effect of selective recruitment was found to be small, never exceeding \pm 5.3 percent.

To summarize this section, there is evidence from both U.S. and foreign studies that drivers who do not wear seat belts are overrepresented in traffic crashes. This difference holds across MUL and non-MUL settings, and may help to explain why the benefits derived from increased belt use may not be as great as anticipated.

\section{The Relationship of Belt Use to Other Risk Behaviors}

In addition to its association with crash involvement, belt use has been found related to a variety of other known health-risk behaviors. Findings here are not entirely consistent, but do show non-users of seat belts to engage more frequently in at least some of the identified high-risk behaviors.

Results from the literature are summarized in Appendix Table A.1. Generally they show that, compared to belt users, belt non-users are more likely to smoke, more likely to drink and/or drink and drive, less likely to exercise, less likely to have regular dental/eye/health checkups, and more likely to engage in various risk-related behaviors when driving (speeding, following too closely, etc.). Results are mixed concerning whether belt users are more likely than non-users to have violations on their driving records.

It should be noted that these studies are all U.S. or Canadian studies carried out prior to enactment of any mandatory belt use legislation. What effect, if any, such legislation might have on the relationship of seat belt non-use to other health-risk behaviors is not known.

\section{Other Characteristics of Belt Users and Non-Users}

The literature contains a wealth of studies describing more generally the differences between seat belt users and non-users. Included here are demographic differences (age, sex, socio-economic status, etc.), situational factors such as trip length or presence of passengers, perceptions of accident risk, and attitudes and opinions concerning belts and belt use laws. Appendix Table A.2 highlights only those study findings that are relevant to the current project effort. While this approach necessarily ignores some very important 
study outcomes, it maintains the focus on this project's objective of identifying the distinguishing characteristics of seat belt users and nonusers,

At the outset it should be noted that the studies appearing in Table A.2 represent a cross-section of countries and a mix of mandatory use law (MUL) and non-MUL settings. As with the risk-related findings already discussed, one can anticipate that this mix of settings will contribute to conflicting results.

Factors most often found related to seat belt use are age, sex, education level, socioeconomic status (SES) and income. Of these, education and the related factors of SES and income are the most consistent. Part of their effect is likely attributable to their impact on car model year, i.e., better educated people get better jobs, make more money, and drive newer model cars with more convenient and comfortable belt systems. And in fact, in some of the earlier studies these factors were not significantly related to belt use once model year of car was held constant. Nevertheless, education, SES and income continue to surface in the more recent studies, and in MUL and non-MUL settings.

The literature is mixed in reporting of any age and sex differences among belt users and non-users. Results in the presence of MULs generally show belt use to be higher for females and linearly proportional to age. In the absence of a MUL age and sex effects are much less consistent: sometimes males are found to have the higher use rate, and older drivers join with the younger drivers in having generally low belt use rates.

Results are also mixed regarding situational factors such as trip length, annual mileage, and highway versus local driving. Trip length was not found to be a factor by Wagennar et al. (1987), but was for Mayas et al. (1983) and Marzoni (1971) (a11 surveys of U.S. drivers, the first conducted in a MUL setting). Similarly, annual mileage was identified as a factor associated with belt use by Fhaner and Hane (1979) in post-MUL Sweden, but not by Heron (1975) in a review of Canadian studies conducted prior to MULs. And finally, Jonah and Dawson (1982) and Bragg (1973) report higher belt use when driving on Canadian highways versus local streets, while Heron (1975) reports that belt use by Canadians is not related to road type most of ten driven.

One issue where agreement does exist concerns the effect of perceived accident risk on belt use. Here, belt use is higher among persons perceiving either a high or a low risk of accident involvement, and lower for those 
perceiving themselves at moderate risk (Jonas \& Lawson, 1986; Heron, 1975; Bragg, 1973). (The theory here is that low and high risk drivers choose to wear belts for different reasons: low-risk drivers as part of a generally cautious and risk-lowering lifestyle, and high-risk drivers in order to protect themselves from their recognized higher propensity for accidents.) Reasons for belt use and non-use are also remarkably consistent, with reasons for use centering on the issues of safety and habit and reasons against use centering on comfort and convenience, the absence of a belt habit, and fear of entrapment.

In addition to these findings and as noted earlier in this chapter, the HSRC has conducted a series of statewide belt observation surveys beginning in September 1985, just prior to enactment of the North Carolina belt law. For these surveys, data is collected on driver and front seat occupant belt use, sex, and race, along with vehicle type (passenger car, pickup, etc.). Linked with this data is information on urban/rural location, region of State (coast, piedmont or mountain) and time of day (commuting, non-commuting). An analysis of the results of the surveys through August 1987 (Reinfurt, Campbell, Stewart and Stutts, 1987) shows higher post-MUL belt use for females, blacks, and persons riding in passenger cars and vans rather than pickups, utility vehicles, etc. The higher use rates for blacks in a post-MUL setting are of particular interest since prior to the MUL, belt use among blacks had been consistently and considerably lower than among whites.

\section{Survey Methodology Literature}

A final group of references provided extremely useful input to the design and construction as well as implementation of the mail and telephone surveys: a 1978 publication by Don Dillman entitled, Mail and Telephone Surveys: The Total Design Method, and two marketing texts, one by Gilbert Churchill (Marketing Research: Methodological Foundations, 1987 Edition) and the other by Boyd, Westfall and Stasch (Marketing Research: Text and Cases, 1985

Edition). Also helpful was a publication from the N.C. State Center for Health Statistics entitled, "Questionnaire Design" (Bowling, 1986).

Several other survey references were more specifically focused on ways to increase response rates (O'Rourke and Blair, 1983; Yu and Cooper, 1983; and Kanuk and Berenson, 1975). While it was not possible for us to follow through with many of the recommendations presented (e.g., we could not send out follow- 
up reminder notices or give preliminary notification), other suggestions did make their way into the final surveys (e.g., use of incentives, inclusion of a stamped return envelope, and assurance of anonymity). 
CHAPTER 2. METHODOLOGY

This project involved two surveys of North Carolina drivers: a short mailback survey distributed to 10,000 drivers in conjunction with ongoing statewide belt use observations, and a more in-depth telephone interview of a specially selected subsample of 200 drivers drawn from the mailback returns. The first (mailback) survey was conducted in June/July 1987, six months after initiation of the $\$ 25$ fine for non-use of seat belts. The telephone survey followed in late October/November.

The following sections describe in greater detail the development and implementation of the two surveys, data processing and linkage with state driver history and accident files, sample characteristics, and analysis methods.

\section{Mailback Survey}

\section{Overall Design}

The mailback survey was planned to "piggyback" onto North Carolina's ongoing evaluation of its mandatory seat belt law. As part of this evaluation, HSRC regularly collects belt use data at 72 randomly selected sites across the State. The sites are stratified by region of the State (Mountain, Piedmont or Coast), urban/rural location, and time of day (weekday rush, weekday non-rush, or weekend). They are all intersection locations, selected so that the data collectors can position themselves close enough to the vehicles to stop them if needed to check on belt use. Thus, we planned to build upon regularly scheduled seat belt observations by having our data collectors hand out the mailback surveys at the same time that they observed and recorded belt use data.

There are several advantages to this approach, in addition to the obvious cost savings. First, we were able to reach a sample of drivers "on the road" as distinct from, say, a sample of "licensed drivers," "registered voters," etc. This we feel is the most appropriate target population for studying belt use opinions and behaviors. Also, by building upon an ongoing survey, we benefitted from our familarity with the data collection sites and, more importantly, the input of data collectors experienced working at these sites. Another expected advantage to merging with the ongoing statewide belt observations was an increased response rate resulting from the personal contact 
between the data collectors and potential respondents. And finally, by handing out color coded survey forms, we had a measure of observed belt use that could be compared with self-reported belt use and used as an additional dependent variable in our analysis.

Questionnaire and Incentive Development and Pilot Testing

A goal of the mailback survey was to obtain basic belt use information from a large sample of North Carolina drivers. We were interested in learning about their self-reported belt use before enactment of the law, during the warning phase, and since the $\$ 25$ fine went into effect. We also wanted information on why people did or did not wear belts, their perceptions of the risks involved in driving, and their overall opinion of the N.C. law.

Beyond this information, we needed the mail survey respondents to give us their full name, address and date of birth so that their survey results could be linked to their driver history records. For those willing to participate in the follow-up telephone interview, we also requested a phone number and a best time to call.

Particularly because of this requirement for identifying information, we felt that there needed to be some incentive for encouraging response. After reviewing the literature and consulting with a marketing specialist at the UNC School of Business Administration, we opted for two forms of incentive: one an "up front" or immediate incentive distributed along with the questionnaire, and the second a "delayed" incentive contingent upon mailing back the completed survey form.

The "up front" incentives that we eventually decided upon were a newly published N.C. road map (obtained at no cost from the State Department of Commerce) and a pen for filling out the questionnaire imprinted with the message, "A pen for your thoughts" (Cost: $31 \$$ each). These materials, along with the survey questionnaire and a self-addressed, stamped envelope, were all neatly packaged into a clear zip-lock bag for easy and attractive distribution (Total packet cost: $59 \notin$ each).

The "delayed" incentive was a chance to win one of two $\$ 500$ prizes. A message on the questionnaire informed potential respondents that their names would be entered into a drawing for a $\$ 500$ cash prize (hence the need to give us their full name and mailing address). They were also told that participants in the telephone survey would be eligible for a second $\$ 500$ prize. 
The mailback questionnaire itself progressed through numerous iterations and reviews over a period of several months. A copy of the final version of the mailback survey is contained in Appendix B. The questionnaire, including a brief cover note, was printed onto a legal size sheet of paper and duplicated in green (for distribution to belted drivers) and yellow (for distribution to unbelted drivers).

The survey form and packet were pilot tested in conjunction with a regularly scheduled data collection that took place in January 1987 (immediately following enactment of the $\$ 25$ fine). A total of 200 packets were distributed. As a way to reduce the number of survey forms given to out-ofstate drivers (and thereby increase the final match rate), data collectors checked for a valid N.C. vehicle inspection sticker on the front windshield before giving out a survey form.

The overall response rate for the pilot survey was 55 percent, with a higher rate for belted than for unbelted drivers (54 versus 46 percent). All but two of the returned forms contained a complete name and address, and we were able to obtain a match with the driver history file for 90 percent of the returns.

\section{Final Sampling and Distribution Procedures}

Based on the pilot test it was determined that distribution of 10,000 packets should be sufficient to reach our overall target of 5,000 mailback responses. In order to obtain a sufficient number of responses from non-users of seat belts, we decided to over-sample this population. Thus, while only about a third of N.C. drivers were observed not wearing seat belts at the time this survey was conducted, we distributed half of our forms to these drivers, i.e., equal numbers of yellow (unbelted) and green (belted) forms were distributed at each site.

The 10,000 forms were distributed across the 72 sites proportional to the traffic volume at the site. We also took into account the number of belt observations typically made at each site. A minimum of 50 and a maximum of 400 surveys were assigned to be handed out at any given site.

Overall the distribution of the mail survey packets proceeded smoothly. Working together as a team, three of our regular data collectors were able to distribute the survey packets (and at the same time collect belt observation data) at all 72 sites over a 5-6 week period. Ground rules for handouts had 
been identified and rehearsed during the pilot testing. As an example, a driver was considered unbelted if he merely had his arm through the shoulder belt without actually buckling the harness. The data collectors informed us that this happened quite frequently. They also acknowledged that some handout errors were made in this situation when traffic volume was heavy. Another difficult situation involved the driver merely laying the belt across his lap without actually fastening the end. These errors would be realized as the vehicle pulled away and there would not be time to retract the packet. The data collectors estimated that this happened at most 50 times during handout of the 10,000 forms. Through their experience, the person handing out packets was sometimes able to spot a driver putting on the belt while approaching the handout position. In this case, the driver was considered unbelted. The driver was considered belted if the belt system was fastened, even if there was excessive slack in the shoulder belt. This is counted as a lap belted driver in normal data collection. Wearing the shoulder belt under the arm would be treated similarly.

All of the above situations could introduce error into the handout process, and indeed there were some discrepancies in observed versus reported belt use (see Chapter 3 for more detail). A good bit of this, we feel, is due to drivers misrepresenting their belt status in their self report.

\section{Data Processing}

The vast majority of the survey returns were received within three weeks of distribution. All information on the forms was keyed, including color of form (identifying observed belt use), site number, responses to the 17 survey items, and the name, address and telephone information appearing at the bottom. Once the data tapes were received at HSRC, additional quality assurance checks were made, including checks for valid site codes, response codes, etc.

\section{Return Characteristics}

A total of 5074 mailback surveys was returned for an overall response rate of 51 percent. Individual response rates across the 72 sites ranged from a low of 32 percent to a high of 69 percent, but showed only small variations across urban/rural location and region of state (Coast, Piedmont or Mountain).

As with the pilot test, we had a higher response rate from belted drivers than from unbelted drivers. The final breakdown was: 


$\begin{array}{lcc} & \text { N } & \text { Percent of Returns } \\ \text { Belted } & 3070 & 60.5 \% \\ \text { Unbelted } & 2004 & 39.5 \%\end{array}$

Despite the slightly lower than expected percentage of returns from non-belted drivers, the overall numbers remained adequate for analysis purposes.

N.C. Driver History File and Linkage to Mailback Returns

One of the project data collection goals was to match the mailback survey form with the corresponding record on the North Carolina driver history file. This would link survey answers about belt use and other variables to an individual's accident and violation record. There are approximately 5,200,000 driver history cases on file. The violation categories appearing on the record include speeding, moving violations, reckless violations, alcohol violations, etc. For each crash on an individual record, a host of data items would be available from the Standard Accident Report Form that describe the crash, driver(s), vehicle(s), and environmental conditions.

Beginning with traffic accident data from 1966, HSRC has created its own North Carolina Traffic Accident File. This process has involved transcribing the data from the Division of Motor Vehicles (DMV) file into a more readily usable form, and adding to it supplemental accident data such as safety belt usage by seat position, which otherwise would not be computerized. It is this transformed and enriched traffic accident file that HSRC uses as its data base.

Matching the mailback survey identifiers (name, address, date of birth) to the driver history file was accomplished primarily using a matching program at the DMV. Of the 5,074 survey returns, two percent had missing or incomplete identifying information and so could not be matched. Of the remaining, 85 percent were matched by the DMV program.

In order to increase the number of matched cases for unbelted drivers, project staff used HSRC's in-house DMV terminal to attempt to locate a license number for these non-matched cases. This effort resulted in $300+$ additional matches with the driver history file. Two cases were eliminated after checking for duplicate entries (i.e., receiving and sending in two survey forms), yielding a final matched total of 4,505 cases ( $90 \%$ of a11 returns). 
From this point the most recent four years (1983-1986) of the driver history file were accessed and crash and violation information appended to each mailback survey record. In addition, accident case numbers from the driver history file were linked to the traffic accident file to append crash information to the record. Thus, a complete record contained mailback survey responses, driver history data, and crash data.

\section{Telephone Survey}

\section{Purpose}

The purpose of the telephone survey was to provide more in-depth information on the characteristics of belt users and belt non-users, including reasons for wearing (not wearing) belts, beliefs and attitudes concerning belts, reasons for supporting (not supporting) the N.C. belt law, and factors that might increase belt use. We also wanted to explore (in a more subjective sense) how previous experience in crashes relates to belt use and whether or not encounters with law enforcement officers affect belt use. Finally, we wanted to examine other risk-related behaviors, such as smoking, drinking and driving, etc. to determine if these were related to seat belt use.

A major focus of the mailback survey had been to link belt use information with reported crash and violation records to study the overrepresentation of non-users of seat belts in traffic crashes. For the telephone survey, we purposely oversampled drivers who had been involved in crashes and/or who had been cited for traffic violations in order to explore further how these "high risk" drivers differed from the rest of the driving population, and what it might take to get them to wear seat belts more often.

\section{Development of Sampling Plan}

The telephone survey sample was a subset of the mailback survey respondents, selected after the mail returns had been linked with their driver histories. The decision was made to conduct 200 interviews, focusing on (1) high risk drivers, and (2) those who indicated they were sometimes or mostof-the-time belt wearers (the hypothesis being that those who already wore seat belts at least occasionally would be more amenable to programmatic interventions to increase be1t use than those who never or very rarely wore belts). High risk drivers were defined as drivers with: 
2 or more accidents;

2 or more violations; or

1 accident and 1 violation

during the four-year period 1983-1986. Low risk drivers were those with 0 accidents and 0 violations, while the remaining drivers composed an intermediate risk group.

Table 2.1 shows how the various belt use and risk categories were represented among the mail survey returns. For the telephone interviews, we

Table 2.1. Distribution of belt use and risk categories among mail survey returns.

\begin{tabular}{|c|c|c|c|}
\hline Belt Use & Risk Category & Sample N 1 & $\underline{\%}$ \\
\hline \multirow[t]{3}{*}{ Never, Rarely } & High & 141 & 4.0 \\
\hline & Medium & 137 & 3.9 \\
\hline & Low & 314 & 8.9 \\
\hline \multirow{3}{*}{$\begin{array}{l}\text { Sometimes, } \\
\text { Most of the Time }\end{array}$} & High & 219 & 6.2 \\
\hline & Medium & 339 & 9.6 \\
\hline & Low & 814 & 23.1 \\
\hline \multirow[t]{4}{*}{ A1ways } & High & 158 & 4.5 \\
\hline & Medium & 323 & 9.2 \\
\hline & Low & 1074 & 30.5 \\
\hline & & 3519 & 99.9 \\
\hline \multicolumn{4}{|c|}{$\begin{array}{l}1_{\text {Sample } N \text { includes only those survey returns }} \\
\text { successfully matched to the driver history file } \\
\text { and excludes ( } 1 \text { ) those cases where the respondent } \\
\text { indicated they always wore their belt but who had } \\
\text { returned a yellow (unbelted) survey form and ( } 2 \text { ) } \\
\text { cases where seat belt use both prior to the belt } \\
\text { law and "now" was reported as "always." }\end{array}$} \\
\hline
\end{tabular}

decided to begin interviewing ten persons in each of the three belt use and two risk categories (high and low). In assessing these results, it appeared that there were no major differences in how the "high" and "low" risk drivers were responding to selected questions. Therefore, it was decided not to interview any of the "medium" risk drivers. This led to the adoption of the following interview sampling scheme: 


\begin{tabular}{llc}
\multicolumn{1}{c}{ Belt Use Category } & $\begin{array}{c}\text { Risk } \\
\text { Category }\end{array}$ & $\begin{array}{c}\text { Number of } \\
\text { Interviews }\end{array}$ \\
\cline { 2 - 3 } Never, Rarely & $\begin{array}{l}\text { High } \\
\text { Low }\end{array}$ & 30 \\
Sometimes, Most of the Time & High & 20 \\
& Low & 60 \\
Always & High & 40 \\
& Low & 30 \\
& & 20
\end{tabular}

In order to generate the lists of people to call and interview, a SAS routine was used to randomize all of the names within each of the (belt use) $x$ (risk category) groups. A list of names and survey identification numbers for each group sufficient to complete its allotted number of interviews was then printed. From this point, our procedure was to pull 20 survey forms from each group, trying to complete as many of these interviews as possible before pulling additional forms.

\section{Questionnaire Development and Pilot Testing}

As with the mail survey, the telephone survey progressed through many reviews and iterations. A copy of the final survey form appears in Appendix $B$.

The telephone survey was initially pilot tested informally among coworkers, spouses and friends. An advantage of such testing is that the interviewer can later query the respondent as to any questions that were difficult to understand or that were seen as invasive, tedious, insignificant, etc. A major portion of the revisions to the survey form actually resulted from this informal pilot testing.

Near the final stages of development, the survey instrument was formally tested on several randomly selected respondents to the earlier mailback pilot test. The result was a more "real life" interview situation that was particularly useful for gauging the length of the survey and gaining experience interviewing persons opposed to seat belts and the N.C. seat belt law.

\section{Interview Procedures}

The interviews were conducted late October - mid November by project personnel and other HSRC staff members. As noted earlier, potential respondents within each belt use/risk category were randomly identified and 
listed on a computer printout, along with their number of recorded accidents and violations. Before calling, their mailback survey forms were also pulled so that we would be aware of any added comments, questions, etc. While this approach obviously produced some potential for bias, we felt that it was important for the interviewer to be aware of any such information before calling.

Interviews generally lasted about 15 minutes, depending on the number of crashes and law enforcement contacts recounted and the respondent's tendency to elaborate. There were three versions of the survey -- one for never wearers, one for always wearers, and one for everyone falling between these extremes. The version used depended on the respondent's reply to an initial question asking what percentage of the time he or she now wore a seat belt when driving.

\section{Data Processing}

The completed interview forms were checked for completeness and accuracy, then entered onto a computer data file. Further processing was required once the data were returned to handle the various "multiple response" questions, including the accident and violation histories.

\section{Characteristics of Responses}

Generally we were quite successful at reaching people, and nearly everyone who was reached agreed to participate in the survey. Calculation of a "contact rate" or "survey completion rate" is difficult: since we were pulling names from a randomly generated list of possible respondents within each belt use/ risk group, we did not necessarily exhaust attempts to call one person on the list before moving on to the next name on the list. Out of a total of approximately 300 forms pulled, we encountered the following:

13 cases where no telephone number appeared on the form;

13 cases where the telephone was out of order, disconnected, or otherwise invalid;

6 refusals;

2 cases where the individual was sick or hospitalized;

8 cases where we were still unable to reach the designated person after 5 attempts.

The remaining $(\approx 45)$ cases were those that we attempted to call at least once but who were not reached and interviewed before the allotted 200 surveys were completed. 
Although the respondents had been categorized on the basis of their reported belt use and crash/violation histories, we found that in many instances belt use had changed -- "rarely" wearers reporting that they were now "most of the time" wearers, etc. Also, since we inquired about any crash experience (and not just reportable crashes which had occurred in the past four years or crashes where they had been the driver), low as well as high risk drivers reported crash involvement. These and other characteristics of the telephone sample are detailed in Chapter 4.

\section{Data Analysis Overview}

Data from the mailback and telephone surveys were analyzed separately. Mailback survey results were used to answer the major question of this research project, namely, are non-users of seat belts overrepresented in crashes? Answering this question required a large, representative sample of both belted and unbelted drivers, with information on observed (as well as self-reported) belt use and accurate driver histories (numbers of accidents and violations). The data were analyzed using contingency table analyses and multivariate categorical data models.

The telephone survey sample was a much smaller $(\mathrm{N}=204)$ and nonrepresentative subsample of the mailback survey respondents (both high risk and sometimes/most-of-the-time belt wearers were purposely oversampled). Analysis of this data was primarily descriptive, with two-way crosstabulations of the variable of interest by observed and self-reported belt use, risk category, and various sample demographics. 
CHAPTER 3. MAILBACK SURVEY RESULTS - OVERREPRESENTATION

OF BELT NON-USERS IN ACCIDENTS AND VIOLATIONS

Overview

Mailback survey returns from all 72 data observation sites, successfully matched to over 4500 driver history records, form the basis of the analysis concerned with whether belt non-users are overrepresented in traffic accidents and violations. To prepare the reader for this analysis, some discussion of the sample and survey response distributions will follow. The remainder of this chapter covers attitudinal and demographic differences between seat belt users and non-users, overrepresentation of non-users in accidents and violations, and additional data analyses directed primarily at identifying target groups for seat belt promotion programs.

\section{Information About the Sample}

\section{Survey Response Distributions}

Since our primary goal was to compare characteristics and driving records between drivers who use seat belts and those who do not, unbelted drivers were oversampled in the survey, as discussed in Chapter 2. As a result, the raw questionnaire response distributions are somewhat skewed toward the responses of the unbelted drivers. Table 3.1 shows response distributions for those questionnaire items whose statewide distributions would be of greatest interest to the reader. Since 61 percent of our returns were from observed belted drivers, the response distributions of Table 3.1 were weighted to reflect the observed statewide seat belt use rate $(66.6 \%)$ at the time the survey was conducted. As an illustration of the weighting procedure, consider Item A of Table 3.1 -- Opinion of the law. This item has 5 responses. If we let $\mathrm{P}_{1}, \mathrm{P}_{2}$, $\ldots, \mathrm{P}_{5}$ denote the statewide response distribution (proportions), then we

estimate these quantities as weighted sums of the corresponding proportions for belted and unbelted drivers. Thus,

$$
\hat{\mathrm{P}}_{\mathrm{k}}=(.666) \mathrm{P}_{\mathrm{k}} \text {, belted }+(.334) \mathrm{P}_{\mathrm{k}} \text {, unbelted }
$$


Table 3.1. Weighted response distributions for selected questionnaire items.

\section{Questionnaire Item}

A. A N.C. Iaw that began Oct. 1985 requires drivers and front seat passengers of motor vehicles to wear seat belts. What is your opinion of this law?

B. Before the law went into effect oct. 1985, how often did you wear your seat belt when driving?

C. Between Oct. 1985 and Jan. 1987, there was no fine for not wearing a seat belt. During this "grace" period how often did you wear your seat belt when driving?

D. Since Jan. 1987 drivers not wearing seat belts may be fined $\$ 25$. How often do you wear a seat belt now when driving?

E. What is your opinion of the $\$ 25$ fine?

F. For those times that you do wear a seat belt, please check the one most important reason.

\section{Response Distribution}

$20.5 \%$ strongly oppose

$11.3 \%$ moderately oppose

$3.9 \%$ not sure

$20.9 \%$ moderately support

$43.5 \%$ strongly support

$24.6 \%$ never

$18.2 \%$ rarely

$22.3 \%$ sometimes

$18.6 \%$ most of the time

$16.4 \%$ always

$13.9 \%$ never

$11.8 \%$ rarely

$17.2 \%$ sometimes

$26.2 \%$ most of the time

$31.0 \%$ always

$4.6 \%$ never

$7.0 \%$ rarely

$8.5 \%$ sometimes

$20.8 \%$ most of the time

$59.0 \%$ always

$35.9 \%$ There should not be a fine

9.3\% There should be a lower fine

$6.1 \%$ There should be a higher fine

$48.7 \%$ The $\$ 25$ fine is about right

$16.0 \%$ To avoid the $\$ 25$ fine

$20.5 \%$ Because it's the law

$36.8 \%$ To prevent injury if in a sccident

3.0\% Because my friends/family want me to

13.6\% It's a habit; I don't think about it

$4.2 \%$ Because of my own experience in an accident

2.3\% Because of someone else's experience in an accident

$3.8 \%$ Check here if you never wear a seat belt 


\section{Questionnaire Item}

G. For those times that you do not wear a seat belt, please check the one most important reason.

H. How much control do you feel you have in preventing an accident?

I. If you could vote today, would you vote to keep the N.C. seat belt law?

\section{Response Distribution}

$2.2 \%$ Seat belts don't-prevent injuries

$1.6 \%$ Seat belts are likely to cause injuries

13.9\% Seat belts are uncomfortable; they don't let me move around

9.5\% I'm afraid of being trapped in my car if it catches on fire or goes under water

$3.4 \%$ I only wear seat belts on long trips/in bad weather

$0.5 \%$ I'm a careful driver; I don't need to wear seat belts

$20.1 \%$ I forget; I'm not in the habit

48.9\% Check here if you always wear a seat belt

10.6\% Almost total control

$39.4 \%$ A lot of control

41.2\% Moderate control

$5.5 \%$ A 1ittle control

3.3\% Very little control

$56.3 \%$ yes

$33.2 \%$ no

$10.5 \%$ not sure 
is the estimate of $P_{k}, k=1, \ldots, 5$, where $p_{k}$, belted is the sample proportion of belted drivers who selected the $k$ th response of item 1 , and $\mathrm{P}_{\mathrm{k}}$, unbelted is the corresponding proportion for unbelted drivers.

In Item A, 64 percent either strongly or moderately support the N.C. seat belt law, while 32 percent either strongly or moderately oppose the law. These results are very similar to those obtained in the fall of 1987 in a statewide telephone survey of randomly selected respondents (Hunter and Geissinger, 1988). Items B, C, and D concern belt wearing before the N.C. seat belt law, during the warning ticket or "grace" period, and after the implementation of the $\$ 25$ fine. The percent of always wearers is about 8-10 percentage points less than the observed use rates for these three time periods (Reinfurt, Campbell, Stewart, and Stutts, 1987).

About half of the mailback respondents felt that the $\$ 25$ fine is about the right amount (Item $\mathrm{E}$ ). The most important reasons for wearing a seat belt (Item F) were: (1) to prevent injury, (2) because it's the law, (3) to avoid the $\$ 25$ fine, and (4) because it's a habit. In contrast, belts are not worn (Item G) due to: (1) lack of a habit, (2) belts being uncomfortable, and (3) fear of being trapped in a vehicle. In preventing an accident, 39 percent felt they have a lot of control and 41 percent moderate control (Item H). Finally, 56 percent said they would vote in favor of keeping the seat belt law (Item I). This differs from the 72 percent who favored keeping the law from the statewide telephone survey and is illustrative of differences between a random sample of households with telephones and an on-road survey of drivers.

The questionnaire portion of the mailback survey form is shown in Appendix Table C.1 along with the raw (unweighted) response distributions.

\section{Driver History File Information}

By matching survey results to the driver history file, we also had information on accident and violation histories for our mailback survey sample (total number of accidents and violations, 1983-1986). This information is summarized below, along with results for all N.C. licensed drivers. The slightly higher accident/violation rate for our survey sample can be expected, since it is a sample of "on the road" rather than licensed drivers. 
Survey Sample

(Weighted)

$\frac{\text { Accident Frequency }}{0}$

1

2 or more

\section{Violation Frequency}

0

1

2

3 or more
$81.5 \%$

$15.1 \%$

$3.4 \%$

$74.4 \%$

$17.3 \%$

$4.8 \%$

$3.3 \%$
N.C. Licensed

Drivers

$82.4 \%$

$14.8 \%$

$2.9 \%$
$77.7 \%$

$14.4 \%$

$4.6 \%$

$3.3 \%$

Also available from the driver history file was information on respondent age, race, and sex. This unweighted information is summarized below.

$\begin{array}{lr}\text { Age } & \\ \leq 25 \text { years } & 15.0 \% \\ 26-54 & 63.5 \% \\ 55 \text { and over } & 21.5 \% \\ & \\ \text { Race } & 88.4 \% \\ \text { White } & 11.0 \% \\ \text { Black } & 0.5 \% \\ \text { Indian } & 0.2 \% \\ \text { Other } & \\ & \\ \text { Sex } & 54.3 \% \\ \text { Male } & 45.7 \% \\ \text { Female } & \end{array}$

Seat Belt Use Among Survey Respondents

The fact that the survey questionnaire forms were color coded to indicate each driver's observed belt use or non-use was a unique feature of this survey. Thus, we have not only an objective on-road measure of belt use at one point in time, but also self-reported belt use information (current self-reported belt use). Both of these belt use variables are employed in the subsequent analyses. Each has its limitations: observed belt use provides only a belted or unbelted response at one point in time, while self-reported belt use may be inflated.

The information concerning belt use among the survey respondents can be maximized by using the observed belt use to provide an interpretation of, and to lend some validity to, current self-reported belt use (Table 3.2). Of the 
Table 3.2 Current self-reported belt use cross-classified by observed belt use.

Observed Belt Use

\begin{tabular}{lcc|r}
$\begin{array}{c}\text { Current } \\
\text { elf-Reported } \\
\text { Belt Use }\end{array}$ & Belted & Unbelted & Total \\
\cline { 2 - 3 } Never & 13 & 223 & 236 \\
& $(6 \%)$ & $(94 \%)$ & \\
Rarely & 24 & 336 & 360 \\
& $(7 \%)$ & $(93 \%)$ & \\
Sometimes & 73 & 350 & 423 \\
& $(17 \%)$ & $(83 \%)$ & \\
Most of the time & 464 & 499 & \\
& $(48 \%)$ & $(52 \%)$ & \\
Always & 2180 & 327 & 2507 \\
& $(87 \%)$ & $(13 \%)$ &
\end{tabular}

2507 drivers who responded by saying they always wear belts, 87 percent were observed wearing belts, while 13 percent were observed not belted. We can think of each driver in this always group as actually using seat belts a certain percent of the time. At one extreme, it could be that the 87 percent observed wearing belts actually wear belts 100 percent of the time, while the other 13 percent never wear belts. At the other extreme each driver in the group may wear seat belts exactly 87 percent of the time. Of course, some inbetween distribution is much more likely. On average, however, the observed data provides a point estimate of 87 percent for the seat belt use rate of survey respondents indicating they always wear seat belts. Thus, in the context of this survey "always" can be taken to mean 87 percent belt use.

Similarly, "most of the time" implies 48 percent belt use, "sometimes" 17 percent, "rarely" 7 percent, and "never" 6 percent. The combined rarely/never response group has an overall use rate of 6 percent. When the most-of-the-time and the sometimes response groups are combined, the overall use rate for this group is 39 percent.

There are discrepancies between self-reported and observed belt use that appear in the always and never categories of Table 3.2. These are revealed by 
13 percent of the respondents who say they always wear their belts but who were observed to be not belted. Likewise, six percent of the respondents who say they never wear their belt were observed belted. For the other belt wearing groups, the part-time wearers, the nature of any discrepancies cannot be determined.

As referenced in the methodology section, discrepancies could arise in various ways. Certainly, some errors could have been made in distributing the forms, especially in high volume situations where the belt was worn either incorrectly or in a manner that attempted to disguise an unbelted driver. Exaggerated self reports of belt use could also lead to discrepancies. The simple nature of self-reporting, whereby respondents are asked for their belt wearing frequency over some extended time period, would tend to yield a higher use rate than that provided by a one-time measurement during a seat belt data collection effort. In an epidemiological setting, the self-reported measure would be referred to as a period prevalence, while the one-time assessment would be called a point prevalence. As stated in Hunter and Geissinger (1988), "the tendency would be to report more frequent belt use over an extended time period (a period prevalence measure), and this would result in a higher use rate than that produced by the on-road observations (a point prevalence measure)" [p. 3-12]. Anecdotes from the data collectors coupled with the experience of staff involved in other seat belt data collection or incentive projects leads to the conclusion that exaggerated self-reported belt use is inevitable, especially when compared with observed use rates. On many occasions, we have heard unbelted motorists proclaim, "Oh, but I always wear my belt," and perhaps they think they do, especially on certain types of trips where they believe belt use to be important.

The mailback survey allowed another check of observed versus self-reported belt use through Item 6 , which asked, "Were you wearing your seat belt at the time this survey was given to you?" The responses to questionnaire Item 6 cross-classified by observed belt use are shown in Table 3.3. In the last row of this table 45 respondents reported that there were no belts in the vehicle they were driving when given the survey form. It seemed quite likely, however, that these drivers would also drive or ride as passengers in other vehicles which did have seat belts. Thus, their general seat belt wearing behavior, their attitude concerning the law, driving records, etc. were still of interest to the overal1 study. In general, the results of Table 3.3 seem quite 
Table 3.3. Self-reported belt use at time of survey by observed belt use.

\begin{tabular}{lcc|c}
$\begin{array}{c}\text { Self-Reported } \\
\text { Belt Use }\end{array}$ & \multicolumn{2}{c|}{ Observed Belt Use } & \\
at Time of Survey & Belted & Unbe1ted & Tota1 \\
\cline { 1 - 2 } & & & \\
Belted & 2690 & 419 & 3109 \\
Not Belted & $(87 \%)$ & $(13 \%)$ & \\
& 50 & 1256 & 1306 \\
No Belts in & $(4 \%)$ & $(96 \%)$ & \\
Vehicle & 3 & 42 & 45
\end{tabular}

consistent with those of Table 3.2. In addition, when Item 6 was crossclassified with current self-reported belt use (Item 4), 97 percent of those respondents who reported being belted at the time of the survey also reported always wearing seat belts.

Many of the analyses which follow involve the use of the current selfreported belt use variable having the three levels: always, mostly/sometimes, and rarely/never. These three levels can be roughly equated to 85 to 90 percent belt use, about 40 percent belt use, and less than 10 percent belt use, respectively.

Attitudinal and Demographic Differences

Between Belt Users and Non-Users

Two-way contingency table analyses were carried out to investigate how the distributions of responses to the questionnaire items and auxiliary items from the driver history file differed between belt users and non-users. Both current self-reported belt use at three levels (always, most of the time/sometimes, rarely/never), and observed belt use were cross classified by each of the other items of interest using SAS PROC FREQ. Statistically significant differences with respect to both variables are 1isted in Table 3.4. 
Table 3.4. Differences between users and non-users, as defined by current self-reported belt use and observed belt use.

$\underline{\text { Variable }}$

1. Opinion of law

2. Opinion of fine

3. Trip length

4. Reasons for belt use

5. Reasons for nonuse

6. Annual mileage

7. Estimate of drivers in accidents

8. Estimate of accident likelihood

9. Control in preventing an accident

10. Vote on law

\section{Education}

12. Marital status

13. Age

$$
\text { users support, }
$$$$
\text { non-users oppose }
$$

Current Self-Reported Belt Use P-value

users say about right, non-users want no fine

never and always users similar .000 .000 for trips of various length, sometimes users more often on short trips

non-users say to avoid fine; sometimes users split among fine, law, \& safety; always users say safety \& habit

non-users say uncomfortable \& fear of being trapped, sometimes say uncomfortable \& forget

higher proportion of non-users reporting more than 20,000 miles

$$
.000
$$

Observed Belt Use P-value

non-users estimate slightly

.043

lower numbers than users

non-users estimate slightly

.027

lower than users

non-users estimate more control

.001

than users

non-users would vote against,

.000 .000 users for, sometimes split

belt use increases monotonically .000 .000 with increasing education

higher percentage married among .000 .000 users, more never married for non-users

higher percentage of non-users 24 and under, higher percentage .000 .000 
Table 3.4. Continued.

Variable

14. Sex of respondent

15. Race
Description

higher proportion of males among non-users

non-whites report higher proportions of always use and lower proportions of never/rarely use than whites
Current

Self-Reported Observed

Belt Use Belt Use

$\underline{\text { P-value } \quad \text { P-value }}$

$.000 \quad .000$

.000

.324

The two sets of P-values given in Table 3.4 are the significance levels of the $\mathrm{X}^{2}$-statistics for testing for differences in the distribution of values of the given variable across the current self-reported belt use categories and observed belt use categories, respectively. Thus, Table 3.4 shows that seat belt users differ from non-users in many respects. The complete set of these contingency tables is included in Appendix C, Tables C.2 - C.20.

An illustration of the format of these appendix tables is shown below as Table 3.5 which gives belt use by educational status. "Grade school" includes those who attended high school but were not graduated. This table clearly shows the trend toward increased belt use with increasing level of education.

Table 3.5. Education by observed and current self-reported belt use.

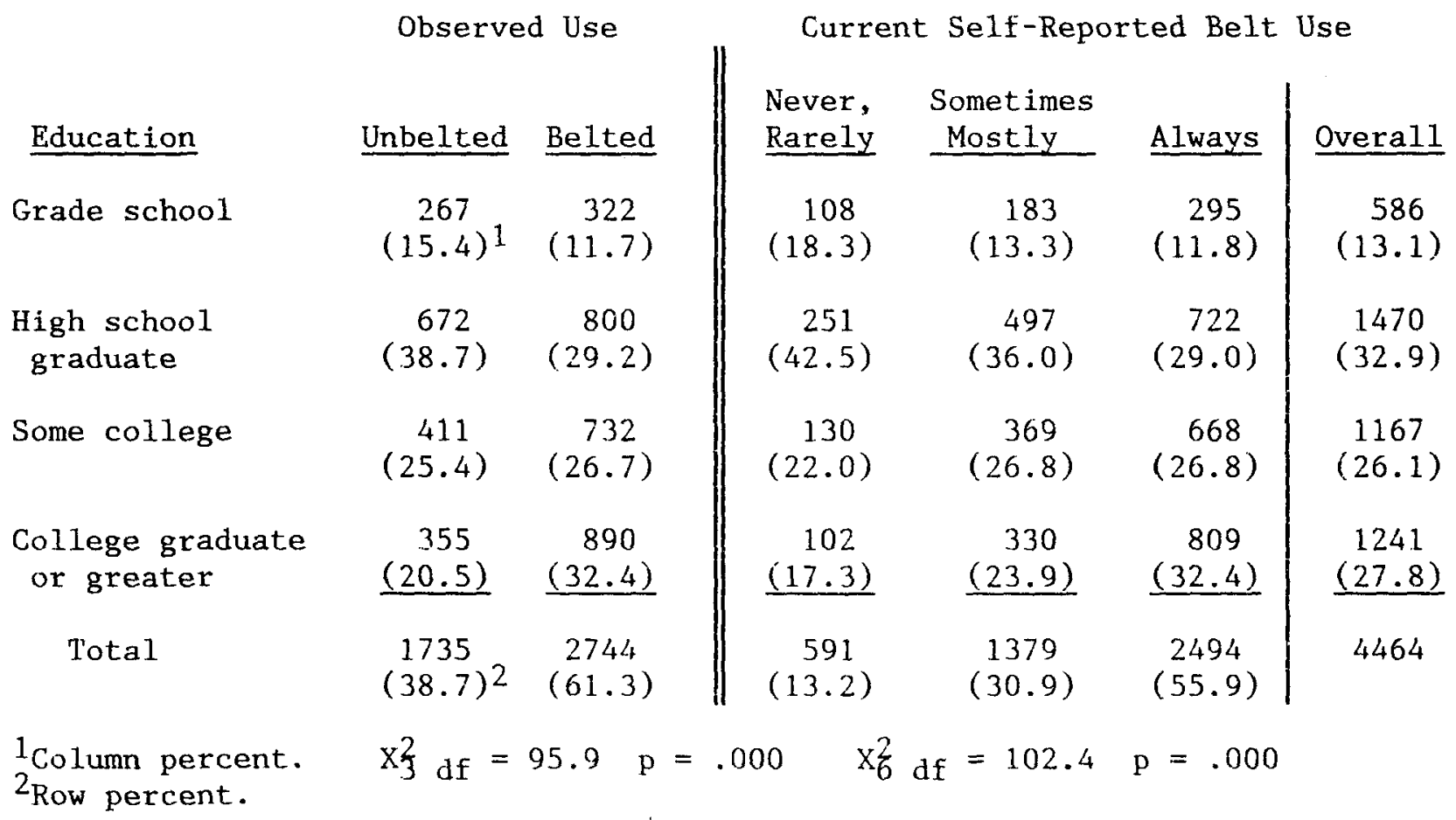


Overrepresentation of Non-Users in Accidents and Violations

The analysis found that non-users of seat belts are overrepresented in accidents and violations. Average numbers of accidents and violations per observed belted and unbelted driver over the four-year (1983-1986) period were:

\begin{tabular}{cccc} 
Observed Belt Status & $\mathbf{N}$ & $\begin{array}{c}\text { Average } \\
\text { Accidents }\end{array}$ & $\begin{array}{c}\text { Average } \\
\text { Violations }\end{array}$ \\
\cline { 1 - 2 } Belted & 2759 & 0.20 & 0.32 \\
Unbelted & 1746 & 0.27 & 0.54
\end{tabular}

On average, each unbelted driver had 35 percent more accidents and 69 percent more violations than did each belted driver. These values match very closely the results reported in Evans (1987), where photographic methods were used to detect seat belt use in separate travel speed and headway studies.

In the same four-year period, of those drivers observed wearing belts

$83 \%$ had no prior accidents while

$17 \%$ had one or more.

Of those observed not belted

79\% had no accidents while

$21 \%$ had one or more.

Similarly, of the belted drivers

$78 \%$ had no prior violations,

$16 \%$ had one violation, and

$6 \%$ had two or more,

while of the drivers observed not wearing belts

$69 \%$ had no prior violations,

$19 \%$ had one violation,

$12 \%$ had 2 or more violations.

The question of overrepresentation is further explored in Table 3.6 which shows the number and percent of respondents having no accidents, one accident, and two or more accidents during the four-year period 1983-1986, crossclassified by current self-reported belt use. Also shown are the average number of accidents per driver for each category. Similar to the observed belted-unbelted results, the rarely-never wearers have, on average, 33 percent 
Table 3.6. Number (percent) of prior accidents by current self-reported belt use.

Number (Percent) of Prior Accidents

\begin{tabular}{|c|c|c|c|c|c|}
\hline $\begin{array}{c}\text { Current } \\
\text { Self-Reported } \\
\text { Belt Use } \\
\end{array}$ & $\underline{0}$ & $\underline{1}$ & $\begin{array}{l}2 \text { or } \\
\text { More }\end{array}$ & Total & $\begin{array}{c}\text { Average } \\
\text { Accidents } \\
\text { Driver } \\
\end{array}$ \\
\hline Rarely/Never & $\begin{array}{c}466 \\
(78.2)\end{array}$ & $\begin{array}{c}104 \\
(17.5)\end{array}$ & $\begin{array}{c}26 \\
(4.4)\end{array}$ & 596 & .28 \\
\hline Mostly/Sometimes & $\begin{array}{c}1102 \\
(79.5)\end{array}$ & $\begin{array}{c}234 \\
(16.9)\end{array}$ & $\begin{array}{c}50 \\
(3.6)\end{array}$ & 1386 & .25 \\
\hline Always & $\begin{array}{c}2082 \\
(83.1)\end{array}$ & $\begin{array}{c}343 \\
(13.7)\end{array}$ & $\begin{array}{c}82 \\
(3.3)\end{array}$ & 2507 & .21 \\
\hline
\end{tabular}

more accidents than the always wearers. While the magnitude of the differences in the accident distributions across belt use categories is not particularly striking, these differences are statistically significant $(p=.016)$. The relationship is monotonic with accident involvement increasing with decreasing belt use.

Overrepresentation of non-users with respect to violations over the same four-year period is more pronounced (Table 3.7). The rarely-never violation rate was more than twice as large as the always violation rate. Again, violation histories get progressively worse as frequency of belt use decreases.

There are many other factors that are correlated both with driver belt use and with accident and violation records. For example, the results of Table 3.4 showed that the group reporting to rarely or never wear seat belts had a higher proportion of young drivers and male drivers than did the other belt use categories. Young males also tend to have the highest accident and violation rates. Therefore, it was of interest to investigate the extent to which the differences in accident and violation rates between the belt use groups could be accounted for by differences in the group demographic composition. To this end higher dimensional tables were generated and categorical models were developed to model the proportions of drivers having one or more accidents and one or more violations as a function of belt use status and other factors. 
Table 3.7. Number (percent) of prior violations by current self-reported belt use.

$$
\text { Number (Percent) of Prior Violations }
$$

\begin{tabular}{|c|c|c|c|c|c|c|}
\hline $\begin{array}{c}\text { Current } \\
\text { Self-Reported } \\
\text { Belt Use } \\
\end{array}$ & $\underline{0}$ & 1 & $\underline{2}$ & $\begin{array}{l}3 \text { or } \\
\text { More }\end{array}$ & Total & $\begin{array}{l}\text { Average } \\
\text { Violations/ } \\
\text { Driver }\end{array}$ \\
\hline Rarely/Never & $\begin{array}{c}373 \\
(62.6)\end{array}$ & $\begin{array}{c}124 \\
(20.8)\end{array}$ & $\begin{array}{c}55 \\
(9.2)\end{array}$ & $\begin{array}{r}44 \\
(7.4)\end{array}$ & 596 & .69 \\
\hline Most1y/Sometimes & $\begin{array}{c}981 \\
(70.8)\end{array}$ & $\begin{array}{c}269 \\
(19.4)\end{array}$ & $\begin{array}{c}81 \\
(5.8)\end{array}$ & $\begin{array}{c}55 \\
(4.0)\end{array}$ & 1386 & .46 \\
\hline Always & $\begin{array}{c}1977 \\
(78.9)\end{array}$ & $\begin{array}{c}388 \\
(15.5)\end{array}$ & $\begin{array}{c}87 \\
(3.5)\end{array}$ & $\begin{array}{c}5.5 \\
(2.2)\end{array}$ & 2507 & .31 \\
\hline
\end{tabular}

Models were developed using both observed belt use and current self-reported belt use. Models for the proportion having accidents contained significant effects for belt use (both observed and self-reported) in addition to effects due to driver age and sex.

For the models concerned with violations, annual mileage could also be taken into account. Table 3.8 gives the analysis of variance table from a model containing the variables:

violations ( 0,1 or more) as the dependent variable with independent variables,

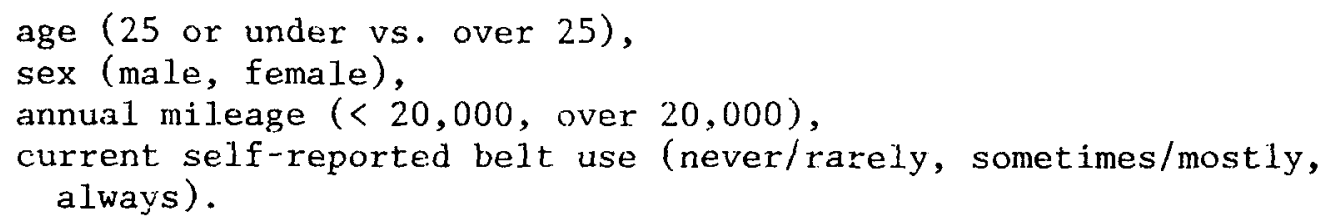

All factors and the age by sex interaction are highly significant, and the model fits well to the data. Figure 3.1 shows a plot of the predicted proportions having one or more violations. The effects of the belt use category can be seen clearly within each subpopulation defined by combinations of the other variables. Similar results were obtained in a model that substituted observed belt use for current self-reported belt use. These models show that drivers who do not wear seat belts tend to have worse driving records than those who do, even after demographic differences have been taken into account. 


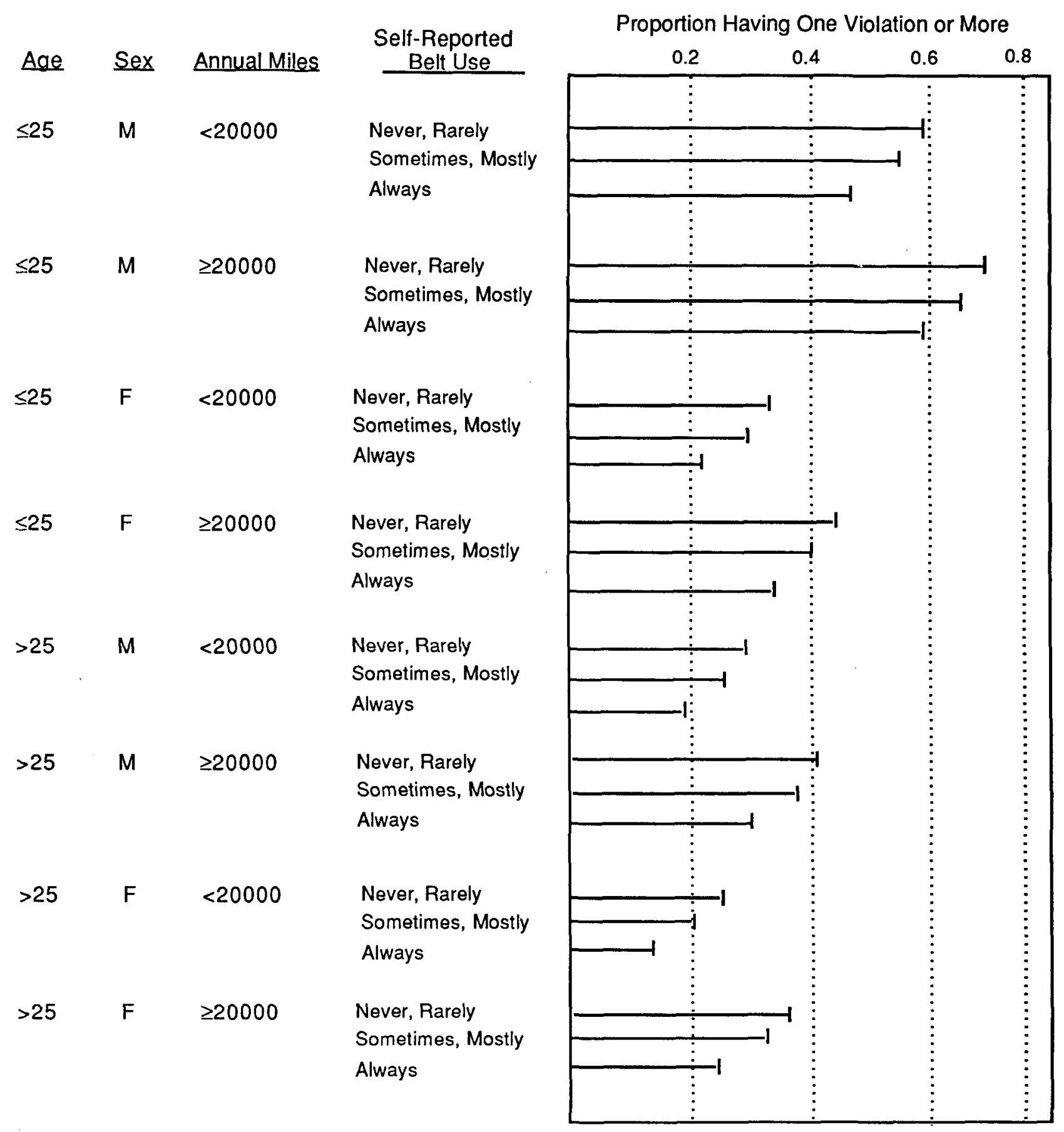

Figure 3.1. Predicted proportions of groups with one violation or more. 
Table 3.8. Analysis of variance from a model with violations as the dependent variable.

$\begin{array}{lccc}\text { Source } & \text { DF } & \text { Chi-Square } & \text { Prob } \\ \text { Intercept } & 1 & 1179.35 & 0.0001 \\ \text { Age } & 1 & 95.21 & 0.0001 \\ \text { Sex } & 1 & 58.58 & 0.0001 \\ \text { Mileage } & 1 & 56.47 & 0.0001 \\ \text { Age*Sex } & 1 & 26.13 & 0.0001 \\ \text { Belt Use } & 2 & 38.21 & 0.0001 \\ \text { Residual } & 17 & 20.00 & 0.2744\end{array}$

To summarize the findings with respect to overrepresentation, drivers observed not wearing seat belts have significantly worse accident and violation records than do drivers observed wearing seat belts. When self reported belt use categories are used, driver records become progressively worse with decreasing frequency of belt use. The differences between accident and violation rates for users and non-users can be partially explained by the differing demographic makeups of the user categories. However, statistically significant belt use effects are found even after factors such as driver age, sex, and estimated annual mileage have been taken into account.

Differences Between the Types of Accidents and Violations for Belt Users and Non-Users

The data file used to examine differences between the accidents of belt users and non-users consisted of accident records from the 1038 accidents involving mailback survey respondents in calendar years 1983-1986. Of these accidents,

- 166 involved rarely/never users.

- 346 involved mostly/sometimes users, and

- 526 involved always users

These numbers of actual crashes reflect the fact that the always users constitute 56 percent of the survey returns, while the mostly/sometimes and rarely/never users constitute 31 percent and 13 percent respectively.

A series of contingency tables of current self-reported belt use by each of the following factors was examined: 
1. Accident severity (no or minor injury vs. moderate to fatal injury).

2. Alcohol involvement (alcohol not a factor vs. alcohol a factor).

3. Speed of accident (0-29 mph, 30-49, 50-79 mph).

4. Accident type (single vehicle, multiple vehicle).

5. Light condition (daylight, other).

6. Vehicle deformation based on TAD scale (minor, moderate, severe).

7. Child in accident (child $<13$ yrs old yes or no).

8. Vehicle drivability (vehicle drivable from scene, not drivable).

9. Rollover (vehicle rollover yes or no)

10. Region of impact (front, right side, left side, rear, unspecified).

11. Driver charged (driver charged with violation yes or no).

12. Driver injury (none or minor vs. moderate to fatal).

Results showed that the accidents of belt users differed statistically from the accidents of non-belt users only with respect to single vehicle accidents, rollover accidents, and accidents in which the driver is charged with a violation. Table 3.9 shows the accident type comparison, with single and multiple vehicle accidents, distributed by current self-reported belt use. With respect to accident type, the percent of single vehicle crashes was

$14 \%$ for rarely/never users,

$10 \%$ for most $1 \mathrm{y} /$ sometimes users, and

$7 \%$ for always users.

The corresponding percents for rollovers were

$7 \%$ for rarely/never,

$2 \%$ for mostly/sometimes, and

$2 \%$ for always,

while the percent of drivers charged with a violation was

$31 \%$ for rarely/never,

$20 \%$ for most $1 y /$ sometimes, and

$20 \%$ for always users.

The p-values associated with the $X^{2}$ statistics for these three groups were $.027, .011$, and .006 respectively. 
Table 3.9. Single and multiple vehicle accidents by current self-reported belt use.

Current

$\begin{gathered}\text { Self-Reported } \\ \text { Belt Use }\end{gathered}$
Never, Rarely

Sometimes, Mostly

Always

Always

Total
Row percent.

$1_{\text {Row percent. }}$
Accident Type

\begin{tabular}{|c|c|c|}
\hline $\begin{array}{l}\text { Single } \\
\text { Vehicle }\end{array}$ & $\begin{array}{l}\text { Multiple } \\
\text { Vehicle }\end{array}$ & Tota1 \\
\hline $\begin{array}{c}23 \\
(13.9)^{1}\end{array}$ & $\begin{array}{c}143 \\
(86.1)\end{array}$ & 166 \\
\hline $\begin{array}{c}36 \\
(10.4)\end{array}$ & $\begin{array}{c}310 \\
(89.6)\end{array}$ & 346 \\
\hline $\begin{array}{r}38 \\
(7.2) \\
\end{array}$ & $\begin{array}{r}488 \\
(92.8) \\
\end{array}$ & 526 \\
\hline $\begin{array}{c}97 \\
(9.3)\end{array}$ & $\begin{array}{c}941 \\
(90.7)\end{array}$ & 1038 \\
\hline
\end{tabular}

$\mathrm{X}_{2}^{2} \mathrm{df}=7.2 \quad \mathrm{p}=.027$

Given differences with respect to these three variables, it seems rather surprising that factors such as accident severity, vehicle deformation, and accident speed did not also vary over the belt use categories, since single vehicle and rollover accidents generally tend to be more severe. Such was not the case. Even so, the group reporting rarely or never to use seat belts seems to be involved in accidents which differ from those of the rest of the North Carolina driving population, namely, single vehicle crashes, rollovers, and accidents in which the driver is charged with a violation.

Similar analyses were carried out with observed belt use replacing current self-reported belt use. None of the twelve factors differed significantly between the belted and not belted populations.

As with numbers of accidents and violations, the question naturally arises as to whether or not the differences discussed above could be explained solely in terms of differing group demographic composition. To investigate this, categorical models were fit to the proportion of accidents in which drivers were charged with a violation. This analysis included the factors,

driver age ( $\leq 25$ vs. over 25 ), driver sex, and self-reported belt use (rarely/never vs. all other). 
Driver age and belt use were both significant with p-values of .0001 and .026 , respectively. Driver sex was not significant, $p=.964$.

During the same four-year period, the always belt users were involved in 802 violations, the mostly/sometimes group had 634, while the rarely/never group had 412 (the numbers again reflecting the composition of the sample). Similar to the accident analysis, contingency tables were analyzed to determine if non-users had higher rates of serious violations; namely, reckless driving and alcohol violations. In three separate analyses involving reckless driving, alcohol violations, and reckless and alcohol combined, no statistically significant relationships were found between current self-reported belt use and these serious violation types.

In summary, the accidents that non-belted drivers were involved in were quite similar to those involving belted drivers in most respects. The group that reported rarely or never wearing seat belts did, however, have accidents that differed from those of other driver groups in that they had higher proportions of single vehicle accidents, higher proportions of rollovers, and a higher proportion in which the driver was charged with a violation. Some but not all of these effects may be attributable to the fact that this group contains a higher proportion of young drivers. No differences in serious violation type were found between belt users and non-users.

\section{Additional Analyses Concerned with Identifying Target Groups for Seat Belt Programs}

\section{Analysis of Change in Belt Use Status}

Some additional analyses were carried out which may help to identify target groups for seat belt promotion programs. The first of these analyses involved examining a change-in-belt-use variable defined in terms of questionnaire Item 2 (belt use prior to October 1985) and Item 4 (current belt use). Three levels of this change-in-belt-use variable were defined as:

\footnotetext{
Low-Low: both prior belt use and current belt use reported to be never, rarely, or sometimes.

Low-High: prior belt use $=$ never, rarely, or sometimes and current belt use $=$ most-of-the-time or always.

High-High: both prior and current belt use reported as most-of-the-time or always.
} 
The respondents whose prior belt use was higher than their current belt use (less than $0.5 \%$ ) were omitted from these analyses.

A series of contingency tables of change-in-belt-use by the following factors was run:

- Age

- Sex

- Race

- Education

- Marital status

- Number of prior accidents

- Number of prior violations

The relationships between these other factors and change-of-belt status are displayed in Figure 3.2. This figure combines the features of both a table and a chart. The rows give the percents of each subpopulation falling into each of the three change-of-belt-use categories. The positions of the entries also provide a graphical representation of the numerical values (percents). This leads to very easy comparisons across subpopulations (i.e., rows) and/or within change-of-belt-use categories (i.e., columns). For example, examining subpopulations within the Low-High categories (i.e., those who increased belt use as a result of the law), we find that:

- A higher percentage of female drivers increased their belt use than did male drivers.

- The percent of drivers increasing their belt use was much higher for non-white drivers than for white drivers.

- A very low percent of drivers having two or more prior violations increased their belt use, while a relatively high percent continued rarely or never to use seat belts.

Other results from Figure 3.2 indicate that, of the respondents 25 years old or younger, 31 percent were in the Low-Low change-in-belt-use group, 44 percent in the Low-High group and 25 percent in the High-High group. A glance down the first column reveals that respondents with two or more prior violations had the highest percent $(41 \%)$ who remained low belt users.

For some factors such as driver age, the variation in change of belt status occurs primarily between the Low-Low group and the High-High group, while the percent in the Low-High remains constant near the overall level. For other factors such as education, variation occurs across all three change-in- 
Change in levels of belt use (Percent)

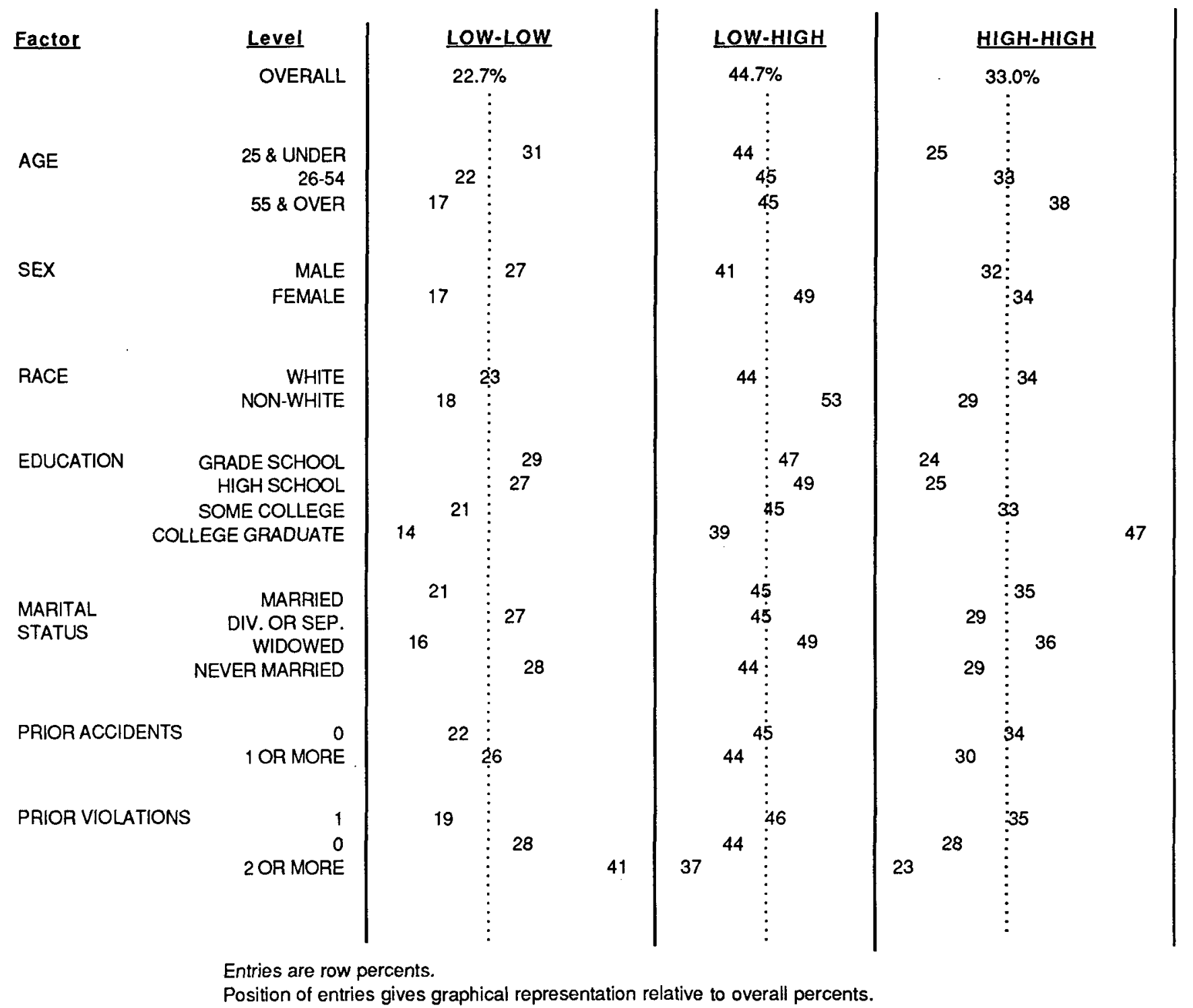

Figure 3.2. Change in belt use by demographic and driver history factors. 
belt-use categories. At the lower levels of education the percents in the LowLow group are greater than average (about 28\%), the percents in the High-High group are smaller than average (about 25\%), but the percents in the Low-High group are larger than average (about 48\%). For college graduates or greater, the percent in the Low-Low group is relatively small (14\%), as is the percent in the Low-High group (39\%); however, the percent in the High-High group is relatively high $(47 \%)$.

Clearly, the most aberrant subpopulation consists of those respondents having two or more prior violations. This group has the largest percent falling into the Low-Low category, the smallest percent in the High-High category, and the smallest percent in the Low-High category.

Reasons Why North Carolina Drivers Use and/or Do Not Use Seat Belts

Analysis of questionnaire Items 8 and 9 , reasons for wearing and not wearing seat belts, also provided insight to target group identification. As a first step in this analysis, the responses to Item 8 and Item 9 were collapsed as follows: with respect to Item 8 respondents stating that they never wore belts were omitted, and responses $4,5,6$, and 7 were combined to yield a "Habit + other" category. Habit was the dominant response in this combined category with no more than $4 \%$ of the respondents checking any of the other categories. Responses 1, 2, and 3 all had relatively high frequencies and each was of interest in its own right. With respect to Item 9, those saying they always wore belts were omitted, responses 1 and 2 were combined into a "Does no good" category, and responses 5, 6, and 7 were combined into a "Forget + other" category. Again, this last combined category was dominated by the forget category. Responses 3 and 4 had relatively high frequencies and were both of particular interest.

Contingency table analyses were then carried out for both "reasons for using belts" and "reasons for not using belts" versus each of the factors

- Race

- Sex

- Education

- Marital Status

- Age

- Number of prior violations, and

- Number of prior accidents 
Significant relationships were found between each factor and "reasons for wearing belts" and between each of the first four factors and "reasons for not wearing belts." Figures 3.3 and 3.4 illustrate the nature of these relationships. In these figures the overall response rates for the four reasons for using or not using seat belts are given across the top of the chart. Variations in the response rates across subpopulations defined by the statistically significant factors are shown within the chart. In Figure 3.3, perhaps the most striking effect is due to education, where the percent indicating that their primary reason for using seat belts was to avoid the fine decreased steadily from 27 percent for those who did not complete high school to 10 percent for those who completed college. Across the same subpopulations the percent giving safety as the primary reason for wearing belts increased from 22 percent to 47 percent. A similar type of pattern can be seen for the subpopulations defined by number of prior violations and, to a lesser extent, by number of prior accidents. From Figure 3.4 a very strong effect due to education is also apparent.

To summarize, drivers who did not complete high school are about three times as likely to give "avoiding the fine" as their primary reason for wearing seat belts and "fear of being trapped" as their reason for not wearing belts relative to college graduates. College graduates are about twice as likely to list "safety" and "forget" as their reasons for wearing and not wearing belts relative to drivers not completing high school. The group of respondents with two or more prior violations had the highest percentage indicating that avoidance of the fine was their primary reason for wearing seat belts.

These results suggest that some combinations of factors might produce an even greater spread in the distribution of responses. A three-way tabulation of number of prior violations by education by reasons for wearing seat belts showed that for the subpopulation who only completed grade school and had 2 or more prior violations, 36.4 percent wore seat belts to avoid the fine, while only 15.2 percent listed safety as the primary reason. At the opposite extreme, of those who had completed college and had no prior violations, 8.6 percent said they used seat belts to avoid the fine, while 48.7 percent listed safety as the primary reason. The ten other subpopulations defined by education and violations had responses falling between these extremes.

A slightly different approach involved examining simultaneously the reasons given for using and not using seat belts. Table 3.10 shows the complete 
Reasons given for wearing seat belts (Percent)

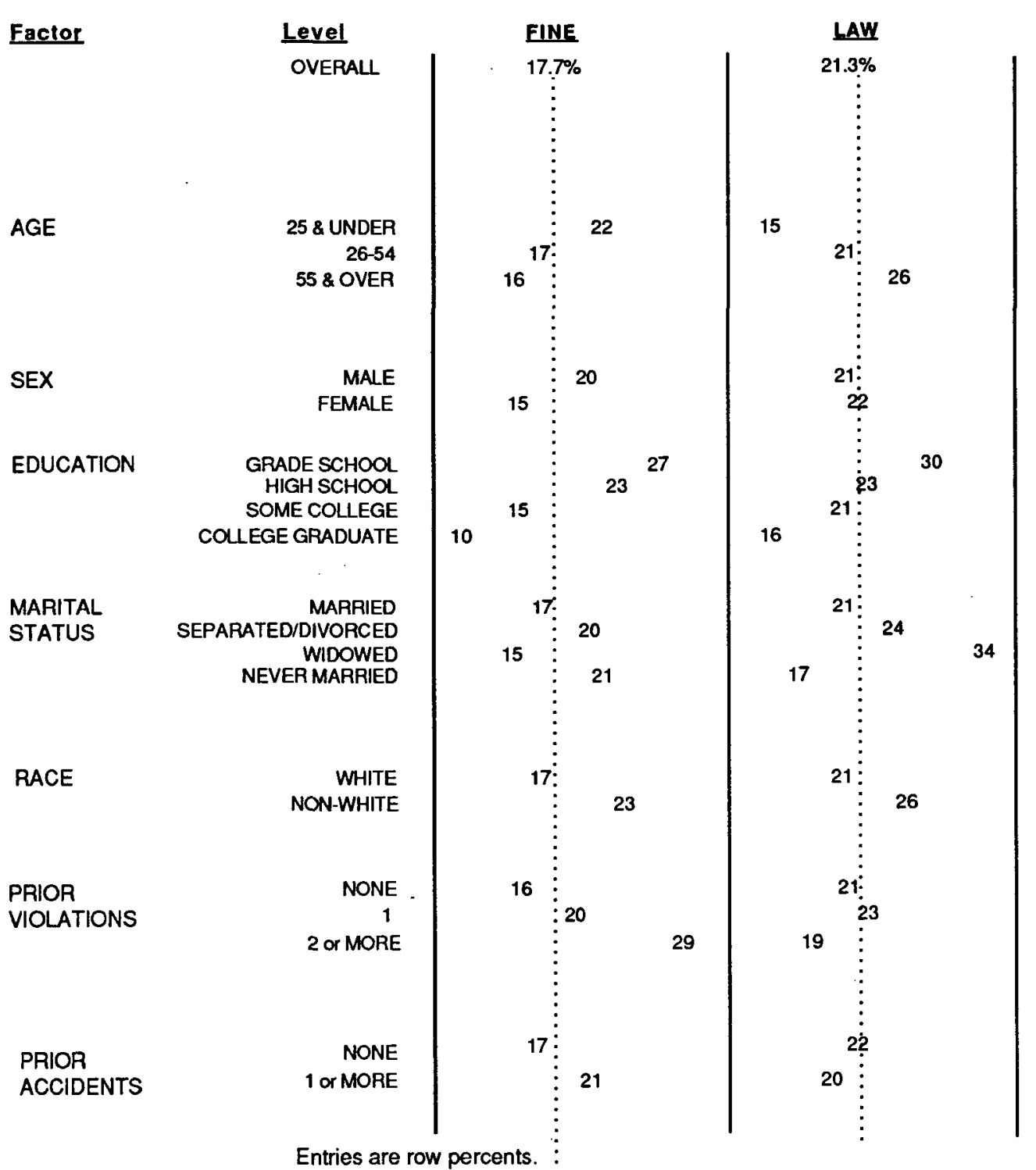

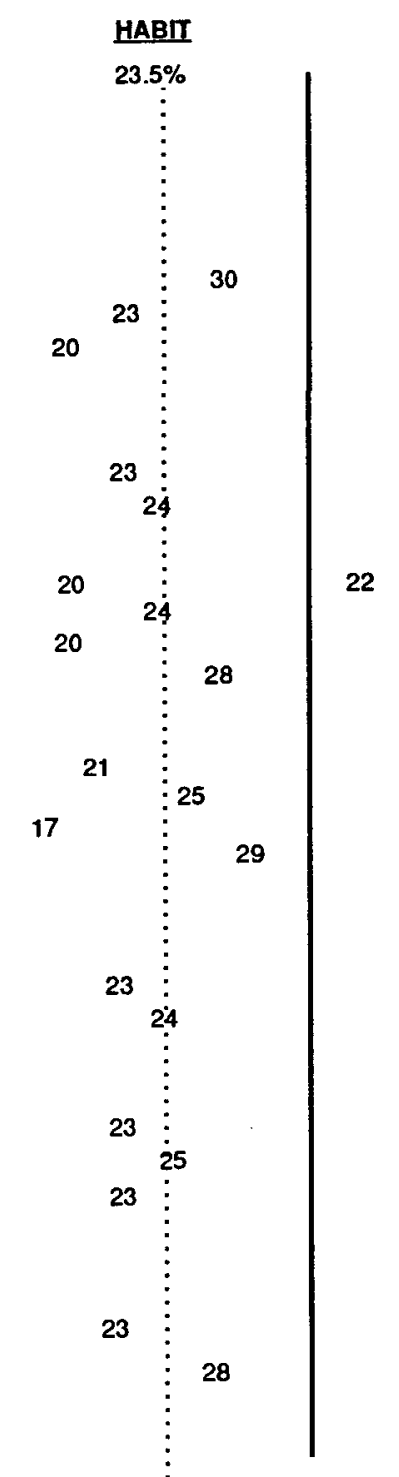




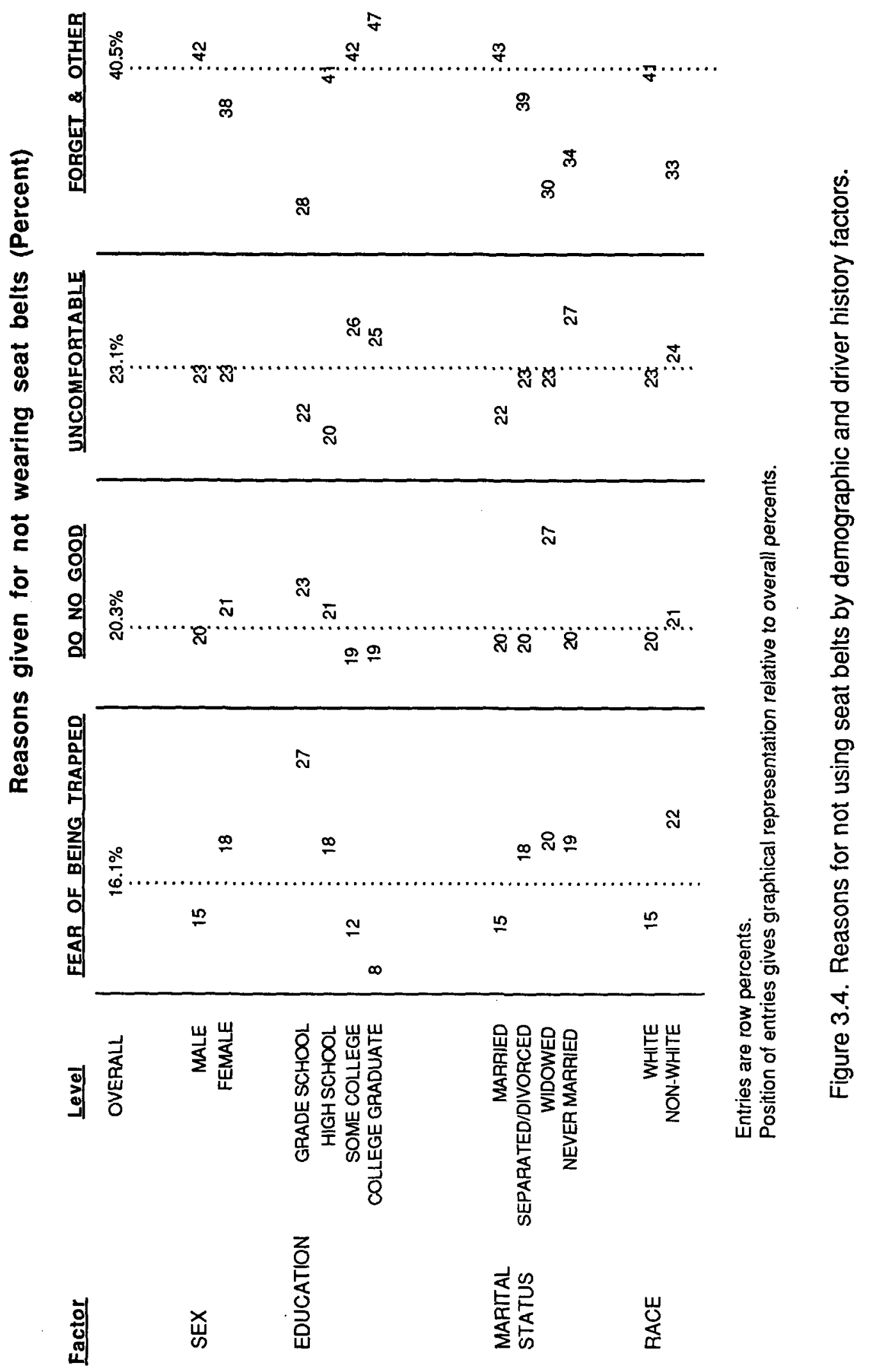


Table 3.10. Reasons for wearing belts by reasons for not wearing belts.

Reasons for Not Wearing Be1ts

\begin{tabular}{|c|c|c|c|c|c|c|c|c|c|c|}
\hline $\begin{array}{r}\text { Reas } \\
\text { We } \\
\end{array}$ & $\begin{array}{l}\text { sons for } \\
\text { earing } \\
\text { Belts }\end{array}$ & $\begin{array}{c}\text { (1) } \\
\text { No } \\
\text { Benefit } \\
\end{array}$ & $\begin{array}{c}\text { (2) } \\
\text { Cause } \\
\text { Injury }\end{array}$ & $\begin{array}{c}(3) \\
\text { Uncomfortable } \\
\end{array}$ & $\begin{array}{c}\text { (4) } \\
\text { Trapped } \\
\end{array}$ & $\begin{array}{c}\text { (5) } \\
\text { Long } \\
\text { Trips On1y } \\
\end{array}$ & $\begin{array}{c}(6) \\
\text { Do Not } \\
\text { Need }\end{array}$ & $\begin{array}{c}(7) \\
\text { Forget }\end{array}$ & $\begin{array}{l}\quad(8) \\
\text { Always } \\
\text { Wear It } \\
\end{array}$ & Total \\
\hline (1) & Avoid fine & $\begin{array}{c}42 \\
(6.6)^{1} \\
(45.7)^{2}\end{array}$ & $\begin{array}{c}19 \\
(3.0) \\
(27.9)\end{array}$ & $\begin{array}{c}181 \\
(28.5) \\
(31.7)\end{array}$ & $\begin{array}{c}162 \\
(25.5) \\
(40.4)\end{array}$ & $\begin{array}{c}35 \\
(5.5) \\
(24.3)\end{array}$ & $\begin{array}{c}9 \\
(1.4) \\
(39.1)\end{array}$ & $\begin{array}{c}143 \\
(22.5) \\
(17.4)\end{array}$ & $\begin{array}{r}45 \\
(7.1) \\
(2.5)\end{array}$ & $\begin{array}{c}636 \\
(16.2)\end{array}$ \\
\hline (2) & Law & $\begin{array}{c}20 \\
(2.5) \\
(21.7)\end{array}$ & $\begin{array}{c}25 \\
(3.1) \\
(36.8)\end{array}$ & $\begin{array}{c}140 \\
(17.2) \\
(24.5)\end{array}$ & $\begin{array}{c}90 \\
(11.1) \\
(22.4)\end{array}$ & $\begin{array}{c}21 \\
(2.6) \\
(14.6)\end{array}$ & $\begin{array}{r}2 \\
(0.3) \\
(8.7)\end{array}$ & $\begin{array}{c}241 \\
(29.7) \\
(24.4)\end{array}$ & $\begin{array}{c}273 \\
(33.6) \\
(15.1)\end{array}$ & $\begin{array}{c}812 \\
(20.7)\end{array}$ \\
\hline (3) & $\begin{array}{l}\text { Prevent } \\
\text { injury }\end{array}$ & $\begin{array}{c}3 \\
(0.2) \\
(3.3)\end{array}$ & $\begin{array}{r}4 \\
(0.3) \\
(5.9)\end{array}$ & $\begin{array}{c}131 \\
(9.1) \\
(27.9)\end{array}$ & $\begin{array}{c}53 \\
(3.7) \\
(13.2)\end{array}$ & $\begin{array}{r}62 \\
(4.3) \\
(43.1)\end{array}$ & $\begin{array}{c}4 \\
(0.3) \\
(17.4)\end{array}$ & $\begin{array}{c}329 \\
(22.9) \\
(40.1)\end{array}$ & $\begin{array}{c}851 \\
(59.2) \\
(\mathbf{4 7 . 0 )}\end{array}$ & $\begin{array}{c}1437 \\
(36.6)\end{array}$ \\
\hline (4) & $\begin{array}{l}\text { Friends/ } \\
\text { family }\end{array}$ & $\begin{array}{c}6 \\
(4.6) \\
(6.5)\end{array}$ & $\begin{array}{c}5 \\
(3.9) \\
(7.4)\end{array}$ & $\begin{array}{c}35 \\
(26.9) \\
(6.1)\end{array}$ & $\begin{array}{c}17 \\
(13.1) \\
(4.2)\end{array}$ & $\begin{array}{c}13 \\
(10.0) \\
(9.0)\end{array}$ & $\begin{array}{c}1 \\
(0.8) \\
(4.4)\end{array}$ & $\begin{array}{r}37 \\
(28.5) \\
(4.5)\end{array}$ & $\begin{array}{c}16 \\
(12.3) \\
(0.9)\end{array}$ & $\begin{array}{c}130 \\
(3.3)\end{array}$ \\
\hline (5) & Habit & $\begin{array}{c}4 \\
(0.8) \\
(4.4)\end{array}$ & $\begin{array}{c}0 \\
(0.0) \\
(0.0)\end{array}$ & $\begin{array}{c}21 \\
(4.1) \\
(3.7)\end{array}$ & $\begin{array}{c}17 \\
(3.3) \\
(4.4)\end{array}$ & $\begin{array}{c}3 \\
(0.6) \\
(2.1)\end{array}$ & $\begin{array}{c}0 \\
(0.0) \\
(0.0)\end{array}$ & $\begin{array}{c}18 \\
(3.5) \\
(2.2)\end{array}$ & $\begin{array}{c}455 \\
(87.8) \\
(25.2)\end{array}$ & $\begin{array}{c}518 \\
(13.2)\end{array}$ \\
\hline (6) & $\begin{array}{l}\text { Own } \\
\text { accident } \\
\text { experience }\end{array}$ & $\begin{array}{c}1 \\
(0.6) \\
(1.1)\end{array}$ & $\begin{array}{c}0 \\
(0.0) \\
(0.0)\end{array}$ & $\begin{array}{c}15 \\
(9.1) \\
(2.6)\end{array}$ & $\begin{array}{c}11 \\
(6.7) \\
(2.7)\end{array}$ & $\begin{array}{c}5 \\
(3.0) \\
(3.5)\end{array}$ & $\begin{array}{c}0 \\
(0.0) \\
(0.0)\end{array}$ & $\begin{array}{c}20 \\
(12.1) \\
(2.4)\end{array}$ & $\begin{array}{r}113 \\
(68.5) \\
(6.3)\end{array}$ & $\begin{array}{c}165 \\
(4.2)\end{array}$ \\
\hline (7) & $\begin{array}{l}\text { Others } \\
\text { accident } \\
\text { experience }\end{array}$ & $\begin{array}{c}0 \\
(0.0) \\
(0.0)\end{array}$ & $\begin{array}{c}1 \\
(1.1) \\
(1.5)\end{array}$ & $\begin{array}{c}9 \\
(9.9) \\
(1.6)\end{array}$ & $\begin{array}{c}4 \\
(4.4) \\
(1.0)\end{array}$ & $\begin{array}{c}2 \\
(2.2) \\
(1.4)\end{array}$ & $\begin{array}{c}0 \\
(0.0) \\
(0.0)\end{array}$ & $\begin{array}{c}20 \\
(22.0) \\
(2.4)\end{array}$ & $\begin{array}{c}55 \\
(60.4) \\
(3.0)\end{array}$ & $\begin{array}{c}91 \\
(2.3)\end{array}$ \\
\hline (8) & $\begin{array}{l}\text { Never } \\
\text { wear it }\end{array}$ & $\begin{array}{c}16 \\
(11.5) \\
(17.4)\end{array}$ & $\begin{array}{c}14 \\
(10.1) \\
(20.6)\end{array}$ & $\begin{array}{c}39 \\
(28.1) \\
(6.8)\end{array}$ & $\begin{array}{c}47 \\
(33.8) \\
(11.7)\end{array}$ & $\begin{array}{c}3 \\
(2.2) \\
(2.1)\end{array}$ & $\begin{array}{c}7 \\
(5.0) \\
(30.4)\end{array}$ & $\begin{array}{c}12 \\
(8.6) \\
(1.5)\end{array}$ & $\begin{array}{c}1 \\
(0.7) \\
(0.1)\end{array}$ & $\begin{array}{c}139 \\
(3.5)\end{array}$ \\
\hline & Total & $\begin{array}{c}92 \\
(2.3)\end{array}$ & $\begin{array}{c}68 \\
(1.7)\end{array}$ & $\begin{array}{c}571 \\
(14.5)\end{array}$ & $\begin{array}{c}401 \\
(10.2)\end{array}$ & $\begin{array}{c}144 \\
(3.7)\end{array}$ & $\begin{array}{c}23 \\
(0.6)\end{array}$ & $\begin{array}{c}820 \\
(20.9)\end{array}$ & $\begin{array}{c}1809 \\
(46.1)\end{array}$ & 3928 \\
\hline
\end{tabular}


crosstabulation of responses to Items 8 and 9 . Interesting information can be obtained both by reading across the rows and down the columns of this table. For example, reading the row percents across the bottom row, one sees that of those who say they never wear seat belts 33.8 percent give fear of being trapped as the primary reason they do not. Another 21.6 percent of this group says belts do no good $(11.5 \%)$ or cause injury $(10.0 \%)$. Those who say they wear belts primarily to avoid the fine (row 1) or because it is the law (row 2) also frequently cite fear of being trapped as a reason for not wearing belts. Reading column percents down column 8, we find that of those who say they always wear belts 47 percent give safety as their primary reason, 25 percent say it's a habit, etc.

Consider the subset of respondents whose reasons fall in rows 1,2 , or 8 and columns $1,2,4,5$, or 6 . These drivers never wear seat belts or only wear them to avoid the fine or because it is the law. At the same time they say they think belts do no good or cause injury, they are afraid of being trapped by the belts, wear belts only on long trips or they don't need them. This subset included 512 (13 percent) of the 3928 respondents who completed both Items 8 and 9 . While nearly 28 percent of the respondents in this group were observed wearing seat belts, less than 5 percent of them responded that they would vote to keep the seat belt law. Thus, this subset of respondents would seem to constitute a general "anti-seat belt" group. Two strategies might be effective in increasing belt use among members of this anti-belt group. One strategy would consist of educational programs to show the benefits of seat belts and to present evidence that fears of being trapped are unfounded. A second strategy would be increased enforcement of the law.

Having identified this anti-seat-belt group, it was then of interest to determine how membership in this subgroup was statistically associated with other subpopulations. From the previous analyses it would certainly seem that anti-seat-belt group membership should be correlated with educational level and past violation history. Indeed, this was found to be the case. Education and prior violations were the variables with the strongest relationships to antiseat belt group membership (as measured by correlation coefficients or $\mathrm{x}^{2} /$ degrees of freedom). Thus, a three-way table of education by prior violations by anti-seat-belt group membership was run. The results are shown in Figure 3.5. There the percent of the various subpopulations belonging to the anti-seat-belt group varies from five percent for college graduates with no 
Anti-Seat-Belt Group Membership

\begin{tabular}{|c|c|c|c|c|}
\hline & OVERALL & $11.4 \%$ & & \\
\hline Education & Violations & & & \\
\hline \multirow[t]{3}{*}{ Completed College } & 0 & 5.2 & & \\
\hline & 1 & 5.3 & & \\
\hline & 2 or more & 5.6 & & \\
\hline \multirow[t]{3}{*}{ Some College } & 0 & 8.7 & & \\
\hline & 1 & 8.6 & & \\
\hline & 2 or more & 9.2 & & \\
\hline \multirow[t]{3}{*}{ High School } & 0 & & 12.1 & \\
\hline & 1 & & 22.6 & \\
\hline & 2 or more & & 20.5 & \\
\hline \multirow[t]{3}{*}{ Grade School } & 0 & & 19.1 & \\
\hline & 1 & & 20.4 & \\
\hline & 2 or more & & & 39.0 \\
\hline
\end{tabular}

Figure 3.5. Anti-seat-belt group membership as a function of education and prior violations. 
prior violations to 39 percent for drivers only completing grade school and having 2 or more prior violations. From this one might conclude that drivers with histories of violations and relatively low educational levels might be potential candidates for educational or other programs on seat belt safety. In addition to education and prior violations, significant correlations were also found for driver sex, prior accident history, and marital status. Approximately 9.5 percent of our female respondents were classified in the anti-seat-belt group as compared to 13 percent of the males. Of those respondents with no prior accidents 11 percent were anti-seat-belt while 13 percent of those with one or more prior accidents belonged to the anti-seatbelt group. With respect to marital status, widowed respondents were most likely to belong to the anti-seat belt group (16\%), followed by separated or divorced (15\%), never married (13\%), and married (10\%). 
CHAPTER 4. TELEPHONE SURVEY RESULTS - CHARACTERISTICS OF USERS AND NON-USERS OF SAFETY BELTS

Background

A telephone survey was constructed that covered a variety of topics, but the primary thrust was to uncover reasons for using or not using belts. It was also envisioned that program ideas to increase belt use would emerge from the interviews. As detailed in the methodology chapter, we oversampled drivers with accidents and/or violations on their driving record (high risk drivers) to determine if their attitudes and opinions concerning belts differed from those of drivers with no accidents or violations on their driving record (low risk drivers). High risk drivers were defined as drivers with:

2 or more accidents,

2 or more violations, or

1 accident and 1 violation.

Interviews were conducted with high and low risk drivers selected from among the mailback self-reported belt use groups of never + rarely, sometimes + most of the time, and always. The sample included 60 percent high risk and 40 percent low risk drivers. It should be stressed that this approach was used in an attempt to uncover programmatic ideas concerning ways to increase belt use, and results from this sample of telephone interviews were not meant to be strictly compared with the mailback survey results or other belt use survey results.

Since 204 telephone interviews were completed, the analysis of these data were primarily descriptive in nature rather than statistical. When statistical tests were used, basic chi square tests were run to check for significant differences in the homogeneity of the distributions, with $\alpha=.05$. Because of a small sample, logical grouping of responses generally was necessary. Even so, chi-square tests were often flagged as possibly invalid because of too many cells with low expected values. Rather than unduly diluting the detail through further collapsing of categories, we generally opted to present more complete tables, especially when the differences in the distributions were practically and programmatically different.

Each variable of interest from the telephone survey was examined in four separate levels of crosstabulations, namely: (1) by the telephone survey belt group (never to always), (2) by high-low risk group, (3) by whether the respondent had been observed as a belted or unbelted driver during the mailback 
survey handout, and (4) by the demographic variables age, race, sex, education, and marital status.

Where appropriate, crosstabulations of the variable of interest by belt wearing group (never to always) will be presented in the text. Other selected crosstabulations by high-low risk group and observed belted and unbelted drivers are presented in Appendix D. This approach is used because most of the risk group and observed belt group comparisons produced statistically insignificant differences. These non-significant differences are probably related to: (1) a small sample size, and (2) the fact that belt use is now around 60 percent in North Carolina, so that belt wearers are now in the mainstream of the population, rather than the 15-20 percent "select" group who were belt wearers prior to the mandatory seat belt law.

Three different forms were used in interviewing respondents -- one for always wearers, one for never wearers, and a third for the remaining part-time wearers. This strategy was chosen because much of our emphasis has to do with increasing belt use among part-time wearers, and several questions were considered inappropriate for never and/or always wearers. Otherwise, the questionnaires were comparable. Responses to individual items showed only small amounts of missing data.

The remaining text in this chapter basically concerns the telephone survey respondents' belt use characteristics and attitudes toward the North Carolina mandatory law, as well as how their accident experience, their seat belt enforcement perceptions and/or experience, and their lifestyle characteristics relate to belt use. Even though some of the text relates primarily to the North Carolina seat belt law, it is felt that these findings are applicable to other states (both with and without seat belt laws) and their planning and programming efforts re]ated to occupant restraints.

\section{Questions Concerning Belt Use}

\section{Personal Belt Use}

On the mailback survey, drivers were asked to state their current belt use group (never, rarely, sometimes, most of the time, always). The telephone interviews were structured to sample a total of $200 \mathrm{high}$ and low risk drivers from three belt wearing groups defined by the current belt use variable, as shown on the left side of Table 4.1. 
Table 4.1. Planned versus actual distribution of telephone survey belt groups.

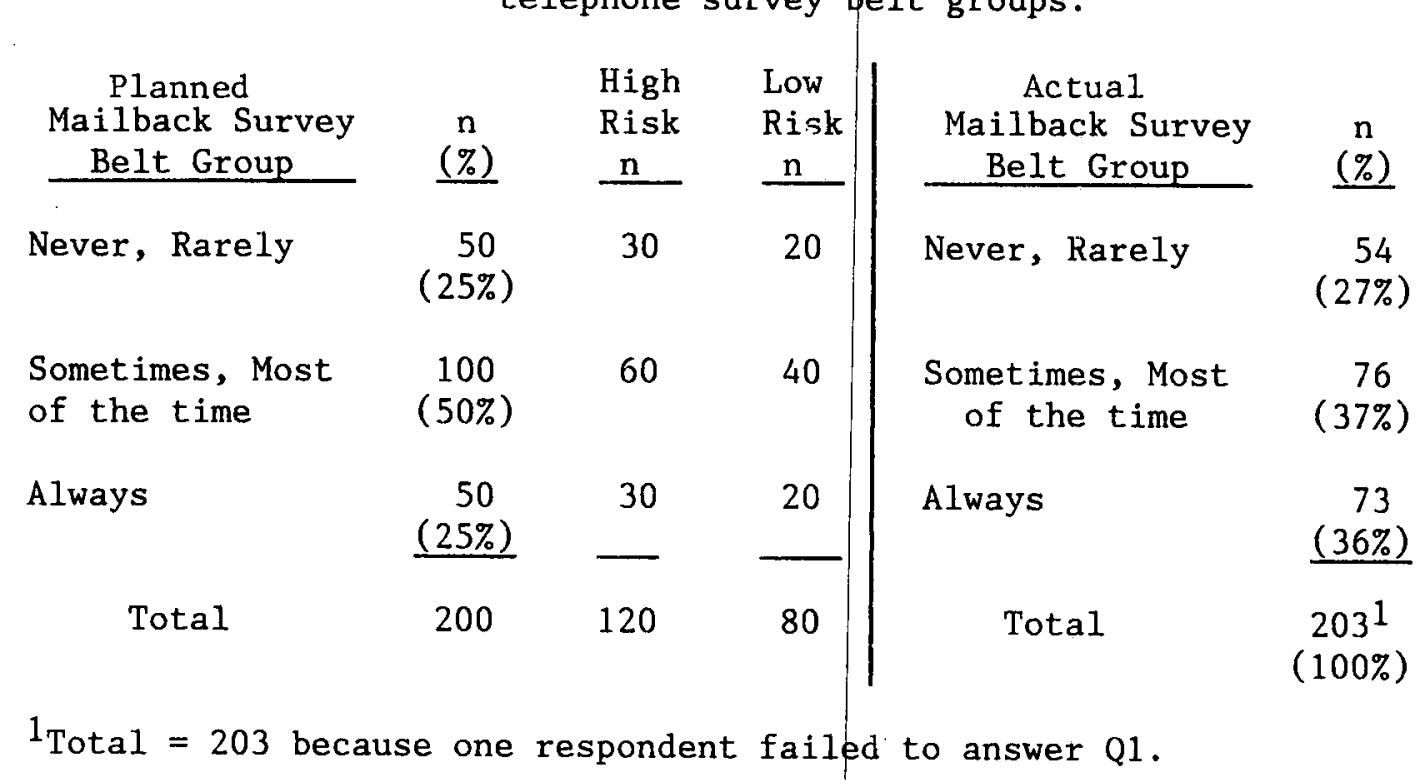

Since the mailback preceded the telephone survey by 4-5 months and belt wearing could have changed, we again asked each respondent to place themselves in one of these groups (Q1). The actual distribution of the telephone survey belt groups, based on their most recent belt use as defined by the first question (Q1), is shown on the right side of Table 4.1. (Collapsed categories are used to compare to the planned distribution on the left). While there were some belt wearing shifts within each group, one primary change was due to former (mailback) most-of-the-time wearers now claiming to wear their belt always. We next asked each respondent what percent of the time they used their belt (Q2). Various measures of belt wearing were calculated (Table 4.2). Here

Table 4.2. Characteristics of the distribution of telephone survey respondents' bel t wearing.

Telephone Survey

Belt Group

Never

Rarely

Sometimes

Most of the time

Always $\mathrm{n}$

(\%)

20

34 (16.8)

24

$(11.8)$

52 $(25.6)$

73 (36.0)

\begin{tabular}{|ccc}
$\begin{array}{c}\text { Percent Belt } \\
\text { Mean }\end{array}$ & $\begin{array}{cc}\text { Median } \\
0.6 \%\end{array}$ & $\underline{\text { Range }}$ \\
7.1 & 4.7 & $0-10 \%$ \\
46.3 & 42.2 & $20-80$ \\
96.3 & 86.0 & $70-99$ \\
99.9 & 100.0 & $95-100$
\end{tabular}


uncollapsed belt categories are used to provide more complete information. The mean and median values in Table 4.2 derive from the respondents' estimates of the percentage of the time the belt is used and turn out to be relatively close in magnitude. Although pilot testing had revealed no difficulties, we were interested in learning whether this question would be easy to answer.

Respondents seemed to have little difficulty estimating the percentage of time they wore their belt. Our subjective opinion was that asking for a percentage value was easier than asking how many times a belt had been used in the last five trips (as has been done on other surveys).

To better understand the characteristics of the sample, the telephone respondents were then distributed by several demographic variables (Table 4.3),

Table 4.3. Percentage estimates of belt use among groups of telephone respondents.

$\underline{\text { Age }}$

$\leq 25$

$\geq 55$

$\underline{\text { Race }}$

White

Black

$\underline{\text { Sex }}$

Male

Female

75

Education

Grade Schoo1

High School

Some College

College Graduate or Greater

\section{Marital Status}

Married

127

Separated,

Divorced, Widowed

Never Married ple

$19 \%$

(1)

63

80

62

70

37

\begin{tabular}{|c|c|}
\hline $\begin{array}{l}\text { Mean } \\
\text { Percent } \\
\text { Belt } \\
\text { Use } \\
\end{array}$ & $\begin{array}{l}\text { Median } \\
\text { Percent } \\
\text { Belt } \\
\text { Use } \\
\end{array}$ \\
\hline $68 \%$ & $80 \%$ \\
\hline 64 & 90 \\
\hline 64 & 90 \\
\hline
\end{tabular}

85

93

80

90

85

75

90

90

68

68 
along with mean and median percent (self-reported) belt use. Examining the mean belt use percentages for this specially constructed sample shows some typical results, namely, that belt use increases with level of education, and that the female use rate exceeds that for males. Somewhat surprisingly, mean percent belt use decreases slightly with age (although median percent belt use does not), and the mean percent belt use for blacks (80\%) is appreciably higher than for whites (63\%), although a higher use rate for blacks has been the recent trend in observations carried out as part of the evaluation of the North Carolina seat belt law (Reinfurt, Campbe11, Stewart, and Stutts, 1987). Since only a few respondents were neither white nor black, these were treated as missing. Thus, all the race comparisons in the telephone survey results reflect the white-black distinction. The mean value for the separated, divorced, and widowed group is quite a bit higher than the married and never married groups. As a rule, and as seen in the mailback survey for this project, the belt use rate for the married people would be higher than the other categories in the marital status group.

Chi-square tests were then used to examine the homogeneity of the telephone survey belt wearing groups within the various levels of age, sex, race, education and marital status. None produced significant differences, even when belt groups were collapsed to never + rarely, sometimes + most of the time, and always categories. Thus, these data do not support trying to identify distinct target groups (e.g., young white males or black college graduates) within a belt wearing category (e.g., part-time users). (For the interested reader, these distributions are shown in Appendix D, Tables D.1 - D.5).

To further understand the composition of the telephone survey respondents, the high-low risk groups were crosstabulated by each demographic variable. By design, 60 percent of the respondents were high risk. As shown below, the age,

\begin{tabular}{|c|c|c|}
\hline Variable & Significance & Comments \\
\hline Age & $p=.002$ & $\begin{array}{l}77 \% \text { of } \leq 25 \text { year olds high risk } \\
\text { versus } 62 \% \text { of } 26-54 \text { year olds and } \\
39 \% \text { of } \geq 55 \text { year olds }\end{array}$ \\
\hline Race & $p=.001$ & $\begin{array}{l}55 \% \text { of white group high risk } \\
\text { versus } 88 \% \text { of black group }\end{array}$ \\
\hline Sex & $p=.185$ & $\begin{array}{l}63 \% \text { of males high risk versus } 53 \% \\
\text { of females }\end{array}$ \\
\hline Education & $p=.205$ & $\begin{array}{l}43 \% \text { of grade school, } 65 \% \text { of high } \\
\text { school, } 63 \% \text { of some college, and } \\
56 \% \text { of college graduates or } \\
\text { greater from the high risk group }\end{array}$ \\
\hline Marital status & $p=.024$ & $\begin{array}{l}52 \% \text { of married; } 65 \% \text { of separated, } \\
\text { divorced, or widowed; and } 76 \% \text { of } \\
\text { never married groups from the } \\
\text { high risk group }\end{array}$ \\
\hline
\end{tabular}


race, and marital status variable crosstabulations produced statistically significant differences. Included in the high risk group are a higher proportion of young people, blacks, and those who never married.

In a final comparison, the observed belted-unbelted groups produced no significantly different distributions when crosstabulated with each demographic variable. Overall, 51 percent of the group had been observed belted and 49 percent unbelted.

\section{Belt Use by Friends}

In order to learn about the social patterns of belt wearing, we asked the respondents what percentage of their friends use belts (Q5), and the results are shown in Table 4.4 by telephone survey belt group. The mean and median percentage values agreed quite well except for the sometimes and rarely wearers, where the medians were somewhat lower than the means. In general, the mean and median values of friends' belt use increased with the belt wearing frequency of the respondent -- from 40 percent or less for the never and rarely wearers to 70-75 percent for most-of-the-time and always wearers. Thus, there does appear to be some "peer group" effect. The ranges in the percentage of friends using belts were quite broad across all belt groups.

\section{Table 4.4. Characteristics of reported belt use by friends} for each respondent belt group.

$$
\text { Percent Belt Use by Friends }
$$

$\begin{array}{lccc}\begin{array}{c}\text { Telephone Survey } \\ \text { Belt Group }\end{array} & \underline{\text { Mean }} & \text { Median } & \text { Range } \\ \text { Never } & 40.6 \% & 40.0 \% & 5-100 \% \\ \text { Rarely } & 34.6 & 23.0 & 0-98 \\ \text { Sometimes } & 48.1 & 37.4 & 10-95 \\ \text { Most of the time } & 69.5 & 70.5 & 25-100 \\ \text { Always } & 74.3 & 74.6 & 10-100\end{array}$

\section{When Belt First Worn}

North Carolina's belt law became effective October 1, 1985, and the $\$ 25$ fine for non-compliance became effective January 1, 1987. To determine if belt wearing changes were associated with the onset of either the mandatory law or the $\$ 25 \mathrm{fine}$, we asked all but the never belt wearers when they first started 
wearing a belt (Q3). Overal1, 26 percent indicated that they first started wearing their belt after the $\$ 25$ fine became effective. However, almost half of the rarely and sometimes wearers said their belt use was coincident with the fine (Table 4.5). Even for the always wearers, about two-thirds said they started using their belt just before the law or thereafter. The distributions for both the high-low risk groups and the observed belted and unbelted drivers were not significantly different (Appendix D, Table D.6).

Table 4.5. When telephone respondents first started wearing belt.

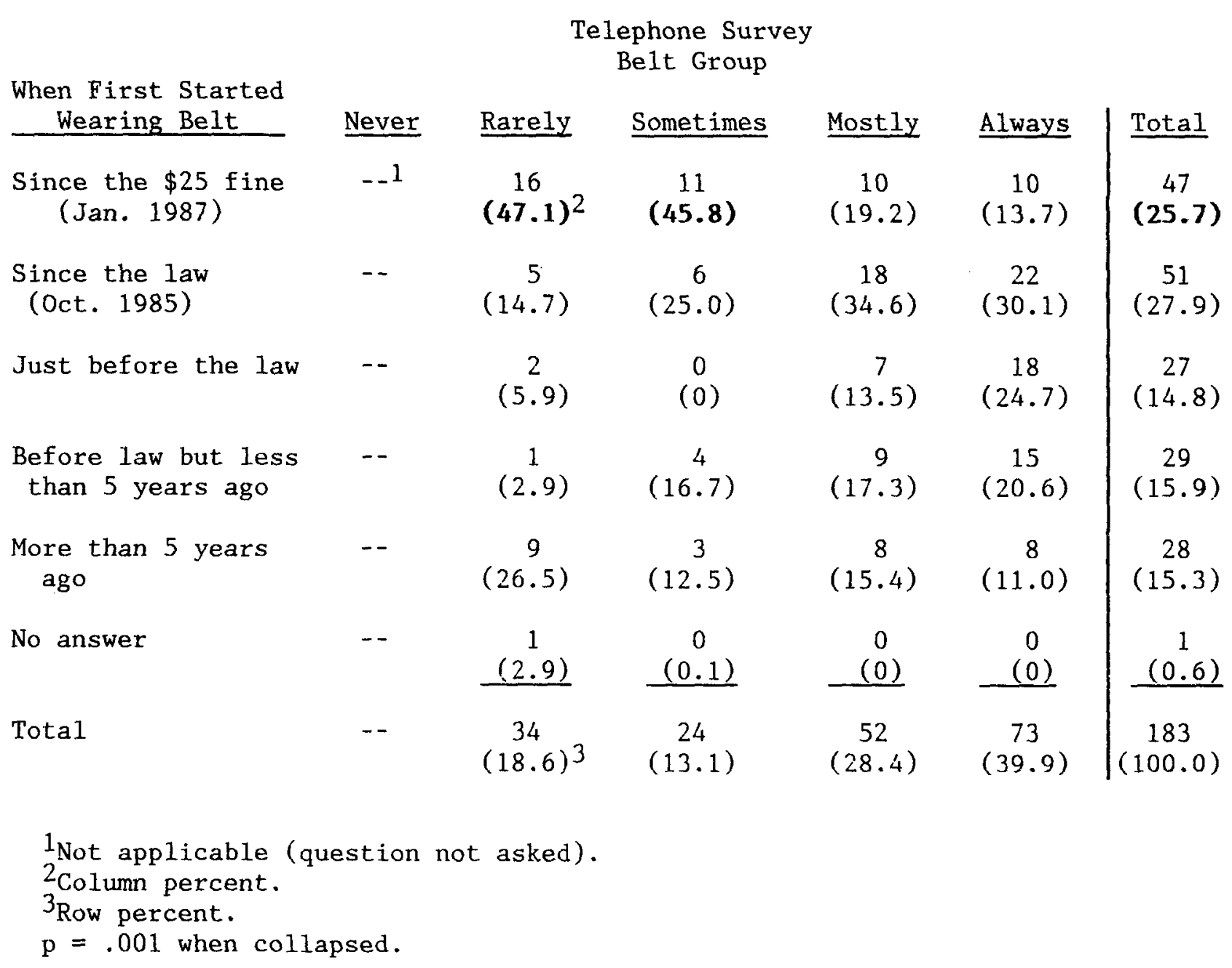

Several demographic crosstabulations produced significant differences. For the youngest age group, a much higher percentage (27\%) first wore their belt just before the law than either the middle aged (12\%) or oldest age group (10\%). Also, none of the youngest age group indicated they first started "buckling up" over five years ago. In regard to gender, twice as many females 
started wearing their belt within the last five years as males, and almost four times as many males started wearing their belt over five years ago.

\section{Factors That Influenced Belt Wearing}

Following up on the question about when belts were first worn, all respondents but the never wearers were asked the open-ended question (Q4), "What influenced you to start wearing seat belts?" Up to three responses were coded for each respondent, beginning with the most important. Examining the first response only, almost half of the respondents gave a reason that was related to the law or the $\$ 25$ fine. These choices related to the law amounted to about two-thirds of the responses given by both the rarely and sometimes belt wearers, as compared to 38 percent and 32 percent of the most-of-the-time and always wearers, respectively (Appendix D, Table D.7). Consistent with these results is the fact that the mandatory belt law was the reason most often given by Michigan respondents for starting to wear belts (Wagenaar, et a1., 1987).

The "other" responses $(n=17)$ for this question covered a variety of topics. Reasons most frequently stated included: (1) having seen many bad accidents, (2) having driven race cars, and (3) driver education.

To test for statistically significant differences, a11 293 responses were combined and grouped into the categories of "just that law was passed;" "concern about being stopped and fined;" a safety category made up of "increased concern for personal safety," "increased awareness of belt effectiveness," and "just makes sense; for safety;" and all other reasons (Appendix D, Table D.8). The distributions were significantly different $(\mathrm{p}=$ .001 ) by telephone survey belt group, primarily because the rarely and sometimes wearers gave the $\$ 25$ fine as their reason for starting to wear a belt while the always and most-of-the-time wearers tended to state safety reasons. These tendencies were also present in the mailback survey results. No significant differences were detected when the same grouping was done for the high-low risk groups and the observed belted versus unbelted drivers (Appendix Tables D.9 and D.10).

\section{Statements About Seat Be1ts}

Six statement items (Q6) were developed to gauge opinions about some frequently stated seat belt issues (e.g., "In an accident, it's better to be 
thrown out of the car than to stay inside."). A five-point Likert scale ranging from strongly agree to strongly disagree was used to assess the attitudes of the respondents. Appendix Table D.11 presents the distributions of responses by frequency of belt wearing for the telephone survey respondents. The results are shown graphically in Figure 4.1. Because of small sample size, chi-square tests could only be used with substantial collapsing of categories (e.g., agree-disagree by three belt groups), and these tests were all statistically significant for each statement but the second. From a practical significance standpoint, the differences shown in Figure 4.1 are considerable and are useful in developing programmatic suggestions. Differences by risk group and observed belt use are given in Tables D.12 and D.13 and highlighted in the text.

1. Belts reduce the chance of serious injury. The first statement concerned whether seat belts reduce the chance of serious injury in a crash, and overall almost 90 percent either agreed (43\%) or strongly agreed (46\%). The responses varied widely by belt group. For example, 68 percent of the always wearers, 38 percent of the sometimes wearers, and none of the never wearers strongly agreed with this statement. The relationship was monotonic proceeding from less to more frequent belt use. Overal1, 87 percent of the high risk group and 89 percent of the low risk group agreed or strongly agreed (n.s.) (Appendix Table D.12), and 95 percent of the observed belted drivers and 82 percent of the observed unbelted drivers agreed or strongly agreed ( $\mathrm{p}=$ .006) (Appendix Table D.13). Another trend was for agreement with this statement to increase with level of education. Thus, across the board there was relatively strong agreement that belts reduce the chance of serious injury in a crash.

2. Better to be thrown out in an accident. The next statement dealt with whether it is better to be thrown out of the car than to stay inside in an accident situation. Overal1 75 percent either disagreed (37\%) or strong1y disagreed (38\%), but 12 percent had no opinion. The variation in responses across belt groups was again large (but not statistically significant). Just over half of the always wearers strongly disagreed with the statement, compared to 15 percent of the never wearers. At the other extreme, about 5 percent of the always wearers strongly agreed compared to 15 percent of the never wearers. Again, the relationship was generally monotonic proceeding from less frequent to more frequent wearers. Examining the responses by high-low risk groups and 
1. Seat belts reduce the chance of serious injury in a crash.

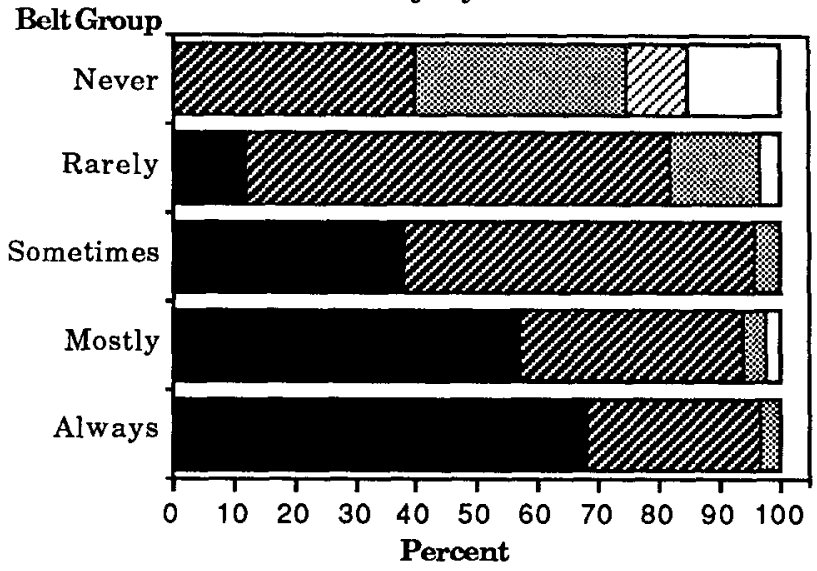

3. Seat belts are easy to use.

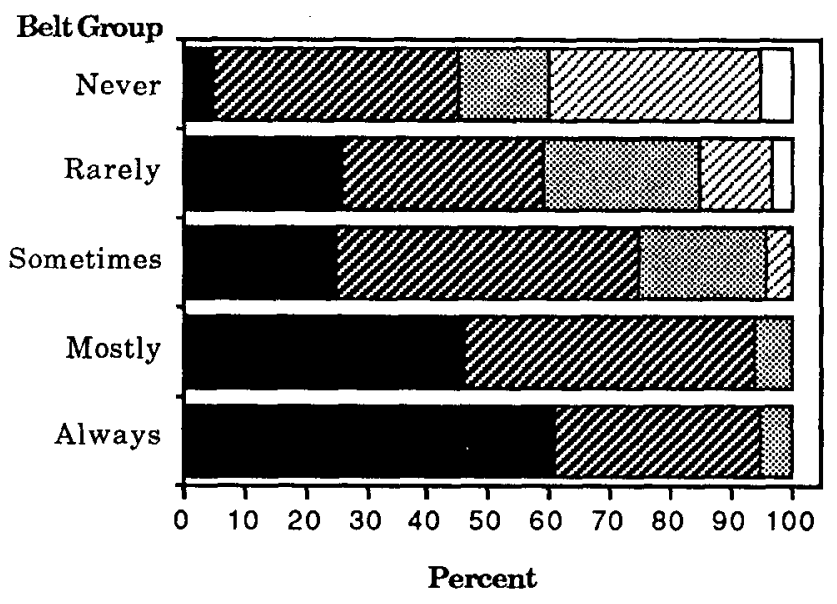

5. Your chances of being trapped in a car if it crashes and catches on fire are greater if wearing a seat belt.

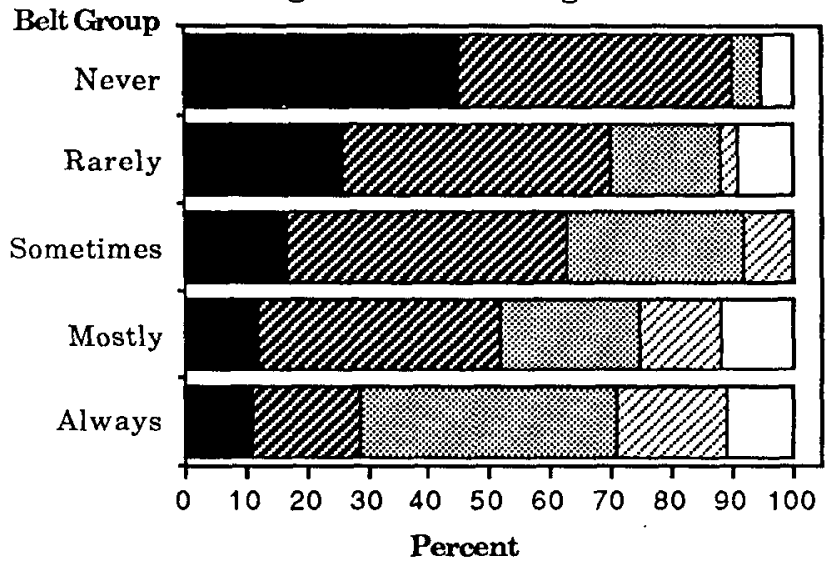

2. In an accident, it's beiter to be thrown out of the car than to stay inside.

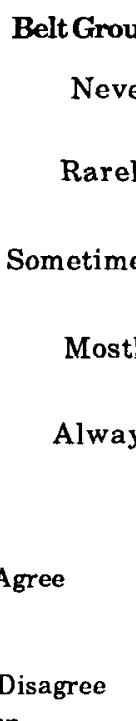

Strongly Agree

Q Agree

Disagree

Strongly Disagree

$\square$ No Opinion
4. Lap belts are not necessary when riding in the back seat of a car.

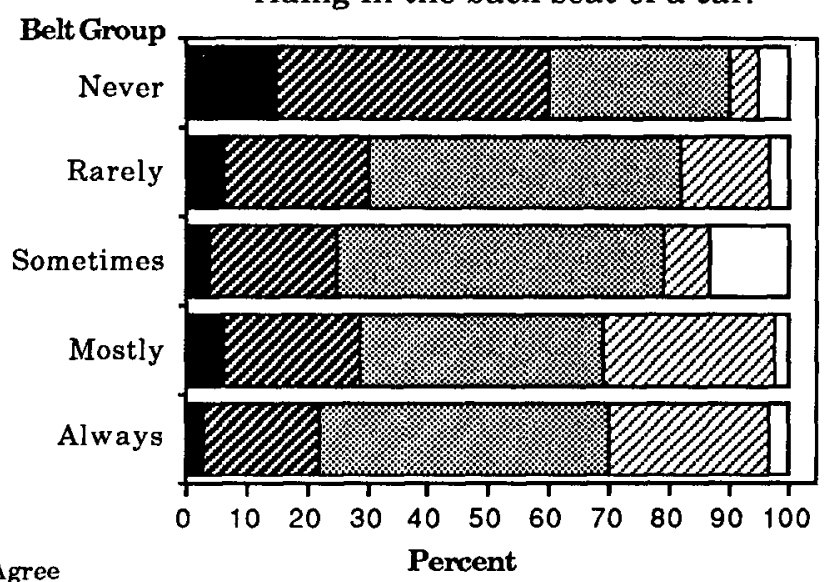

\footnotetext{
Strongly Agree

Agree

Disagree

Q Strongly Disagree

No Opinion
}

6. Seat belts can cause more injuries than they prevent.

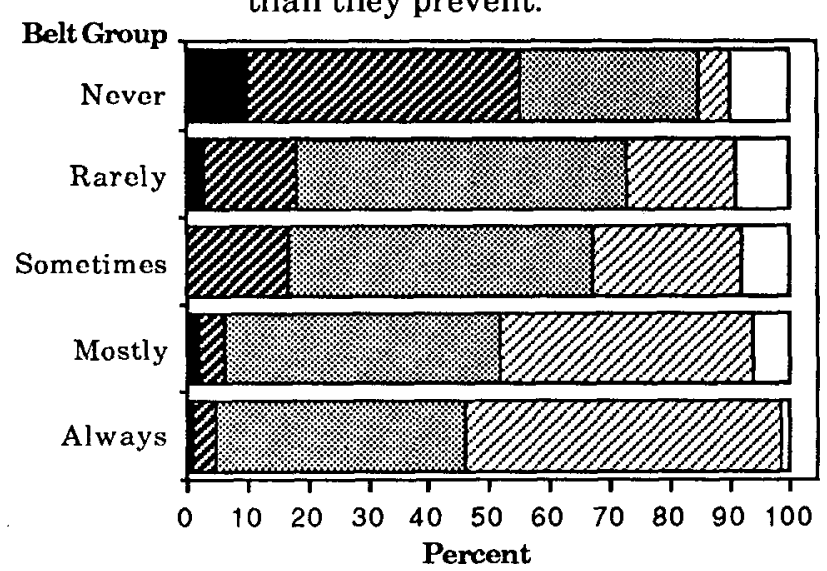

Figure 4.1. Respondents' opinions regarding six statements about seat belts by telephone survey belt group. 
observed belted and unbelted drivers showed no significant differences. Like the previous statement, the amount of agreement was associated with education, with the less educated tending to agree that it is better to be thrown out in an accident.

3. Belts are easy to use. The third statement was that belts are easy to use, and the responses were similar to the previous two statements, with 40 percent agreeing and 41 percent strongly agreeing. Thirty-five percent of the never wearers strongly disagreed compared to none of the always and most-ofthe-time wearers. At the opposite end of the scale, 60 percent of the always wearers strongly agreed that belts are easy to use compared to 5 percent of the never wearers. Once again, the part-time wearers tended to fall in between, with the rarely wearers resembling the never wearers and the most-of-the-time wearers like the always wearers. The high-low risk comparison produced statistically significant differences $(p=.025)$ but in a surprising way. Here 50 percent of the high risk group strongly agreed that belts are easy to use compared to 29 percent of the low risk group (perhaps because of more younger people in the high risk group). Also, 55 percent of the observed belted drivers strongly agreed that belts are easy to use compared to 27 percent of the observed unbelted drivers $(p=.000)$.

4. Lap belts are not necessary in the back seat. Given the controversy surrounding the National Transportation Safety Board report (1986) concerning the efficacy of lap belts, we developed a statement that read, "Lap belts are not necessary when riding in the back seat of a car." This was a difficult question to answer and frequently had to be repeated. Here 46 percent

disagreed and 21 percent strongly disagreed. For the belt wearing groups, the tendencies were similar to previous statements, an example being that 15 percent of the never wearers strongly agreed compared to 3 percent of the always wearers. About 13 percent of the sometimes wearers were uncertain of their answer. The high-low risk and observed driver distributions produced no statistically significant differences. Once again the education crosstabulation showed significant differences $(p=.001)$, with 63 percent of those with a grade school education agreeing with the statement.

5. Chances of being trapped are greater if belted. The fifth statement dealt with the fear of being belted and trapped in a burning car, and slightly over half of the respondents agreed that the chances of being trapped were greater if belted (18 percent strongly agreeing and 34 percent agreeing). 
About 40 percent disagreed (11 percent strongly), and nine percent had no opinion. Since belt non-users frequently state that the fear of being trapped in a vehicle is a reason for non-use, this statement was examined by belt groups to see if answers followed this tendency. The tendency was indeed upheld as 45 percent of the never wearers strongly agreed and another 45 percent agreed. By comparison, 11 percent of the always wearers strongly agreed and another 18 percent agreed. Combining responses to form agree and disagree categories produced significant differences $(p=.000)$ and left the impression that the most-of-the-time and sometimes wearers were similar on this issue, with the always wearers standing alone from the other groups. Removing the "no opinion" response and testing for differences showed that neither the high and low risk group nor the observed belted versus unbelted driver distributions produced significant differences. This again appeared to be a difficult question to answer, especially with all the contingencies in the statement, and required a good deal of repetition.

6. Belts can cause more injuries than they prevent. The last in the list of statements concerned whether belts can cause more injuries than they prevent, and the findings for the belt groups followed the tendencies of the other five statements. In other words, the more frequent belt wearers felt that belts do not cause more injuries than they prevent and the less frequent belt wearers (particularly the never wearers) felt the opposite. Slightly less than 14 percent of all respondents agreed that belts can cause more injuries than they prevent. The tendency was similar in the observed group comparison, with 14 percent of the belted drivers agreeing and 86 percent of the unbelted drivers agreeing $(p=.000)$.

\section{Belt Use in Various Driving Situations}

To ascertain differential belt wearing patterns in various driving situations, seven scenarios were presented to all but the never and always respondents (Q7). The situations pertained to weather, time of the trip, traffic patterns, etc. For each situation, the respondent was asked to "please tell me if you are more 1ikely than usual to wear a seat belt. Just answer yes or no." Prompting was done frequently to try to ensure that the respondent was answering the "more likely than usual" part of the question, rather than merely describing his/her general belt use. 
Table 4.6 shows the percentage of respondents answering the question positively (i.e., stating that they wore belts more than normal in the situation). There was considerable variation in the responses of the rarely wearers and relatively little variation for the most-of-the-time wearers. Deleting the few "no response" answers allowed statistical testing. Each of the seven driving situations produced highly statistically significant differences $(p<.01)$ among the distributions of the telephone survey belt wearing groups.

Table 4.6. Effect of various driving situations on belt use of part-time wearers from the telephone survey (percent indicating more likely than usual to wear a seat belt).

Telephone Survey Belt Group

\begin{tabular}{|c|c|c|c|c|}
\hline Situation* & $\underline{\text { Rarely }}$ & Sometimes & $\begin{array}{l}\text { Most of } \\
\text { the time }\end{array}$ & Overa11 \\
\hline $\begin{array}{l}\text { 1. Driving in bad weather, } \\
\text { like rain, snow or fog }\end{array}$ & $68 \%$ & $92 \%$ & $92 \%$ & 847 \\
\hline 2. Driving at night & 9 & 67 & 82 & 56 \\
\hline $\begin{array}{l}\text { 3. Driving on interstate } \\
\text { highways }\end{array}$ & 38 & 54 & 88 & 66 \\
\hline 4. Making a long trip & 44 & 63 & 92 & 71 \\
\hline $\begin{array}{l}\text { 5. Driving with children } \\
\text { in car }\end{array}$ & 56 & 71 & 96 & 78 \\
\hline $\begin{array}{l}\text { 6. Driving in rush hour } \\
\text { traffic }\end{array}$ & 15 & 58 & 90 & 60 \\
\hline $\begin{array}{l}\text { 7. Driving on weekends } \\
\text { or holidays }\end{array}$ & 24 & 54 & 84 & 59 \\
\hline
\end{tabular}

The most likely situations to increase belt wearing overall were driving in bad weather (84\%), driving with children in the car (78\%), and making a long trip (71\%). The same pattern held for the different belt wearing groups, the only exception being that the sometimes wearers selected driving at night as their third more likely choice. All of these leading choices perhaps point to the fact that belts are seen to enhance safety by the various belt wearers. 
Given that only nine percent of the rarely wearers gave a positive response for driving at night and 15 percent for driving in rush hour traffic, perhaps more emphasis could be given to public information and education (PI\&E) efforts focusing on the crash probability of these situations.

By deleting the "no response" answers, both the high-low risk group and belted-unbelted driver distributions could be checked for significance. The only situations showing any statistical significance involved the beltedunbelted drivers as shown below:

\begin{tabular}{lcc|c} 
& \multicolumn{2}{c}{$\begin{array}{c}\text { Percent Indicating More } \\
\text { Likely Than Usual to Wear Belts }\end{array}$} \\
Situation & Belted & Unbelted & Significance \\
Making a long trip & $84 \%$ & $65 \%$ & $p=.032$ \\
Driving in rush hour traffic & $84 \%$ & $48 \%$ & $p=.000$
\end{tabular}

(The complete distributions for these two comparison groups may be found in Appendix Table D.14.)

Upon examining all the demographic comparisons for these driving situations, only a few showed significant differences, as indicated below:

Driving Situation

Driving at night

Driving on weekends or holidays
Result

Blacks would wear belt more than usual.

Blacks and separated, divorced, or widowed group would wear belt more than usual.

\section{Items Leading to Belt Use "Every Time You Get In a Car"}

Instead of asking an open-ended question like, "What would get you to wear your seat belt every time you get in a car," we chose to probe for information with two questions. First, we dealt with the $\$ 25$ fine for non-seat-be1t compliance in North Carolina (Q8) and then elicited responses to a prepared list of items (Q9).

In regard to the fine, we stated that the current fine was $\$ 25$ and then asked all but the always wearers, "What amount of fine would get you to wear your seat be1t EVERY TIME you get in a car?" From the responses, 26 percent 
stated that the current $\$ 25$ fine would be enough, 15 percent stated $\$ 100$, and 40 percent stated (without prompting) that no amount of fine would affect their belt use. Responses to a similar question on the Michigan survey were different, where 38 percent said that the current $\$ 25$ fine would be enough, 15 percent stated $\$ 100$, and nine percent volunteered that no amount of fine would yield full-time belt use (Wagenaar, et al., 1987).

Table 4.7 shows responses to this question by the belt wearing groups. About two-thirds of the never wearers and one-half of the rarely wearers stated that no amount of fine would get them to "buckle up" every time they get in the car. Half of the sometimes wearers chose a fine amount between $\$ 26-100$. It was obvious in the interviews that the never or infrequent belt wearers have very strong anti-fine sentiments. Another comment often heard was the current fine was adequate if the law were more strictly enforced.

Chi-square tests on these grouped responses showed that the observed belted-unbelted distributions were significantly different $(p=.013$, Appendix Table D.15). Here 43 percent of the belted drivers compared to 20 percent of the unbelted drivers stated that the $\$ 25$ fine would get them to "buckle up" on every trip. In addition, none of the belted drivers compared to 12 percent of the unbelted drivers stated a fine amount in excess of $\$ 100$ would be necessary to produce belt wearing on every trip. Differences by risk group were not significant.

Table 4.7. Amount of fine that would produce belt wearing on every trip.

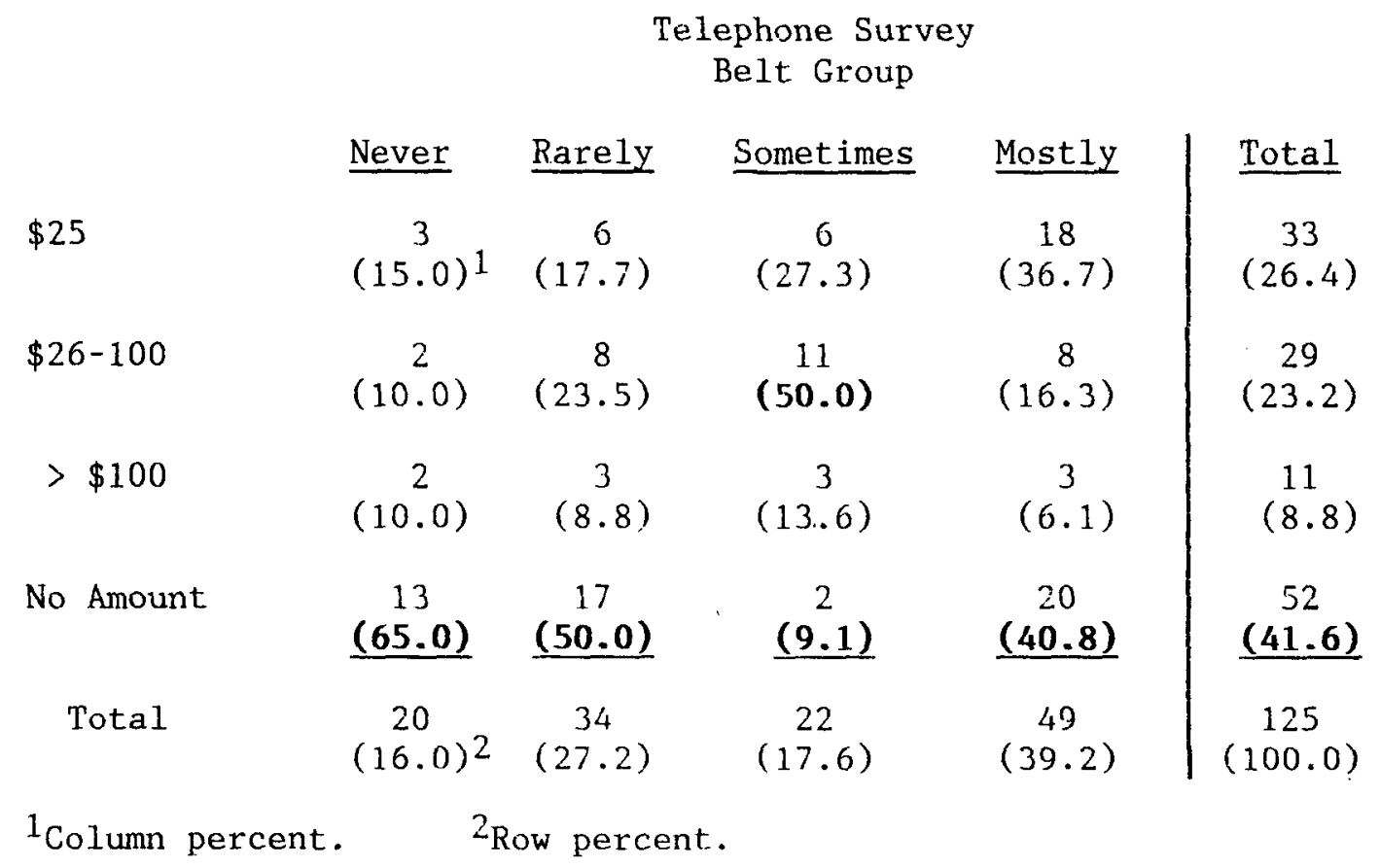


Following the question about the fine amount, a list of eight items was presented, and respondents were asked if any of these would get them to "buckle up" on every trip. The choices were yes, no, or maybe for each item. Considerable prompting was done to try to ensure that "yes" meant full time belt use, as opposed to an item that was just a good idea. The ideas generating the most positive responses overall (Table 4.8 ) were:

- Item 1 - Having the car insurance payment greatly reduced (69\%),

- Item 8 - Having points assessed on the driving record in addition to the fine for belt non-use (69\%),

- Item 5 - Having a belt that was more comfortable or easier to use $(62 \%)$, and

- Item 7 - Having been personally stopped and ticketed for belt non-use (58\%).

Table 4.8. Items that would produce belt wearing for every trip (percent of telephone respondents indicating a positive response).

Telephone Survey Belt Group

$\underline{\text { Item }}$

1. If your car insurance payment was greatly reduced.

2. If you heard someone give a first-hand account of how wearing a seat belt had saved their life.

3. If you personally knew someone whose life was saved by wearing a seat belt.

4. If a friend or family member reminded you to wear your belt.

5. If your belt was more comfortable or easier to use.

6. If a friend had been stopped and ticketed for not wearing a seat belt.

7. If YOU had been stopped and ticketed for not wearing a seat belt.

8. If in addition to the fine, points could be assessed on . Neve Never

$25 \%$

Rare1

\section{Sometimes}

Most 1y

Overa11

$0 \quad 12$

$75 \%$

$88 \%$

697

$62 \%$

12

54

63

$$
0
$$

24

58

69

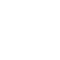

1

5

26

46

71

$15 \quad 59$

67

80

62

10

18

38

51

34

20

41

67

78

58 your driver license record for not wearing a seat belt.
30

59

88

82

69 
As shown before for the driving situations, there was considerable variation among the belt groups. ${ }^{1}$ For example, while 30 percent of the never wearers stated that having points assessed to their driving record would get them to wear their belt every time they get in a car, this was true for 59 percent of the rarely wearers and 88 percent of the sometimes wearers. Similar differences were shown for the item concerning the reduction of the car insurance payment. Belt comfort and convenience was also an important issue. Interestingly, none of the never wearers (and few of the rarely wearers) indicated that first-hand accounts about belts saving lives (Item 2) would be effective in getting full time belt use.

Chi-square tests were performed on both the high-low risk group and observed belted-unbelted driver distributions (Table D.16). Concerning the risk groups, the only item yielding significantly different distributions was having the belt more comfortable and easier to use, where 74 percent of the low risk group (containing a higher proportion of older people) said this would prompt full-time belt use. All of the observed belted-unbelted distributions were significantly different except for the third and fifth items concerning personally knowing someone whose life had been saved by wearing a belt and having the belt more comfortable and easier to use. Where differences existed, the pattern was one of higher agreement with the item by the belted drivers.

$1_{\text {The always wearers were not asked this question, which resulted in small }}$ cell sizes and made chi-square testing difficult. The responses by belt wearing group were highly significantly different for each item, but five of the eight items had too many cells with low expected values, possibly invalidating the chi-square test. Further collapsing was considered impractical. From a practical standpoint, the differences among the distributions are considerable. 
Once again the large number of demographic comparisons yielded few significant differences, and these are shown below:

$\underline{\text { Item }}$

Car insurance payment greatly reduced

First hand account of how belt saved life

Friend ticketed

YOU ticketed

Points assessed to driving record

\section{$\underline{\text { Result }}$}

Grade school education group less 1ikely to answer "yes" (would "buckle up" every time) but much more likely to answer "maybe"

Blacks more likely to "buckle up" every time

Females more likely to "buckle up" every time

Females more likely to "buckle up" every time

Females more likely to "buckle up" every time

To conclude this sequence of questions, we gave the respondent a chance to name anything else that would get them to wear their belt every time they get in a car ( $Q 10)$. About one third $(n=43$, again absent the always wearers) gave a positive response. Although the comments were varied, the most frequent new item mentioned was automatic belts. Many who answered "yes" simply reiterated the need for a more comfortable belt system, a better fitting system, or a system made with more comfortable material. Other examples were: (1) if a family member were killed or injured in a crash, (2) if the respondent were in a crash, and (3) if only a lap belt had to be worn. One innovative respondent suggested a tax credit of $\$ 1$ might be a gesture that would increase the use rate.

Opinion of the North Carolina Law

A short series of questions (Q14-15) was constructed to gain knowledge of how respondents felt about the North Carolina mandatory seat belt law.

Provisions of the law are contained in Chapter 1.

Feelings About Belts and the Law

An hypothesis concerning seat belt laws is that people may support the use of belts but object to having a mandatory law. To test this hypothesis, the following question was asked of all telephone respondents: 
Please tell me which of the following statements best describes the way you feel about the N.C. law requiring drivers and front seat passengers to wear seat belts: (Read first three only)

1. I think wearing seat belts is a good idea, and I support the N.C. seat belt law.

2. I think wearing seat belts is a good idea, but I oppose the law.

3. I don't think seat belts are a good idea, and I oppose the law.

9. Don't know/no answer.

In general, almost half chose the first response, that wearing a belt is a good idea and also indicating support for the law (Table 4.9). Another 42 percent felt belt wearing is a good idea but opposed the law, while eight percent opposed both belt wearing and the law. Crosstabulating by belt wearing group produced what might be termed an expected result. Support for belts and the law was expressed by about two-thirds of the most-of-the-time and

Table 4.9. Telephone respondents' feelings about belts and the North Carolina law.

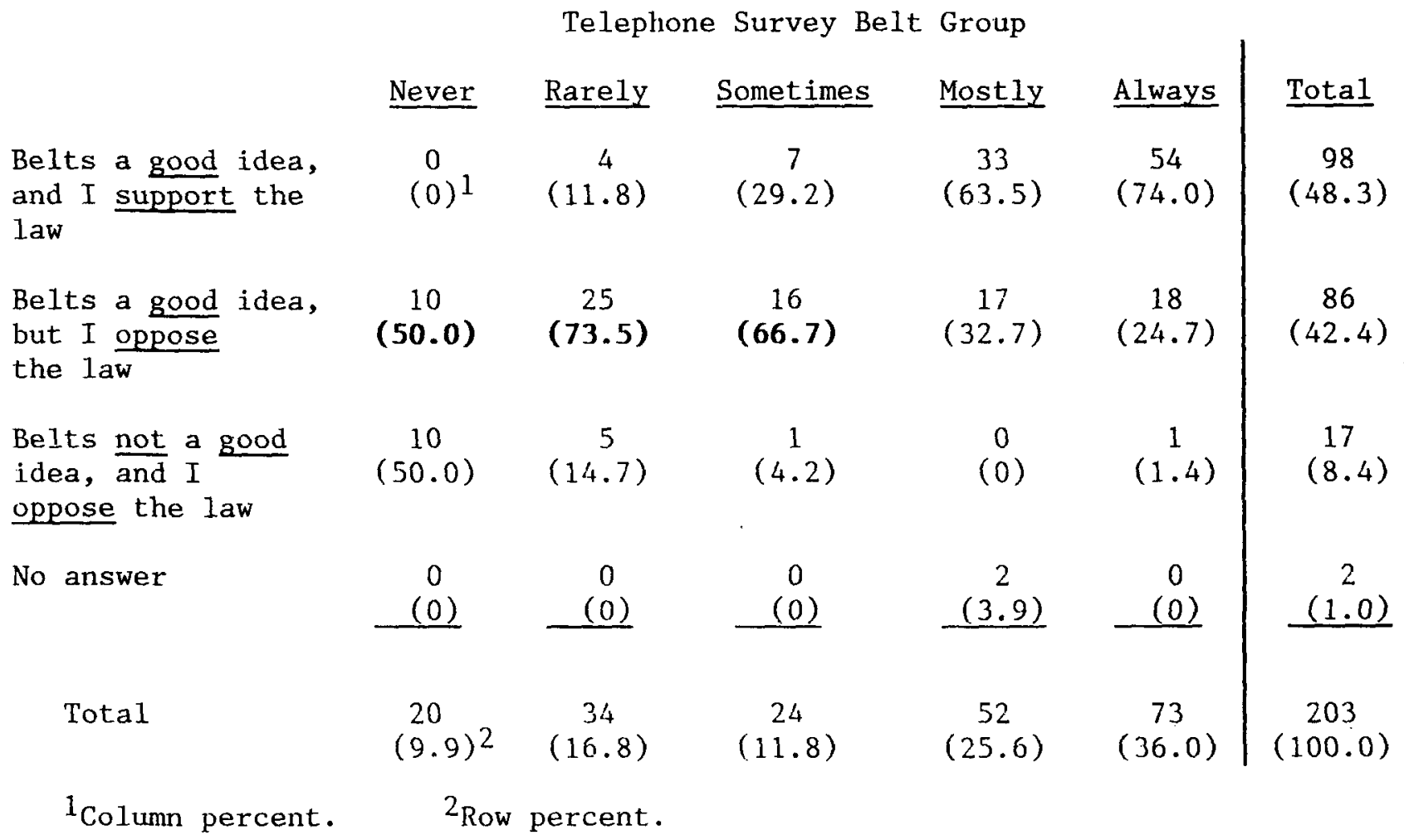


about three-fourths of the always wearers, while opposition to both the law and belts was expressed by half of the never wearers. Those who stated that they think wearing belts is a good idea but oppose the law included half of the never wearers, about three-fourths of the rarely wearers, and two-thirds of the sometimes wearers. The same tendency was followed by those drivers observed wearing their belt, with almost 70 percent indicating that belts are a good idea and they support the law (Table D.17). Promotional messages could certainly be developed around this concept.

\section{Main Reasons for Supporting the North Carolina Law}

Following the above question, we asked those who supported the North Carolina law (Table 4.9, first row) their main reasons (open-ended) for so doing, and up to three responses were coded. For both the first response given ( $n=98$ ) and for all responses combined $(n=158)$, the most frequently cited item was that belts save lives and reduce injuries (Figure 4.2). Next most frequent was that the law will get more people to wear belts. The "other" category included items such as belt laws are good for children, wearing belts will protect me/my family, make people more safety conscious, etc. (See Appendix Table D.18 for complete distributions).

Examining responses by belt wearing group, high-low risk group, and other demographics and grouping the first and third items (i.e., belts save lives, belts will protect me) versus all others showed little variability for either the first response or all responses combined. In other words, the efficacy of belts in crashes was the dominant response. (The never wearers were not included in the telephone survey belt group comparison because none indicated that they favored the law.)

\section{Main Reasons for Opposing the Law}

In like fashion, we asked those who opposed the law (Table 4.9, middle two rows) their main reasons for so doing. The overwhelming reason cited for opposition was the infringement on rights issue ( 80 percent of the first responses and 56 percent of all responses combined) (Figure 4.2). For al1 responses combined, the next most frequently cited reasons were that belts are uncomfortable or inconvenient (10.4\%) and the fear of entrapment (8.5\%) (Figure 4.2). The other category includes opposition to the $\$ 25$ fine, feeling that 


\section{Main Reasons for Supporting the Law.}

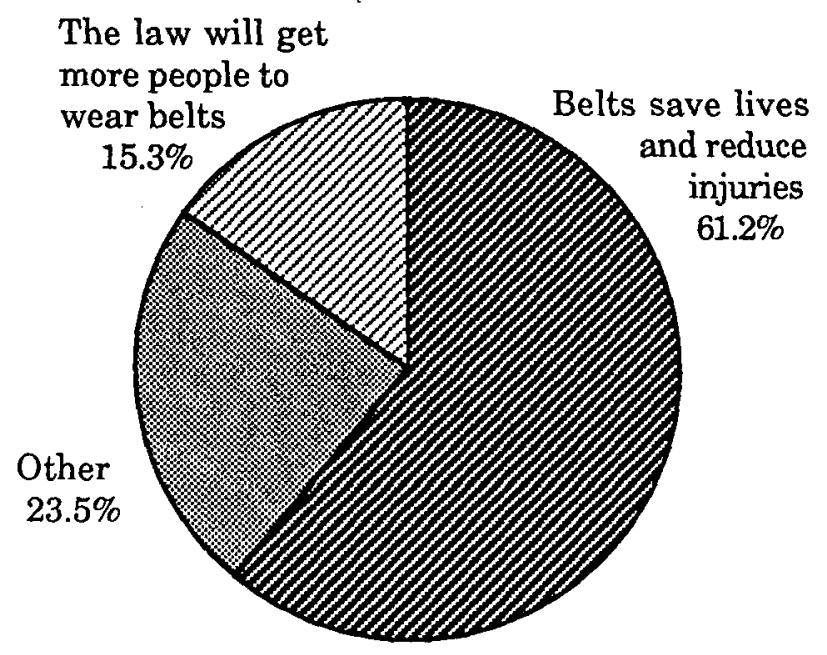

First Response Only

$\mathrm{n}=98$

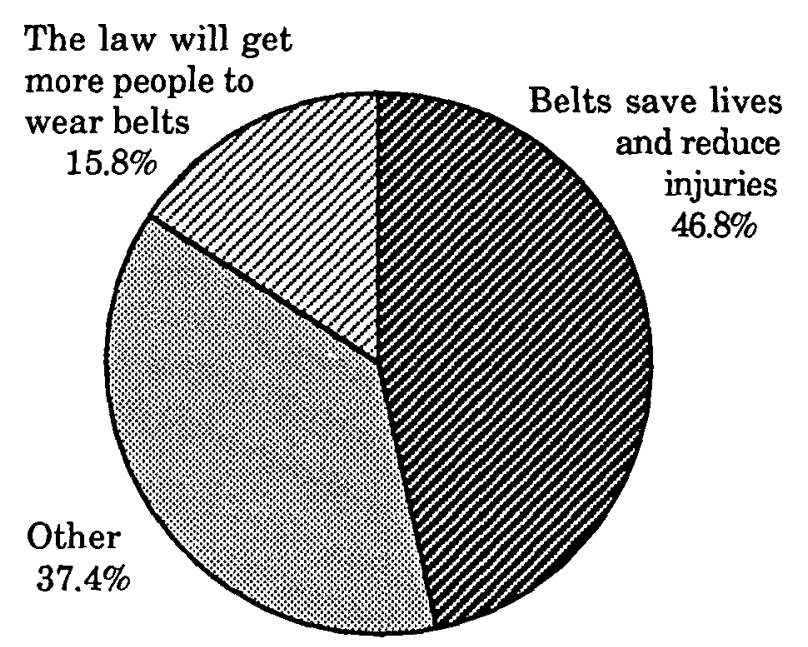

All Responses Combined

$\mathrm{n}=158$

\section{Main Reasons for Opposing the Law.}

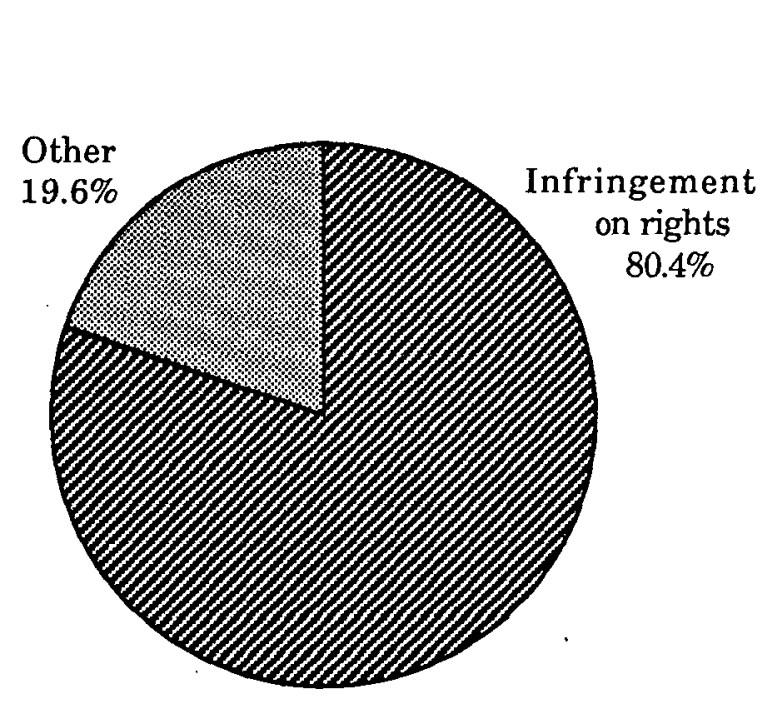

First Response Only

$\mathrm{n}=102$

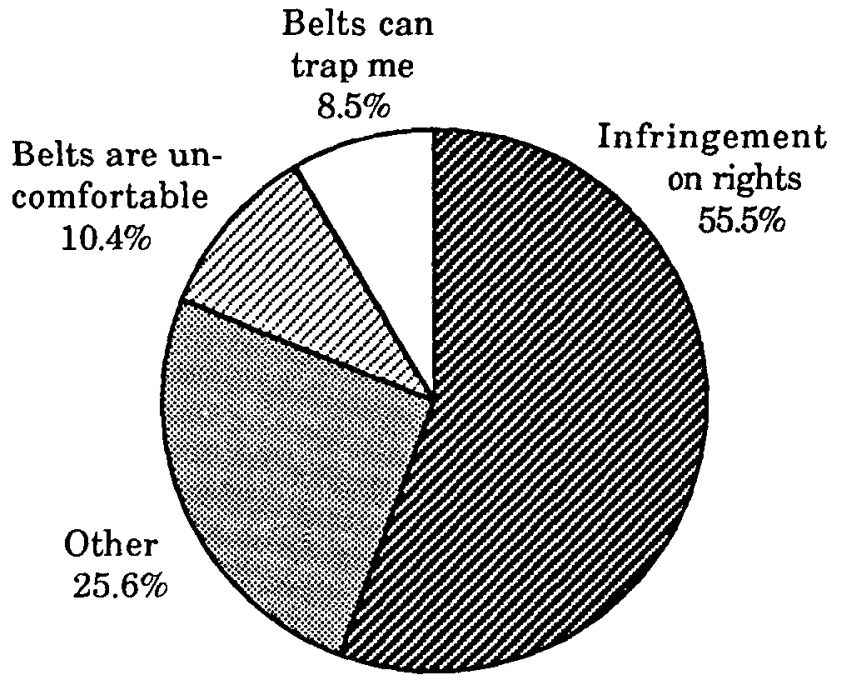

All Responses Combined

$\mathrm{n}=164$

Figure 4.2. Telephone respondents' main reasons for supporting and opposing the North Carolina seat belt law. 
belts are not effective, etc. (See Appendix Table D.19 for complete distributions.) One respondent even stated a belief in predestination. Further grouping of the responses (infringement versus all others) produced little variation in the distribution of responses by telephone survey belt wearers, risk groups, observed belted-unbelted drivers, or the demographic variables.

\section{Information Transfer}

Several questions (Q11-Q13) on the survey were devoted to issues concerned with the communication of seat belt information. We were interested in this group of North Carolinians' recall of television advertisements, billboards, and other roadside signs. Further, we asked an open-ended question to ascertain who would be good spokespersons for seat belt advertisements. Since these responses apply specifically to North Carolina advertisements, etc., only limited discussion of the findings will be presented.

\section{Television and Other Advertisements}

Interviewers asked open-endedly if the respondent remembered seeing or hearing any television advertisements about belts in the last year (Q12). If yes, we then asked what had been seen and coded up to three answers. We also inquired if they liked the ad and whether it affected their belt use. Almost 87 percent $(n=177)$ of the respondents remembered seeing or hearing television advertisements about seat belts during the past year. The advertisement recalled most frequently involved the NHTSA crash test dummies Vince and Larry, with 44 percent $(n=92)$ of the respondents mentioning this spot $(s)$ (Appendix Table D.20). In general, about half of each belt wearing group mentioned the crash test dummies ( 30 percent for the sometimes wearers). The crash test dummies were well received, and one respondent went so far as to say, "You can really believe those dummies!" Ninety-one percent of those seeing the crash dummies said they liked the ad, and 61 percent said it had affected their belt use.

Besides ads specifically developed and shown in North Carolina (including professional basketball star Michael Jordan, Air Force fighter pilots, and North Carolina State Highway Patrol troopers), six percent of the respondents referred to seeing crash test film, and another 27 percent mentioned a variety of "other" things. The "other" category included the Barbara Mandrell spot, references to 
slogans like "It's a Snap" or "It's the law" (probably referring to spots initiated by the NC Governor's Highway Safety Program), hearing accident survivors tell their story, and a short message at the bottom of the television screen referring to belts.

In crosstabulating by demographic variables to determine which groups had seen the television ads, the only variable producing significant differences was age. Those who remembered seeing ads included 92 percent of the young group, 92 percent of the middle age group, and 75 percent of the oldest group.

In addition to television advertisements, 72 percent of the respondents ( $n=159$ ) said they had seen seat belt billboards, parking lot signs, or other roadside signs (Q13). Of this group, two-thirds mentioned billboards. (The North Carolina Governor's Highway Safety Program used their "It's A Snap" slogan on a number of billboards across the state.) The billboard recall was quite consistent across belt wearing groups, with approximately two-thirds of each group mentioning this item.

\section{Seat Belt Spokesperson}

To obtain feedback about good seat belt spokespersons, we asked the following open-ended question:

If someone were developing an advertisement or TV spot to get more people in North Carolina to use belts, who do you think would be a good spokesperson?

PROMPT IF NECESSARY: What we would like to know is if there is some specific person or type of person that you think would be good to use in an advertisement for seat belts.

Interviewers listed the responses and then asked the respondent to rank order the three most important. People did not have a ready answer for this question, and 19 percent gave no answer (including 55 percent of the never wearers and 30 percent of the rarely wearers).

Television or movie celebrities were most frequently mentioned, followed by the "other" category, highway patrol or police officers, and belted crash survivors. (Appendix Table D.21 contains the distributions for the first response and for all responses combined.) Concerning television or movie celebrities, Bill Cosby and Barbara Mandre11 were named frequently, and others included Clint Eastwood, Sylvester Stallone, Paul Newman, Andy Griffith, and Bob Barker. Although the numbers were small, 3 (15\%) of the 20 never wearers and 
$3(12.57)$ of the 24 sometimes wearers mentioned a race car driver as their first choice (also true for 10 percent of the observed unbelted drivers). Richard Petty and Bill Elliott were named as spokesperson candidates. Another 4 (16.7\%) of the sometimes wearers said that someone who had been in an accident would be their first choice. The majority of the "other" category was supplied by mostof-the-time and always wearers and included candidates like children, the average man/woman on the street (or "every day" people), other local persons, and truck/bus drivers. Perhaps some PI\&E emphasis should be given to "local people" that some of these respondents seemed to be able to identify with.

One demographic crosstabulation was of interest here. With all responses combined, males preferred sports-related spokespersons by a ratio of 6:1 compared to females, and females preferred accident-related spokespersons by a ratio of $1.6: 1$.

\section{Accident Experience}

A series of questions was asked to examine how previous accident experience might impact on current use of seat belts. Whereas for the mailback survey analysis accident information was obtained from driver history records over a four year time span, for the telephone survey we asked about any accident involvement over one's lifetime. The rationale was that even an accident occurring ten or twenty years ago, before seat belts were widely available, could affect one's current use of belts, particularly if it involved personal injury.

of the 203 persons responding, 158 (78 percent) reported having been in an accident (Q16). There were no significant differences in reported accident involvement by telephone survey belt group (always, most of the time, etc.) or observed belt use at the time of the mailback survey. However, as expected, high risk drivers reported greater accident involvement than low risk drivers (82 percent of the high risk drivers reported having been in an accident, compared with 71 percent of the low risk drivers, $\mathrm{p}=.06)$. 
The distribution of the number of accidents reported for ali respondents was as follows:

\begin{tabular}{c|cc} 
& \multicolumn{2}{|c}{ Number of } \\
Number of & Persons & Reporting \\
Accidents & $\underline{N}$ & $\%$ \\
\hline 0 & 45 & 22.3 \\
1 & 63 & 31.2 \\
2 & 53 & 26.2 \\
3 & 27 & 13.4 \\
4 & 8 & 4.0 \\
25 & 6 & 3.0 \\
& & 100.1
\end{tabular}

The total number of accidents reported was 319. (Note that the above accident distribution should not be compared to state accident data since it includes all accidents in the respondents' lifetime, includes accidents where the respondent could have been a passenger and not just the driver, and because our telephone survey sample was purposely selected to overrepresent high risk (accident. involved) drivers.)

More detailed information was obtained on up to three accidents per respondent, focusing first on "the most serious" accident, then "next most serious," etc. (If a second or third accident was very minor, the interviewer could opt to omit the detailed questioning.) The text and tables that follow present information on the 158 most serious (or only) accidents. Where any differences exist between these accidents and all accidents reported, these are noted in the text.

Table 4.10 summarizes the information captured concerning past accident experience and its relationship to reported belt use group (always, most of the time, etc.), observed belt use, and identified risk category. Only eight percent of the reported accidents had occurred within the past year; the major portion, 54 percent, had occurred more than five years ago. As might be expected, drivers identified as "high risk" were more likely to report an accident occurring within the past five years ( 60 percent of their accidents, as compared with 34 percent for the low risk group). Also, drivers observed not wearing a seat belt at the time they received the mail survey were more likely to report having had an accident either within the past year or more than five years ago. 
Table 4.10. Telephone respondents' reported accident experience and impact on belt use. ${ }^{1}$

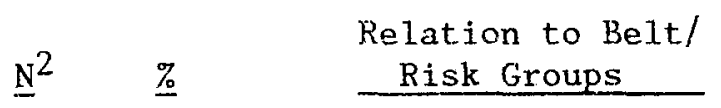

A. Time since accident

Less than a year

1 to 3 years

3 to 5 years

More than 5 years

$\begin{array}{lrlc}13 & (8.2) & \text { Belt group } & \text { n.s. } \\ 41 & (25.9) & \text { Risk group } & \mathrm{p}<.01 \\ 19 & (12.0) & \text { Observed use } & \mathrm{p}<.01 \\ 85 & (53.8) & & \end{array}$

B. Driver status

Driver

Passenger

$136 \quad(86.1)$

Belt group

n.s.

$22(13.9)$

Risk group

n.s.

Observed use

n.s.

C. Vehicle at fault

Own vehicle

Other vehicle

Not applicable (sv acc)

$50 \quad(32.3)$

Belt group

n.s.

$78 \quad(50.3)$

Risk group

n.s.

$27 \quad(1.7 .4)$

Observed use

n.s.

D. You injured?

No

101

Yes - minor

Yes - moderate ${ }^{3}$

Yes - serious

$33 \quad(20.9)$

$10 \quad(6.3)$

$14 \quad(8.9)$

Belt group

Risk group

n.s.

Observed use

n.s.

n.s.

E. Wearing a seat belt?

No

Yes

$117 \quad(76.0)$

Belt group

Risk group

$\mathrm{p}<.01$

$37(24.0)$

Observed use

n.s.

$\mathrm{p}<.01$

F. Anyone else injured?

No

103

$(65.2)$

Belt group

n.s.

Yes - minor

Yes - moderate ${ }^{3}$

$23 \quad(14.6)$

Risk group

n.s.

Yes - serious

$(7.0)$

Observed use

n.s.

Not applicable

$11 \quad(7.0)$

$10 \quad(6.3)$

G. They wearing a seat belt?

No

$76 \quad(48.4)$

$18(11.5)$

Belt group

n.s.

Yes

$63(27.4)$

Risk group

n.s.

Not applicable/DK

Observed use

n.s.

H. Accident affect your belt use?

No

Yes - use increased $]^{3}$

$103 \quad(66.5)$

$47 \quad(30.3)$

$5 \quad(3.2)$

Belt group

Risk group

$\mathrm{p}<.01$

Yes - use decreased

Observed use

n.s.

n.s.

I. Why (why not)?

Belts helped/would have

$53 \quad(35.3)$

Belt group

helped

Belts did not help/would

$51(34.0)$

Risk group

$\mathrm{p}<.01$

not have helped

Other.

$46 \quad(30.7)$

$1_{\text {Based on }} 158$ "only" or "most serious" accidents.

2 Totals less than 204 due to missing data.

${ }^{3}$ Grouped for testing purposes. $\quad-74$ 
The overwhelming majority of those surveyed indicated that they were the driver rather than a passenger in their accident ( 86 versus 14 percent), and they were more likely to judge the other driver at fault in crashes involving two or more vehicles. Current belt use, either self reported or observed, was not associated with either of these responses.

Injury information was obtained for the respondent and for any other driver/passenger in the accident, along with their belt use at the time. Overall 15 percent of the accidents resulted in moderate or worse injury, and 24 percent of those interviewed said that they were "buckled up" at the time. Neither telephone survey belt use, observed belt use, nor risk category was found to be related to reported injury level in an accident. However, both telephone survey belt group and observed belt use were strongly correlated with the respondent's reported belt use at the time of the accident, as shown below:

\begin{tabular}{lc|cc}
$\begin{array}{c}\text { Telephone Survey } \\
\text { Belt Group }\end{array}$ & $\begin{array}{c}\text { Reported Belt } \\
\text { Use at Time } \\
\text { of Accident }\end{array}$ & $\begin{array}{c}\text { Observed } \\
\text { Belt Use }\end{array}$ & $\begin{array}{c}\text { Reported Belt } \\
\text { Use at Time } \\
\text { of Accident }\end{array}$ \\
\cline { 1 - 3 } Never & $0 \%$ & Belted & $36 \%$ \\
Rarely & $4 \%$ & Not Belted & $14 \%$ \\
Sometimes & $16 \%$ & & \\
Most of the time & $21 \%$ & & \\
Always & $48 \%$ &
\end{tabular}

Information on others that may have been injured in the accident was less revealing, and was not found to be related to the respondent's current use of belts.

Overa11, a third of the respondents indicated that their accident had affected their use of seat belts - 30 percent positively (their use had increased) and three percent negatively (their use had decreased). Current never and rarely users were the least likely to report that their accident had caused a change in their belt wearing habits, and the never wearers were also the most likely to report that their belt use had decreased following the accident.

When questioned as to why their accident had/had not affected their use of seat belts, those who now wear their belts sometimes, most of the time, or always were much more likely to indicate that belts either helped or would have helped to prevent injuries. In contrast, never and rarely wearers were more likely to respond that belts did not or would not have helped (Table D.22). Beliefs about 
whether belts helped or did not help were also significantly related to risk group $(p<.05)$. Drivers in the high risk group were significantly more likely to feel that belts helped or would have helped in their accident (41 percent of the high risk drivers said that belts helped, as compared with 26 percent of the low risk drivers). However, this result is likely confounded with length of time since accident. The low risk drivers, who had a greater proportion of accidents occurring more than five years ago, were much more likely to give an "other" response. The most cited "other" reasons had to do with the fact that the accident happened too long ago $(n=16)$, when the respondent was too young $(n=4)$, before he had even begun thinking about belts $(n=6)$, or that it was simply too minor to make an impression $(n=13)$.

There were virtually no differences in reported accident experience by the various demographic variables examined (age, race, sex, educational level and marital status). Those with a grade school education or less were more likely to report that seat belts did not or would not have helped in their accident (58\%), but this difference was not significant.

\section{Enforcement Experience}

In focusing on enforcement issues, we were interested in learning about encounters with police or highway patrol officers for any reason (e.g., license or registration check) since the N.C. belt law went into effect October 1985, and how this experience impacted on subsequent belt use. As with the accident questioning, we first asked whether or not the respondent had had any encounters with law enforcement officials and, if so, how many. We then probed further up to three occasions stopped, beginning with the most recent occasion, then next most recent, etc.

of the 204 respondents interviewed, 119 or (58 percent) indicated that they had been stopped by a law enforcement officer since October of 1985 (Q17). There were no significant differences by telephone survey belt group; however, drivers in the high risk group (as expected) were significantly more likely to have been stopped than drivers in the low risk group ${ }^{1}$ (69 percent versus 42 percent, p <

$1_{\text {Low }}$ risk encounters could include license checks, seat belt checks, stops not resulting in a written citation, and stops made since January 1,1987 . The driver history file used in identifying the high and low risk groups was for the years $1983-86$. 
$.01)$. The total number of encounters with law enforcement officers reported by our sample was 230 . The distribution was as follows:

Number of Times

$\begin{array}{crc}\text { Stopped } & \underline{\mathbf{N}} & \underline{\%} \\ 0 & 84 & 41.6 \\ 1 & 57 & 28.2 \\ 2 & 35 & 17.3 \\ 3 & 13 & 6.4 \\ 4 & 5 & 2.5 \\ 5 & 4 & 2.0 \\ 6 & \frac{4}{202} & 100.0 \\ \text { Unknown } & \frac{2}{204} & \end{array}$

Table 4.11 summarizes the more detailed information gathered for the encounters for which we sought additional information. The large majority of

Table 4.11. Reported violation experience and impact on belt use.

\section{Violation Experience}

Reason stopped

Seat belt or license check

other

When stopped

Before January 1987

Since January 1987

Belt use when stopped

Not wearing belt

Wearing belt

Buckled up before being seen

Enforcement outcome

Nothing

Nothing - already wearing belt 12

Verbal wearing or reminder

Written warning

Ticketed and fined

other

Effect on subsequent belt use

None

Use increased

Use decreased
$\underline{N}^{1} \quad \underline{\%}$

$139 \quad(70.2)$

$59(29.8)$

$65 \quad(34.8)$

$122(65.2)$

$57 \quad(28.6)$

$126 \quad(63.3)$

$16 \quad(8.0)$

$35 \quad(17.5)$

$(60.5)$

$(11.0)$

(3.5)

$(3.0)$

$9 \quad(4.5)$

$141(70.5)$

$59 \quad(29.5)$

$0 \quad(0.0)$
Relation to Belt/

Risk Groups

$\begin{array}{lc}\text { Belt group } & \mathrm{n} . \mathrm{s} . \\ \text { Risk group } & \mathrm{p}<.01 \\ \text { Observed use } & \mathrm{p}<.05 \\ \text { Belt group } & \mathrm{p}<.01 \\ \text { Risk group } & \mathrm{n} . \mathrm{s} . \\ \text { Observed use } & \mathrm{p}<.01 \\ \text { Belt group } & \mathrm{p}<.01 \\ \text { Risk group } & \mathrm{n} . \mathrm{s} . \\ \text { Observed use } & \mathrm{p}<.01\end{array}$

Belt group

$--2$

Risk group

Observed use
Belt group

Risk group

Observed use $\mathrm{p}<.01$

n.s.

n.s.

1 Totals less than 204 reflect missing data.

2 Tests not valid due to small cell sizes. 
the encounters reported were simple license or seat belt checks (respondents had difficulty actually distinguishing between the two) -- 70 percent. Results by telephone survey belt group were not significant. Those who had been observed wearing a belt, however, were more likely to have been stopped for only a license or seat belt check than those observed not wearing a belt (77 percent versus 63 percent, $\mathrm{p}=.03)$. Also, drivers identified as high risk were more likely to have been stopped for "other" reasons such as running a stop sign, speeding, or reckless driving -- 38 percent versus 9 percent, $\mathrm{p}<.01$. (These are the sorts of violations which, if on their violation record, would have caused them to be labeled "high risk".)

Information on when the stops were made indicates that nearly two-thirds (65 percent) had been since the fine went into effect in January 1987. Here, results by belt group are of particular interest:

\begin{tabular}{lc} 
Belt Group & $\begin{array}{c}\text { \% Stopped Since } \\
\text { January 1987 }\end{array}$ \\
\hline Never & 15 \\
Rarely & 44 \\
Sometimes & 48 \\
Mostly & 75 \\
Always & 84
\end{tabular}

Thus, although never wearers reported being stopped altogether as frequently as those in the other belt use groups, they were much less likely to report having been stopped since the fine went into effect. Similarly, those observed not belted were less likely to have been stopped since the fine:

\begin{tabular}{lc} 
& \multicolumn{2}{c}{$\%$ Stopped } \\
Observed Use & $\begin{array}{c}\text { Since Jan. } 1987 \\
\text { Not belted }\end{array}$ \\
\cline { 2 - 2 } Belted & 89
\end{tabular}

These patterns for the self-reported and observed belt groups run counter to the notion that belt non-users are more likely to be stopped than belt users. The reasons for these patterns are not clear. The patterns may be reflecting enforcement exposure differences, reluctance on the part of violators to admit to being stopped, and other factors. It might also be that the lower number of 
enforcement encounters reported for the never and rarely groups is a reason behind their continued non-use.

Overa11, 63 percent of those interviewed reported that they were "buckled up" at the time they were stopped, and an additional eight percent admitted to "buckling up" before being seen by the officer. As expected, these results were strongly correlated with belt use, since none of the never wearers reported having a belt on when stopped, compared with 92 percent of the always wearers. Similarly, 85 percent of those observed wearing their belt reported that they also had a belt on when stopped, compared with only 40 percent for those observed not wearing a belt.

Examination of the outcome of these encounters shows that tickets and fines were levied in only six cases. Although written or verbal warnings were issued in an additional 29 cases, nothing was said or done in 35 cases, despite the fact that a belt was not being worn. For the never belt group, 50 percent of their encounters resulted in no feedback regarding belt use.

Finally, when questioned as to whether or not their encounter with a law enforcement officer had affected their belt use, 70 percent indicated that it had not, and 30 percent that it had. Results by belt group are shown below:

\begin{tabular}{|c|c|}
\hline $\begin{array}{c}\text { Telephone Survey } \\
\text { Belt Group }\end{array}$ & $\begin{array}{c}\text { \% Indicating An } \\
\text { Increase in Belt Use } \\
\text { Following a Law Enforcement } \\
\text { Encounter }\end{array}$ \\
\hline Never & 0.0 \\
\hline Rarely & 20.0 \\
\hline Sometimes & 52.2 \\
\hline Mostly & 45.1 \\
\hline Always & 22.2 \\
\hline
\end{tabular}

Simply by the fact that they remain rarely or never users, one would not expect these two groups to report an increase in belt use (at least not in any long term sense). Similarly, always wearers might be less likely to report a change, since many of these may have been always wearers before the encounter. Nevertheless, 20 percent of the always wearers did report an increase, and the implication is that their encounter contributed to their present status as an always belt wearer. The impact was greatest for the sometimes and mostly wearers, approximately half of whom reported an increase in belt wearing following their encounter with the law. 
In addition to asking about their personal encounters with law enforcement officers, we asked those we interviewed if they knew anyone (else) who had been stopped and checked for seat belt use (Q18). The overall percentage of "yes" responses here was lower ( 37 percent), but the cases were ones resulting in more significant enforcement outcomes ( 40 percent a ticket and fine, 29 percent a written warning, 29 percent a verbal warning, 3 percent other). Knowledge of others being stopped and checked for belt use did not differ across the various belt use and risk groups; however, always wearers were less likely to report that the person they knew had been ticketed and fined compared with those in the other belt use groups $(\mathrm{p}=.02)$. This result probably reflects the greater likelihood that acquaintances of belt wearers are also belt wearers.

When asked, "How strongly do you think the seat belt law is being enforced in your community?"(Q19), six out of ten respondents said that the law was not being strongly enforced. While results by belt group are not statistically significant after grouping to produce sufficient cell counts, never wearers perceived the least amount of enforcement ( 80 percent not very strongly or not at a11) and always wearers the greatest level of enforcement ( 34 percent very strongly or somewhat strongly) (Table D.23). Results are statistically significant when strongly/not strongly enforcement levels are crossed by observed belt use at the time of the survey. Among those observed belted, 40 percent felt that the law was being strongly or somewhat strongly enforced, compared with only 23 percent for drivers observed unbelted.

Race is the only demographic factor where any clear-cut effect appeared in the enforcement data. While there were no differences in perceived level of enforcement by age, sex, educational level, or marital status, 58 percent of the black respondents felt that the N.C. seat belt law was being either very strongly or strongly enforced, compared to only 27 percent of the white respondents.

Some belt use differences also appear in response to the question, "Do the police officers or sheriffs in your community wear seat belts?"(Q20) (Table 4.12). The majority ( 53 percent) of respondents reported that the law enforcement officers in the community always wear seat belts, and only two percent reported that they did not wear seat belts. A substantial proportion of those interviewed ( 28 percent) had not noticed if law enforcement officers in their community used seat belts. Looking within belt groups, never wearers 
Table 4.12. Perceived belt use by local law enforcement officers.

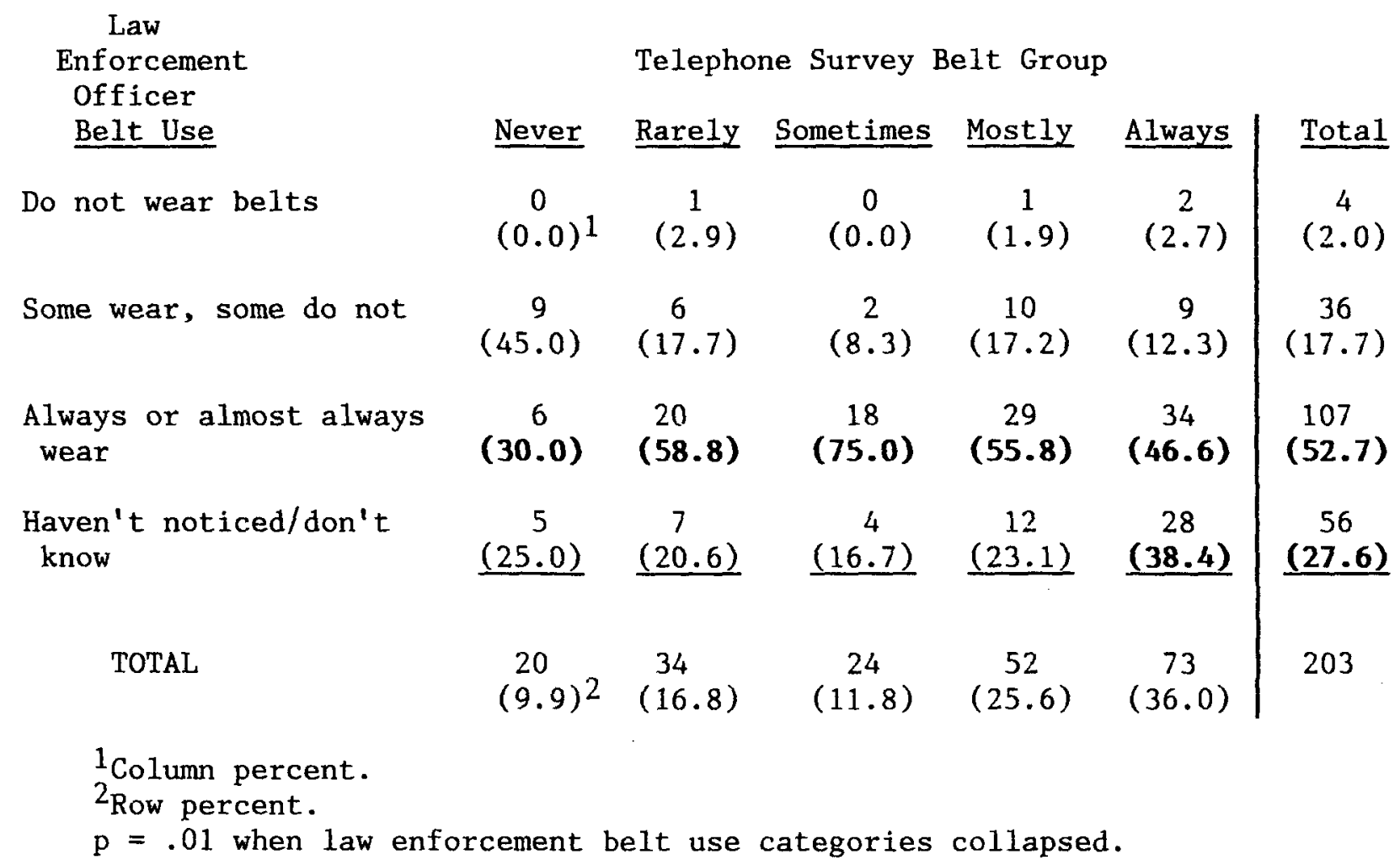

are the most likely to report that some law enforcement officers in their community do not always "buckle up", while always wearers are the most likely to have paid no attention to the issue. When the "do not wear" and "some wear, some do not" categories are combined to increase cell sizes, these results are significant at $\mathrm{p}=.01$. Results are also significant at the .05 level for observed belt use, with belted drivers much more likely than unbelted drivers to report that they had not noticed whether officers in their community used seat belts ( 35 percent versus 20 percent). Differences by risk group were not significant, as were any demographic differences.

A few final enforcement oriented questions (Q21-23) inquired about any other actions on the part of a law enforcement officer to encourage use of seat belts and, in particular, use of "the seat belt salute." The latter involves an officer pulling up alongside in his patrol car and giving a tug on his belt as a reminder to buckle up. Only 12 percent of the respondents indicated that an officer had said or done something to personally encourage them to "buckle up", with no significant differences by belt or risk groups. When this was mentioned, it was very often that the respondent and the officer were friends, or members of the same family. Roadblocks and other "checks" were also 
mentioned, as well as a few individual encounters with law enforcement officers. One person stated that a police officer in his community knocks on car windows and tells people to buckle up while they are stopped at a downtown traffic signal.

When asked specifically about a "seat belt salute," (Q22) only seven percent of the telephone respondents indicated that this had occurred to them. However, there was a strong age effect, with 18 percent of those 25 or under saying that they had been given a "seat belt salute," compared with 12 percent of the 26-54 year olds and only seven percent of those 55 and older $(p<.01)$. Younger respondents were also more likely to feel that the "seat belt salute" was a good way to get more people to wear belts (100 percent said they thought it was a good idea, compared with 85 and 88 percent for the 26-54 and 55+ groups, respectively, $\mathrm{p}<.05)$. Perhaps not surprisingly, high risk drivers were less likely to feel that seat belt salutes were a good idea than low risk drivers ( 85 percent versus 94 percent, $\mathrm{p}=.07$ ), and never and rarely wearers were less favorably inclined than more frequent belt users (Table 4.13). Results are significant at $\mathrm{p}<.05$ when belt categories are grouped.

Table 4.13. Opinion regarding use of "seat belt salute" to encourage belt use.

"Seat Belt Salute"
a Good Way to
Encourage Belt Use?

No

Yes

TOTAL

${ }^{1}$ Column percent.
Telephone Survey

Belt Group

\begin{tabular}{ccccc|c} 
Never & Rare1y & Sometimes & Mostly & Always & Total \\
6 & 5 & 0 & 4 & 7 & 22 \\
$(33.3)^{1}$ & $(15.2)$ & $(0.0)$ & $(8.2)$ & $(9.7)$ & $(11.4)$ \\
12 & 28 & 21 & 45 & 65 & 171 \\
$\underline{(66.7)}$ & $\underline{(84.9)}$ & $\underline{(100.0)}$ & $\underline{(91.8)}$ & $\underline{(\mathbf{9 0 . 3})}$ & $\underline{\mathbf{( 8 8 . 6 )}}$ \\
18 & 33 & 21 & 49 & 72 & 193 \\
$(9.3)^{2}$ & $(17.1)$ & $(10.9)$ & $(25.4)$ & $(37.3)$ &
\end{tabular}

$2_{\text {Row percent. }}$

Health and Lifestyle

A final series of questions focused on current practices regarding exercise, smoking, drinking, and willingness to drive within the posted speed limit on highways. It was hypothesized that persons following a "less healthy" or "more risk oriented" lifestyle by failing to exercise, smoking excessively, 
etc. would also be less inclined to wear a seat belt. To some extent this was indeed found to be the case. Table 4.14 summarizes responses to these health related questions and indicates where significant relationships were found with respect to reported belt use group, risk group, and observed belt use. More

Table 4.14. Health behaviors of telephone respondents and relationships to belt use and risk group.

\begin{tabular}{|c|c|c|c|c|}
\hline Health Behavior & $\underline{\mathbf{N}}^{1}$ & $\underline{\%}$ & $\begin{array}{l}\text { Relationshi } \\
\text { Belt/Risk G }\end{array}$ & $\begin{array}{l}\text { to } \\
\text { oup }\end{array}$ \\
\hline \multicolumn{5}{|l|}{ Exercise regularly? } \\
\hline Yes & 69 & 34.2 & Belt group & n.s. \\
\hline Maybe & 13 & 6.4 & Risk group & n.s. \\
\hline No & 120 & 59.4 & Observed use & $\mathrm{p}<.01$ \\
\hline \multicolumn{5}{|l|}{ Smoke? } \\
\hline Yes & 72. & 35.8 & Belt group & $\mathrm{p}<.05$ \\
\hline No & 129 & 64.2 & $\begin{array}{l}\text { Risk group } \\
\text { Observed use }\end{array}$ & $\begin{array}{l}\mathrm{n} . \mathrm{s} . \\
\mathrm{p}<.01\end{array}$ \\
\hline \multicolumn{5}{|l|}{ If Yes, > pack/day? } \\
\hline Yes & 28 & 38.9 & Belt group & n.s. \\
\hline No & 44 & 61.1 & $\begin{array}{l}\text { Risk group } \\
\text { Observed use }\end{array}$ & $\begin{array}{l}\text { n.s. } \\
\text { n.s. }\end{array}$ \\
\hline \multicolumn{5}{|l|}{ How often drink? } \\
\hline Never & 82 & 40.8 & Belt group & n.s. \\
\hline Twice a month or less & 74 & 36.8 & Risk group & n.s. \\
\hline Once a week or more & 45 & 22.4 & Observed use & n.s. \\
\hline \multicolumn{5}{|c|}{$\begin{array}{l}\text { How often in past year driven } \\
\text { within } 1 \mathrm{hr} \text {. of drinking? }\end{array}$} \\
\hline 0 times & 61 & 51.3 & Belt group & $\mathrm{p}<.05$ \\
\hline$\geq 1$ time & 58 & 48.7 & $\begin{array}{l}\text { Risk group } \\
\text { Observed use }\end{array}$ & $\begin{array}{l}\mathrm{p}<.05 \\
\mathrm{n} . \mathrm{s} .\end{array}$ \\
\hline \multicolumn{5}{|c|}{$\begin{array}{l}\text { How often in past month driven } \\
\text { after drinking too much? }\end{array}$} \\
\hline 0 times & 106 & 39.1 & Belt group & $\mathrm{n} . \mathrm{s}$. \\
\hline$\geq 1$ time & 13 & 10.9 & $\begin{array}{l}\text { Risk group } \\
\text { Observed use }\end{array}$ & $\begin{array}{l}\text { n.s. } \\
\text { n.s. }\end{array}$ \\
\hline \multicolumn{5}{|l|}{ Driving speed on highways } \\
\hline At speed limit & 75 & 37.1 & Belt group & n.s. \\
\hline $5-10 \mathrm{mph}$ below & 37 & 18.3 & Risk group & n.s. \\
\hline$>5 \mathrm{mph}$ above & 90 & 44.6 & Observed use & n.s. \\
\hline
\end{tabular}


detailed tables are presented in the Appendix: Table D.24 shows responses to the questions by reported belt group and Table 0.25 shows responses by risk group and observed belt use. Responses to each of the questions were also crosstabulated by the various demographic variables. Differences appeared here as well, but in most instances they were not deemed relevant to the current project goals and are not reported.

\section{Exercise}

The telephone respondents were asked if they exercised routinely and if they had been doing so for more than six months (Q24). Only a third of the respondents gave an unqualified "yes"; six percent said "maybe", and 59 percent "no". For those who exercised regularly, 85 percent had been doing so for more than six months.

While the various belt use groups did not differ significantly with respect to exercise practices $(p=.08)$, always wearers were the most likely to exercise regularly ( 43 percent). Results were significant $(p<.01)$ in terms of observed belt use. Among those observed wearing a belt, 46 percent were exercisers, compared with only 26 percent for those observed not wearing a belt. Differences by risk group were not significant.

\section{Smoking}

Results for smoking (Q25) are similar. Again, never wearers are the most likely to engage in the identified "high risk" or "unhealthy" behavior. Sometimes wearers also have a high percentage of smokers, but surprisingly, rarely wearers do not. (This is the same trend as found regarding exercise, where rarely wearers actually fell in the middle between sometimes and mostly wearers.) Looking at observed belt use, results were again significant, with 45 percent of the unbelted drivers indicating that they smoke, compared with 27 percent of the belted drivers ( $\mathbf{p} \leq .01$ ) (Table D.25). For high versus low risk drivers there were no such differences.

In contrast to whether or not one smokes, how much one smokes was not found related to belt use. Overall, 37 percent of the smokers in the sample smoked more than a pack a day. However, differences across belt use and risk groups were not significant. 


\section{Drinking}

When questioned regarding their drinking habits (Q26), 41 percent of our sample indicated that they never drink beer, wine, or liquor, and only onefourth admitted to drinking more than once or twice a month. Due to the sensitive nature of the question, these figures are likely to underestimate the level of drinking in our sample (and indeed this feeling was expressed by several of the interviewers). With this in mind, it is noted that there were no significant differences in how often our sample drank beer, wine or liquor by either reported or observed belt use, or by risk group.

For the 119 persons who indicated they did drink, there were some differences in response to a second question, "How often in the last year would you say you have driven within one hour of drinking beer, wine, or liquor?" The differences by observed belt use were not significant. However, differences by reported belt group and risk group were both significant at the $\mathrm{p} \leq .05$ level. Mostly and always wearers were less likely to report having driven within one hour of drinking, as were the identified low risk drivers: 27 percent of the low risk drivers reporting having driven within an hour of drinking on two or more occasions, compared with 47 percent of the high risk drivers (Table D.25). Younger drivers were also more likely to report driving after drinking on at least one occasion $(p=.01)$.

A fina1 drinking related question asked to those who had indicated some level of drinking concerned how many times in the past month they had driven "after perhaps having too much to drink." As anticipated, the large majority of respondents ( 89 percent) replied "none." Again there were no significant differences by belt or risk groups, but high risk drivers were more likely to report having driven after drinking too much than low risk drivers ( 15 percent versus 6 percent, $p=.09$ ).

\section{Driving Speed}

In addition to the questions on exercise, smoking and drinking, a final "risk" question (and the last question on the survey) asked about usual driving speeds on the highway. Most of the respondents indicated that they drove either at the speed limit (37 percent) or 5-10 mph above the speed limit (41 percent). This particular variable showed no significant differences across any of the belt use or risk groups. 
This chapter will attempt to draw together the various pieces of the project and make some sense of what has resulted, especially in regard to potential programs to increase belt use. The discussion will be based on findings from both the mailback and telephone surveys, including some qualitative assessment of the telephone interviews. Our view is that there are actions that can be taken to increase belt use at national, state, and local levels. Two key action items that pervade many possible programmatic considerations are education and enforcement. Targeting of certain efforts toward specific population sub-groups can also be done.

\section{Project Considerations}

Survey design typically involves many iterations, and this project was no exception. After the pilot testing of the mailback survey, we became more familiar with the types of questions UMTRI was implementing in their roadside interviews of belted and unbelted drivers in Michigan (Wagenaar, et al., 1987). As a result, some questions concerning risk were substituted for questions concerning knowledge of the N.C. seat belt law. In retrospect, it appears that the risk questions were not very fruitful, in that respondents seemed to do considerable guessing of answers. Another question that dropped out after the pilot testing dealt with how many times the belt was worn on the five most recent trips. This question appeared to cause no problems during pilot testing and would have been interesting to examine for some 5,000 respondents. In the end, we asked a somewhat similar question to the telephone respondents, but this sample only involved about 200 people.

The telephone survey contained a set of questions about drinking and driving taken from another NHTSA questionnaire entirely on a1coho1-related topics (Lacey, Stewart, Marchetti, Popkin, Murphy, Luckey, and Jones, 1986). All of the interviewers felt uncomfortable in asking how often one had driven within one hour of drinking and how many times one had driven after perhaps having had too much to drink. In general, the interviewers lacked confidence that these responses were reliable. Questions such as these are probably best answered as part of a comprehensive survey dealing with alcohol and driving. 
Finally, concerning questionnaire content, the telephone survey asked a series of questions about prior accident and violation involvement in attempting to understand the relationship between these factors and current belt use. The plan was to discuss up to three accidents, starting with the most serious. However, since most of the accidents brought up by the respondents were relatively minor, discussion was typically dropped after one iteration. In addition, most respondents seemed to have a single experience, if any, that was meaningful for them. In reality, more probably would have been gained by asking some rather open-ended questions about prior accidents and their effect on current belt use. The sequence concerning multiple violations also could have been shortened.

Some Qualitative Results from the Telephone Survey

From the initial grant proposal writing it was assumed that much could be learned from simply talking to several hundred observed belt users and nonusers through a survey instrument. While we started survey development with more open-ended questions, project review led to subsequent iterations that contained more closed-response questions, which in turn detracted from the ability to get more qualitative findings from the survey. Nonetheless, this section represents an attempt to bridge this gap - to try to convey some of what was gleaned subjectively from 200 conversations, including some which were wel1 over 30 minutes in length.

There were several groups of issues that were frequently discussed, especially by the less frequent belt wearers, as pertain to a seat belt law or belts in general. These included:

- personal freedom,

- discomfort associated with belts,

- the $\$ 25$ fine for non-compliance,

- myths that have not been dispelled,

- the lack of a seat belt habit, and

- the lack of seat belt enforcement. 
Personal Freedom and Belt Discomfort

When asked to state their main reason for opposing the N.C. seat belt law, the overwhelming choice was the personal freedom issue. Many conveyed the impression that belts were acceptable but a mandatory law was not. Some dissenters said they would have felt better about the seat belt law if they had been allowed to express their opinion in a referendum.

Coupled with the feeling that a belt law is an infringement on rights is the attitude that belts, and in particular 3-point shoulder harness systems, are inconvenient and uncomfortable. Some see belts as too confining, while others are unhappy with the fit of the system. Several people interviewed stated that they became claustrophobic when forced to "buckle up," and as a result were especially resentful of any belt law.

An earlier telephone survey of North Carolinians showed similar feelings regarding infringement on rights and the comfort and convenience of belts (Hunter and Geissinger, 1988). At the same time the respondents acknowledged the societal benefits of belts and belt laws. They supported the N.C. seat belt law by a clear majority.

In reality, what can or should be made of personal freedom comments? Is it worthwhile to attempt to defuse the argument? Perhaps the best approach in public support messages is to point out how similar belt laws are to many other laws where the public has considered the tradeoff between regulation and benefit and has concluded that the regulation is acceptable. Highway safety examples referenced in the Hunter and Geissinger report include laws pertaining to stop signs, drunk driving, and jaywalking, and other examples include air and water quality.

\section{The $\$ 25$ Fine}

Many people were adamant in their opposition to the $\$ 25$ fine for noncompliance with the seat belt law. A common view by the less frequent wearers was that the fine was unfair, even though the great majority had been free of any enforcement contacts. For about one-fourth of the respondents, the current $\$ 25$ fine, if enforced, would be adequate to affect their belt use, while an additional 40 percent stated on their own that no amount of fine would increase their belt use.

Sometimes during the discussion of the fine, the conversation would take a different twist and turn toward prizes or incentives for wearing belts. 
Respondents clearly liked this approach, and during one conversation the following tactic was discussed -- would it be feasible to consider an incentive-like program where the $\$ 25$ fine would be dropped if the statewide wearing rate stayed above a certain percentage, say 75 percent?

\section{Myths}

It was somewhat sobering to hear people talk of their fear of belts as pertains to post-crash fires and the chances of being trapped inside a vehicle. While those working in highway safety may tend to feel that myths like these have been dispelled, the telephone survey reinforced that such was not the case. Clearly, there is a need for more education on issues like being trapped by a belt and being "thrown clear" of the crash.

The Lack of a Seat Belt Habit

The inability to form a seat belt habit unquestionably leads to non-use by many people. Although this was apparent in numerous conversations, perhaps the following case highlights the problem. A lengthy conversation was held with a personable lady. She was in the high risk group and confirmed that she had been involved in multiple accidents and had experienced multiple enforcement contacts. Despite all this, she described herself as a person who just could not get into the habit of wearing a belt. Her view was that people should have a choice about using belts. She thought seat belt commercials could be misleading -- that belts are not as good as sometimes portrayed (and yet not as bad as others say they are). Listening to a politician do an advertisement for belts was considered repulsive. Even a seat belt salute would be only a temporary solution for her. She stated that she needs a car that simply will not start unless her belt is buckled. She was enthusiastic about the idea of an incentive program as a way to form a habit.

\section{The Lack of Seat Belt Enforcement}

The final issue in the qualitative list pertained to the lack of seat belt enforcement. Several respondents discussed enforcement as was applicable to their small hometown. A case can again be used to outline the problem. The conversation was held with a pleasant, sensible man who drives a number of different trucks for his company. Partly because of this multi-vehicle use pattern, he says he has never developed a seat belt habit, even though his 
family tries to remind him and he believes that belts are beneficial. He lives in a small town and says he knows all the police and highway patrolmen. Their kids go to school and play sports together. He thinks it is difficult for enforcement people to issue $\$ 25$ citations to people whom they know in a community like his. The case highlights an example where non-sanctions, such as the "seat belt salute," could be used by enforcement personnel hesitant to ticket their friends.

It is noteworthy that this same argument has been heard from the other side -- from small town law enforcement officers. In a statewide survey of enforcement practices with regard to belts, police often stated that reminders and friendly warnings were (in their opinion) more appropriate and effective than tickets (Reinfurt, Campbe11, Stewart, and Stutts, 1987).

Improvements in seat belt law enforcement will likely not emerge unless the problem is attacked comprehensively. Besides "seat belt salutes" and incentive program possibilities, the attitudes of the police and public must be changed to the point that non-compliance with the seat belt law is similar to other traffic offenses.

\section{A Complex Decision}

To conclude this section, it is perhaps worth noting that rationality does not always prevail in decisions concerning seat belt use. Some of the telephone conversations leave one with the impression that some people like the N.C. seat belt law because it increases belt use by other members of their family. However, these same people may say that they themselves simply do not want to wear a seat belt all the time. As a mother/real estate agent expressed the thought, "I want to be able to take some risks in my 1ife."

Cases like this and the others referred to in this section indicate that modifying the seat belt behavior of non-users is a difficult endeavor. Even though many non-users believe in the efficacy of belts, the reasons given for not "buckling up" are varied and often complex. Measures to increase belt wearing will likewise need to be varied to achieve their purpose.

Implications of Belt Non-Use by High Risk Drivers As Related to Belt Law Effectiveness Evaluations

This research confirms that belt non-users are overrepresented in crashes. Using the observed belt use obtained in the field, belt non-users have, on 
average, about 35 percent more accidents than belt users (based on 0.20 accidents per belted driver and 0.27 accidents per unbelted driver over a fouryear period). What are the implications of this finding as they relate to belt effectiveness estimates derived from seat belt law evaluations?

In North Carolina, it has been calculated that fatalities have been reduced by about 7.6 percent since the implementation of the seat belt law. This results from observed use rates ranging generally between 60-70 percent, up from the pre-law or baseline use rate of about 25 percent (Reinfurt, Campbe11, Stewart, and Stutts, 1987). In other words, the pool of belt users has increased by about 35-40 percentage points. Using the accident rates noted above, what would be the effect of adding the remaining belt non-users (another 35-40 percent) to the pool of belt users?

As a rough approximation, one could assume that since the initial group of non-users of belts who became belt users decreased fatalities by 7.6 percent, the next group (of the same size) would do likewise, but with an increased propensity for accidents. Thus, if the belt use rate increased, say, from 65 to 100 percent, then the expected reduction in fatalities would be 7.6 percent $x$ 1.35, or about 10.3 percent (assuming the same types of crashes for the new belt users). Then the overall decrease in fatalities resulting from an increase in belt use from 25 to 100 percent would be 7.6 percent plus 10.3 percent, or about 17.9 percent. This agrees well with reported results from Great Britain, where the fatalities among front seat occupants of cars and the occupants of vans decreased 16 percent between February 1984 to January 1985, and where the belt use rate has been fairly stable at around 90 percent (Durbin and Harvey, 1985).

Another comparison of the expected reduction in fatalities can be made using the equations developed by Evans (1987b) that take into account "selective recruitment," whereby "drivers who change from being nonusers to being users have lower accident involvement rates than the remaining nonusers." Evans assumes that a driver's crash rate is a monotonically increasing function of the use rate, and employs the finding that unbelted driver involvement rates are higher than those for belted drivers. Choice of a parameter called "m" determines the shape of the function, and $m=2$ is considered to be the most appropriate choice. Using the unsimplified method, two equations must be used to calculate the expected fatality reduction associated with a belt use 
increase, $\Delta u$, over an initial use rate, $u_{1}$. The first equation (Evans' equation 16) is

$$
\alpha=\frac{(R-1)(m+1)}{\frac{1-u_{1}^{m+1}}{1-u_{1}}-R u_{1}^{m}}
$$

where $R$ is the ratio of unbelted driver to belted driver accident involvement rates. For the North Carolina data used here, $R=1.35$. Using $m=2, \alpha$ is calculated to be 0.694 , or approximately 0.7 .

The reduction in driver fatalities, F, (Evans' equation 23) is given by

$$
F=\frac{E\left\{\Delta u+\frac{\alpha}{m+1}-\left[\left(U_{1}+\Delta U\right)^{m+1}-U_{1}^{m+1}\right]\right\}}{1+\frac{\alpha}{m+1}-E\left(U_{1}+\frac{\alpha}{m+1} U_{1}^{m+1}\right)},
$$

where $E$ is the belt effectiveness at preventing fatalities. Evans has calculated $E=0.43$ in a previous paper (Evans, 1986), while NHTSA's belt effectiveness estimate is 0.45 (National Highway Traffic Safety Administration, 1984). Using $\mathrm{E}=0.43, \mathrm{~m}=2, \mathrm{U}_{1}=.666, \Delta \mathrm{u}=.334$, and $\alpha=0.7$ (calculated above), the calculated value of $F$ would approximate the fractional reduction in fatalities expected if the North Carolina belt use rate increased from 66.6 percent to 100 percent. Performing the mathematics yields $F=.2336$, or a 23 percent reduction in fatalities.

Strategies to Increase Seat Belt Use

Analyses of mailback questionnaires resulted in the identification of subpopulations of North Carolina drivers who differed significantly from other drivers with respect to their lower levels of belt use, their reluctance to increase their belt use, and their beliefs concerning the advantages and disadvantages of using seat belts. These subpopulations sometimes included 40 percent of the drivers having worse than average driving records and lower than average educational levels. More detail concerning the beliefs and attitudes of these and other groups was obtained through the telephone survey. This section will focus on results from the analysis of the data and what sorts of 
candidate programs or strategies might be considered to increase seat belt use. Most of these comments are oriented toward initiatives that would logically be led by state officials, and many could be applied at the community level.

Target groups, strategies, spokespersons, and themes are all considered within the following subsections.

\section{Target Groups}

Results of analyses in Chapters 3 and 4 show that various groups differ in their attitudes and beliefs about seat belts and would be suitable candidates for target groups. Because of small samples interviewed by telephone, these data do not lend themselves to multi-way breakdown, and typical target groups for certain strategies include large segments of the population, such as those age 25 and under, those age 55 and greater, male or female drivers, and black or white drivers.

On a more positive note, the analyses of the mailback survey/driver history data can be more useful in identifying target populations for various programs aimed at increasing seat belt usage. The target group which stands out most clearly consists of those drivers with two or more prior violations. More than 40 percent of the respondents in this group reported very low seat belt use, both before and after the seat belt law. When these respondents do wear seat belts it is most often to avoid the $\$ 25$ fine. Moreover, they often give fear of being trapped or belt ineffectiveness as reasons for not wearing seat belts.

Drivers who did not complete high school might be considered a second target group. This group displays essentially the same characteristics as those with 2 or more prior violations but to a slightly lesser degree. Educational and/or incentive programs aimed at pre-drivers in their early teens (e.g., in junior high schools) might be effective in reaching this target group.

Groups Whose Belt Use Was Unchanged by the Law

The mailback survey data permitted identification of groups whose belt use had changed following the implementation of the N.C. seat belt law. Those whose belt use failed to increase as much as their counterparts included those age 25 and under, males, white drivers (though their initial belt use was much higher), drivers having two or more prior violations, and drivers with 
relatively low levels of education. It could be that these people are less intimidated by the seat belt law and the possibility of a ticket.

Some consideration could be given to developing special educational or support messages for these groups through media outlets, and additional information could be conveyed through driver license renewal channels. In addition, those who attend alcohol and drug education training schools and driver improvement clinics would be part of this target group.

\section{Messages About Myths and Seat Belt Effectiveness}

Telephone respondent opinions about frequently stated seat belt issues contribute to ideas about increasing seat belt use. There is reasonably good agreement across the belt wearing groups that belts reduce the chance of serious injury in a crash. This provides a good starting point for the development of support messages. There was considerably less agreement on statements about being thrown out of the car, about lap belt use in the back seat, and about being belted and trapped in a car.

Analysis of the mailback survey items pertaining to reasons for not using belts also aids in developing ideas for messages for specific groups. For example, those who fear being trapped in a vehicle by belts include females, those with less education, and blacks. Females and the less educated are more likely to think belts do not prevent injuries. More research is needed to develop and test specific approaches for encouraging belt use by young males and/or beginning drivers.

A trend in these results was that those with less formal education need understandable information about belt effectiveness and myths such as being "thrown clear" of the crash. PI\&E spots with simple themes for radio and television could be used in disseminating belt effectiveness information. Perhaps NHTSA's brochure entitled "How Many of These Fairy Tales Have You Been Told?" could be targeted for dissemination to those with less education.

\section{Messages About Various Driving Situations}

The most likely driving situations to increase belt wearing overall were driving in bad weather, driving with children in the car, and making a long trip. Few of the rarely wearers said that night driving or driving in rush hour traffic increases their belt use. Thus, PI\&E messages focusing on the relative crash probability of these situations would be useful. Numerous 
themes could be pursued, one example being, "You already wear belts when driving in bad weather. What about all those trips you make in busy and sometimes crazy rush hour traffic?"

Items That Would Produce Belt Wearing "Every Time You Get Into Car"

Positive replies to a list of items that might "get you to wear your seat belt every time you get in the car" tended to relate to economic and/or enforcement themes (car insurance greatly reduced and points added to driving record for seat belt violation). Both of these examples are unlikely to be realized because of stiff opposition to the concept. Given the harsh nature of remarks by less frequent belt wearers about the $\$ 25$ fine, debate about assessing points to the driving record would be spirited. There were also some other enforcement items in this list, and these will be discussed separately.

A third item receiving positive replies concerned making belts more comfortable or easier to use. Seventy-four percent of the low risk group said that making belts more comfortable and convenient to use would prompt full-time belt use. The low risk group includes older people, whites, females, and those with more formal education.

Besides emphasizing comfort and convenience to auto manufacturers, perhaps more effort should be made to encourage trying on belts when purchasing vehicles and viewing belts as an important purchasing item for consideration. A problem with the shift to automatic bags and belts after 1990 is that a sizable portion of the fleet will be older vehicles containing (at least to many non-users) the less comfortable belt systems. Given that wholesale retrofitting of belt systems is highly unlikely, perhaps belt advocates should give more thought to ways (e.g., belt extenders) that present systems can be made more comfortable.

\section{Thoughts on Seat Belt Messages}

Since most of the ideas for increasing belt use presented so far pertain to media efforts, perhaps we should restate some of the positive comments received about seat belt advertisements. First, the NHTSA crash dummies Vince and Larry were well received and should receive more emphasis in media messages and other promotions. Other candidate spokespersons include television and movie stars, sports and race car professionals, highway patrol officers, belted crash survivors, and "every day" people. In terms of spokesperson preference, 
part-time wearers like "every day" people, males like sports figures, and females accident-related spokespersons.

Given the frequency of recall of the Barbara Mandrell spot, it would seem that this was a believable episode that could serve as a pattern for other spots. The data suggest that such testimonials would be effective with parttime ("sometimes") belt wearers, rather than the never and rarely wearers, as we11 as blacks. These activities could be undertaken by Governor's Highway Safety Programs, with spokespersons possibly coming from a "Saved-by-the-Belt" club. Race car drivers would also be excellent candidates, especially given their mention by the less frequent belt wearers.

Mention was also made of using local police and "every day" people as seat belt spokespersons. As a way of using "every day" people, consider the following message format:

A grandmother at the open door stooping to greet her young grandchildren as they run up to meet her with greetings and laughter, then, "It's worth the one second it takes to buckle up. Think what you could miss if you don't." The same message could be used with a variety of other pictures or audio backgrounds, such as:

Parents watching proudly as their baby takes its first step, Young hikers out on a mountain trail, A group of black youths playing a pick-up basketball game, A little girl skipping rope with her friend, and A young man with his date at the beach or on a dance floor.

With the same message reported for each of the various scenes, the theme would gain some strength through repetition while the variety should hold the attention.

\section{Strategies Pertaining to Enforcement of the Law}

Within the results of these surveys are clear indications of the need for more enforcement of the seat belt law. Although the reasons are not clear, those who never wear their belt and the observed unbelted drivers were much less likely to have been stopped since the implementation of the $\$ 25$ fine for a seat belt violation. If stopped, half of the never wearers reported that the police officer said/did nothing regarding their non-use of belts. Overa11, 70 percent reported that an enforcement encounter (many of which were license checks) had no effect on their subsequent belt use. These are prime opportunities to enforce the law. 
Regarding perception of enforcement, the never wearers and the observed unbelted drivers were least likely to perceive the law as being strongly enforced (a total of 80 percent of the never wearers reporting the law being either not strongly enforced or not at all enforced). There were also significant differences by race, with blacks perceiving the law as being more strongly enforced. This factor probably has a strong impact on the recent gains in the black use rate in N.C. If messages are developed to increase the perception of seat belt enforcement, the data indicate that females would be more influenced by these than males.

As part of a comprehensive enforcement strategy, there is a need for law enforcement officers to use their belts consistently. The never wearers were the most likely to report that police do not always wear their belts.

Finally, the "seat belt salute" was viewed as a good way to encourage belt use by 89 percent of the respondents. The younger drivers were most likely to have encountered a salute, and they were also most likely to feel the practice is a good idea ( 100 percent agreement).

\section{Health and Lifestyle}

When questioned about activities like regular exercise, smoking, and drinking, the observed unbelted drivers and the sometimes and never belt wearers were overrepresented in terms of getting no regular exercise and smoking. Younger drivers were more likely to admit driving after drinking. Given these results, promotions could relate belt use to other "healthy lifestyle" behaviors such as exercising regularly and not smoking. The theme could also be tied to alcohol and risk with a message like, "You don't drive after drinking, but how do you know that some other person won't? Protect yourself by buckling up."

\section{Recommendations}

This section will focus on some particular recommendations that grow out of both analyzing the data and working through the development of strategies and candidate program ideas for increasing seat belt use in the previous section.

1. National television special programming of one hour in duration should be developed to deal with the topic of seat belts. The special should show crash test footage of a variety of crashes 
involving lap belted, shoulder belted, and unbelted occupants. The approach to why seat belts should be worn should be based on logical reasoning and reflect reality. That is, seat belts will not save all occupants from death or serious injury in all crashes; however, the odds of surviving any single crash are much better if the restraints are worn, and worn correctly. The importance of correct use should be emphasized. Some discussion should focus on the effectiveness of belts in various kinds of crashes (e.g., frontal, angle, rollover, etc.).

Based on their acceptance, the NHTSA crash dummies, Vince and Larry, should have a central role in the narration of the special. If necessary, other prominent scientists, highway safety evaluators, crash reconstructionists, etc. from around the world who are knowledgeable about crash forces and the effectiveness of restraints could have supporting roles in the presentation.

In addition, examples should be given of other laws passed for the protection of many, even at the cost of personal freedom. As an example, while the use of hard hats in construction areas was once viewed as unnecessary regulation, the hard hat has now become a symbol of the industry. Mention should also be made of the societal costs of motor vehicle accidents and how this cost affects health insurance, auto insurance, life insurance, and the overall cost of goods and services (because motor vehicle injuries account for so much lost work time).

2. There needs to be more interaction with NASCAR, the national stock car racing association, in various seat belt promotions. From the results of the telephone survey, it is apparent that more education about the effectiveness of seat belts in crashes is needed. In discussing the use of television advertisements about seat belts, race car drivers and people who have been in an accident were viewed as good spokespersons. When asked what influenced belt wearing, the reasons most frequently stated in the "other" category included having seen many bad accidents and having raced stock cars.

Stock car racing is one of the most popular spectator sports in the United States. In this competition, many lives are saved and serious injuries averted by the use of belt systems, and spectators are aware of this fact. More frequent use should be inade of this valuable source of seat belt testimonials, particularly in the southeastern part of the United States.

3. More research and demonstration projects are needed that concern learning how to increase the level of seat belt law enforcement. In North Carolina, indications are that the State Highway Patro1 does an active job of enforcing, but that the quality and frequency of belt law enforcement decreases at the local level. This is understandable in smaller towns, given that local police often know personally a possible recipient of a seat belt citation. 
We need to learn how to increase seat belt enforcement at the local level. It is feasible that emphasis on practices like the "seat belt salute" and other non-sanctions could be accepted by police as alternatives to citations, and this could be examined in a research setting using experimental and control localities and measuring belt use rates.

4. The auto industry should strive to develop belt systems that are more comfortable, acceptable, and have a better fit. Even though current belt systems are far superior in comfort and convenience to the older systems, it is clear that all the problems have not been solved. New technology is emerging, such as rear seat shoulder belt systems mounted onto rods to allow adjustment for passengers of different heights (particularly children). Is such a system feasible for drivers and right front seat occupants? What can be done to improve the fit of the lap belt portion in the area of the hips? Could reminder systems be made more effective, less easy to circumvent, etc? More research and development is necessary to answer these questions. 
REFERENCES

Ashton, S. and Warr, P. (1976). Drivers use of seat belts as a function of attitude and anxiety. British Journal of Social and Clinical Psychology, Vo1. 15, pp. 261-265.

Bradstock, M.K., Marks, J.S., Forman, M.R., Gentry, E.M., Hogelin, G.C., Binkin, N.J. and Trowbridge, F.L. (1987). Drinking-driving and health lifestyle in the United States: Behavioral Risk Factor Surveys. Journal of Studies on Alcohol, Vol. 48, No. 2, pp. 147-152.

Bragg, B.W.E. (1973). Seat belts: "A good idea but they are too much bother." Ottawa, Ontario, Canada: The Department of Transport, Road and Motor Vehicle Traffic Safety Branch.

Bowling, J.M. (1986). Questionnaire design. State Center for Health Statistics Statistical Primer, No. 7. Raleigh, North Carolina: Department of Human Resources, Division of Health Services.

Boyd, H.W., Westfall, R. and Stasch, S.F. (1985). Marketing Research: Text and Cases, Sixth Edition. Homewood, IL: Richard D. Irwin, Inc.

Campbe11, B.J. (1969). Seat belt use among drivers in accidents and drivers in the population at risk. Chapel Hill: University of North Carolina Highway Safety Research Center.

Campbel1, B.J., Stewart, J.R. and Campbel1, F.A. (1987). 1985-1986 experience with belt laws in the United States. Chapel Hill: University of North Carolina Highway Safety Research Center.

Churchil1, G.A. Jr. (1987). Marketing Research: Methodological Foundations, Fourth Edition. New York: The Dryden Press.

Dillman, D.A. (1978). Mail and Telephone Surveys: The Total Design Method. New York: John Wiley \& Sons.

Durbin, J. and Harvey, A.C. (1985). The effects of seat belt legislation on road casualties in Great Britain: Report on assessment of the statistical evidence. In "Compulsory Seat Belt Wearing Report by the Department of Transport." London: HMSO Publications Center.

Evans, L. (1987a). Belted and unbelted driver accident involvement rates compared. Journal of Safety Research, Vo1. 18, No. 2, pp. 57-64.

Evans, L. (1987b). Estimating fatality reductions from increased safety belt use. Risk Analysis, Vol. 7, No. 1, pp. 49-57.

Evans, L. (1986) The effectiveness of safety belts in preventing fatalities. Accident Analysis \& Prevention, Vol. 18, No. 3, pp. 229-241.

Evans, L. and Wasielewski, P. (1983). Risky driving related to driver and vehicle characteristics. Áccident Analysis and Prevention, Vol. 15, No. 2, pp. 121-136. 


\section{REFERENCES (Con't $t$ )}

Fhaner, G. and Hane, M. (1979). Seat belts: Opinion effects of law-induced use. Journal of Applied Psychology, Vo1. 64, No. 2, pp. 205-212.

Freedman, K., Wood, R. and Henderson, M. (1974). Compulsory seat belts: A survey of public reaction and stated usage. New South Wales: Department of Motor Transport, Traffic Accident Research Unit.

Goldbaum, G.M., Remington, P.L., Powe1l, K.E., Hogelin, G.C. and Gentry, E.M. (1986). Failure to use seat belts in the United States. Journal of the American Medical Association, Vo1. 255, No. 18, pp. 2459-2462.

Hatle, H. and Stewart, J.R. (1980). Highway safety survey: Phase II. Vermillion: University of South Dakota.

Helsing, K.J. and Comstock, G.W. (1977). What kinds of people do not use seat belts?: American Journal of Public Health, Vol. 67, No. 11, pp. 1043-1050.

Heron, R.M. (1975). A review of three studies attempting to relate seat belt usage to seat belt attitudes and other variables. Ottawa, Ontario, Canada: Ministry of Transport, Road and Motor Vehicle Traffic Safety Branch.

Highway and Vehicle Safety Report. March 14, 1988. Branford, CT: Stamler Publishing Co.

Hunter, W.W. and Geissinger, S.B. (1988). Understanding and acceptance of the North Carolina safety belt use law. Chapel Hill: University of North Carolina Highway Safety Research Center.

Jonah, B.A. and Dawson, N.E. (1982). The National Vehicle Occupant Restraint Survey: Attitudes toward and use of restraints by Canadians. Ottawa, Ontario: Transport Canada, Road and Motor Vehicle Traffic Safety Branch.

Jonah, B.A. and Lawson, J.J. (1986). Safety belt use rates and user characteristics. In Effectiveness of Safety Belt Use Laws: A Multinational Examination. Washington, D.C.: National Highway Traffic Safety Administration, October 1986. [DOT HS-807 018].

Kanuk, L. and Berenson, C. (1975). Mail surveys and response rates: A literature review. Journal of Marketing Research, Vo1. 12, pp. 440-453.

Lacey, J.H., Stewart, J.R., Marchetti, L.M., Popkin, C.L., Murphy, P.V., Luckey, R.E., and Jones, R.K. Enforcement and Public Information Strategies for DWI General Deterrence: ARREST DRUNK DRIVING - The Clearwater and Largo, Florida Experience. Chapel Hill, N.C.: University of North Carolina Highway Safety Research Center (Contract No. DTNH22-81C-07071), December 1986.

Marzoni, P., Jr. (1971). Motivating factors in the use of restraint systems. Philadelphia, Pennsylvania: National Analysts, Inc. [PB 204 187]. 
Mayas, J.M.B., Boyd, N.K., Collins, M.A. and Harris, B.I. (1983). A study of demographic, situational, and motivational factors affecting restraint usage in automobiles. Washington, D.C.: Lawrence Johnson \& Associates, Inc. [DOT HS-806-402]

McCarthy, R.L., Taylor, R.K., Sanford, S.B., and Lange, R.C. (1984). Seat belts: Effectiveness of mandatory use requirements. In Advances in Belt Restraint Systems: Design, Performance and Usage, pp. 161-171. Warrendale, Pennsylvania: Society of Automotive Engineers, Inc.

Mozo, A.E. (1986). A study of the relationships between safety belt use and risk-taking behavior. Master's paper submitted to the University of North Carolina, Department of Health Policy and Administration, Chape1 Hil1, N.C.

National Highway Traffic Safety Administration (1984). Final Regulatory Impact Analysis: Amendment to Federal Motor Vehicle Safety Standard 208 (Passenger Car Front Seat Occupant Protection). Washington, D.C.: Author. [DOT HS 806 572]

National Transportation Safety Board. (1986). Performance of lap belts in 26 frontal crashes. NTSB Report No. 55-86/03. Washington, DC: Author.

O'Day, J. and Filkins, L.D. (1983). Attitudes toward wearing belts: A survey of Michigan drivers. Ann Arbor: University of Michigan Transportation Research Institute.

O'Rourke, D. and Blair, J. (1983). Improving random respondent selection in telephone surveys. Journal of Marketing Research, Vol. 20, pp. 428-432.

Reinfurt, D.W., Campbe11, B.J., Stewart, J.R. and Stutts, J.C. (1987). North Carolina occupant restraint law: An evaluation. Chapel Hill: University of North Carolina Highway Safety Research Center.

Robertson, L.S. and Williams, A.F. (1978). Some international comparisons of the effects of motor vehicle seat belt use and child restraint laws. (Paper presented at the Child Passenger Safety Conference, Nashville, Tennessee, May 1978). Washington, D.C.: Insurance Institute for Highway Safety.

Rood, D.H. and Kraichy, P.P. (1985). Evaluation of New York State's mandatory occupant restraint law, Volume II: Attitudinal Surveys of Licensed Drivers in New York State. Albany, N.Y.: Institute for Traffic Safety Management and Research.

Stewart, J.R. and Campbell, B.J. (1972). The statistical association between past and future accidents and violations. Chapel Hill: University of North Carolina Highway Safety Research Center.

Teknekron Research, Inc. (1979). 1979 survey of public perceptions on highway safety. McLean, Virginia: Author. [PB 80 125982] 
Wagenaar, A.C., Streff, F.M., Molnar, L.J. Businski, K.L. and Schultz, R.H. (1987). Factors related to non-use of seat belts in Michigan. Ann Arbor: University of Michigan Transportation Research Institute.

Wagenaar, A.C. and Wiviott, M.B.T. (1986). Effects of mandating seatbelt use: A series of surveys on compliance in Michigan. Public Health Reports, 101 (5), September-October 1986, pp. 505-513.

Waller, P.F. and Barry, P.Z. (1969). Seat belts: A comparison of observed and reported use. Chapel Hill: University of North Carolina Highway Safety Research Center.

Waller, P.F., Li, L.K., Stewart, J.R. and Ma, J.M. (1983). Evaluation of the effect of perception of risk messages on observed safety belt usage. Chapel Hill: University of North Carolina Highway Safety Research Center.

Wasielewski, P. (1984). Speed as a measure of driver risk: Observed speeds versus driver and vehicle characteristics. Accident Analysis and Prevention, Vol. 16, No. 2, pp. 89-103.

Yu, J. and Cooper, H. (1983). A quantitative review of research design effects on response rates to questionnaires. Journal of Marketing Research, Vo1. 20, pp. 36-44. 


\section{APPENDIX A}

Summary Tables for Literature Review

A-1 
Table A.1 Summary of literature findings pertaining to belt use and other risk behaviors.

Study

Goldbaum, et al (1986) and Bradstock, et al. (1987)

Jonah \& Lawson (1986)

Mozo (1986)

(Unpublished Master's thesis paper)

Wasielewski (1984)

Evans \& Wasielewski (1983)

Mayas, et al (1983)
Method

Telephone survey of 22,236 adults in 28 states + DC from 1981-1983 (part of the CDC-sponsored Behavior Risk Factor Survey).

Review of literature.

Written questionnaire to 207 licensed drivers and observational survey of 215 drivers with linkage to driver histories, conducted in Durham, N.C.

Measured speed and photographed driver and vehicle characteristic data for 6,638 passenger cars at a low volume two-lane road near Detroit.

Photographed headway data on a sample of 2000 vehicles on high speed freeways (Toronto and Michigan sites).

Nationwide telephone survey of 1200 licensed drivers; observations followed by face-to-face interviews with $197 \mathrm{dri-}$ vers in the Baltimore SMSA. $\underline{\text { Results }}$

Belt use significantly lower for smokers, binge drinkers, chronic drinkers, drunk drivers, and overweight and inactive drivers.

Non-users more likely to consume alcohol, take risks in driving (follow more closely, run red lights, etc.), have accident and violation points on their record, and generally exhibit a more risk-oriented lifestyle.

Belt use associated with nonsmokers, persons who would not participate in a state lottery, exercises for at least 6 months, and no speeding or other traffic violations.

Seat belt use not found associated with higher speeds; however, belt use was lower for drivers with reported accidents and violation points.

Shorter headways, corresponding to higher risk, found for drivers with prior accidents or violations, young drivers, male drivers, drivers with no passengers, and drivers not wearing a seat belt.

More frequent belt users more likely to engage in other health-related behaviors such as visiting the dentist, not smoking, exercising, etc. 
Table A.1 (Con't)

\section{$\underline{\text { Study }}$}

Waller, et al (1983)

Helsing \& Comstock

(1977)

Teknekron Research, Inc. (1979)

Heron (1975)
Method

A series of seat belt observations to assess effect of various safety belt messages on sample of $200+$ N.C. drivers. Questionnaires on various health-related issues also included.

National probability telephone sample of 1500 licensed drivers.

Telephone interviews with 1009 residents of Washington County, MD.

Review of three Canadian studies.
Results

Observed belt use associated with greater reported frequency of eye examinations but was not related to other reported health maintenance behaviors included in the questionnaire.

Belt use not found related to either accident risk perception or past accident involvement, but was related to speed limit compliance and frequency of driving on $55 \mathrm{mph}$ highways.

Belt use associated with time since last PAP Test (for women) and time since last dental checkup. Belt use not associated with cigarette smoking, time since last physical exam, last TB exam, or last electrocardiogram.

Belt use not related to fastest speed driven, ratings of the safety of driving and of one's car, miles driven per year, tickets issued (or accidents) (results of study by Hannah, 1975). 
Table A.2 Summary of literature findings pertaining to characteristics of seat belt users and non-users.

Study

Reinfurt, et a1. (1987)

Wagenaar, et al. (1987)

Wagenaar \& Wiviott (1986)

Jonah \& Lawson

(1986)

Rood \& Kraichy

$(1985)$
Method

Series of statewide belt use surveys to evaluate effectiveness of N.C. Belt law (pre-and postMUL). $\mathrm{N}=140,000+$ tota 1 observations.

Seat belt observations and roadside interviews with 1,864 Michigan drivers (post MUL).

Observed belt use at 240 intersections in Michigan before and after passage of MUL.

Review of Iiterature.

A series of three attitudinal surveys, including a baseline and two postMUL surveys, conducted in New York State. Each involved 1000 telephone interviews. $\underline{\text { Results }}$

Pre-MUL use rates higher for females, whites, drivers of cars and vans (vs. pickups), and urban drivers. Post-MUL rates show no distinction between use rates for whites and blacks.

Belt use lower for males, persons of lower SES, minorities, persons under age 30 , drinkers, urban drivers and married persons under age 25 .

Belt use not related to situational factors such as trip length; trip origin, destination, or purpose; or riding with friends.

MUL produced greatest increase among persons aged 60 and older. Use rates consistently higher for females, drivers, occupants of small and mid-size cars, and at freeway exits.

Belt use higher for women, married people, and persons of higher SES. With MUL, use increases linearly with age. Use higher for those perceiving either a high or a low likelihood of accident involvement. Belt comfort and convenience major factors in attitudes toward and use of belts. Reasons for non-use: lack of habit and fear of entrapment.

Higher reported belt use rates for females and more educated persons. Greatest increases in belt use postMUL for older (55+) drivers and those in the lowest income group. Support for law generally highest for females and persons with higher income and education levels. Groups perceiving strictest enforcement of the law included females, youngest and oldest age drivers, lower income drivers, and drivers with less than high school education. 
Table A.2 (Con't)

Study

Ashton \& Warr

(1976)

Heron (1975)

Freedman, et al. (1974)

Bragg (1973)

Marzoni (1971)
Method

Questionnaires coded for belt use/non-use given to 278 drivers observed entering parking areas in Sheffield and Birmingham, England (before MUL).

Review of three Canadian studies (including the Bragg, 1973 report referenced below).

Brief face-to-face interviews with (non-random) samples of 995 persons before MUL and 1,251 persons after MUL in New South Wales, Australia.

Mail questionnaire to 1,000 randomly selected Ontario drivers (before MUL). 687 returns.

In-house interviews with a national probability sample of 1500 licensed U.S. drivers; observed belt use plus interviews for 250 drivers. $\underline{\text { Results }}$

Demographic results not presented. Strong correlation between opinions about the comfort and effectiveness of belts and their use (both observed and reported).

Education and occupational status not significant factors once car model year held constant. Use also not related to annual mileage, road type most often driven, tickets issued, or accidents.

Reasons for belt use: safety \& habit. Reasons for non-use: habit, inconvenience, discomfort, danger, and lack of protection. High belt use associated with both high and low perceived likelihood of crash involvement.

No significant differences in reported belt use by sex since MUL; no age differences for males, but older females significantly more likely to wear belts than younger. Reasons for belt use: safety, the law, habit. Reasons for non-use: belts unavailable, inconvenient, uncomfortable.

Size of community, highway/city driving, education and income level significantly related to belt use. Age, sex, marital status, involvement in traffic accidents and number of years driving not related to belt use. Belt use highest among those with either a high or a low expectation of accident involvement.

Reported belt use positively associated with education, occupation category, income leve1, and trip length. Target groups identified for programs to increase belt use. 
Table A.2 (Con't)

Study

Mayas, et al.

(1983)

O'Day and Filkins

(1983)

Jonah \& Dawson

(1982)

Hatle \& Stewart (1980)

Fhaner \& Hane

(1979)
Method

Nationwide telephone survey of 1200 licensed drivers; observations followed by face-to-face interviews with 197 drivers in the Baltimore SMSA.

Random telephone survey of 1200 Michigan drivers (pre-MUL).

Face-to-face interviews with random sample of $2,000+$ Canadians from all 10 provinces (some with MUL).

Mail questionnaire to 1,000 licensed South Dakota drivers (non MUL). 425 returns.

Mail questionnaire to 694 car owners in Sweden following passage of MUL. 526 returns.

Telephone interviews with 1009 residents of Washington County, Md. $\underline{\text { Results }}$

Use higher for older persons (especially 65+) more educated persons, and those driving more on divided highways. Frequent users more likely to rate their belt systems as comfortable or convenient and less likely to be concerned about entrapment.

Belt use higher for females, those with a college degree, white collar employees, and those with family income > $\$ 25,000$. Reasons for nonuse: fear of entrapment, not in habit, belts too uncomfortable.

Reported belt use higher for females, older persons, and more educated persons, and in provinces with MUL. Use also higher on highways vs. local streets and for drivers vs. passengers.

Age, sex, education leve1, marital status, and family income not found significantly correlated with seat belt use. Factors judged most likely to increase belt use: improvement in belt comfort and convenience and reduction in auto insurance costs.

Non-users had significantly higher reported annual mileage. No differences with respect to age, sex, education level or years of driving experience. Since MUL, more positive opinions and attitudes regarding belts, but consistent non-users even more negative towards be1ts.

Reported belt use higher for males, persons with high school (or greater) education, persons with higher household income levels, and persons attending church.
Helsing \& Comstock (1977) 
APPENDIX B

Survey Forms

B-1 


\section{B.1. Mailback Survey Form}

\section{UNC Seat Belt Survey}

1. A N.C. law that began Oct. 1985 requires drivers and front seat passengers of motor vehicles to wear seat belts. What is your opinion of this law?
$\square$ ' strongly oppose
口2 moderately oppose
as not sure
$\square 4$ moderately support
$\square$ s strongly support

2. Before the law went into effect Oct. 1985, how often did you wear your seat belt when driving?

$$
\begin{aligned}
& \square \text { ' never } \\
& \square 2 \text { rarely } \\
& \square \text { s sometimes } \\
& \square \text { s most of the time } \\
& \square \text { s always }
\end{aligned}
$$

3. Between Oct. 1985 and Jan. 1987, there was no fine for not wearing a seat belt. During thls "grace" period how often did you wear your seat belt when driving?

$$
\begin{aligned}
& \square 1 \text { never } \\
& \square 2 \text { rarely } \\
& \square \text { s sometimes } \\
& \square \text {. most of the time } \\
& \square \text { always }
\end{aligned}
$$

4. Since Jan. 1987 drivers not wearing seat belts may be fined $\$ 25$. How often do you wear a seat belt now when driving?

$$
\begin{array}{ll}
\square & \text { never } \\
\square & \text { rarely } \\
\square & \text { sometimes } \\
\square & \text { most of the time } \\
\square \text { s always }
\end{array}
$$

5. What is your opinion of the $\$ 25$ fine?
$\square$ i There should not be a fine
$\square 2$ There should be a lower fine $\rightarrow \$$
$\square$. There should be a higher fine $\rightarrow$
$\square 4$ The $\$ 25$ fine is about right
6. Were you wearing your seat belt at the time this survey was given to you?

$$
\square \text { ' no } \square \text { yes } \quad \square \text { ' no belts in vehicle }
$$

7. How many total miles was the trip you were making at the time this survey was given to you?

$$
\begin{aligned}
& \square: \text { Less than } 5 \text { miles } \\
& \square: 9 \text { miles } \\
& \square: 10-19 \text { miles } \\
& \square: 20-49 \text { miles } \\
& \square: 50 \text { miles or more }
\end{aligned}
$$

8. For those times that you do wear a seat belt, please check the one most important reason.

$\square$ To avoid the $\$ 25$ fine.

$\square 2$ Because it's the law.

$\square$. To prevent injury if in an accident.

口. Because my friends/family want me to.

口s It's a habit; I don't think about it.

$\square$. Because of my own experience in an accident

प Because of someone else's experience in an accident.

$\square^{:}$Check here if you never wear a seat belt.
9. For those times that you do not wear a seat belt, please check the one most important reason.

$\square$ ' Seat belts don't prevent injuries.

$\square 2$ Seat belts are likely to cause injuries.

$\square$ ' Seat belts are uncomfortable; they don't let me move around.

ar I'm afraid of being trapped in my car if it catches on fire or goes under water.

$\square$ I I only wear seat belts on long trips or in bad weather.

$\square^{\circ}$ I'm a careful driver; I don't need to wear seat belts.

$\square$ I forget; I'm not in the habit.

$\square$. Check here if you always wear a seat belt.

10. About how many total miles do you drive or ride each year?
$\square 1$ Less than 5,000 miles
口2 $5,000-9,999$ miles
口, $10,000-14,999$ miles
$\square=20,000-29,999$ miles
$\square$ 15,000 - 19,999 miles
$\square \cdot 30,000-39,999$ miles
r 40,000 - 49,999 miles
$\square \cdot 50,000$ or more miles

11. Out of 100 N.C. drivers, how many do you think are likely to be in an accident in the next 2 years?

drivers

12. On a scale from 0 to 100 , please tell us how likely you think you are to be in an accident in the next two years. (o means that you certainly will not be in an accident and 100 that you certainly will.)

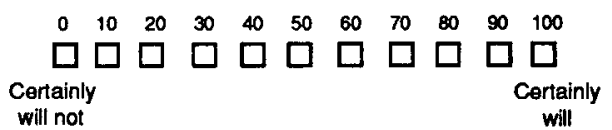

13. How much control do you feel you have in preventing an accident?

$\square$ । Almost total control

口2 A lot of control

$\square$ s Moderate control

$\square$ a little control

$\square$ ' Very little control

14. If you could vote today, would you vote to keep the N.C. seat belt law?

$\square$ ' yes $\square$ e no $\quad \square$ s not sure

15. What is your highest level of education?

$\square$ grade school $\square 4$ attended college

$\square 2$ attended high school $\square$; graduated college

$\square$, graduated high school $\square$. post college degree

16. Your marital status?
$\square$ ' married
$\square_{2}$ separated or divorced $\square$ 4 never married

17. Your date of birth?

$$
\overline{\text { month }} \overline{\text { day }} \overline{\text { year }}
$$

Please complete the following. This part of the survey will be your entry for the drawing and our way of notifying you if you win, so please print clearly. We would also like to contact a few of you later by telephone for a brief follow-up interview. Those who are interviewed will have a chance to win an additional $\$ 500$. If willing to be called, be sure to give us your telephone number and a best time to call.

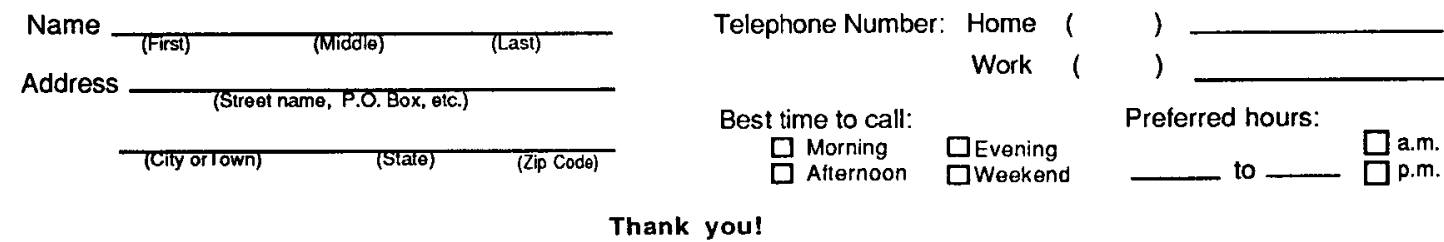




\section{How do you feel about North Carolina's seat belt law?}

A Pen for Your Thoughts!

The UNC Highway Safety Research Center is conducting a study to learn more about why people do or do not use car seat belts. We also want to know how you feel about the law requiring seat belt use in N.C. Won't you please help us by filling out the enclosed survey form and dropping it in the mail?

Gifts now, plus a chance to win $\$ 500$ later!

The pen and road map are our way of saying "thanks" for sharing this information with us. We will also be entering the names of those returning completed forms into a drawing for a grand prize of $\$ 500$ I If questions...

Thank you very much for your cooperation in this research effort. Any information you provide will be confidential and used strictly for research purposes. If you have questions, call us (toll free in N.C.) at 1-800-672-4527. 


\section{B.2. Telephone Survey Form}

\section{NHTSA Seat Belt Telephone Survey October 1987}

Hello. Could I speak to $?$

(IF PERSON NOT AT HOME OR CANNOT COME TO THE PHONE)

O.K. When can I call back to reach him/her? (RECORD IN BOX)

Thank you very much. Good-bye.

(IF CONFUSED, WRONG NUMBER)

Is this (number) ?

I'm sorry. I have the wrong number.

\section{(IF REACH CORRECT PERSON)}

This is of the University of North Carolina Highway Safety Research Center. Earlier this summer you were given a seat belt questionnaire by one of our data collectors standing near the roadway. We appreciate your completing this survey and mailing it back to us. Your completed form is your entry for a $\$ 500$ cash drawing that we will be holding soon after Thanksgiving.

When you returned the survey you indicated that you would be willing to participate in a follow-up telephone interview. This would make you eligible for an additional $\$ 500$ prize. The questions I need to ask take about 15 minutes, and your answers will be kept confidential. Would it be all right to do the survey now?

(IF YES) Great! Any questions before we begin?

(IF NO) O.K. Is there a good time when I can call you back to complete the interview? (RECORD AT RIGHT)

\section{Seat Belt Use}

INTRODUCTION: First I have some questions about seat belt use.

1. Would you please tell me how often you wear a seat belt now when driving.

\section{Is it (Read categories 1-5 below)}

(10)
1. Never
2. Rarely

3. Sometimes

4. Most of the time

5. Always

9. Don't know / no answer

2. Approximately what percent of the time. would you say that is?

$$
-\overline{(11-13)} \text { percent }
$$

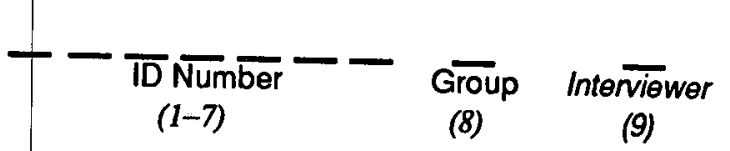

(For HSRC Use Only)

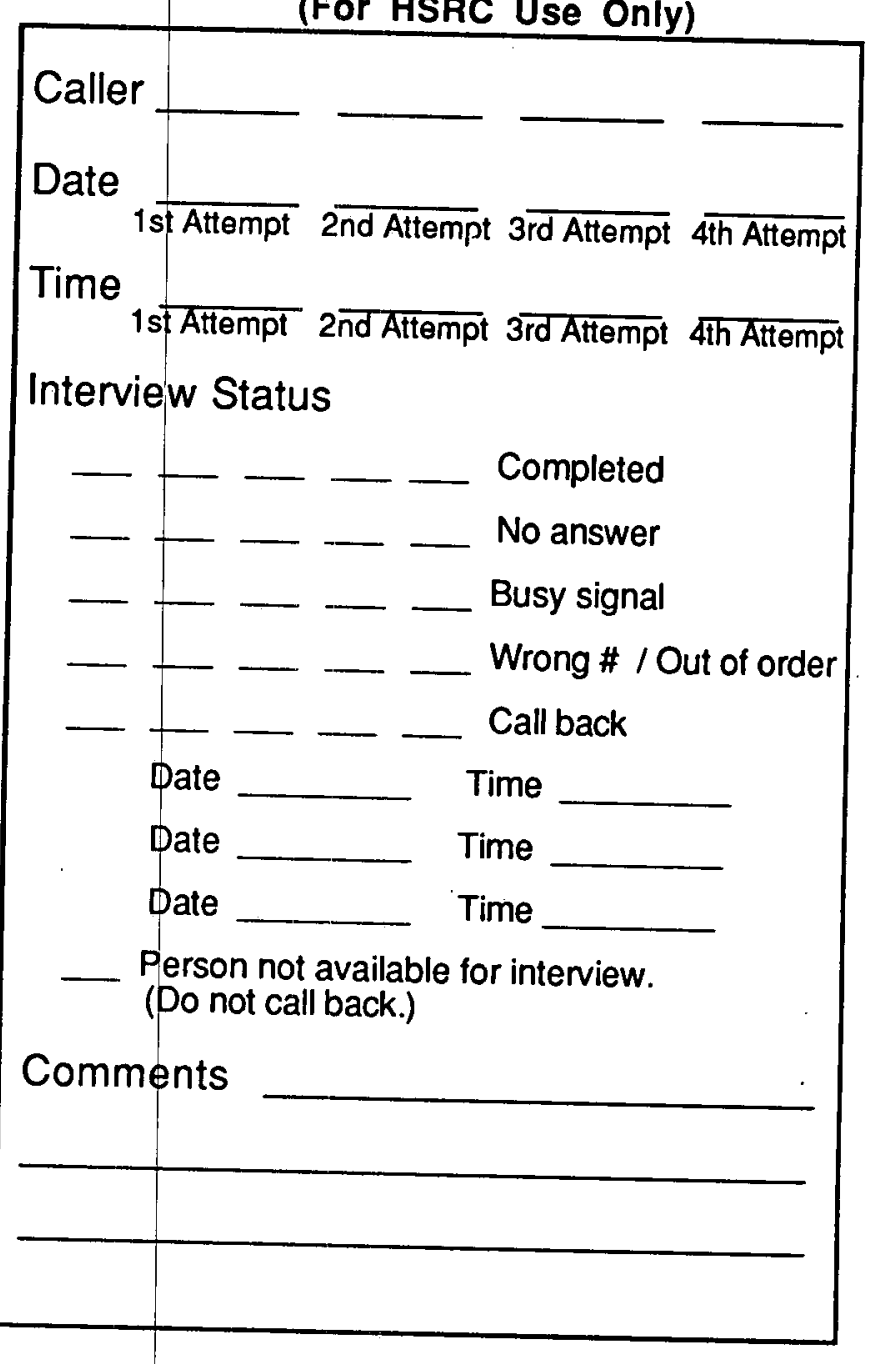

If $0 \%$, go to NEVER form

If $1-99 \%$, go to COMPLETE form

If $100 \%$, go to ALWAYS form 


\section{COMPLETE FORM}

\section{Belt Use (Cont.)}

3. When did you first start wearing a seat belt? Has it been

(Read categories to right, then probe as necessary)

1. Since the fine went into effect Jan. 1987

2. Since the law went into effect Oct. 1985

(14) 3. JUST before the law went into effect

4. Before the law but less than 5 years ago

5. More than 5 years ago

9. Don't know / no answer

Since the belt law went into effect Oct 1985

I

4. What influenced you to start wearing seat belts? (Code up to 3, in descending order of importance).

Before the belt law went into effect

01. Just that the law was passed

02. Concern about being stopped/fined by police

$\overline{(15-16)} \quad \overline{(17-18)} \quad \overline{(19}-\overline{20})$

03. Was stopped and warned by police

04. Was stopped and ticketed/fined by police

05. Increased concern for personal safety

06. Increased awareness of effectiveness of safety belts

07. Because of family/friends (set example for children, etc.)

08. Involved in accident

09. Friend/relative in accident

10. Something read or heard about belts (TV ad, news story, etc.)

11. Just makes sense; for safety

98. Other

99. Don't know / no answer

5. What percentage of your friends use seat belts?

(Prompt if necessary, e.g., is it 25\%, 50\%, 75\%?)

(21-23) percent

6. I'd like to read to you some things we've heard other people say about seat belts. For each statement, please tell me whether you strongly agree, agree, disagree, or strongly disagree.

(Prompt as necessary: Do you SA, $A, D$, or SD?)

Seat belts reduce the chance of serious injury in a crash. (Prompt: Do you SA, $A, D$, or SD?)

In an accident, it's better to be thrown out. of the car than to stay inside.

Seat belts are easy to use.

Lap belts are not necessary when riding in the back seat of a car.

Your chances of being trapped in a car if it crashes and catches on fire are greater if wearing a seat belt.

Seat belts can cause more injuries than they prevent.

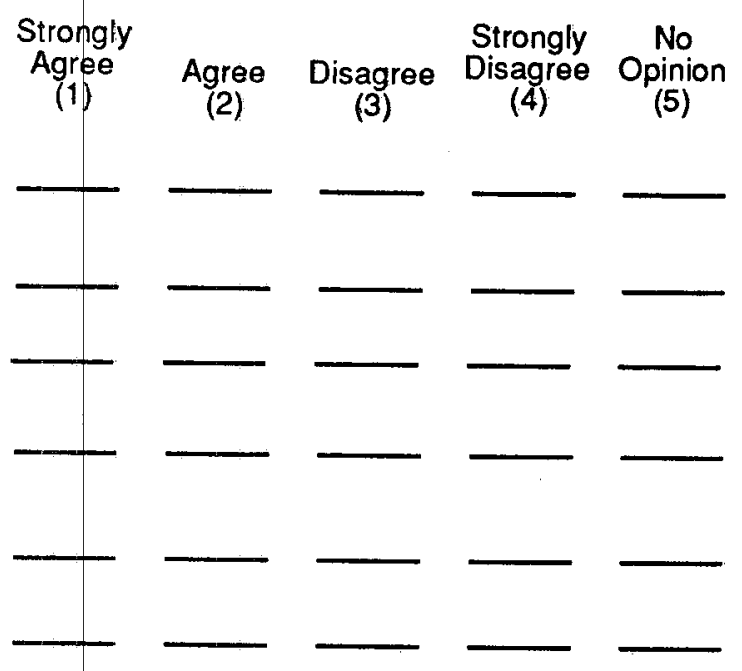


7. I am going to describe some driving situations. For each situation please tell me if you are more likely than usual to wear a seat belt. Just answer "yes" or "no".

(Prompt as necessary: Are you more likely to wear a seat belt if ---)

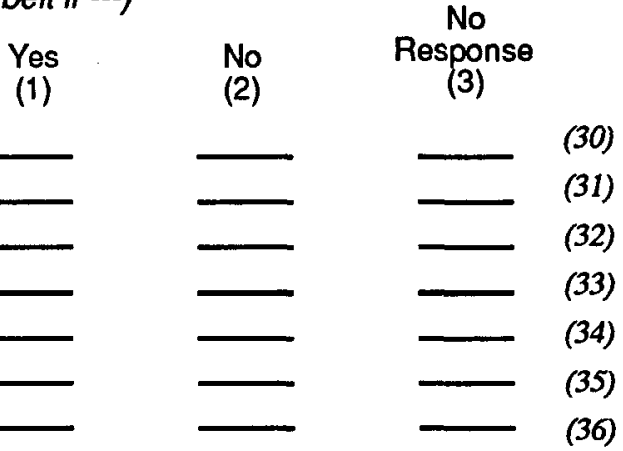

8. The current fine for not wearing a seat belt is $\$ 25$. What amount of fine would get you to wear your seat belt EVERY TIME you get in a car?

$$
\$ \quad \begin{aligned}
& \text { (Enter amount stated. } \$ 997=\$ 997 \text { or greater. } \\
& \$ 998=\text { no amount, fine would never affect belt use, etc. }
\end{aligned}
$$

Driving in bad weather, like rain, snow or fog

Driving at night

Driving on interstate highways

Making a long trip

Driving with children in the car

Driving in rush hour traffic

Driving on weekends or holidays

9. Now, would you please tell me if any of these other things would cause you to wear your seat belt EVERY TIME you get in a car? Just tell me Yes, No, or Maybe for each.

(Prompt as necessary: Would THIS get you to wear your seat belt EVERY TIME you get in a car?)

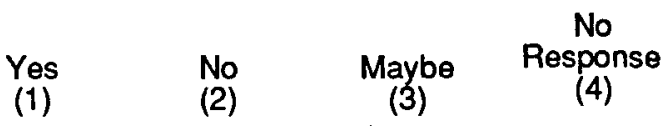

(1) If your car insurance payment was greatly reduced.

(Would this get you to wear ...EVERY TIME...?)

No

(3)

(4)

(2) If you heard someone give a first-hand account of how wearing a seat belt had saved their life.

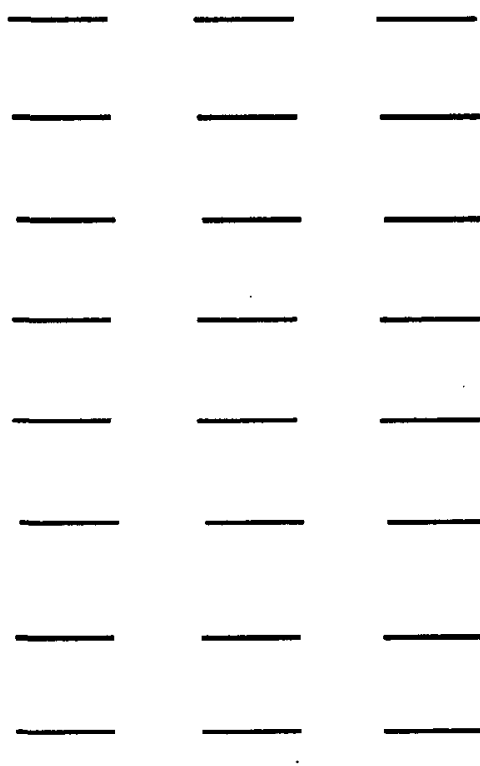

(3) If you personally knew someone whose life was saved by wearing a seat belt.

(4) If a friend or family member reminded you to wear your belt.

(5) If your belt was more comfortable or easier to use. (Would this get you to wear ...EVERY TIME...?)

(6) If a friend had been stopped and ticketed for not wearing a seat belt.

(7) If YOU had been stopped and ticketed for not wearing a seat belt.

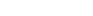

10. Is there anything ELSE that would make you wear your seat belt EVERY TIME you get in a car?
1. No
2. Yes (Write in below)
9. Don't know / no answer 
11. If someone were developing an advertisement or TV spot to get more people in North Carolina to use belts, who do you think would be a good spokesperson?

PROMPT IF NECESSARY: What we would like to know is if there is some specific person or type of person that you think would be good to use in an advertisement for seat belts.

(Write out responses, then categorize up to 3 in order of importance)
$\overline{(49-50)} \quad \overline{(51-52)} \quad \overline{(53-54)}$
01. Highway patrol officer, police officer
02. TV or movie celebrity
03. Sports star
04. Race car driver
05. Government official
06. Medical person - doctor, rescue squad volunteer, etc.
07. Someone who had been in an accident
08. Stunt car driver
09. Crash survivor (belted)
10. Close family of deceased non-user
11. Local news/TV/radio personality
12. Local pastor, religious teader, etc.
98. Other
99. Don't know / no answer

12. Do you remember seeing or hearing any TV advertisments about seat belts during the past year?

1. No

2. Yes

9. Don't know / no answer

What was it? Any more? (Circle up to 3)

$(56-58)$

$(59-61)$

$(62-64)$
1. Michael Jordan

2. Seymour AF Base

3. Seat belt convincer

4. Crash test film

5. Crash test dummies (Vince \& Larry)

6. Highway patrol officer

8. Other (describe below)

9. Don't know / no answer
(Code to right of each ad mentioned)

Like the ad?

1. Yes

2. No

9. Don't know / no answer

Affect belt use?

1. Yes

2. No

9. Don't know / no answer

13. What about billboards, parking lot signs, or other roadside signs. Have you seen any of these with seat belt messages?

1. No

2. Yes

9. Don't know / no answer

What was it? (Circle up to 3)

(66-67)

$(68-69)$

$(70-71)$
1. Billboard ("It's a Snap", etc.)

2. Parking lot sign

3. Other roadside sign (describe below)

4. Other non-roadside sign mentioned ((describe below)

9. Don't know / no answer
(Code to right of each item mentioned)

Get you to buckle up?

1. Yes

2. No

3. No - already buckled up

9. Don't know / no answer 


\section{Opinion of N.C. Law}

INTRODUCTION: Now I have a few questions about the N.C. seat belt law.

14. Please tell me which of the following statements best describes the way you feel about the N.C. law requiring drivers and front seat passengers to wear seat belts: (Read first three only)

1. I think wearing seat belts is a good idea, and I support the N.C. seat belt law.

2. I think wearing seat belts is a good idea, but I oppose the law.

3. I don't think seat belts are a good idea, and I oppose the law.

9. Don't know / no answer

15. Please tell me your MAIN REASONS for (supporting / opposing) the N.C. seat belt law. (Probe as necessary to determine most important reason, next most important, etc.

Code up to 3.)

$\begin{array}{llc}\begin{array}{c}\text { 1st Reason } \\ \text { (73-74) }\end{array} & \begin{array}{c}\text { 2nd Reason } \\ \text { (75-76) }\end{array} & \begin{array}{c}\text { 3rd Reason } \\ (77-78)\end{array}\end{array}$

Favorable Responses (for those supporting the law):

01 . Seat belts save lives / reduce injuries (in general)

02. The law will get more people to wear belts

03 . Wearing belts will protect me / my family

04 . Good for children / help them form habit of wearing belts

05. Make people more safety conscious in general (more careful drivers)

06. Reduce costs (to society) of accidents, injuries

07. Lower insurance premiums

19. Other

Unfavorable Responses (for those opposing the law):

21. Adults should have a choice / Infringement on rights

22. My seat belt doesn't work / doesn't lock up

23. Seat belts aren't effective / don't really help in an accident

24. Seat belts are uncomfortable / inconvenient to use

25 . Seat belts can cause injuries

26. Seat belts can trap me in my car

27. The law is not being enforced

28. The law is impossible to enforce

29. There shouldn't be a fine / fine is too high

39. Other

99. Don't know / no answer 


\section{Accident Experience}

INTRODUCTION: O.K., now I have a few questions about any accidents you may have been in. Your answers here are confidential and will be used only to see how people's accident experience might affect their use of seat belts.

16. Have you ever been involved in any traffic accidents?

1. No

(79)

2. Yes

3. Don't know / no answer

A. How long ago did the accident occur? Was it

1. Less than a year

2. 1 to 3 years

3. 3 to 5 years

4. More than 5 years

9. Don't know / no answer

B. Were you the driver or a passenger?

1. Driver

2. Passenger

9. Don't know / no answer

C. Can you tell me what caused the accident?

(Probe as necessary to determine fault)

1. Own vehicle

2. Other vehicle

8. Not applicable (s.v. accident, etc.)

9. Don't know / no answer

D. Were you injured?

1. No

2. Yes - minor injury

3. Yes - moderate injury (Describe in margin)

4. Yes - serious injury

9. Don't know / no answer

E. Were you wearing your seat belt at the time?

1. No

2. Yes

9. Don't know / no answer

$F$. Was anyone else in the accident injured?

1. No
2. Yes - minor injury

3. Yes - moderate injury (Describe in margin)

4. Yes - serious injury

8. Not applicable (single veh., driver only)

9. Don't know / no answer

G. Were they wearing a seat belt?

1. No

2. Yes

8. Not applicable

9. Don't know / no answer

$H$. Did this accident have any effect on your use of seat belts? (Probe if necessary)

1. No - no change

2. Yes - belt use increased

3. Yes - belt use decreased

9. Don't know / no answer

I. Why? (or Why not?)

1. Seat belts helped (would have helped)

2. Seat belts did not help (would not have helped)

8. Other (write in)

9. Don't know / no answer

( $8=8$ or more; $9=$ don $t$ know / no answer)

(If more than 1)

(80) Let's talk a minute about your MOST SERIOUS accident

1

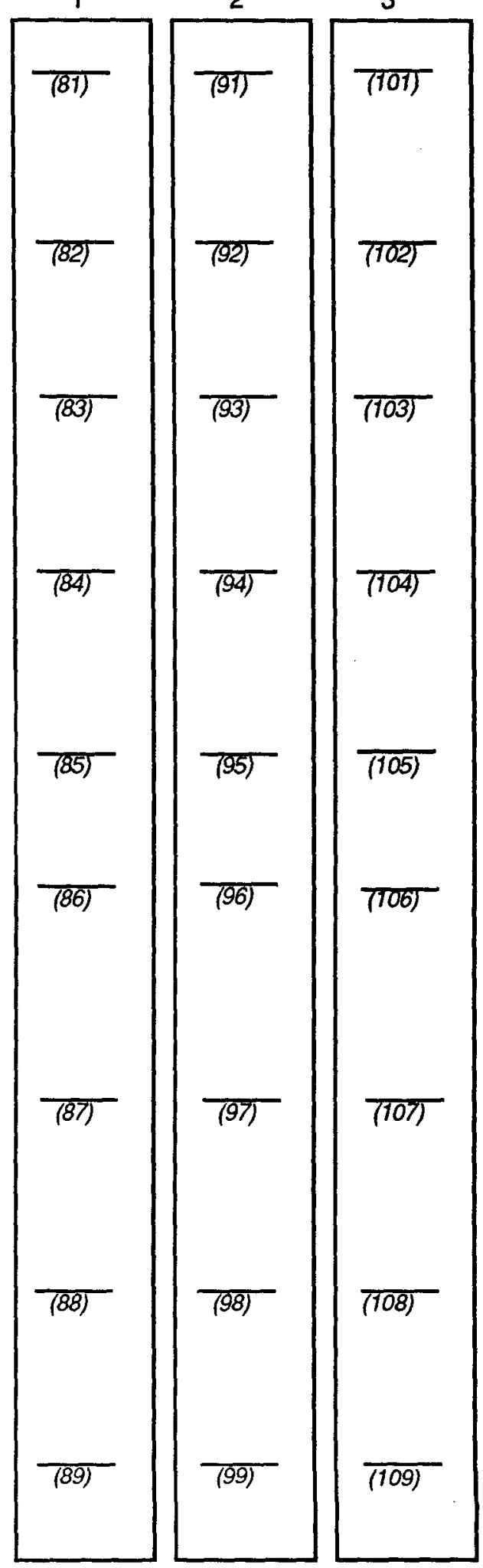




\section{Perceptions of Enforcement}

INTRODUCTION: Now for the next few questions we are trying to learn about the level of seat belt enforcement in North Carolina. I want to ask you about any contacts you may have had with the police or the State Highway Patrol. (If needed, add statement below.)

Again, let me assure you that your answers are confidential and will be used only to determine the level of enforcement of the seat belt law in NC and its effect on belt use.

17. Since the belt law went into effect in October 1985, have you been stopped by a law enforcement officer for any reason? (Prompt: Any license checks, anything?)

1. No

2. Yes

17a. How many times?

( $8=8$ or more; $9=$ don't know / no answer)

9. Don't remember / No answer

(111)

(Answer questions below for the 3 most recent occasions stopped -

1 is most recent, 2 next most recent, etc.)

A. Were you stopped just for a seat belt

check or was it for something else?

1. Seat belt check

2. License check

3. Other (Write in violation if given)

9. Don't know / no answer

B. When were you stopped? Was it (Read 1 and 2 below)

1. Before January, 1987 (during the warning period)

2. Since January of this year (since the fine went into effect)

9. Don't know / no answer

C. Were you wearing your seat belt at the time?

1. No

2. Yes (Code 2 to $D$ below)

3. Buckled up before being seen

4. Other (describe)

9. Don't know / no answer

D. What happened? Did the officer say or do anything about seat belt use?

1. Nothing

2. Nothing - already wearing belt

3. Verbal warning or reminder

4. Written warning about belt use

5. Ticketed and fined for nonuse of belt

6. Other

9. Don't know / no answer

E. Did this experience have any impact on your use of seat belts? (Probe as necessary)

1. No - no change

2. Yes - belt use increased

3. Yes - belt use decreased

9. Don't know / no answer

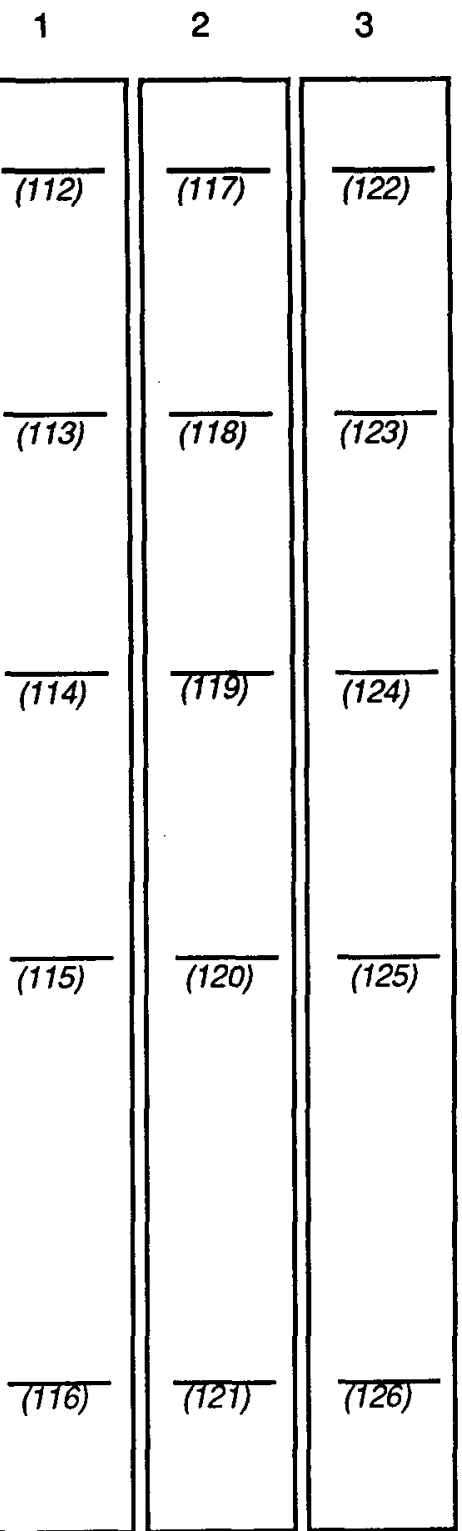


18. Do you personally know anyone (else) who has been stopped and checked for seat belt use?

1. No

2. Yes

9. Don't know / no answer

18a. How many times altogether have they been stopped?

18b. What happened? (in regards to belts)
(Answer for the 3 most recent times - 1 is most recent)
$\begin{array}{llll}\text { (128) } & \text { (2) } & \text { (3) } & \begin{array}{l}\text { 1. Nothing } \\ \text { 2. Verbal warning or reminder }\end{array} \\ \text { 3. Written warning about belt use } \\ \text { 4. Ticketed and fined for nonuse of belt }\end{array}$
$\begin{array}{llll}\text { (129) } & \text { (130) Other } & \text { (131) } & \text { 9. Don't know/ no answer }\end{array}$

19. How strongly do you think the seat belt law is being enforced in your community?

Would you say
1. Very strongly
2. Somewhat strongly
3. Not very strongly
4. Not at all
9. Don't know / no answer

20. Have you noticed whether or not the police officers or sheriffs in (your community) wear seat belts? (Note: Want for local law enforcement agencies - not NC Highway Patrol.)

1. They do not

2. Some do, some do not

3. They always or almost always do

4. Haven't noticed / Don't know

9. No answer

21. (Other than the time you were stopped -...)

Has a police officer or other law enforcement officer in your community ever said or done anything to personally encourage you to buckle up?

(134) 1. No

2. Yes $\longrightarrow$ What was it?

1. Talk at a meeting, etc.

2. "Salute"

3. Other

22. (If "seat belt salute" hasn't already been mentioned)

What about a "seat belt salute," where an officer pulls up beside you in his patrol car and gives a tug on his belt to remind you to buckle up? Has this ever happened to you?

1. No

2. Yes

3. Not applicable (seat belt salute already mentioned)

9. Don't know / no answer

23. Do you think this would be a good way to get more people to wear seat belts?

1. No

2. Yes

9. Don't know / no answer 


\section{Risk and Demographic Questions}

INTRODUCTION - Now we would like to finish by asking you just a few questions about your lifestyle, because we're interested in knowing if these things are related to whether people do or do not wear seat belts. You'll just need to answer "yes" or "no", OK?

24. Do you have an exercise program that you follow regularly?

1. Yes

2. Maybe (not a definite yes)

3. No

9. No answer

24a. Have you been doing this for more than 6 months?

1. Yes

2. No

9. Don't know / no answer

25. Do you smoke cigarettes?

1. Yes

2. No

9. Don't know / no answer

25a. Do you smoke more than a pack a day?
1. Yes
2. No
9. Don't know / no answer

26. How often do you drink beer, wine, or liquor? Would you say (Read categories and clarify as necessary.)

1. Never

2. Less than once a month

3. Once or twice a month

(142)

4. Once or twice a week

5. Several times a week

6. Every day

9. Don't know / no answer

26a. How often in the last year would you say you have driven within one hour of drinking beer, wine or liquor?

$$
\overline{(143-145)} \text { times } \quad \begin{aligned}
& \text { (Code actual number of times, 001-998. } \\
& 999=\text { don't know } / \text { no answer.) }
\end{aligned}
$$

26b. Some people occasionally drive after they have had too much to drink. Remembering that this survey is strictly confidential, l'd like to ask: In the past month, how many times have you driven after you've perhaps had too much to drink?

$$
\begin{array}{ll}
\overline{(146-148)} & \text { (Code actual number of times, } 001-998 . \\
999=d o n ' t ~ k n o w / \text { no answer.) }
\end{array}
$$

27. And the last question, when driving on the highway, do you usually drive:

(Read responses)

1. At the speed limit

2. 5 to 10 miles below the speed limit

(149) 3. 5 to 10 miles above the speed limit

4. More than 10 miles per hour above the speed limit

9. Don't know / no answer

CLOSING REMARKS: That's all the questions. Thank you very much for your help. Good luck in the drawings. 
APPENDIX C

Mailback Survey - Supplementary Tables 


\section{Table C.1. Unweighted summary results of mailback survey.}

1. A N.C. law that began Oct. 1985 requires drivers and front seat passengers of motor vehicles to wear seat belts. What is your opinion of this law?

$21.9 \%$ strongly oppose

$11.8 \%$ moderately oppose

$3.9 \%$ not sure

$20.8 \%$ moderately support

$41.6 \%$ strongly support

2. Beforethe law went into effect Oct. 1985, how often did you wear your seat belt when driving?

$25.8 \%$ never

$18.6 \%$ rarely

$22.3 \%$ sometimes

$17.9 \%$ most of the time

$15.4 \%$ always

3. Between Oct. 1985 and Jan. 1987, there was no fine for not wearing a seat belt. During this "grace" period how often did you wear your seat belt when driving?
$15.1 \%$ never
$12.6 \%$ rarely
$17.6 \%$ sometimes
$25.6 \%$ most of the time
$29.1 \%$ always

4. Since Jan. 1987 drivers not wearing seat belts may be fined $\$ 25$. How often do you wear a seat belt now when driving?

$$
\begin{aligned}
& \mathbf{5 . 3} \% \text { never } \\
& \mathbf{8 . 0} \% \text { rarely } \\
& \mathbf{9 . 4} \% \text { sometimes } \\
& \mathbf{2 1 . 5} \% \text { most of the time } \\
& \mathbf{5 5 . 8} \% \text { always }
\end{aligned}
$$

5. What is your opinion of the $\$ 25$ fine?

$38.0 \%$ There should not be a fine

$9.2 \%$ There should be a lower fine $\rightarrow \$$

$5.8 \%$ There should be a higher fine $\rightarrow \$$

$47.0 \%$ The $\$ 25$ fine is about right

6. Were you wearing your seat belt at the time this survey was given to you?

$29.3 \%$ no $69.7 \%$ yes $1.0 \%$ no belts in vehicle

7. How many total miles was the trip you were making at the time this survey was given to you?

$20.0 \%$ Less than 5 miles

$20.5 \% 5-9$ miles

$26.5 \% 10-19$ miles

$18.3 \% 20-49$ miles

$14.7 \% 50$ miles or more

8. For those times that you do wear a seat belt, please check the one most important reason.

$17.0 \%$ To avoid the $\$ 25$ fine.

$20.4 \%$ Because it's the law.

$36.0 \%$ To prevent injury if in an accident.

$3.3 \%$ Because my friends/family want me to.

$12.8 \%$ It's a habit; I don't think about it.

4.1\% Because of my own experience in an accident.

$2.3 \%$ Because of someone else's experience in an accident.

$4.2 \%$ Check here if you never wear a seat belt.
9. For those times that you do notwear a seat belt, please check the onemost important reason.

2.3\% Seat belts don't prevent injuries.

$1.7 \%$ Seat belts are likely to cause injuries.

$14.2 \%$ Seat belts are uncomfortable; they don't let me move around.

$10.0 \%$ I'm afraid of being trapped in my car if it catches on fire or goes under water.

$3.6 \%$ I only wear seat belts on long trips/in bad weather.

$0.6 \%$ I'm a careful driver; I don't need to wear seat belts.

$\mathbf{2 0 . 7 \%}$ I forget; I' $m$ not in the habit.

$46.9 \%$ Check here if you always wear a seat belt.

10. About how many total miles do you drive or ride each year?
$7.8 \%$ Less than $5,000 \mathrm{mi}$

$15.8 \% \quad 5,000-9,999 \mathrm{mi}$.

$25.4 \% \quad 10,000-14,999 \mathrm{mi}$.

$19.4 \% \quad 15,000-19,999 \mathrm{mi}$.
$15.9 \% 20,000-29,999 \mathrm{mi}$. $8.6 \% 30,000-39,999 \mathrm{mi}$. $2.8 \% 40,000-49,999 \mathrm{mi}$. $4.3 \% 50,000$ or more mi.
11. Out of 100 N.C. drivers, how many do you think are likely to be in an accident in the next 2 years?

$$
\bar{X}=\mathbf{3 2 . 6} \text { drivers }
$$

12. On a scale from 0 to 100 , please tell us how likely you think youare to be in an accident in the next two years. (0 means that you certainly will not be in an accident and 100 that you certainly will.)

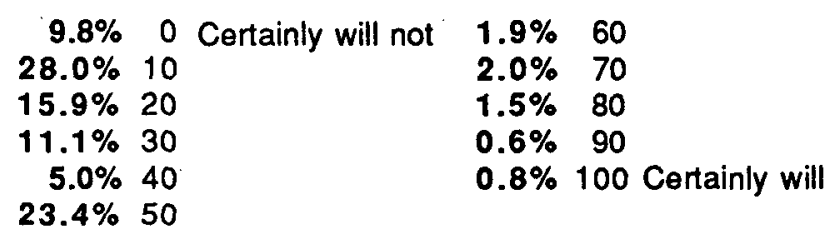

13. How much control do you feel you have in preventing an accident?

$10.8 \%$ Almost total control

$39.2 \%$ A lot of control

$41.1 \%$ Moderate control

$5.5 \%$ A little control

$3.3 \%$ Very little control

14. If you could vote today, would you vote to keep the N.C. seat belt law?
$54.2 \%$ yes
$35.2 \%$ no
$10.6 \%$ not sure

15. What is your highest level of education?
$3.0 \%$ grade school $10.2 \%$ attended H.S. $32.9 \%$ graduated H.S.

16. Your marital status?

$68.3 \%$ married

$11.2 \%$ separated/divorced

$26.2 \%$ attended college

$20.0 \%$ graduated college

$7.8 \%$ post college degree

$3.9 \%$ widowed $16.6 \%$ never married
17. Your date of birth?

$\overline{\text { month }} \overline{\text { day }}$


Table C.2. Opinion of the law by observed and current self-reported belt use.

\begin{tabular}{|c|c|c|c|c|c|c|}
\hline \multirow[b]{2}{*}{ Opinion of the Law } & \multicolumn{2}{|c|}{ Observed Use } & \multicolumn{3}{|c|}{ Self-Reported Use } & \multirow[b]{2}{*}{ Overal1 } \\
\hline & Unbelted & Belted & $\begin{array}{l}\text { Never, } \\
\text { Rarely }\end{array}$ & $\begin{array}{l}\text { Sometimes, } \\
\text { Most } 1 \mathrm{y}\end{array}$ & Always & \\
\hline Strongly oppose & $\begin{array}{c}667 \\
(38.7)^{1}\end{array}$ & $\begin{array}{c}310 \\
(11.3)\end{array}$ & $\begin{array}{c}418 \\
(71.0)\end{array}$ & $\begin{array}{c}370 \\
(27.0)\end{array}$ & $\begin{array}{c}188 \\
(7.6)\end{array}$ & $\begin{array}{c}976 \\
(21.9)\end{array}$ \\
\hline Moderately oppose & $\begin{array}{c}295 \\
(17.1)\end{array}$ & $\begin{array}{l}230 \\
(8.4)\end{array}$ & $\begin{array}{c}113 \\
(19.2)\end{array}$ & $\begin{array}{c}263 \\
(19.2)\end{array}$ & $\begin{array}{l}148 \\
(6.0)\end{array}$ & $\begin{array}{c}524 \\
(11.8)\end{array}$ \\
\hline Not sure & $\begin{array}{c}86 \\
(5.0)\end{array}$ & $\begin{array}{c}90 \\
(3.3)\end{array}$ & $\begin{array}{c}24 \\
(4.1)\end{array}$ & $\begin{array}{c}77 \\
(5.6)\end{array}$ & $\begin{array}{c}74 \\
(3.0)\end{array}$ & $\begin{array}{l}175 \\
(3.9)\end{array}$ \\
\hline Moderately support & $\begin{array}{c}353 \\
(20.5)\end{array}$ & $\begin{array}{c}577 \\
(21.1)\end{array}$ & $\begin{array}{c}28 \\
(4.8)\end{array}$ & $\begin{array}{c}431 \\
(31.4)\end{array}$ & $\begin{array}{c}466 \\
(18.7)\end{array}$ & $\begin{array}{c}925 \\
(20.8)\end{array}$ \\
\hline Strongly support & $\begin{array}{r}323 \\
(18.7) \\
\end{array}$ & $\begin{array}{r}1531 \\
(55.9) \\
\end{array}$ & $\begin{array}{c}6 \\
(1.0) \\
\end{array}$ & $\begin{array}{r}232 \\
(16.9) \\
\end{array}$ & $\begin{array}{r}1610 \\
(64.8) \\
\end{array}$ & $\begin{array}{r}1848 \\
(41.6) \\
\end{array}$ \\
\hline Total & $\begin{array}{c}1724 \\
(38.6)^{2}\end{array}$ & $\begin{array}{c}2738 \\
(61.4)\end{array}$ & $\begin{array}{c}589 \\
(13.2)\end{array}$ & $\begin{array}{c}1373 \\
(30.9)\end{array}$ & $\begin{array}{c}2486 \\
(55.9)\end{array}$ & 4448 \\
\hline $\begin{array}{l}{ }^{1} \text { Column percentage. } \\
{ }^{2} \text { Row percentage. }\end{array}$ & $x_{4}^{2} \mathrm{df}=790.0$ & $p=.000$ & $x_{8}^{2}$ & $\mathrm{df}=1981.4$ & $\mathrm{p}=.0$ & \\
\hline
\end{tabular}

Table C.3. Belt use before the law by observed and self-reported belt use.

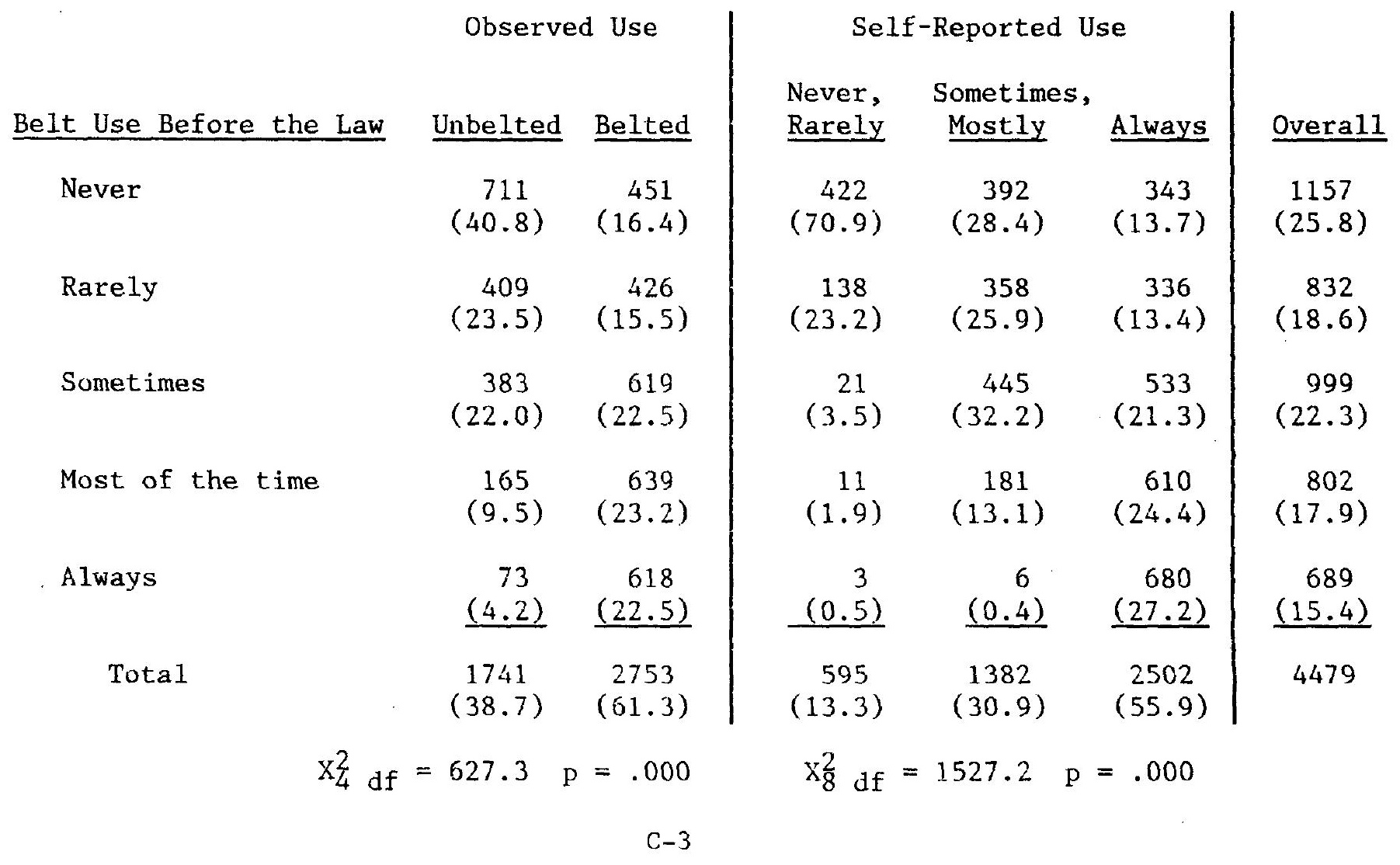


Table C.4. Belt use during the grace period by observed and self-reported belt use.

\begin{tabular}{|c|c|c|c|c|c|c|}
\hline \multirow[b]{2}{*}{$\begin{array}{l}\text { Belt Use } \\
\text { During Grace Period }\end{array}$} & \multicolumn{2}{|c|}{ Observed Use } & \multicolumn{3}{|c|}{ Self-Reported Use } & \multirow[b]{2}{*}{ Overa 11} \\
\hline & Unbelted & Belted & $\begin{array}{l}\text { Never, } \\
\text { Rarely } \\
\end{array}$ & $\begin{array}{l}\text { Sometimes, } \\
\text { Mostly }\end{array}$ & Always & \\
\hline Never & $\begin{array}{c}500 \\
(28.8)\end{array}$ & $\begin{array}{c}176 \\
(6.4)\end{array}$ & $\begin{array}{c}369 \\
(62.2)\end{array}$ & $\begin{array}{c}195 \\
(14.1)\end{array}$ & $\begin{array}{c}110 \\
(4.4)\end{array}$ & $\begin{array}{c}674 \\
(15.0)\end{array}$ \\
\hline Rarely & $\begin{array}{c}389 \\
(22.4)\end{array}$ & $\begin{array}{c}178 \\
(6.5)\end{array}$ & $\begin{array}{c}190 \\
(32.0)\end{array}$ & $\begin{array}{c}279 \\
(20.2)\end{array}$ & $\begin{array}{c}95 \\
(3.8)\end{array}$ & $\begin{array}{c}564 \\
(12.6)\end{array}$ \\
\hline Sometimes & $\begin{array}{c}397 \\
(22.9)\end{array}$ & $\begin{array}{c}394 \\
(14.3)\end{array}$ & $\begin{array}{c}21 \\
(3.5)\end{array}$ & $\begin{array}{c}516 \\
(37.3)\end{array}$ & $\begin{array}{c}252 \\
(10.1)\end{array}$ & $\begin{array}{c}789 \\
(17.6)\end{array}$ \\
\hline Most of the time & $\begin{array}{c}320 \\
(18.4)\end{array}$ & $\begin{array}{c}830 \\
(30.1)\end{array}$ & $\begin{array}{c}10 \\
(1.7)\end{array}$ & $\begin{array}{c}383 \\
(27.7)\end{array}$ & $\begin{array}{c}754 \\
(30.1)\end{array}$ & $\begin{array}{l}1147 \\
(25.6)\end{array}$ \\
\hline Always & $\begin{array}{r}131 \\
(7.5) \\
\end{array}$ & $\begin{array}{l}1178 \\
(42.7) \\
\end{array}$ & $\begin{array}{c}3 \\
(0.5) \\
\end{array}$ & $\begin{array}{c}9 \\
(0.7) \\
\end{array}$ & $\begin{array}{r}1295 \\
(51.7) \\
\end{array}$ & $\begin{array}{r}1307 \\
(29.2) \\
\end{array}$ \\
\hline Total & $\begin{array}{c}1737 \\
(38.7)\end{array}$ & $\begin{array}{c}2756 \\
(61.3)\end{array}$ & $\begin{array}{c}593 \\
(13.2)\end{array}$ & $\begin{array}{c}1382 \\
(30.8)\end{array}$ & $\begin{array}{c}2506 \\
(55.9)\end{array}$ & 4481 \\
\hline & 1124.2 & $=.000$ & $x_{8}^{2} d f$ & 3058.9 & $=.000$ & \\
\hline
\end{tabular}

Table C.5. Opinion of the $\$ 25$ fine by observed and self-reported belt use.

\begin{tabular}{|c|c|c|c|c|c|c|}
\hline \multirow[b]{2}{*}{ Opinion of the $\$ 25$ Fine } & \multicolumn{2}{|c|}{ Observed Use } & \multicolumn{3}{|c|}{ Self-Reported Use } & \multirow[b]{2}{*}{ Overal1 } \\
\hline & Unbelted & Belted & $\begin{array}{l}\text { Never, } \\
\text { Rarely }\end{array}$ & $\begin{array}{l}\text { Sometim } \\
\text { Most 1y }\end{array}$ & Always & \\
\hline Should not be a fine & $\begin{array}{c}1045 \\
(60.7)\end{array}$ & $\begin{array}{c}635 \\
(23.5)\end{array}$ & $\begin{array}{c}540 \\
(91.2)\end{array}$ & $\begin{array}{c}715 \\
(52.3)\end{array}$ & $\begin{array}{c}422 \\
(17.2)\end{array}$ & $\begin{array}{c}1677 \\
(38.0)\end{array}$ \\
\hline Should be a lower fine & $\begin{array}{c}154 \\
(8.9)\end{array}$ & $\begin{array}{c}255 \\
(9.4)\end{array}$ & $\begin{array}{c}24 \\
(4.1)\end{array}$ & $\begin{array}{c}175 \\
(12.8)\end{array}$ & $\begin{array}{c}208 \\
(8.5)\end{array}$ & $\begin{array}{c}407 \\
(9.2)\end{array}$ \\
\hline Should be a higher fine & $\begin{array}{c}34 \\
(2.0)\end{array}$ & $\begin{array}{c}222 \\
(8.2)\end{array}$ & $\left(\begin{array}{c}1 \\
0.2)\end{array}\right.$ & $\begin{array}{c}15 \\
(1.1)\end{array}$ & $\begin{array}{c}238 \\
(9.7)\end{array}$ & $\begin{array}{c}254 \\
(5.8)\end{array}$ \\
\hline$\$ 25$ fine about right & $\begin{array}{r}490 \\
(28.4) \\
\end{array}$ & $\begin{array}{r}1590 \\
(58.9) \\
\end{array}$ & $\begin{array}{r}27 \\
(4.6) \\
\end{array}$ & $\begin{array}{r}461 \\
(33.8) \\
\end{array}$ & $\begin{array}{r}1587 \\
(64.6) \\
\end{array}$ & $\begin{array}{r}2075 \\
(47.0) \\
\end{array}$ \\
\hline Total & $\begin{array}{c}1723 \\
(38.9)\end{array}$ & $\begin{array}{c}2702 \\
(61.1)\end{array}$ & $\begin{array}{c}592 \\
(13.4)\end{array}$ & $\begin{array}{c}1366 \\
(31.0)\end{array}$ & $\begin{array}{c}2455 \\
(55.6)\end{array}$ & 4413 \\
\hline
\end{tabular}


Table C.6. Amount of fine by observed and self-reported belt use.

\begin{tabular}{|c|c|c|c|c|c|c|}
\hline \multirow{2}{*}{ Amount of Fine } & \multicolumn{2}{|c|}{ Observed Use } & \multicolumn{3}{|c|}{ Self-Reported Use } & \multirow[b]{2}{*}{ Overa11 } \\
\hline & Unbelted & Belted & $\begin{array}{l}\text { Never, } \\
\text { Rarely }\end{array}$ & $\begin{array}{l}\text { Sometimes, } \\
\text { Mostly }\end{array}$ & Always & \\
\hline $\begin{array}{l}\text { Fine should be less } \\
\text { than } \$ 25\end{array}$ & $\begin{array}{c}110 \\
(90.2)\end{array}$ & $\begin{array}{c}173 \\
(60.7)\end{array}$ & $\begin{array}{c}17 \\
(100.0)\end{array}$ & $\begin{array}{c}117 \\
(97.5)\end{array}$ & $\begin{array}{c}147 \\
(55.1)\end{array}$ & $\begin{array}{c}281 \\
(69.6)\end{array}$ \\
\hline $\begin{array}{l}\text { Fine should be equal } \\
\text { or greater than } \$ 25\end{array}$ & $\begin{array}{r}12 \\
(9.8) \\
\end{array}$ & $\begin{array}{r}112 \\
(39.3) \\
\end{array}$ & $\begin{array}{c}0 \\
(0.0) \\
\end{array}$ & $\begin{array}{c}3 \\
(2.5) \\
\end{array}$ & $\begin{array}{r}120 \\
(44.9) \\
\end{array}$ & $\begin{array}{r}123 \\
(30.5) \\
\end{array}$ \\
\hline Total & $\begin{array}{c}122 \\
(30.0)\end{array}$ & $\begin{array}{c}285 \\
(70.0)\end{array}$ & $\begin{array}{c}17 \\
(4.2)\end{array}$ & $\begin{array}{c}120 \\
(29.7)\end{array}$ & $\begin{array}{c}167 \\
(66.1)\end{array}$ & 404 \\
\hline & $=35.0$ & $=.000$ & $x_{2}^{2} d f$ & $=78.2$ & .000 & \\
\hline
\end{tabular}

Table C.7. Wearing seat belt at time of survey by observed and self-reported belt use.

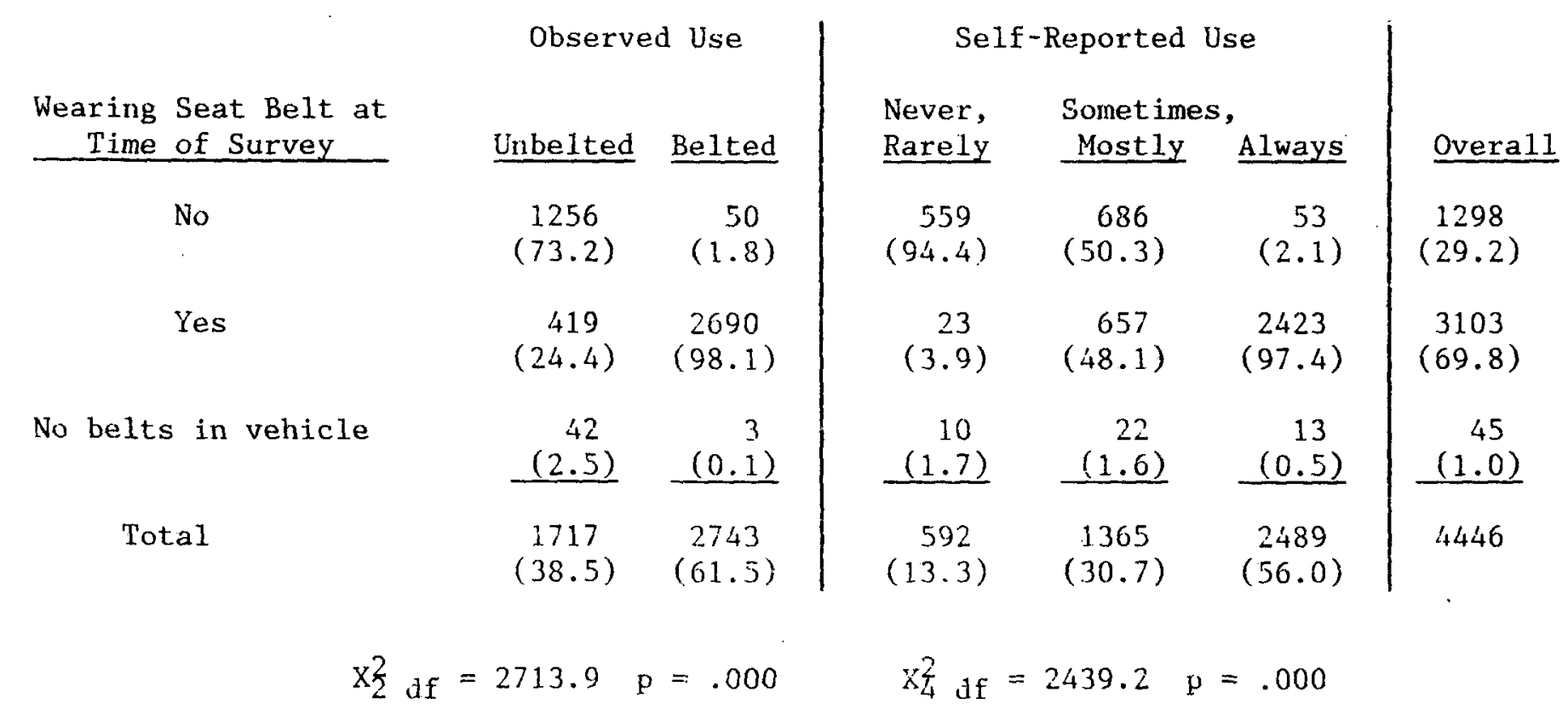


Table C.8. Length of trip by observed and self-reported belt use.

\begin{tabular}{|c|c|c|c|c|c|c|}
\hline \multirow[b]{2}{*}{ Length of Trip } & \multicolumn{2}{|c|}{ Observed Use } & \multicolumn{3}{|c|}{ Self-Reported Use } & \multirow[b]{2}{*}{ Overall } \\
\hline & Unbelted & Belted & $\begin{array}{l}\text { Never, } \\
\text { Rarely }\end{array}$ & $\begin{array}{l}\text { Sometimes, } \\
\text { Mostly }\end{array}$ & Always & \\
\hline Less than 5 miles & $\begin{array}{c}484 \\
(27.9)\end{array}$ & $\begin{array}{c}415 \\
(15.1)\end{array}$ & $\begin{array}{c}111 \\
(18.7)\end{array}$ & $\begin{array}{c}364 \\
(26.3)\end{array}$ & $\begin{array}{c}416 \\
(16.7)\end{array}$ & $\begin{array}{c}891 \\
(19.9)\end{array}$ \\
\hline $5-9$ miles & $\begin{array}{c}340 \\
(19.6)\end{array}$ & $\begin{array}{c}581 \\
(21.1)\end{array}$ & $\begin{array}{c}107 \\
(18.0)\end{array}$ & $\begin{array}{c}274 \\
(19.8)\end{array}$ & $\begin{array}{c}537 \\
(21.5)\end{array}$ & $\begin{array}{c}918 \\
(20.5)\end{array}$ \\
\hline 10-19 miles & $\begin{array}{c}409 \\
(23.6)\end{array}$ & $\begin{array}{c}779 \\
(28.3)\end{array}$ & $\begin{array}{c}144 \\
(24.3)\end{array}$ & $\begin{array}{c}334 \\
(24.2)\end{array}$ & $\begin{array}{c}707 \\
(28.3)\end{array}$ & $\begin{array}{c}1185 \\
(26.5)\end{array}$ \\
\hline $20-49$ miles & $\begin{array}{c}279 \\
(16.1)\end{array}$ & $\begin{array}{c}544 \\
(19.8)\end{array}$ & $\begin{array}{c}118 \\
(19.9)\end{array}$ & $\begin{array}{c}241 \\
(17.4)\end{array}$ & $\begin{array}{c}463 \\
(18.5)\end{array}$ & $\begin{array}{c}822 \\
(18.4)\end{array}$ \\
\hline 50 miles or more & $\begin{array}{r}224 \\
(12.9) \\
\end{array}$ & $\begin{array}{r}435 \\
(15.8) \\
\end{array}$ & $\begin{array}{r}113 \\
(19.1) \\
\end{array}$ & $\begin{array}{r}170 \\
(12.3) \\
\end{array}$ & $\begin{array}{r}376 \\
(15.1) \\
\end{array}$ & $\begin{array}{r}659 \\
(14.7) \\
\end{array}$ \\
\hline Total & $\begin{array}{c}1736 \\
(38.7)\end{array}$ & $\begin{array}{c}2754 \\
(61.3)\end{array}$ & $\begin{array}{c}593 \\
(13.3)\end{array}$ & $\begin{array}{c}1383 \\
(30.9)\end{array}$ & $\begin{array}{c}2499 \\
(55.8)\end{array}$ & 4475 \\
\hline
\end{tabular}


Table C.9. Most important reason for wearing a belt by observed and self-reported belt use.

\begin{tabular}{|c|c|c|c|c|c|c|}
\hline & & & & & & \\
\hline $\begin{array}{l}\text { Most Important Reason } \\
\text { for Belt Wearing } \\
\end{array}$ & Unbelted & Belted & $\begin{array}{l}\text { Never, } \\
\text { Rarely }\end{array}$ & $\begin{array}{l}\text { Sometimes, } \\
\text { Mostly }\end{array}$ & Always & Overa11 \\
\hline To avoid the $\$ 25$ fine & $\begin{array}{c}456 \\
(27.4)\end{array}$ & $\begin{array}{c}264 \\
(10.3)\end{array}$ & $\begin{array}{c}230 \\
(39.7)\end{array}$ & $\begin{array}{c}333 \\
(25.3)\end{array}$ & $\begin{array}{l}153 \\
(6.6)\end{array}$ & $\begin{array}{c}716 \\
(17.0)\end{array}$ \\
\hline Because it's the law & $\begin{array}{c}323 \\
(19.4)\end{array}$ & $\begin{array}{c}540 \\
(21.0)\end{array}$ & $\begin{array}{c}51 \\
(8.8)\end{array}$ & $\begin{array}{c}372 \\
(28.3)\end{array}$ & $\begin{array}{c}438 \\
(18.8)\end{array}$ & $\begin{array}{c}861 \\
(20.4)\end{array}$ \\
\hline To prevent injury & $\begin{array}{c}460 \\
(27.7)\end{array}$ & $\begin{array}{l}1065 \\
(41.4)\end{array}$ & $\begin{array}{c}49 \\
(8.5)\end{array}$ & $\begin{array}{c}440 \\
(33.5)\end{array}$ & $\begin{array}{c}1031 \\
(44.3)\end{array}$ & $\begin{array}{c}1520 \\
(36.0)\end{array}$ \\
\hline $\begin{array}{l}\text { Friends/family want } \\
\text { me to }\end{array}$ & $\begin{array}{c}111 \\
(6.7)\end{array}$ & $\begin{array}{c}29 \\
(1.1)\end{array}$ & $\begin{array}{c}66 \\
(11.4)\end{array}$ & $\begin{array}{c}53 \\
(4.0)\end{array}$ & $\begin{array}{c}19 \\
(0.8)\end{array}$ & $\begin{array}{c}138 \\
(3.3)\end{array}$ \\
\hline $\begin{array}{l}\text { Habit/don't think } \\
\text { about it }\end{array}$ & $\begin{array}{c}68 \\
(4.1)\end{array}$ & $\begin{array}{c}475 \\
(18.5)\end{array}$ & $\left(\begin{array}{c}3 \\
(0.5)\end{array}\right.$ & $\begin{array}{c}50 \\
(3.8)\end{array}$ & $\begin{array}{c}488 \\
(21.0)\end{array}$ & $\begin{array}{c}541 \\
(12.8)\end{array}$ \\
\hline $\begin{array}{l}\text { My own experience in } \\
\text { an accident }\end{array}$ & $\begin{array}{c}42 \\
(2.5)\end{array}$ & $\begin{array}{c}131 \\
(5.1)\end{array}$ & $\begin{array}{c}3 \\
(0.5)\end{array}$ & $\begin{array}{c}38 \\
(2.9)\end{array}$ & $\begin{array}{c}132 \\
(5.7)\end{array}$ & $\begin{array}{l}173 \\
(4.1)\end{array}$ \\
\hline $\begin{array}{l}\text { Someone else's exper- } \\
\text { ience in an accident }\end{array}$ & $(2.0)$ & $\begin{array}{c}64 \\
(2.5)\end{array}$ & $\left(\begin{array}{c}5 \\
(0.9)\end{array}\right.$ & $\begin{array}{c}26 \\
(2.0)\end{array}$ & $\begin{array}{c}66 \\
(2.8)\end{array}$ & $\begin{array}{c}97 \\
(2.3)\end{array}$ \\
\hline Never wear a belt & $\begin{array}{c}169 \\
(10.2) \\
\end{array}$ & $\begin{array}{r}7 \\
(0.3) \\
\end{array}$ & $\begin{array}{r}173 \\
(29.8) \\
\end{array}$ & $\begin{array}{r}3 \\
(0.2) \\
\end{array}$ & $\begin{array}{c}0 \\
(0.0) \\
\end{array}$ & $\begin{array}{r}176 \\
(4.2) \\
\end{array}$ \\
\hline Total & $\begin{array}{c}1662 \\
(39.2)\end{array}$ & $\begin{array}{c}2575 \\
(60.8)\end{array}$ & $\begin{array}{c}580 \\
(13.7)\end{array}$ & $\begin{array}{c}1315 \\
(31.2)\end{array}$ & $\begin{array}{c}2327 \\
(55.1)\end{array}$ & 4222 \\
\hline
\end{tabular}


Table C.10. Most important reason for not wearing a belt by observed and self-reported belt use.

Most Important Reason

For Not Wearing a Belt

\section{Belts don't prevent}

injuries

Belts likely to cause injuries

Belts uncomfortable/don't let me move around

Afraid of being trapped

On1y wear belts on long

trips or in bad weather

Careful driver/don't

need belts

Forget/not in habit

Always wear a seat belt

Total
Observed Use

\section{Unbelted Belted}

$68 \quad 27$

$(4.4)$

$(1.0)$

$\begin{array}{cc}48 & 22 \\ (3.1) & (0.8)\end{array}$

314

(20.4)

276

$(10.6)$

$275 \quad 138$

(17.9)

(5.3)

121

(7.9)

30

(1.2)

$16 \quad 7$

(1.0)

$(0.3)$

487

373

(31.7)

(14.3)

209

(5.0)

1737

(69.6)

1538

2610

(37.1)

(62.9)

$$
x^{2} d f=1148.1 \quad p=.000
$$

\begin{tabular}{|c|c|c|c|}
\hline \multicolumn{3}{|c|}{ Self-Reported Use } & \multirow[b]{2}{*}{ Overa 11} \\
\hline $\begin{array}{l}\text { Never, } \\
\text { Rarely }\end{array}$ & $\begin{array}{l}\text { Sometimes, } \\
\text { Mostly }\end{array}$ & Always & \\
\hline $\begin{array}{c}47 \\
(9.4)\end{array}$ & $\begin{array}{c}32 \\
(2.6)\end{array}$ & $\begin{array}{c}16 \\
(0.7)\end{array}$ & $\begin{array}{c}95 \\
(2.3)\end{array}$ \\
\hline $\begin{array}{c}30 \\
(6.0)\end{array}$ & $\begin{array}{c}27 \\
(2.2)\end{array}$ & $\begin{array}{c}13 \\
(0.5)\end{array}$ & $\begin{array}{c}70 \\
(1.7)\end{array}$ \\
\hline $\begin{array}{c}145 \\
(29.1)\end{array}$ & $\begin{array}{c}289 \\
(23.4)\end{array}$ & $\begin{array}{c}153 \\
(6.4)\end{array}$ & $\begin{array}{c}587 \\
(14.2)\end{array}$ \\
\hline $\begin{array}{c}141 \\
(28.3)\end{array}$ & $\begin{array}{c}153 \\
(12.4)\end{array}$ & $\begin{array}{l}118 \\
(4.9)\end{array}$ & $\begin{array}{c}412 \\
(10.0)\end{array}$ \\
\hline $\begin{array}{c}43 \\
(8.6)\end{array}$ & $\begin{array}{c}99 \\
(8.0)\end{array}$ & $\begin{array}{c}9 \\
(0.4)\end{array}$ & $\begin{array}{c}151 \\
(3.7)\end{array}$ \\
\hline $\begin{array}{c}16 \\
(3.2)\end{array}$ & $\begin{array}{c}4 \\
(0.3)\end{array}$ & $\begin{array}{c}3 \\
(0.1)\end{array}$ & $\begin{array}{c}23 \\
(0.6)\end{array}$ \\
\hline $\begin{array}{c}75 \\
(15.0)\end{array}$ & $\begin{array}{c}587 \\
(47.5)\end{array}$ & $\begin{array}{c}194 \\
(8.1)\end{array}$ & $\begin{array}{c}856 \\
(20.7)\end{array}$ \\
\hline $\begin{array}{r}2 \\
(0.4) \\
\end{array}$ & $\begin{array}{r}46 \\
(3.7) \\
\end{array}$ & $\begin{array}{r}1894 \\
(78.9) \\
\end{array}$ & $\begin{array}{r}1942 \\
(47.0) \\
\end{array}$ \\
\hline $\begin{array}{c}499 \\
(12.1)\end{array}$ & $\begin{array}{c}1237 \\
(29.9)\end{array}$ & $\begin{array}{c}2400 \\
(58.0)\end{array}$ & 4136 \\
\hline & & & \\
\hline$x_{14}^{2} \mathrm{df}$ & 2810.3 & $=.000$ & \\
\hline
\end{tabular}


Table C.11. Total annual miles by observed and self-reported belt use.

\begin{tabular}{|c|c|c|c|c|c|c|}
\hline \multirow[b]{2}{*}{ Total Annual Miles } & \multicolumn{2}{|c|}{ Observed Use } & \multicolumn{3}{|c|}{ Self-Reported Use } & \multirow[b]{2}{*}{ Overall } \\
\hline & Unbelted & Be1ted & $\begin{array}{l}\text { Never, } \\
\text { Rarely }\end{array}$ & $\begin{array}{l}\text { Sometimes, } \\
\text { Mostly }\end{array}$ & Always & \\
\hline Less than 10,000 & $\begin{array}{c}425 \\
(24.5)\end{array}$ & $\begin{array}{c}630 \\
(23.0)\end{array}$ & $\begin{array}{c}121 \\
(20.5)\end{array}$ & $\begin{array}{c}322 \\
(23.4)\end{array}$ & $\begin{array}{c}607 \\
(24.4)\end{array}$ & $\begin{array}{l}1050 \\
(23.6)\end{array}$ \\
\hline $10,000-19,999$ & $\begin{array}{c}741 \\
(42.8)\end{array}$ & $\begin{array}{c}1261 \\
(46.1)\end{array}$ & $\begin{array}{c}228 \\
(38.6)\end{array}$ & $\begin{array}{c}623 \\
(45.2)\end{array}$ & $\begin{array}{c}1143 \\
(46.0)\end{array}$ & $\begin{array}{c}1994 \\
(44.8)\end{array}$ \\
\hline $\begin{array}{l}\text { Equal to or greater } \\
\text { than } 20,000\end{array}$ & $\begin{array}{r}566 \\
(32.7) \\
\end{array}$ & $\begin{array}{r}847 \\
(30.9) \\
\end{array}$ & $\begin{array}{r}242 \\
(41.0) \\
\end{array}$ & $\begin{array}{r}432 \\
(31.4) \\
\end{array}$ & $\begin{array}{r}736 \\
(29.6) \\
\end{array}$ & $\begin{array}{r}1410 \\
(31.7) \\
\end{array}$ \\
\hline Total & $\begin{array}{c}1732 \\
(38.8)\end{array}$ & $\begin{array}{c}2738 \\
(61.3)\end{array}$ & $\begin{array}{c}591 \\
(13.3)\end{array}$ & $\begin{array}{c}1377 \\
(30.9)\end{array}$ & $\begin{array}{c}2486 \\
(55.8)\end{array}$ & 4454 \\
\hline
\end{tabular}

Table C.12. Number of accidents per 100 N.C. drivers over next two years by observed and self-reported belt use.

\begin{tabular}{|c|c|c|c|c|c|c|}
\hline \multirow[b]{2}{*}{$\begin{array}{l}\text { No. of Accidents Per } 100 \\
\text { N.C. Drivers Next } 2 \text { Years }\end{array}$} & \multicolumn{2}{|c|}{ Observed Use } & \multicolumn{3}{|c|}{ Self-Reported Use } & \multirow[b]{2}{*}{ Overa11 } \\
\hline & Unbelted & Belted & $\begin{array}{l}\text { Never, } \\
\text { Rarely } \\
\end{array}$ & $\begin{array}{l}\text { Sometime } \\
\text { Most1y } \\
\end{array}$ & Always & \\
\hline Less than 20 & $\begin{array}{c}507 \\
(32.7)\end{array}$ & $\begin{array}{c}762 \\
(30.6)\end{array}$ & $\begin{array}{c}182 \\
(34.9)\end{array}$ & $\begin{array}{c}416 \\
(33.3)\end{array}$ & $\begin{array}{c}660 \\
(29.2)\end{array}$ & $\begin{array}{c}1258 \\
(31.2)\end{array}$ \\
\hline $20-49$ & $\begin{array}{c}560 \\
(36.1)\end{array}$ & $\begin{array}{c}983 \\
(39.5)\end{array}$ & $\begin{array}{c}189 \\
(36.2)\end{array}$ & $\begin{array}{c}470 \\
(37.6)\end{array}$ & $\begin{array}{c}883 \\
(39.2)\end{array}$ & $\begin{array}{c}1542 \\
(38.3)\end{array}$ \\
\hline $50-100$ & $\begin{array}{r}486 \\
(31.3) \\
\end{array}$ & $\begin{array}{r}744 \\
(29.9) \\
\end{array}$ & $\begin{array}{c}151 \\
(28.9) \\
\end{array}$ & $\begin{array}{r}365 \\
(29.2) \\
\end{array}$ & $\begin{array}{r}712 \\
(31.6) \\
\end{array}$ & $\begin{array}{r}1228 \\
(30.5) \\
\end{array}$ \\
\hline Total & $\begin{array}{c}1553 \\
(38.4)\end{array}$ & $\begin{array}{l}2489 \\
(61.6)\end{array}$ & $\begin{array}{c}522 \\
(13.0)\end{array}$ & $\begin{array}{c}1251 \\
(31.1)\end{array}$ & $\begin{array}{l}2255 \\
(56.0)\end{array}$ & 4028 \\
\hline
\end{tabular}


Table C.13. How likely respondent to be in an accident next two years by observed and self-reported use.

How Likely

Respondent to be in Accident Next 2 Years

0,10

$20,30,40$

$50-100$

Total
Obs rved Use

Unbelted Belted

655

$(38.8)$

989

(37.3)

$496 \quad 890$

(29.4)

(33.6)

539

(31.9)

773

(29.2)

$1690 \quad 2652$

(38.9)

$(61.1)$

$X_{2}^{2} \mathrm{df}=8.9 \quad \mathrm{p}=.012$

$\mathrm{x}_{4}^{2} \mathrm{df}=11.0 \quad \mathrm{p}=.027$

Table C.14. Control in preventing an accident by observed and selfreported belt use.

\begin{tabular}{|c|c|c|c|c|c|c|}
\hline \multirow[b]{2}{*}{$\begin{array}{c}\text { Control in Preventing } \\
\text { An Accident } \\
\end{array}$} & \multicolumn{2}{|c|}{ Observed Use } & \multicolumn{3}{|c|}{ Self-Reported Use } & \multirow[b]{2}{*}{ Overall } \\
\hline & Unbelted & Belted & $\begin{array}{l}\text { Never, } \\
\text { Rarely }\end{array}$ & $\begin{array}{r}\text { Sometim } \\
\text { Most 1y } \\
\end{array}$ & Always & \\
\hline Almost total & $\begin{array}{c}208 \\
(12.0)\end{array}$ & $\begin{array}{c}274 \\
(10.0)\end{array}$ & $\begin{array}{c}87 \\
(14.8)\end{array}$ & $\begin{array}{l}126 \\
(9.2)\end{array}$ & $\begin{array}{c}268 \\
(10.8)\end{array}$ & $\begin{array}{c}481 \\
(10.8)\end{array}$ \\
\hline A lot & $\begin{array}{c}652 \\
(37.7)\end{array}$ & $\begin{array}{l}1098 \\
(40.2)\end{array}$ & $\begin{array}{c}242 \\
(41.1)\end{array}$ & $\begin{array}{c}518 \\
(37.7)\end{array}$ & $\begin{array}{c}984 \\
(39.7)\end{array}$ & $\begin{array}{c}1744 \\
(39.2)\end{array}$ \\
\hline Moderate & $\begin{array}{c}703 \\
(40.6)\end{array}$ & $\begin{array}{l}1133 \\
(41.5)\end{array}$ & $\begin{array}{c}214 \\
(36.3)\end{array}$ & $\begin{array}{c}591 \\
(43.0)\end{array}$ & $\begin{array}{c}1025 \\
(41.3)\end{array}$ & $\begin{array}{c}1830 \\
(41.2)\end{array}$ \\
\hline $\begin{array}{l}\text { Little or } \\
\text { very little }\end{array}$ & $\begin{array}{l}168 \\
(9.7) \\
\end{array}$ & $\begin{array}{r}226 \\
(8.3) \\
\end{array}$ & $\begin{array}{r}46 \\
(7.8) \\
\end{array}$ & $\begin{array}{c}141 \\
(10.3) \\
\end{array}$ & $\begin{array}{r}204 \\
(8.2) \\
\end{array}$ & $\begin{array}{r}391 \\
(8.8) \\
\end{array}$ \\
\hline Total & $\begin{array}{c}1731 \\
(38.8)\end{array}$ & $\begin{array}{c}2731 \\
(61.2)\end{array}$ & $\begin{array}{c}589 \\
(13.3)\end{array}$ & $\begin{array}{c}1376 \\
(31.0)\end{array}$ & $\begin{array}{c}2481 \\
(55.8)\end{array}$ & 4446 \\
\hline
\end{tabular}


Table C.15. Keep the N.C. seat belt law by observed and self-reported use.

\begin{tabular}{|c|c|c|c|c|c|c|}
\hline \multirow[b]{2}{*}{$\begin{array}{l}\text { Keep the N.C. } \\
\text { Seat Belt Law? }\end{array}$} & \multicolumn{2}{|c|}{ Observed Use } & \multicolumn{3}{|c|}{ Self-Reported Use } & \multirow[b]{2}{*}{ Overall } \\
\hline & Unbelted & Belted & $\begin{array}{l}\text { Never, } \\
\text { Rarely } \\
\end{array}$ & $\begin{array}{l}\text { Sometimes, } \\
\text { Mostly }\end{array}$ & Always & \\
\hline Yes & $\begin{array}{c}531 \\
(30.5)\end{array}$ & $\begin{array}{c}1896 \\
(69.2)\end{array}$ & $\begin{array}{c}21 \\
(3.5)\end{array}$ & $\begin{array}{c}488 \\
(35.4)\end{array}$ & $\begin{array}{c}1909 \\
(76.6)\end{array}$ & $\begin{array}{c}2418 \\
(54.2)\end{array}$ \\
\hline No & $\begin{array}{c}1004 \\
(57.7)\end{array}$ & $\begin{array}{c}571 \\
(20.9)\end{array}$ & $\begin{array}{c}540 \\
(90.9)\end{array}$ & $\begin{array}{c}681 \\
(49.4)\end{array}$ & $\begin{array}{c}351 \\
(14.1)\end{array}$ & $\begin{array}{c}1572 \\
(35.2)\end{array}$ \\
\hline Not Sure & $\begin{array}{r}204 \\
(11.7) \\
\end{array}$ & $\begin{array}{r}272 \\
(9.9) \\
\end{array}$ & $\begin{array}{r}33 \\
(5.6) \\
\end{array}$ & $\begin{array}{r}210 \\
(15.2) \\
\end{array}$ & $\begin{array}{r}231 \\
(9.3) \\
\end{array}$ & $\begin{array}{r}474 \\
(10.6) \\
\end{array}$ \\
\hline Total & $\begin{array}{c}1739 \\
(38.8)\end{array}$ & $\begin{array}{c}2739 \\
(61.2)\end{array}$ & $\begin{array}{c}594 \\
(13.3)\end{array}$ & $\begin{array}{c}1379 \\
(30.9)\end{array}$ & $\begin{array}{c}2491 \\
(55.8)\end{array}$ & 4464 \\
\hline & 708.5 & $=.000$ & $x_{4}^{2} \mathrm{df}$ & $=1566.7$ & $=.000$ & \\
\hline
\end{tabular}

Table C.16. Education by observed and self-reported belt use.

\begin{tabular}{|c|c|c|c|c|c|c|}
\hline \multirow[b]{2}{*}{ Education } & \multicolumn{2}{|c|}{ Observed Use } & \multicolumn{3}{|c|}{ Self-Reported Use } & \multirow[b]{2}{*}{ Overa11 } \\
\hline & Unbelted & Belted & $\begin{array}{l}\text { Never, } \\
\text { Rarely }\end{array}$ & $\begin{array}{l}\text { Sometim } \\
\text { Most1y } \\
\end{array}$ & Always & \\
\hline Grade school & $\begin{array}{c}267 \\
(15.4)\end{array}$ & $\begin{array}{c}322 \\
(1.1 .7)\end{array}$ & $\begin{array}{c}108 \\
(18.3)\end{array}$ & $\begin{array}{c}183 \\
(13.3)\end{array}$ & $\begin{array}{c}295 \\
(11.8)\end{array}$ & $\begin{array}{c}586 \\
(13.1)\end{array}$ \\
\hline High school & $\begin{array}{c}672 \\
(38.7)\end{array}$ & $\begin{array}{c}800 \\
(29.2)\end{array}$ & $\begin{array}{c}251 \\
(42.5)\end{array}$ & $\begin{array}{c}497 \\
(36.0)\end{array}$ & $\begin{array}{c}722 \\
(29.0)\end{array}$ & $\begin{array}{c}1470 \\
(32.9)\end{array}$ \\
\hline Some college & $\begin{array}{c}441 \\
(25.4)\end{array}$ & $\begin{array}{c}732 \\
(26.7)\end{array}$ & $\begin{array}{c}130 \\
(22.0)\end{array}$ & $\begin{array}{c}369 \\
(26.8)\end{array}$ & $\begin{array}{c}668 \\
(26.8)\end{array}$ & $\begin{array}{l}1167 \\
(26.1)\end{array}$ \\
\hline $\begin{array}{l}\text { College graduate } \\
\text { or greater }\end{array}$ & $\begin{array}{r}355 \\
(20.5) \\
\end{array}$ & $\begin{array}{r}890 \\
(32.4) \\
\end{array}$ & $\begin{array}{r}102 \\
(17.3) \\
\end{array}$ & $\begin{array}{r}330 \\
(23.9) \\
\end{array}$ & $\begin{array}{r}809 \\
(32.4) \\
\end{array}$ & $\begin{array}{r}1241 \\
(27.8) \\
\end{array}$ \\
\hline Total & $\begin{array}{c}1735 \\
(38.7)\end{array}$ & $\begin{array}{c}2744 \\
(61.3)\end{array}$ & $\begin{array}{c}591 \\
(13.2)\end{array}$ & $\begin{array}{c}1379 \\
(30.9)\end{array}$ & $\begin{array}{c}2494 \\
(55.9)\end{array}$ & 4464 \\
\hline
\end{tabular}


Table C.17. Marital status by observed and self-reported use.

\begin{tabular}{|c|c|c|c|c|c|c|}
\hline \multirow[b]{2}{*}{ Marital Status } & \multicolumn{2}{|c|}{ Observed Use } & \multicolumn{3}{|c|}{ Self-Reported Use } & \multirow[b]{2}{*}{ Overall } \\
\hline & Unbelted & Belted & $\begin{array}{l}\text { Never, } \\
\text { Rarely } \\
\end{array}$ & $\begin{array}{l}\text { Sometimes, } \\
\text { Most 1y }\end{array}$ & Always & \\
\hline Married & $\begin{array}{c}1128 \\
(64.8)\end{array}$ & $\begin{array}{c}1940 \\
(70.5)\end{array}$ & $\begin{array}{c}352 \\
(59.5)\end{array}$ & $\begin{array}{c}943 \\
(68.2)\end{array}$ & $\begin{array}{c}1760 \\
(70.4)\end{array}$ & $\begin{array}{c}3055 \\
(68.3)\end{array}$ \\
\hline $\begin{array}{l}\text { Separated or } \\
\text { divorced }\end{array}$ & $\begin{array}{c}236 \\
(13.6)\end{array}$ & $\begin{array}{c}269 \\
(9.8)\end{array}$ & $\begin{array}{c}85 \\
(14.4)\end{array}$ & $\begin{array}{c}171 \\
(12.4)\end{array}$ & $\begin{array}{c}248 \\
(9.9)\end{array}$ & $\begin{array}{c}504 \\
(11.3)\end{array}$ \\
\hline Widowed & $\begin{array}{c}51 \\
(2.9)\end{array}$ & $\begin{array}{l}124 \\
(4.5)\end{array}$ & $\begin{array}{c}13 \\
(2.2)\end{array}$ & $\begin{array}{c}52 \\
(3.8)\end{array}$ & $\begin{array}{c}109 \\
(4.4)\end{array}$ & $\begin{array}{c}174 \\
(3.9)\end{array}$ \\
\hline Near married & $\begin{array}{r}325 \\
(18.7) \\
\end{array}$ & $\begin{array}{r}419 \\
(15.2) \\
\end{array}$ & $\begin{array}{r}142 \\
(24.0) \\
\end{array}$ & $\begin{array}{r}217 \\
(15.7) \\
\end{array}$ & $\begin{array}{r}384 \\
(15.4) \\
\end{array}$ & $\begin{array}{r}743 \\
(16.6) \\
\end{array}$ \\
\hline Total & $\begin{array}{l}1740 \\
(38.7)\end{array}$ & $\begin{array}{c}2752 \\
(61.3)\end{array}$ & $\begin{array}{c}592 \\
(13.2)\end{array}$ & $\begin{array}{c}1383 \\
(30.9)\end{array}$ & $\begin{array}{c}2501 \\
(55.9)\end{array}$ & 4476 \\
\hline
\end{tabular}

Table C.18. Age by observed and self-reported belt use.

\begin{tabular}{|c|c|c|c|c|c|c|}
\hline \multirow[b]{2}{*}{ Age } & \multicolumn{2}{|c|}{ Observed Use } & \multicolumn{3}{|c|}{ Self-Reported Use } & \multirow[b]{2}{*}{ Overal1 } \\
\hline & Unbelted & Belted & $\begin{array}{l}\text { Never, } \\
\text { Rarely }\end{array}$ & $\begin{array}{l}\text { Sometime } \\
\text { Mostly }\end{array}$ & Always & \\
\hline $\begin{array}{l}\text { Less than or equal } \\
\text { to } 25\end{array}$ & $\begin{array}{c}314 \\
(18.0)\end{array}$ & $\begin{array}{c}358 \\
(13.0)\end{array}$ & $\begin{array}{c}138 \\
(23.2)\end{array}$ & $\begin{array}{c}215 \\
(15.5)\end{array}$ & $\begin{array}{c}319 \\
(12.8)\end{array}$ & $\begin{array}{c}672 \\
(15.0)\end{array}$ \\
\hline $26-54$ & $\begin{array}{c}1094 \\
(62.8)\end{array}$ & $\begin{array}{c}1762 \\
(64.0)\end{array}$ & $\begin{array}{c}363 \\
(61.0)\end{array}$ & $\begin{array}{c}878 \\
(63.4)\end{array}$ & $\begin{array}{c}1605 \\
(64.2)\end{array}$ & $\begin{array}{c}2846 \\
(63.5)\end{array}$ \\
\hline $\begin{array}{l}\text { Equal to or greater } \\
\text { than } 55\end{array}$ & $\begin{array}{r}334 \\
(19.2) \\
\end{array}$ & $\begin{array}{r}633 \\
(23.0) \\
\end{array}$ & $\begin{array}{r}94 \\
(15.8) \\
\end{array}$ & $\begin{array}{c}291 \\
(21.0) \\
\end{array}$ & $\begin{array}{r}576 \\
(23.0) \\
\end{array}$ & $\begin{array}{r}961 \\
(21.5) \\
\end{array}$ \\
\hline Total & $\begin{array}{c}1742 \\
(38.8)\end{array}$ & $\begin{array}{l}2753 \\
(61.3)\end{array}$ & $\begin{array}{c}595 \\
(13.3)\end{array}$ & $\begin{array}{l}1384 \\
(30.9)\end{array}$ & $\begin{array}{c}2500 \\
(55.8)\end{array}$ & 4479 \\
\hline & $=25.5$ & $=.000$ & $x_{4}^{2}$ af & 47.9 & .000 & \\
\hline
\end{tabular}


Table C.19. Race by observed and self-reported use.

\begin{tabular}{|c|c|c|c|c|c|c|}
\hline \multirow[b]{2}{*}{$\underline{\text { Race }}$} & \multicolumn{2}{|c|}{ Observed Use } & \multicolumn{3}{|c|}{ Self-Reported Use } & \multirow[b]{2}{*}{ Overall } \\
\hline & Unbelted & Belted & $\begin{array}{l}\text { Never, } \\
\text { Rarely }\end{array}$ & $\begin{array}{l}\text { Sometimes, } \\
\text { Most } 1 \mathrm{y}\end{array}$ & Always & \\
\hline White & $\begin{array}{c}1544 \\
(88.4)\end{array}$ & $\begin{array}{c}2437 \\
(88.3)\end{array}$ & $\begin{array}{c}557 \\
(93.5)\end{array}$ & $\begin{array}{c}1229 \\
(88.7)\end{array}$ & $\begin{array}{c}2179 \\
(86.9)\end{array}$ & $\begin{array}{c}3965 \\
(88.3)\end{array}$ \\
\hline Black & $\begin{array}{c}187 \\
(10.7)\end{array}$ & $\begin{array}{c}308 \\
(11.2)\end{array}$ & $\begin{array}{c}37 \\
(5.2)\end{array}$ & $\begin{array}{c}146 \\
(10.5)\end{array}$ & $\begin{array}{c}312 \\
(12.5)\end{array}$ & $\begin{array}{c}495 \\
(11.0)\end{array}$ \\
\hline Other & $\begin{array}{r}15 \\
(0.9) \\
\end{array}$ & $\begin{array}{r}14 \\
(0.5) \\
\end{array}$ & $\begin{array}{r}2 \\
(0.3) \\
\end{array}$ & $\begin{array}{r}11 \\
(0.8) \\
\end{array}$ & $\begin{array}{r}16 \\
(0.4) \\
\end{array}$ & $\begin{array}{r}29 \\
(0.7) \\
\end{array}$ \\
\hline Total & $\begin{array}{c}1746 \\
(38.8)\end{array}$ & $\begin{array}{c}2759 \\
(61.2)\end{array}$ & $\begin{array}{c}596 \\
(13.3)\end{array}$ & $\begin{array}{c}1386 \\
(30.9)\end{array}$ & $\begin{array}{c}2507 \\
(55.9)\end{array}$ & 4489 \\
\hline & $f=2.3$ & $=.324$ & $x_{4}^{2}$ df & $=21.1$ & .000 & \\
\hline
\end{tabular}

Table C.20. Sex by observed and self-reported belt use.

$\underline{\text { Sex }}$

Male

Female

Total

\begin{tabular}{|c|c|c|c|c|c|c|}
\hline \multirow[b]{2}{*}{ Sex } & \multicolumn{2}{|c|}{ Observed Use } & \multicolumn{3}{|c|}{ Self-Reported Use } & \multirow[b]{2}{*}{ Overal1 } \\
\hline & Unbelted & Belted & $\begin{array}{l}\text { Never, } \\
\text { Rarely } \\
\end{array}$ & $\begin{array}{r}\text { Sometim } \\
\text { Most } 1 \mathrm{y} \\
\end{array}$ & Always & \\
\hline Male & $\begin{array}{c}1025 \\
(58.7)\end{array}$ & $\begin{array}{c}1420 \\
(51.5)\end{array}$ & $\begin{array}{c}410 \\
(68.8)\end{array}$ & $\begin{array}{c}805 \\
(58.1)\end{array}$ & $\begin{array}{c}1221 \\
(48.7)\end{array}$ & $\begin{array}{c}2436 \\
(54.3)\end{array}$ \\
\hline Female & $\begin{array}{r}721 \\
(41.3) \\
\end{array}$ & $\begin{array}{r}13.39 \\
(48.5) \\
\end{array}$ & $\begin{array}{r}186 \\
(31.2) \\
\end{array}$ & $\begin{array}{r}581 \\
(41.9) \\
\end{array}$ & $\begin{array}{c}1286 \\
(51.3) \\
\end{array}$ & $\begin{array}{c}2053 \\
(45.7) \\
\end{array}$ \\
\hline Total & $\begin{array}{c}1746 \\
(38.8)\end{array}$ & $\begin{array}{c}2759 \\
(61.2)\end{array}$ & $\begin{array}{c}596 \\
(13.3)\end{array}$ & $\begin{array}{c}1386 \\
(30.9)\end{array}$ & $\begin{array}{c}2507 \\
(55.9)\end{array}$ & 4489 \\
\hline
\end{tabular}




\section{APPENDIX D}

Telephone Survey - Supplementary Tables 
Table D.1. Age by telephone survey belt group.

Telephone Survey Belt Group

\begin{tabular}{|c|c|c|c|c|c|c|}
\hline Age & Never & Rarely & Sometimes & Most ly & Always & Total \\
\hline$\leq 25$ & $(10.0)^{2}$ & $\begin{array}{c}6 \\
(17.7)\end{array}$ & $\begin{array}{c}7 \\
(30.4)\end{array}$ & $\begin{array}{c}10 \\
(19.2)\end{array}$ & $\begin{array}{c}14 \\
(19.2)\end{array}$ & $\begin{array}{c}39 \\
(19.3)\end{array}$ \\
\hline $26-54$ & $\begin{array}{c}14 \\
(70.0)\end{array}$ & $\begin{array}{c}21 \\
(61.8)\end{array}$ & $\begin{array}{c}10 \\
(43.5)\end{array}$ & $\begin{array}{c}30 \\
(57.7)\end{array}$ & $\begin{array}{c}45 \\
(61.6)\end{array}$ & $\begin{array}{c}120 \\
(59.4)\end{array}$ \\
\hline$\geq 55$ & $\begin{array}{c}4 \\
(20.0) \\
\end{array}$ & $\begin{array}{c}7 \\
(20.6) \\
\end{array}$ & $\begin{array}{c}6 \\
(26.1) \\
\end{array}$ & $\begin{array}{c}12 \\
(23.1) \\
\end{array}$ & $\begin{array}{c}14 \\
(19.2) \\
\end{array}$ & $\begin{array}{c}43 \\
(21.3) \\
\end{array}$ \\
\hline Total & $\begin{array}{l}20 \\
(9.9)^{2}\end{array}$ & $\begin{array}{c}34 \\
(16.8)\end{array}$ & $\begin{array}{c}23 \\
(11.4)\end{array}$ & $\begin{array}{c}52 \\
(25.7)\end{array}$ & $\begin{array}{c}73 \\
(36.1)\end{array}$ & 202 \\
\hline
\end{tabular}

$\mathrm{X}^{2}=$ n.s. (even with belt groups collapsed)

${ }^{1}$ Column percent.

${ }^{2}$ Row percent. 
Table D.2. Race by telephone survey. belt group.

Telephone Survey Belt Group

\begin{tabular}{|c|c|c|c|c|c|c|}
\hline Race & Never & Rarely & Sometimes & Most 1y & Always & Total \\
\hline White & $\begin{array}{c}18 \\
(90.0)\end{array}$ & $\begin{array}{c}34 \\
(100.0)\end{array}$ & $\begin{array}{c}19 \\
(79.2)\end{array}$ & $\begin{array}{c}44 \\
(84.6)\end{array}$ & $\begin{array}{c}62 \\
(84.9)\end{array}$ & $\begin{array}{l}177 \\
(87.2)\end{array}$ \\
\hline Black & $\begin{array}{c}2 \\
(10.0) \\
\end{array}$ & $\begin{array}{c}0 \\
(0.0) \\
\end{array}$ & $\begin{array}{c}5 \\
(20.8) \\
\end{array}$ & $\begin{array}{r}8 \\
(15.4) \\
\end{array}$ & $\begin{array}{c}11 \\
(15.1) \\
\end{array}$ & $\begin{array}{c}26 \\
(12.8) \\
\end{array}$ \\
\hline Total & $\begin{array}{l}20 \\
(9.9)\end{array}$ & $\begin{array}{c}34 \\
(16.8)\end{array}$ & $\left(\begin{array}{l}23 \\
(11.8)\end{array}\right.$ & $\begin{array}{c}52 \\
(25.6)\end{array}$ & $\begin{array}{c}73 \\
(36.1)\end{array}$ & 203 \\
\hline
\end{tabular}


Table D.3. Sex by telephone survey belt group.

\begin{tabular}{|c|c|c|c|c|c|c|}
\hline \multirow[b]{2}{*}{$\underline{\text { Sex }}$} & \multicolumn{3}{|c|}{ Telephone Survey Belt } & \multicolumn{2}{|l|}{ Group } & \multirow[b]{2}{*}{ Total } \\
\hline & Never & Rarely & Sometimes & Mostly & Always & \\
\hline Male & $\begin{array}{c}16 \\
(80.0)\end{array}$ & $\begin{array}{c}22 \\
(64.7)\end{array}$ & $\begin{array}{c}14 \\
(58.3)\end{array}$ & $\begin{array}{c}34 \\
(65.4)\end{array}$ & $\begin{array}{c}42 \\
(57.5)\end{array}$ & $\begin{array}{l}128 \\
(63.1)\end{array}$ \\
\hline Female & $\begin{array}{c}4 \\
(20.0) \\
\end{array}$ & $\begin{array}{c}12 \\
(35.3) \\
\end{array}$ & $\begin{array}{c}10 \\
(41.7) \\
\end{array}$ & $\begin{array}{c}18 \\
(34.6) \\
\end{array}$ & $\begin{array}{c}31 \\
(42.5) \\
\end{array}$ & $\begin{array}{c}75 \\
(37.0) \\
\end{array}$ \\
\hline Total & $\begin{array}{l}20 \\
(9.9)\end{array}$ & $\begin{array}{c}34 \\
(16.8)\end{array}$ & $\begin{array}{c}24 \\
(11.8)\end{array}$ & $\begin{array}{c}52 \\
(25.6)\end{array}$ & $\begin{array}{c}73 \\
(36.0)\end{array}$ & 203 \\
\hline
\end{tabular}

$\mathrm{X}^{2}=\mathrm{n} . \mathrm{s}$. (even with belt groups collapsed) 
Table D.4. Education by telephone survey belt group.

\begin{tabular}{|c|c|c|c|c|c|c|}
\hline & & elephone & Survey Belt & Group & & \\
\hline Education & Never & Rarely & Sometimes & Most1y & Always & Total \\
\hline Grade School & $\left(15^{3} .0\right)$ & $\begin{array}{c}4 \\
(11.8)\end{array}$ & $\begin{array}{c}4 \\
(16.7)\end{array}$ & $\begin{array}{c}5 \\
(9.6)\end{array}$ & $\begin{array}{c}12 \\
(16.4)\end{array}$ & $\begin{array}{c}28 \\
(13.8)\end{array}$ \\
\hline High School & $\begin{array}{c}9 \\
(45.0)\end{array}$ & $\begin{array}{c}15 \\
(44.1)\end{array}$ & $\begin{array}{c}7 \\
(29.2)\end{array}$ & $\begin{array}{c}21 \\
(40.4)\end{array}$ & $\begin{array}{c}24 \\
(32.9)\end{array}$ & $\begin{array}{c}76 \\
(37.4)\end{array}$ \\
\hline Some College & $\begin{array}{c}4 \\
(20.0)\end{array}$ & $\begin{array}{c}8 \\
(23.5)\end{array}$ & $\begin{array}{c}6 \\
(25.0)\end{array}$ & $\begin{array}{c}16 \\
(30.8)\end{array}$ & $\begin{array}{c}17 \\
(23.3)\end{array}$ & $\begin{array}{c}51 \\
(25.1)\end{array}$ \\
\hline $\begin{array}{l}\text { College Graduate } \\
\text { or greater }\end{array}$ & $\begin{array}{r}4 \\
(20.0) \\
\end{array}$ & $\begin{array}{c}7 \\
(20.6) \\
\end{array}$ & $\begin{array}{r}7 \\
\left(29^{7} 2\right) \\
\end{array}$ & $\begin{array}{c}10 \\
(19.2) \\
\end{array}$ & $\begin{array}{r}20 \\
(27.4) \\
\end{array}$ & $\begin{array}{c}48 \\
(23.7) \\
\end{array}$ \\
\hline Total & $\begin{array}{l}20 \\
(9.9)\end{array}$ & $\begin{array}{c}34 \\
(16.8)\end{array}$ & $\begin{array}{c}24 \\
(11.8)\end{array}$ & $\begin{array}{c}52 \\
(25.6)\end{array}$ & $\begin{array}{c}73 \\
(36.0)\end{array}$ & 203 \\
\hline
\end{tabular}

$x^{2}=$ n.s. (even with belt groups collapsed) 
Table D.5. Marita1 status by telephone survey belt group.

\begin{tabular}{|c|c|c|c|c|c|c|}
\hline & & elephone & Survey Belt & Group & & \\
\hline Marital Status & $\underline{\text { Never }}$ & Rarely & Sometimes & Mostly & Always & Total \\
\hline Married & $\begin{array}{c}12 \\
(60.0)\end{array}$ & $\begin{array}{c}22 \\
(66.7)\end{array}$ & $\begin{array}{c}16 \\
(66.7)\end{array}$ & $\begin{array}{c}33 \\
(63.5)\end{array}$ & $\begin{array}{c}44 \\
(60.3)\end{array}$ & $\begin{array}{c}127 \\
(62.9)\end{array}$ \\
\hline $\begin{array}{l}\text { Separated, } \\
\text { divorced, or } \\
\text { widowed }\end{array}$ & $(15.0)$ & $\left(\begin{array}{c}3 \\
(9.1)\end{array}\right.$ & $(12.5)$ & $\begin{array}{c}11 \\
(21.2)\end{array}$ & $\begin{array}{c}14 \\
(19.2)\end{array}$ & $\begin{array}{c}34 \\
(16.8)\end{array}$ \\
\hline Never married & $\begin{array}{c}5 \\
(25.0) \\
\end{array}$ & $\begin{array}{r}8 \\
(24.2) \\
\end{array}$ & $\begin{array}{c}5 \\
(20.8) \\
\end{array}$ & $\begin{array}{c}8 \\
(15.4) \\
\end{array}$ & $\begin{array}{c}15 \\
(20.6) \\
\end{array}$ & $\begin{array}{r}41 \\
(20.3) \\
\end{array}$ \\
\hline Total & $\begin{array}{l}20 \\
(9.9)\end{array}$ & $\begin{array}{c}33 \\
(16.3)\end{array}$ & $\begin{array}{c}24 \\
(11.9)\end{array}$ & $\begin{array}{c}52 \\
(25.7)\end{array}$ & $\begin{array}{c}73 \\
(36.1)\end{array}$ & 202 \\
\hline
\end{tabular}

$$
x^{2}=\text { n.s. (even with belt groups collapsed) }
$$


Table D.6. When first started wearing belt by risk group and observed use.

\begin{tabular}{|c|c|c|c|c|c|}
\hline \multirow{2}{*}{$\begin{array}{c}\text { When First } \\
\text { Started } \\
\text { Wearing Belt }\end{array}$} & \multicolumn{2}{|c|}{ Risk Group } & \multicolumn{2}{|c|}{ Observed Use } & \multirow[b]{2}{*}{ Total } \\
\hline & $\underline{\mathrm{High}}$ & Low & Belted & Unbelted & \\
\hline $\begin{array}{l}\text { Since the } \$ 25 \text { fine } \\
\text { (Jan. 1987) }\end{array}$ & $\begin{array}{c}29 \\
(26.9)\end{array}$ & $\begin{array}{c}19 \\
(25.3)\end{array}$ & $\begin{array}{c}21 \\
(20.6)\end{array}$ & $\begin{array}{r}27 \\
(33.3)\end{array}$ & $\begin{array}{c}48 \\
(26.2)\end{array}$ \\
\hline $\begin{array}{l}\text { Since the law } \\
\text { (Oct. 1985) }\end{array}$ & $\begin{array}{c}29 \\
(26.9)\end{array}$ & $\begin{array}{c}22 \\
(29.3)\end{array}$ & $\begin{array}{c}33 \\
(32.4)\end{array}$ & $\begin{array}{r}18 \\
(22.2)\end{array}$ & $\begin{array}{c}51 \\
(27.9)\end{array}$ \\
\hline Just before the law & $\begin{array}{c}16 \\
(14.8)\end{array}$ & $\begin{array}{c}11 \\
(14.7)\end{array}$ & $\begin{array}{c}18 \\
(17.7)\end{array}$ & $\left(11^{9} .1\right)$ & $\begin{array}{c}27 \\
(14.8)\end{array}$ \\
\hline $\begin{array}{l}\text { Before law but less } \\
\text { than } 5 \text { years ago }\end{array}$ & $\begin{array}{c}16 \\
(14.8)\end{array}$ & $\begin{array}{c}13 \\
(17.3)\end{array}$ & $\begin{array}{c}16 \\
(15.7)\end{array}$ & $\begin{array}{c}13 \\
(16.1)\end{array}$ & $\begin{array}{c}29 \\
(15.9)\end{array}$ \\
\hline $\begin{array}{l}\text { More than } 5 \text { years } \\
\text { ago }\end{array}$ & $\begin{array}{c}18 \\
(16.7) \\
\end{array}$ & $\begin{array}{c}10 \\
(13.3) \\
\end{array}$ & $\begin{array}{c}14 \\
(13.7) \\
\end{array}$ & $\begin{array}{c}14 \\
(17.3) \\
\end{array}$ & $\begin{array}{c}28 \\
(15.3) \\
\end{array}$ \\
\hline Total & $\begin{array}{l}108 \\
(59.0)\end{array}$ & $\begin{array}{c}75 \\
(41.0)\end{array}$ & $\begin{array}{l}102 \\
(55.7)\end{array}$ & $\begin{array}{c}81 \\
(44.3)\end{array}$ & $\begin{array}{c}183 \\
(100.0)\end{array}$ \\
\hline
\end{tabular}


Table D.7. Factors that influenced belt wearing (first reason stated) by telephone survey belt group.

\begin{tabular}{|c|c|c|c|c|c|c|}
\hline \multirow[b]{2}{*}{ Factor } & \multicolumn{5}{|c|}{$\begin{array}{c}\text { Telephone Survey } \\
\text { Belt Group }\end{array}$} & \multirow[b]{2}{*}{ Tota1 } \\
\hline & Never & Rarely & Sometimes & Most 1y & Always & \\
\hline $\begin{array}{l}\text { Just that law was } \\
\text { passed }\end{array}$ & -- & $\begin{array}{c}9 \\
(26.5)\end{array}$ & $\begin{array}{c}9 \\
(37.5)\end{array}$ & $\begin{array}{c}12 \\
(23.1)\end{array}$ & $\begin{array}{c}20 \\
(27.4)\end{array}$ & $\begin{array}{c}50 \\
(27.3)\end{array}$ \\
\hline $\begin{array}{l}\text { Concern about being } \\
\text { stopped/fined }\end{array}$ & -- & $\begin{array}{c}13 \\
(38.2)\end{array}$ & $\begin{array}{c}7 \\
(29.2)\end{array}$ & $\begin{array}{c}8 \\
(15.4)\end{array}$ & $\begin{array}{c}3 \\
(4.1)\end{array}$ & $\begin{array}{c}31 \\
(16.9)\end{array}$ \\
\hline $\begin{array}{l}\text { Increased concern } \\
\text { for personal safety }\end{array}$ & -- & $\begin{array}{c}2 \\
(5.9)\end{array}$ & $\begin{array}{c}4 \\
(16.7)\end{array}$ & $\begin{array}{c}8 \\
(15.4)\end{array}$ & $\begin{array}{c}5 \\
(6.9)\end{array}$ & $\begin{array}{c}19 \\
(10.4)\end{array}$ \\
\hline $\begin{array}{l}\text { Increased awareness } \\
\text { of belt effectiveness }\end{array}$ & - & $\begin{array}{l}0 \\
(0)\end{array}$ & $\begin{array}{c}0 \\
(0)\end{array}$ & $\begin{array}{c}3 \\
(5.8)\end{array}$ & $(4.1)$ & $\begin{array}{c}6 \\
(3.3)\end{array}$ \\
\hline $\begin{array}{l}\text { Because of family/ } \\
\text { friends }\end{array}$ & -- & $(8.8)$ & $\begin{array}{c}1 \\
(4.2)\end{array}$ & $\begin{array}{c}6 \\
(11.5)\end{array}$ & $\begin{array}{c}9 \\
(12.3)\end{array}$ & $\begin{array}{c}19 \\
(10.4)\end{array}$ \\
\hline $\begin{array}{l}\text { Involved in an } \\
\text { accident }\end{array}$ & -- & $\begin{array}{c}0 \\
(0)\end{array}$ & $\begin{array}{c}0 \\
(0)\end{array}$ & $\begin{array}{c}2 \\
(3.9)\end{array}$ & $\begin{array}{c}4 \\
(5.5)\end{array}$ & $\begin{array}{c}6 \\
(3.3)\end{array}$ \\
\hline $\begin{array}{l}\text { Friend/relative in } \\
\text { accident }\end{array}$ & -- & $\begin{array}{c}0 \\
(0)\end{array}$ & $\begin{array}{c}0 \\
(0)\end{array}$ & $\begin{array}{c}0 \\
(0)\end{array}$ & $\begin{array}{c}1 \\
(1.4)\end{array}$ & $\begin{array}{c}1 \\
(0.6)\end{array}$ \\
\hline $\begin{array}{l}\text { Something read or } \\
\text { heard about belts }\end{array}$ & -- & $\begin{array}{c}0 \\
(0)\end{array}$ & $\begin{array}{c}1 \\
(4.2)\end{array}$ & $(3.9)$ & $(9.6)$ & $\begin{array}{l}10 \\
(5.5)\end{array}$ \\
\hline $\begin{array}{l}\text { Just makes sense; } \\
\text { for safety }\end{array}$ & -- & $(11.8)$ & $\begin{array}{c}1 \\
(4.2)\end{array}$ & $\left(\begin{array}{l}5 \\
(9.6)\end{array}\right.$ & $\begin{array}{c}14 \\
(19.2)\end{array}$ & $\begin{array}{c}24 \\
(13.1)\end{array}$ \\
\hline Other & - & $\begin{array}{c}3 \\
(8.8) \\
\end{array}$ & $\begin{array}{c}1 \\
(4.2) \\
\end{array}$ & $\begin{array}{c}6 \\
(11.5) \\
\end{array}$ & $\begin{array}{c}7 \\
(9.6) \\
\end{array}$ & $\begin{array}{c}17 \\
(9.3) \\
\end{array}$ \\
\hline Total & -- & $\begin{array}{c}34 \\
(18.6)\end{array}$ & $\begin{array}{c}24 \\
(13.1)\end{array}$ & $\begin{array}{c}52 \\
(28.4)\end{array}$ & $\begin{array}{c}73 \\
(39.9)\end{array}$ & $\begin{array}{c}183 \\
(100.0)\end{array}$ \\
\hline
\end{tabular}


Table D.8. Factors that influenced belt wearing (a11 responses combined) by telephone survey belt group.

\begin{tabular}{|c|c|c|c|c|c|c|}
\hline \multirow[b]{2}{*}{ Factor } & \multicolumn{5}{|c|}{$\begin{array}{c}\text { Telephone Survey } \\
\text { Belt Group }\end{array}$} & \multirow[b]{2}{*}{ Total } \\
\hline & Never & Rarely & Somet imes & Most 1y & Always & \\
\hline $\begin{array}{l}\text { Just that law was } \\
\text { passed }\end{array}$ & -- & $(20.0)$ & $\begin{array}{c}10 \\
(30.3)\end{array}$ & $\begin{array}{c}17 \\
(19.8)\end{array}$ & $\begin{array}{c}26 \\
(20.2)\end{array}$ & $\begin{array}{c}62 \\
(21.2)\end{array}$ \\
\hline $\begin{array}{l}\text { Concern about being } \\
\text { stopped/fined }\end{array}$ & -- & $\begin{array}{c}15 \\
(33.3)\end{array}$ & $\begin{array}{c}8 \\
(24.2)\end{array}$ & $\begin{array}{c}11 \\
(12.8)\end{array}$ & $\begin{array}{c}7 \\
(5.4)\end{array}$ & $\begin{array}{c}41 \\
(14.0)\end{array}$ \\
\hline Safety & - & $\begin{array}{c}11 \\
(24.4)\end{array}$ & $\begin{array}{c}7 \\
(21.2)\end{array}$ & $\begin{array}{c}29 \\
(33.7)\end{array}$ & $\begin{array}{c}50 \\
(38.8)\end{array}$ & $\begin{array}{c}97 \\
(33.1)\end{array}$ \\
\hline Other & - & $\begin{array}{c}10 \\
(22.2) \\
\end{array}$ & $\begin{array}{c}8 \\
(24.2) \\
\end{array}$ & $\begin{array}{r}29 \\
(33.7) \\
\end{array}$ & $\begin{array}{c}46 \\
(35.7) \\
\end{array}$ & $\begin{array}{c}93 \\
(31.7) \\
\end{array}$ \\
\hline Total & -- & $\begin{array}{c}45 \\
(15.4)\end{array}$ & $\begin{array}{c}33 \\
(11.3)\end{array}$ & $\begin{array}{c}86 \\
(29.4)\end{array}$ & $\begin{array}{c}129 \\
(44.0)\end{array}$ & $\begin{array}{c}293 \\
(100.0)\end{array}$ \\
\hline
\end{tabular}


Table D.9. Factors that influenced belt wearing (first reason stated) by risk group and observed use.

\begin{tabular}{|c|c|c|c|c|c|}
\hline \multirow[b]{2}{*}{ Factor } & \multicolumn{2}{|c|}{ Risk Group } & \multicolumn{2}{|c|}{ Observed Use } & \multirow[b]{2}{*}{ Total } \\
\hline & $\underline{\text { High }}$ & Low & Belted & Unbelted & \\
\hline $\begin{array}{l}\text { Just that law was } \\
\text { passed }\end{array}$ & $\begin{array}{c}26 \\
(23.9)\end{array}$ & $\begin{array}{c}25 \\
(33.3)\end{array}$ & $\begin{array}{c}31 \\
(30.1)\end{array}$ & $\begin{array}{c}20 \\
(24.7)\end{array}$ & $\begin{array}{c}51 \\
(27.7)\end{array}$ \\
\hline $\begin{array}{l}\text { Concern about being } \\
\text { stopped/fined }\end{array}$ & $\begin{array}{c}21 \\
(19.3)\end{array}$ & $\begin{array}{c}10 \\
(13.3)\end{array}$ & $\begin{array}{c}13 \\
(12.6)\end{array}$ & $\begin{array}{c}18 \\
(22.2)\end{array}$ & $\begin{array}{c}31 \\
(16.9)\end{array}$ \\
\hline $\begin{array}{l}\text { Was stopped and } \\
\text { warned by police }\end{array}$ & $\begin{array}{c}0 \\
(0)\end{array}$ & $\begin{array}{c}0 \\
(0)\end{array}$ & $\begin{array}{c}0 \\
(0)\end{array}$ & $\begin{array}{c}0 \\
(0)\end{array}$ & $\begin{array}{c}0 \\
(0)\end{array}$ \\
\hline $\begin{array}{l}\text { Was stopped and } \\
\text { fined by police }\end{array}$ & $\begin{array}{c}0 \\
(0)\end{array}$ & $\begin{array}{c}0 \\
(0)\end{array}$ & $\begin{array}{c}0 \\
(0)\end{array}$ & $\begin{array}{c}0 \\
(0)\end{array}$ & $\begin{array}{c}0 \\
(0)\end{array}$ \\
\hline $\begin{array}{l}\text { Increased concern } \\
\text { for personal safety }\end{array}$ & $\begin{array}{c}11 \\
(10.1)\end{array}$ & $\begin{array}{c}8 \\
(10.7)\end{array}$ & $\begin{array}{l}10 \\
(9.7)\end{array}$ & $(11.1)$ & $\begin{array}{c}19 \\
(10.3)\end{array}$ \\
\hline $\begin{array}{l}\text { Increased awareness of } \\
\text { belt effectiveness }\end{array}$ & $\begin{array}{c}3 \\
(2.8)\end{array}$ & $\begin{array}{c}3 \\
(4.0)\end{array}$ & $\begin{array}{c}4 \\
(3.9)\end{array}$ & $(2.5)$ & $\begin{array}{c}6 \\
(3.3)\end{array}$ \\
\hline $\begin{array}{l}\text { Because of family/ } \\
\text { friends }\end{array}$ & $\begin{array}{c}14 \\
(12.8)\end{array}$ & $\begin{array}{c}5 \\
(6.7)\end{array}$ & $\left(8^{9} .7\right)$ & $\begin{array}{c}10 \\
(12.4)\end{array}$ & $\begin{array}{c}19 \\
(10.3)\end{array}$ \\
\hline $\begin{array}{l}\text { Involved in an } \\
\text { accident }\end{array}$ & $\begin{array}{c}6 \\
(5.5)\end{array}$ & $\begin{array}{c}0 \\
(0)\end{array}$ & $\begin{array}{c}3 \\
(2.9)\end{array}$ & $(3.7)$ & $\begin{array}{c}6 \\
(3.3)\end{array}$ \\
\hline $\begin{array}{l}\text { Friend/relative } \\
\text { in accident }\end{array}$ & $\begin{array}{c}0 \\
(0)\end{array}$ & $\begin{array}{c}1 \\
(1.3)\end{array}$ & $\begin{array}{c}1 \\
(1.0)\end{array}$ & $\begin{array}{c}0 \\
(0)\end{array}$ & $\left(\begin{array}{c}1 \\
(0.5)\end{array}\right.$ \\
\hline $\begin{array}{l}\text { Something read or } \\
\text { heard about belts }\end{array}$ & $\begin{array}{c}6 \\
(5.5)\end{array}$ & $\begin{array}{c}4 \\
(5.3)\end{array}$ & $\begin{array}{c}7 \\
(6.8)\end{array}$ & $\begin{array}{c}3 \\
(3.7)\end{array}$ & $\begin{array}{l}10 \\
(5.4)\end{array}$ \\
\hline $\begin{array}{l}\text { Just makes sense; } \\
\text { for safety }\end{array}$ & $\begin{array}{c}13 \\
(11.9)\end{array}$ & $\begin{array}{c}11 \\
(14.7)\end{array}$ & $\begin{array}{c}15 \\
(14.6)\end{array}$ & $(11.1)$ & $\begin{array}{c}24 \\
(13.0)\end{array}$ \\
\hline Other & $\begin{array}{c}9 \\
(8.3) \\
\end{array}$ & $\begin{array}{c}8 \\
(10.7) \\
\end{array}$ & $\begin{array}{l}10 \\
(9.7) \\
\end{array}$ & $\begin{array}{c}7 \\
(8.6) \\
\end{array}$ & $\begin{array}{l}17 \\
(9.2) \\
\end{array}$ \\
\hline Tota1 & $\begin{array}{l}109 \\
(59.2)\end{array}$ & $\begin{array}{c}75 \\
(40.8)\end{array}$ & $\begin{array}{l}103 \\
(56.0)\end{array}$ & $\begin{array}{c}81 \\
(44.0)\end{array}$ & $\begin{array}{c}184 \\
(100.0)\end{array}$ \\
\hline & $x^{2}$ & lid & $x^{2}$ & valid & \\
\hline
\end{tabular}


Table D.10. Factors that influenced belt wearing (all responses combined) by risk group and observed use.

\begin{tabular}{|c|c|c|c|c|c|}
\hline \multirow[b]{2}{*}{ Factor } & \multicolumn{2}{|c|}{ Risk Group } & \multicolumn{2}{|c|}{ Observed Use } & \multirow[b]{2}{*}{ Total } \\
\hline & High & Low & Belted & Unbelted & \\
\hline $\begin{array}{l}\text { Just the law was } \\
\text { passed }\end{array}$ & $\begin{array}{l}34 \\
(19.1)\end{array}$ & $\begin{array}{c}29 \\
(25.0)\end{array}$ & $\begin{array}{c}39 \\
(22.0)\end{array}$ & $\begin{array}{c}24 \\
(20.5)\end{array}$ & $\begin{array}{c}63 \\
(21.4)\end{array}$ \\
\hline $\begin{array}{l}\text { Concern about being } \\
\text { stopped/fined }\end{array}$ & $\begin{array}{c}29 \\
(16.3)\end{array}$ & $\begin{array}{c}12 \\
(10.3)\end{array}$ & $\begin{array}{c}18 \\
(10.2)\end{array}$ & $\begin{array}{l}23 \\
(19.7)\end{array}$ & $\begin{array}{c}41 \\
(14.0)\end{array}$ \\
\hline Safety & $\begin{array}{c}55 \\
(30.9)\end{array}$ & $\begin{array}{c}42 \\
(36.2)\end{array}$ & $\begin{array}{c}63 \\
(35.6)\end{array}$ & $\begin{array}{c}34 \\
(29.1)\end{array}$ & $\begin{array}{c}97 \\
(33.0)\end{array}$ \\
\hline Other & $\begin{array}{c}60 \\
(33.7) \\
\end{array}$ & $\begin{array}{c}33 \\
(28.5) \\
\end{array}$ & $\begin{array}{c}57 \\
(32.2) \\
\end{array}$ & $\begin{array}{c}36 \\
(30.8) \\
\end{array}$ & $\begin{array}{c}93 \\
(31.6) \\
\end{array}$ \\
\hline Total & $\begin{array}{c}178 \\
(60.5)\end{array}$ & $\begin{array}{c}116 \\
(39.5)\end{array}$ & $\begin{array}{l}177 \\
(60.2)\end{array}$ & $\begin{array}{c}117 \\
(39.8)\end{array}$ & $\begin{array}{c}294 \\
(100.0)\end{array}$ \\
\hline
\end{tabular}


Table 1).11. Attitudes concerning statements about seat belts for each telephone survey beit group (percent of respondents).

1. * Seat belts reduce the chance of serious injury in a crash.

In an accident, it's better to be thrown out of the car than to stay inside.

3. * Seat belts are easy to use.

4. *Iap belts are not necessary when riding in the back seat of a car.

5. *Your chances of being trapped in a car if it crashes and catches on fire are greater if wearing a seat beit.

6. *Seat belts can cause more injuries than they prevent.

\begin{tabular}{|c|c|c|c|c|c|}
\hline $\begin{array}{c}\text { Telephone } \\
\text { Survey } \\
\text { Belt } \\
\text { Group } \\
\end{array}$ & $\begin{array}{l}\text { Strongly } \\
\text { Agree } \\
\end{array}$ & Agree & Disagree & $\begin{array}{l}\text { Strongly } \\
\text { Disagree }\end{array}$ & $\begin{array}{c}\text { No } \\
\text { Opinion }\end{array}$ \\
\hline Never & $0 \%$ & $40 \%$ & $35 \%$ & $10 \%$ & $15 \%$ \\
\hline Rarely & 12 & 71. & 15 & 0 & 3 \\
\hline Sometimes & 38 & 58 & 4 & 0 & 0 \\
\hline Mostly & 58 & 37. & 4 & 0 & 2 \\
\hline Always & 68 & 29 & 3 & 0 & 0 \\
\hline Never & 15 & 10 & 30 & 15 & 30 \\
\hline Rarely & 0 & 9 & 56 & 24 & 12 \\
\hline Sometimes & 4 & 13 & 42 & 29 & 13 \\
\hline Mostly & 0 & 4 & 40 & 40 & 15 \\
\hline Always & 5 & 11 & 27 & 52 & 4 \\
\hline Never & 5 & 40 & 15 & 35 & 5 \\
\hline Rarely & 26 & 32 & 26 & 12 & 3 \\
\hline Somet imes & 25 & 50 & 21 & 4 & 0 \\
\hline Mostly & 46 & 48 & 6 & 0 & 0 \\
\hline Always & 60 & 34 & 5 & 0 & 0 \\
\hline Never & 15 & 45 & 30 & 5 & 5 \\
\hline Rarely & 6 & 24 & 53 & 15 & 3 \\
\hline Sometimes & 4 & 21 & 54 & 8 & 13 \\
\hline Mostly & 6 & 23 & 40 & 29 & 2 \\
\hline Always & 3 & 19 & 48 & 27 & 3 \\
\hline Never & 45 & 45 & 5 & 0 & 5 \\
\hline Rarely & 26 & 44 & 18 & 3 & 9 \\
\hline Sometimes & 17 & 46 & 29 & 8 & 0 \\
\hline Mostly & 12 & 40 & 23 & 13 & 12 \\
\hline Always & 11 & 18 & 42 & 18 & 11 \\
\hline Never & 10 & 45 & 30 & 5 & 10 \\
\hline Rarely & 3 & 15 & 56 & 18 & 9 \\
\hline Sometimes & 0 & 17 & 50 & 25 & 8 \\
\hline Mostly & 2 & 4 & 46 & 42 & 6 \\
\hline Always & 1 & 4 & 41 & 52 & 1 \\
\hline
\end{tabular}

\footnotetext{
*Indicates significant differences (belt use and agreement categories coll.apsed to permit testing).
} 
Table D.12. Attitudes concerning statements about seat beits by the high and low risk groups (percent of respondents).

\section{Seat Belt Statements}

1. Seat belts reduce the chance of serious injury in a crash.

2. In an accident, it's better to be High thrown out of the car than to stay Low inside.

3. *Seat belts are easy to use.

4. Lap belts are not necessary when riding in the back seat of a car

5. Your changes of being trapped in a High car if it crashes and catches on fire are greater if wearing a seat belt.

6. Seat belts can cause more injuries High than they prevent.

\begin{tabular}{|c|c|c|c|c|c|}
\hline $\begin{array}{l}\text { Risk } \\
\text { Level }\end{array}$ & $\begin{array}{c}\text { Strongly } \\
\text { Agree } \\
\end{array}$ & Agree & Disagree & $\begin{array}{l}\text { Strongly } \\
\text { Disagree }\end{array}$ & $\begin{array}{c}\text { No } \\
\text { Opinion }\end{array}$ \\
\hline High & $45 \%$ & $42 \%$ & $9 \%$ & $2 \%$ & $2 \%$ \\
\hline Low & 46 & 43 & 7 & 0 & 4 \\
\hline High & 3 & 6 & 37 & 38 & 16 \\
\hline Low & 5 & 14 & 37 & 37 & 6 \\
\hline High & .50 & 33 & 12 & 5 & 1 \\
\hline Low & 29 & 51 & 12 & 7 & 1 \\
\hline High & 6 & 20 & 45 & 26 & 3 \\
\hline Low & 5 & 30 & 46 & 14 & 5 \\
\hline High & 18 & 32 & 26 & 16 & 8 \\
\hline Low & 17 & 37 & 31 & 5 & 10 \\
\hline High & 2 & 12 & 44 & 36 & 6 \\
\hline Low & 2 & 10 & 47 & 36 & 5 \\
\hline
\end{tabular}

*Indicates significant differences when agreement categories collapsed to permit testing. 
Table D.13. Attitudes concerning statements about seat belts by the belted and unbelted drivers (percent of respondents).

\section{Seat. Belt Statements}

1. *Seat belts reduce the chance of serious injury in a crash.

2. In an accident, it's better to be thrown out of the car than to stay inside.

3. *Seat belts are easy to use.

4. Lap belts are not necessary when riding in the back seat of a car

5. Your changes of heing trapped in a car if it crashes and catches on fire are greater if wearing a seat belt.

6. *Seat belts can cause more injuries than they prevent.

Belt
Status
Belted
Unbelted
Belted
Unbelted

Strongly

Agree

$60 \%$

31

5

3

Belted

Unbe1ted

Belted

Unbelted

Belted

Unbelted

belted

Unbelted
55

27

$5 \quad 20$

6

16

20

0

5

37

44

20

28

27

42

4
19
Agree

$3.5 \%$

51

9

10

45

46
Strong.ly

Disagree Opinion

$0 \%$

2

46

30

0

12

25

17

15

8

48

24
$1 \%$

4

9

15

0

2

2

6

11

7

4

7

*Indicates significant differences when agreement categories collapsed to permit testing. 
Table D.14. Effect of various driving situations on belt use by risk group and observed use (percent indicating more likely than usual to wear a seat belt).

\section{Driving Situation}

1. Driving in bad weather, like rain, snow or fog

2. Driving at night

3. Driving on interstate highways

4. *Making a long trip

5. Driving with children in car

6. *Driving in rush hour traffic

7. Driving on weekends or holidays

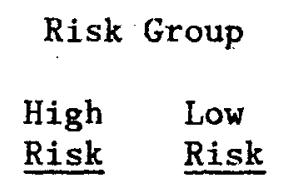

$86 \%$

$57 \quad 59$

67

$72 \quad 71$

82

59

55
Observed Use

Belted Unbelted

Drivers Drivers

$\begin{array}{ll}89 \% & 82 \% \\ 68 & 51 \\ 74 & 61 \\ 84 & 65^{*} \\ 89 & 75 \\ 84 & 48 * \\ 71 & 54\end{array}$

Overa1l

$84 \%$

56

66

71

78

60

59

\footnotetext{
*Indicates significant differences for belted-unbelted comparison.
} 
Table D.15. Amount of fine that would produce belt wearing on every trip by risk group and observed use.

\begin{tabular}{|c|c|c|c|c|c|}
\hline Amount & Risk & roup & Obse & ed Use & \\
\hline Fine & High & Low & Belted & Unbe1ted & Tota1 \\
\hline$\$ 25$ & $\begin{array}{c}21 \\
(26.9)\end{array}$ & $\begin{array}{c}13 \\
(27.1)\end{array}$ & $\begin{array}{c}16 \\
(43.2)\end{array}$ & $\begin{array}{c}18 \\
(20.2)\end{array}$ & $\begin{array}{c}34 \\
(27.0)\end{array}$ \\
\hline$\$ 26-100$ & $\begin{array}{c}17 \\
(21.8)\end{array}$ & $\begin{array}{c}12 \\
(25.0)\end{array}$ & $\begin{array}{c}6 \\
(16.2)\end{array}$ & $\begin{array}{c}23 \\
(25.8)\end{array}$ & $\begin{array}{c}29 \\
(23.0)\end{array}$ \\
\hline$>\$ 100$ & $\begin{array}{c}5 \\
(6.4)\end{array}$ & $\begin{array}{c}6 \\
(12.5)\end{array}$ & $\begin{array}{c}n \\
(0.0)\end{array}$ & $\begin{array}{c}11 \\
(12.4)\end{array}$ & $\begin{array}{c}11 \\
(8.7)\end{array}$ \\
\hline No Amount & $\begin{array}{c}35 \\
(44.9) \\
\end{array}$ & $\begin{array}{r}17 \\
(35.4) \\
\end{array}$ & $\begin{array}{c}15 \\
(40.5) \\
\end{array}$ & $\begin{array}{r}37 \\
(41.6) \\
\end{array}$ & $\begin{array}{c}52 \\
(41.3) \\
\end{array}$ \\
\hline Total & $\begin{array}{c}78 \\
(61.9)\end{array}$ & $\begin{array}{c}48 \\
(38.1)\end{array}$ & $\begin{array}{c}37 \\
(29.4)\end{array}$ & $\begin{array}{c}89 \\
(70.6)\end{array}$ & $\begin{array}{c}126 \\
(100.0)\end{array}$ \\
\hline
\end{tabular}


Table D.16 Items that would produce belt wearing for every trip by risk group and observed use (percent indicating a positive response).

Item
greatly reduced.
you heard someone give a
t-hand account of how wearing
at belt had saved their life.

3. If you personally knew someone whose life was saved by wearing a seat belt.

4. If a friend or family member reminded you to wear your belt.

5. If your belt was more comfortable 54 or easier to use.

\begin{tabular}{|c|c|c|c|c|}
\hline \multicolumn{2}{|c|}{ Risk Group } & \multicolumn{2}{|c|}{ Observed Use } & \multirow[b]{2}{*}{ Total } \\
\hline High & Low & Belted & Unbelted & \\
\hline $70 \%$ & $69 \%$ & $92 \%$ & $60 \% *$ & $69 \%$ \\
\hline 34 & 45 & 55 & $32 *$ & 38 \\
\hline 42 & 49 & 61 & 38 & 45 \\
\hline 39 & 53 & 63 & $37 *$ & 45 \\
\hline 54 & $74 *$ & 76 & 57 & 62 \\
\hline 33 & 35 & 53 & $26 *$ & 34 \\
\hline 62 & 51 & 79 & $49 *$ & 58 \\
\hline 75 & 61 & 84 & $63 *$ & 69 \\
\hline
\end{tabular}

*Indicates significant differences. 
Table D.17. Feelings about belts and the North Carolina law by risk group and observed use.

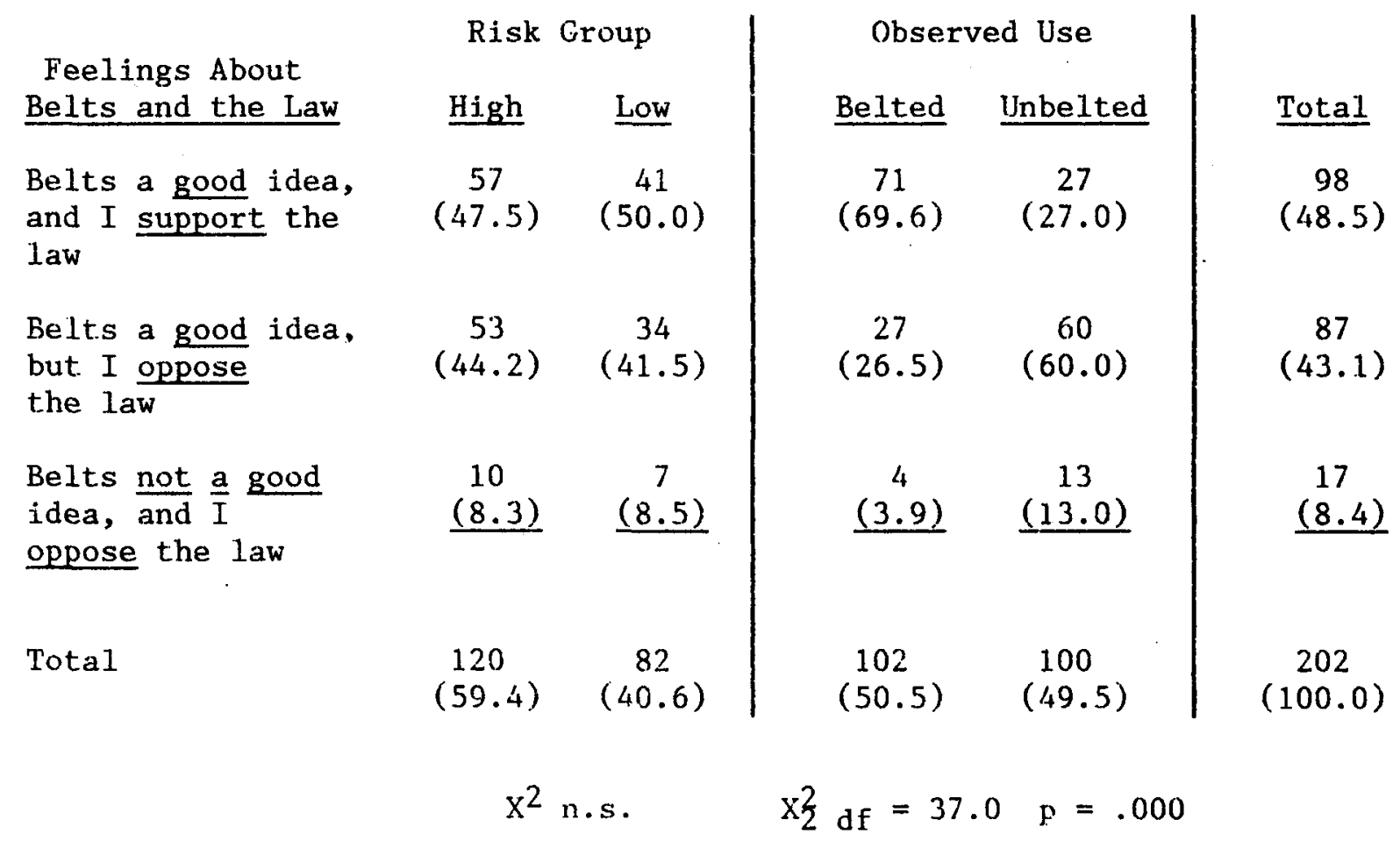


Table D.18. Telephone respondents' main reason(s) for supporting the North Carolina seat belt law.

\begin{tabular}{|c|c|c|}
\hline Reasons for Supporting & $\begin{array}{c}\text { First } \\
\text { Response } \\
\text { Only } \\
\end{array}$ & $\begin{array}{c}\text { A11 } \\
\text { Responses } \\
\text { Combined } \\
\end{array}$ \\
\hline Seat belts save lives/reduce injuries & $\begin{array}{c}60 \\
(61.2)\end{array}$ & $\begin{array}{c}74 \\
(46.8)\end{array}$ \\
\hline $\begin{array}{l}\text { The law will get more people to wear } \\
\text { belts }\end{array}$ & $\begin{array}{c}15 \\
(15.3)\end{array}$ & $\begin{array}{c}25 \\
(15.8)\end{array}$ \\
\hline Wearing belts will protect me/my family & $\begin{array}{c}5 \\
(5.1)\end{array}$ & $\begin{array}{c}20 \\
(12.7)\end{array}$ \\
\hline Good for children/help them form habit & $\begin{array}{c}6 \\
(6.1)\end{array}$ & $\begin{array}{c}16 \\
(10.1)\end{array}$ \\
\hline Make people more safety conscious & $\begin{array}{c}2 \\
(2.0)\end{array}$ & $\begin{array}{c}2 \\
(1.3)\end{array}$ \\
\hline $\begin{array}{l}\text { Reduce costs (to society) of accidents, } \\
\text { injuries }\end{array}$ & $\begin{array}{c}1 \\
(1.0)\end{array}$ & $(1.3)$ \\
\hline Lower insurance premiums & $\begin{array}{c}0 \\
(0.0)\end{array}$ & $(0.6)$ \\
\hline Other & $\begin{array}{c}9 \\
(9.2) \\
\end{array}$ & $\begin{array}{c}18 \\
(11.4) \\
\end{array}$ \\
\hline & $\begin{array}{c}98 \\
(99.9)\end{array}$ & $\begin{array}{c}158 \\
(100.0)\end{array}$ \\
\hline
\end{tabular}


Table D.19. Telephone respondents' main reasons for opposing the North Carolina seat belt law.

Reasons for Opposing

Adults should have a choice/infringement on rights

Seat belts aren't effective/don't really help in an accident

Seat belts are uncomfortable/inconvenient to use

Seat belts can cause injuries

Seat belts can trap me in my car

The law is impossible to enforce

There shouldn't be a fine/fine is too high

Other

First
Response
Only

82

$(80.4)$

3

(2.9)

4

(3.9)

$(1,0)$

$(1.0)$

3

(2.9)

$(1.0)$

2

(2.0)

6

$\underline{(6.0)}$

102

(100.1)
A11

Responses Combined

91

(55.5)

5

(3.1)

17

(10.4)

6

(3.7)

14

(8.5)

3

(1.8)

9

19

$\underline{(11.6)}$

164

(100.1) 
Table D.20. Telephone respondents' recall of television advertisements about seat belts (a11 responses combined).

\begin{tabular}{|c|c|c|c|}
\hline Advert isement & $\begin{array}{l}\text { Number } \\
\text { Seeing } \\
\text { the } \\
\text { Ad }\end{array}$ & $\begin{array}{c}\text { Number } \\
\text { Who } \\
\text { Liked } \\
\text { Ad } \\
\end{array}$ & $\begin{array}{c}\text { Ad } \\
\text { Affected } \\
\text { Belt } \\
\text { Use } \\
\end{array}$ \\
\hline Michael Jordan & $\begin{array}{c}13 \\
(6.3)^{1}\end{array}$ & $\begin{array}{c}13 \\
(100.0)^{2}\end{array}$ & $\begin{array}{c}8 \\
(61.5)^{2}\end{array}$ \\
\hline $\begin{array}{l}\text { Seymour Johnson } \\
\text { Air Force Base }\end{array}$ & $\begin{array}{c}6 \\
(2.9)\end{array}$ & $\begin{array}{c}6 \\
(100.0)\end{array}$ & $\begin{array}{c}4 \\
(66.7)\end{array}$ \\
\hline Crash test film & $\begin{array}{c}12 \\
(5.8)\end{array}$ & $\begin{array}{c}11 \\
(91.7)\end{array}$ & $\begin{array}{c}7 \\
(58.3)\end{array}$ \\
\hline $\begin{array}{l}\text { Crash test dummies } \\
\text { Vince and Larry }\end{array}$ & $\begin{array}{c}92 \\
(44.2)\end{array}$ & $\begin{array}{c}84 \\
(91.3)\end{array}$ & $\begin{array}{c}56 \\
(60.9)\end{array}$ \\
\hline Highway Patrolman & $\begin{array}{c}28 \\
(13.5)\end{array}$ & $\begin{array}{c}24 \\
(85.7)\end{array}$ & $\begin{array}{c}17 \\
(60.7)\end{array}$ \\
\hline Other & $\begin{array}{c}56 \\
(26.9)\end{array}$ & $\begin{array}{c}44 \\
(78.6)\end{array}$ & $\begin{array}{c}30 \\
(53.6)\end{array}$ \\
\hline No Answer & $\begin{array}{c}1 \\
(0.5) \\
\end{array}$ & $\cdots$ & -- \\
\hline & $\begin{array}{c}208 \\
(100.0)\end{array}$ & $\begin{array}{c}182 \\
(87.5)\end{array}$ & $\begin{array}{c}122 \\
(58.7)\end{array}$ \\
\hline
\end{tabular}


Table D.21. Telephone respondents' recommendations of good spokespersons for seat belt advertisements.

\section{Spokesperson}

TV or movie celebrity

Highway patrol officer, police officer

Crash survivor (belted)

Someone who had been in an accident

Race car driver

Government officials

Sports star

Local news/TV/radio personality

Local pastor, religious leader, etc.

Medical person - doctor, rescue squad volunteer, etc.

Close family of deceased non-user

Stunt car driver

Other

No answer

Total
A11

First

Response

36

(17.8)

45

(14.6)

18

(8.9)

26

(8.4)

17

39

(8.4)

(12.6)

16

(7.9)

24

(7.8)

14

(6.9)

19

(6.1)

11

(5.5)

24

(7.8)

8

(4.0)

17

4

(2.0)

9

(2.9)

$(1.5)$

3

$(1.0)$

2

(1.0)

9

2

2

(1.0)

$(0.6)$

1

$(0.5)$

31

(15.4)

51

(16.5)

39

$\underline{(19.3)}$

39

$\underline{(12.6)}$

202

(100.1)

(100.0) 
Table D.22. Accident effect on seat belt use.

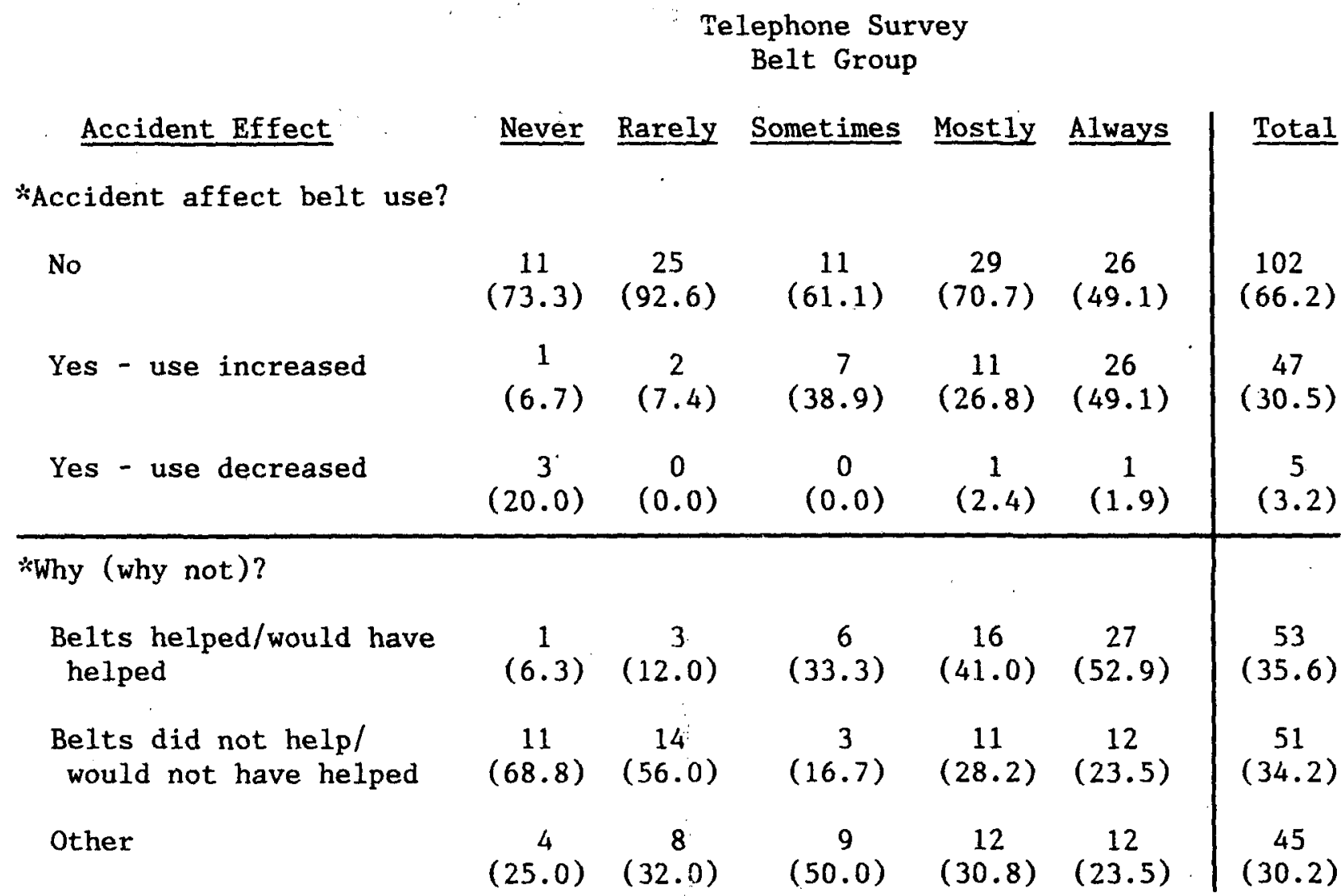

*Indicates significant differences (some variable levels collapsed for testing purposes). 
Table D.23. Perceived level of enforcement of the seat belt law by telephone survey belt group.

Telephone Survey

Belt Group

\begin{tabular}{|c|c|c|c|c|c|c|}
\hline Level of Enforcement & Never & Rarely & Sometimes & Monthly & Always & Tota1 \\
\hline Very strongly & $\begin{array}{c}1 \\
(5.0)\end{array}$ & $\begin{array}{c}1 \\
(2.9)\end{array}$ & $\begin{array}{c}0 \\
(0.0)\end{array}$ & $\begin{array}{c}2 \\
(3.9)\end{array}$ & $\begin{array}{c}13 \\
(17.8)\end{array}$ & $\begin{array}{l}17 \\
(8.4)\end{array}$ \\
\hline Somewhat strongly & $\begin{array}{c}1 \\
(5.0)\end{array}$ & $\begin{array}{c}6 \\
(17.7)\end{array}$ & $\begin{array}{c}6 \\
(25.0)\end{array}$ & $\begin{array}{c}13 \\
(25.0)\end{array}$ & $\begin{array}{c}12 \\
(16.4)\end{array}$ & $\begin{array}{c}38 \\
(1.8 .7)\end{array}$ \\
\hline Not very strongly & $\begin{array}{c}11 \\
(55.0)\end{array}$ & $\begin{array}{c}18 \\
(52.9)\end{array}$ & $\begin{array}{c}15 \\
(62.5)\end{array}$ & $\begin{array}{c}24 \\
(46.2)\end{array}$ & $\begin{array}{c}36 \\
(49.3)\end{array}$ & $\begin{array}{c}104 \\
(51.2)\end{array}$ \\
\hline Not at a11 & $\begin{array}{c}5 \\
(25.0)\end{array}$ & $\left(\begin{array}{c}3 \\
(8.8)\end{array}\right.$ & $\begin{array}{c}1 \\
(4.2)\end{array}$ & $\begin{array}{c}5 \\
(9.6)\end{array}$ & $\begin{array}{c}3 \\
(4.1)\end{array}$ & $\begin{array}{l}17 \\
(8.4)\end{array}$ \\
\hline Don't know/no answer & $\begin{array}{c}2 \\
(10.0) \\
\end{array}$ & $\begin{array}{c}6 \\
\left(17^{6} .7\right) \\
\end{array}$ & $\begin{array}{c}2 \\
(8.3) \\
\end{array}$ & $\begin{array}{c}8 \\
(15.4) \\
\end{array}$ & $\begin{array}{c}9 \\
(12.3) \\
\end{array}$ & $\begin{array}{c}27 \\
(13.3) \\
\end{array}$ \\
\hline Total & $\begin{array}{l}20 \\
(9.9)\end{array}$ & $\begin{array}{c}34 \\
(16.8)\end{array}$ & $\begin{array}{c}24 \\
(11.8)\end{array}$ & $\begin{array}{c}52 \\
(25.6)\end{array}$ & $\begin{array}{c}73 \\
(36.0)\end{array}$ & 203 \\
\hline
\end{tabular}

$x^{2}$ n.s. (enforcement levels collapsed for testing purposes). 
Table D.24. Health behaviors of telephone respondents by risk group and observed belt use.

Reported Belt Group

Never Rarely Sometimes Mostly Always Total

Exercise Regularly?

Yes

\begin{tabular}{ccccc|c}
4 & 12 & 3 & 39 & 31 & 69 \\
$(20.0)$ & $(35.3)$ & $(12.5)$ & $(36.5)$ & $(43.1)$ & $(34.2)$ \\
2 & 1 & 3 & 4 & 3 & 13 \\
$(10.0)$ & $(2.9)$ & $(12.5)$ & $(7.7)$ & $(4.2)$ & $(6.4)$ \\
14 & 21 & 18 & 29 & 38 & 120 \\
$(70.0)$ & $(51.8)$ & $(75.0)$ & $(55.8)$ & $(52.8)$ & $(59.4)$
\end{tabular}

"Smoke Cigarettes?

\begin{tabular}{cccccc|c} 
Yes & 12 & 8 & 13 & 16 & 23 & 72 \\
& $(60.0)$ & $(24.2)$ & $(54.2)$ & $(31.4)$ & $(31.5)$ & $(35.8)$ \\
No & 8 & 25 & 11 & 35 & 50 & 129 \\
& $(40.0)$ & $(75.8)$ & $(45.8)$ & $(68.6)$ & $(68.5)$ & $(64.2)$
\end{tabular}

Drinking Behavior?

How often drink?

Never

\begin{tabular}{ccccc|c}
10 & 12 & 7 & 19 & 34 & 82 \\
$(50.0)$ & $(36.4)$ & $(29.2)$ & $(37.3)$ & $(46.6)$ & $(40.8)$ \\
6 & 14 & & & & 20 \\
$(3.0)$ & $(42.4)$ & $(29.2)$ & $(39.2)$ & $(37.0)$ & $(36.8)$ \\
4 & 7 & 10 & 12 & 12 & 45 \\
$(20.0)$ & $(21.2)$ & $(41.7)$ & $(23.5)$ & $(16.4)$ & $(22.4)$
\end{tabular}

*How often in past year driven within

$1 \mathrm{hr}$. of drinking?

\begin{tabular}{lccccc|c}
0 times & 5 & 8 & 4 & 19 & 25 & 01 \\
1 time & $(50.0)$ & $(38.1)$ & $(23.5)$ & $(59.4)$ & $(64.1)$ & $(51.3)$ \\
& 1 & 2 & 4 & 2 & 2 & 1.1 \\
22 times & $(10.0)$ & $(9.5)$ & $(23.5)$ & $(6.3)$ & $(5.1)$ & $(9.2)$ \\
& 4 & 11 & 9 & 11 & 12 & 47 \\
& $(40.0)$ & $(52.4)$ & $(52.9)$ & $(34.4)$ & $(30.8)$ & $(39.5)$
\end{tabular}


Table D.24. (Continued).

Reported Belt Group

Never Rarely Sometimes Mostly Always / Total

How often in past month driven after drinking too much?

0 times $\begin{array}{ccccc}9 & 19 & 13 & 30 & 35 \\ (90.0) & (90.5) & (76.5) & (93.8) & (89.7)\end{array}$

$\geq 1$ time

\begin{tabular}{ccccc|c}
1 & 2 & 4 & 2 & 4 & 13 \\
$(10.0)$ & $(9.5)$ & $(23.5)$ & $(6.3)$ & $(10.3)$ & $(10.9)$
\end{tabular}

Driving Speed?

At speed limit

\begin{tabular}{ccccc|c}
5 & 14 & 7 & 14 & 35 & 75 \\
$(25.0)$ & $(41.2)$ & $(29.2)$ & $(27.5)$ & $(48.0)$ & $(37.1)$ \\
6 & 6 & 4 & 11 & 10 & 37 \\
$(30.0)$ & $(17.7)$ & $(16.7)$ & $(21.6)$ & $(13.7)$ & $(18.3)$ \\
8 & 11 & 12 & 24 & 27 & 82 \\
$(40.0)$ & $(32.4)$ & $(50.0)$ & $(47.1)$ & $(37.0)$ & $(40.6)$ \\
1 & 3 & 1 & & & 1 \\
$(5.0)$ & $(8.8)$ & $(4.2)$ & $(3.9)$ & $(1.4)$ & $(4.0)$
\end{tabular}

\footnotetext{
*Indicates significant differences (belt groups and/or variable levels sometimes collapsed for testing purposes).
} 
Table D.25. Health behaviors of telephone respondents by risk group and observed belt use.

$\begin{array}{ll}\text { Risk Group } & \text { Observed Use } \\ \text { High } \quad \text { Low } & \text { Belted Unbelted }\end{array}$

\section{Exercise Regularly?}

Yes

No

Smoke Cigarettes?

Yes

No

$\begin{array}{cc}40 & 29 \\ (35.4) & (37.7) \\ 73 & 48 \\ (64.6) & (62.3)\end{array}$

$\begin{array}{cc}45 & 24 * \\ (46.4) & (25.8)\end{array}$

52

$(53.6)$
69

(74.2)
Drinking Behavior?

How often drink?

Never

Twice a month

or less

Once a week or more

$\begin{array}{cccc}45 & 27 & 27 & 45 * \\ (37.8) & (32.5) & (26.7) & (44.6) \\ 74 & 56 & & \\ (62.2) & (67.5) & (73.3) & (55.5)\end{array}$


Table D.25. (Continued).

$\begin{array}{ll}\text { Risk Group } & \text { Observed Use } \\ \text { High L Low } & \text { Belted Unbelted }\end{array}$

How often in past. month driven after drinking too much?

$$
\begin{aligned}
& 0 \text { times } \\
& \geq 1 \text { time }
\end{aligned}
$$

$\begin{array}{cccc}64 & 42 & 52 & 54 \\ (85.3) & (95.5) & (89.7) & (88.5) \\ 11 & & & 6 \\ (14.7) & (4.6) & (1.0 .3) & (11.5)\end{array}$

\section{Driving Speed on Highways?}

$$
\begin{aligned}
& \text { At speed limit } \\
& 5-10 \mathrm{mph} \text { below the } \\
& \text { speed limit } \\
& =5 \mathrm{mph} \text { above the } \\
& \text { speed limit }
\end{aligned}
$$$$
\begin{array}{cc}
42 & 34 \\
(35.0) & (41.0)
\end{array}
$$$$
45 \quad 31
$$$$
\text { (44.1) (30.7) }
$$$$
\begin{array}{cc}
18 & 19 \\
(15.0) & (22.9
\end{array}
$$

$\begin{array}{cc}60 & 30 \\ (50.0) & (36.1)\end{array}$

$\begin{array}{cc}15 & 22 \\ (14.7) & (21.8) \\ 42 & 48 \\ (41.2) & (47.5)\end{array}$

